\title{
Small-scale Wind Energy Portable Turbine (SWEPT)
}

\author{
Ravi Anant Kishore
}

Thesis submitted to the faculty of the Virginia Polytechnic Institute and State University in partial fulfillment of the requirements for the degree of

\author{
Master of Science \\ In \\ Mechanical Engineering \\ Shashank Priya, Chair \\ Walter F. O'Brien \\ Danesh K. Tafti
}

May 06, 2013

Blacksburg, VA

Keywords: Wind energy, turbine, diffuser augmentation, windmill efficiency, BEM

Theory, Portable power, Piezoelectricity, Reynolds number, tip speed ratio

Copyright (C) Ravi Anant Kishore 


\title{
Small-scale Wind Energy Portable Turbine (SWEPT)
}

\author{
Ravi Anant Kishore
}

\begin{abstract}
Large Scale Wind Turbines (LSWTs) have been extensively examined for decades but very few studies have been conducted on the small scale wind turbines (SSWTs) especially for the applications near ground level where wind speed is of order of few meters per second. This study provides the first systematic effort towards design and development of SSWTs (rotor diameter $<50 \mathrm{~cm})$ targeted to operate at low wind speeds $(<5 \mathrm{~m} / \mathrm{s})$. An inverse design and optimization tool based on Blade Element Momentum theory is proposed. The utility and efficacy of the tool was validated by demonstrating a $40 \mathrm{~cm}$ diameter small-scale wind energy portable turbine (SWEPT) operating in very low wind speed range of $1 \mathrm{~m} / \mathrm{s}-5 \mathrm{~m} / \mathrm{s}$ with extremely high power coefficient. In comparison to the published literature, SWEPT is one of the most efficient wind turbines at the small scale and very low wind speeds with the power coefficient of $32 \%$ and overall efficiency of $21 \%$ at its rated wind speed of $4.0 \mathrm{~m} / \mathrm{s}$. It has very low cut-in speed of $1.7 \mathrm{~m} / \mathrm{s}$. Wind tunnel experiments revealed that SWEPT has rated power output of $1 \mathrm{~W}$ at $4.0 \mathrm{~m} / \mathrm{s}$, and it is capable of producing power output up to 9.3 $\mathrm{W}$ at wind speed of $10 \mathrm{~m} / \mathrm{s}$. The study was further extended to develop a piezoelectric wind turbine which operates below $2.0 \mathrm{~m} / \mathrm{s}$ wind speed. The piezoelectric wind turbine of overall dimension of $100 \mathrm{~mm} \times 78 \mathrm{~mm} \times 65 \mathrm{~mm}$ is capable of producing peak electric power of about 450 microwatt at the rated wind speed of $1.9 \mathrm{~m} / \mathrm{s}$.
\end{abstract}




\section{Dedication}

I dedicate my work to my dear parents: Bijendra Prasad Sinha and Veena Devi, and my beloved: Dipika for their unconditional love and support. 


\section{Acknowledgements}

First and foremost, I would like to express my sincere thanks to Prof. Shashank Priya for being my advisor over last two years. This work would not have been possible without his guidance, support and encouragement. He has been a great mentor and I have learned a lot from him, both in academic research and in personal life. He didn't only provide me the necessary infrastructure and resources to complete this project, but also gave me enough freedom and opportunities to test and implement my own ideas. He always encouraged me to think 'out of box' and allowed me to work on several other projects apart from the subject of this thesis. Prof. Priya has his own style; his dedication towards the work, his courage and conviction to take new challenges, his optimism, and the most importantly, his attachment with the students are few of the many qualities that has always inspired me and will always motivate me in future to move ahead.

I would also like to extend my heartfelt gratitude to Prof. Walter O'Brien and Prof. Danesh Tafti for mentoring me in many academic courses and serving on my MS committee. I am extremely indebted to them for their time, invaluable advice, constructive feedback, and extensive discussions around the course works and the research project.

Justin, Beth, Ai, and Erin- I am grateful to all of you for helping me at every aspect since the first day I started working at CIMSS/CEHMS lab.

I would also like extend my appreciation to the Department of Mechanical Engineering and the Graduate School for giving me the opportunity to study at a great school like Virginia Tech. I thank the ME department, once again, for honoring me with Pratt Fellowship.

I have no word to thank my friends and colleagues at CIMSS/CEHMS/BMDL laboratory. I especially appreciate Joseph Cuadrado, Anthony Marin, Dragan Avirovik, Keyur Joshi, Bridget Buehrle, and Sriram Malladi for being my friend and helping me out at several occasions. I wish a very happy and bright future to all of them.

Last but not least, I would like to thank my dear parents: Bijendra Prasad Sinha and Veena Devi, and my beloved: Dipika for their unconditional love and support. According to me, they are the best engineers in the world. They may not know how to make a good machine, but they do know how to make a good human being. I owe every bit of my achievements to all of them. 


\section{Tables of Contents}

Abstract.................................................................................... Ii

Dedication................................................................................ iii

Acknowledgements............................................................. Iv

Tables of Contents....................................................................... V V

List of Figures...................................................................... viii

List of Tables...................................................................... xii

1 Introduction.................................................................... 1

1.1 Historical development of wind turbines.................................. 1

1.2 Current status of wind energy ...................................... 3

1.3 Classification of wind turbines.......................................... 5

1.3.1 Vertical axis vs. horizontal axis wind turbines....................... 6

1.3.2 Drag type and lift type wind turbines........................... 10

1.3.3 Large scale vs. small scale wind turbines.......................... 12

1.4 Some terminologies.................................................... 13

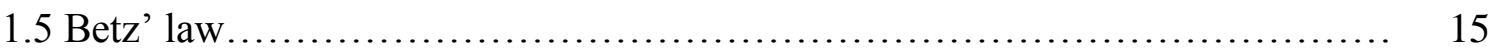

1.6 Need and applications of small scale wind turbines (SSWTs) .................. 18

1.7 Research scope....................................................... 19

1.8 Literature review.................................................... 22

1.9 Objectives of the thesis.............................................. 23

1.10 Layout of the thesis................................................... 24

2 First generation small-scale wind energy portable turbine....................... 27

2.1 SWEPT design specifications and construction.......................... 27

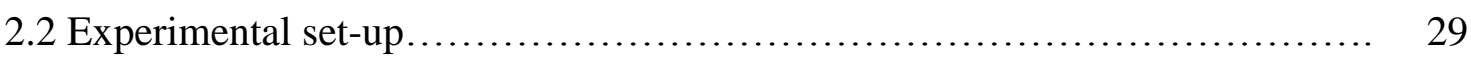

2.3 Results and discussion.............................................. 30

2.3.1 Mechanical power by SWEPT $\ldots \ldots \ldots \ldots \ldots \ldots \ldots \ldots \ldots \ldots \ldots \ldots \ldots, \quad 30$

2.3.2 Coefficient of performance.................................... 33

2.3.3 Overall performance of SWEPT $\ldots \ldots \ldots \ldots \ldots \ldots \ldots \ldots \ldots \ldots \ldots \ldots \ldots, 34$

2.4 Summary and conclusions ............................................ 35

3 Diffuser augmented small-scale wind energy portable turbine.................. 37

3.1 Diffuser: design optimization and construction.......................... 37

3.2 Solution strategy............................................... 38

3.3 Diffuser design optimization........................................ 40 
3.4 Diffuser construction..................................................... 44

3.5 Velocity augmentation.................................................. 45

3.6 Experimental set-up................................................. 46

3.7 Power by ducted- SWEPT ............................................... 46

3.8 Summary and conclusions............................................. 48

4 An inverse design and optimization tool for small scale wind turbines............... 50

4.1 Blade element momentum theory ..................................... 50

4.2 Iterative scheme ........................................................ 52

4.3 Design procedure ........................................................ 53

4.4 Size of the wind turbine ................................................. 54

4.5 Airfoil selection................................................................ 55

4.6 Blade twist angle ....................................................... 56

4.7 Solidity of the wind turbine ............................................. 58

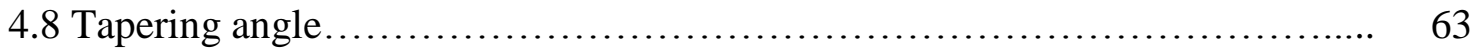

4.9 Blade construction.................................................... 65

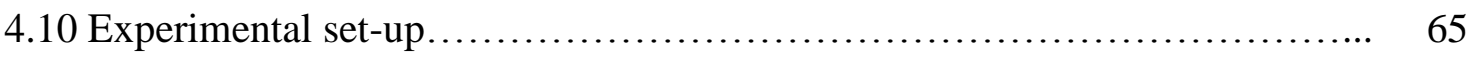

4.11 Power output of the wind turbine........................................ 66

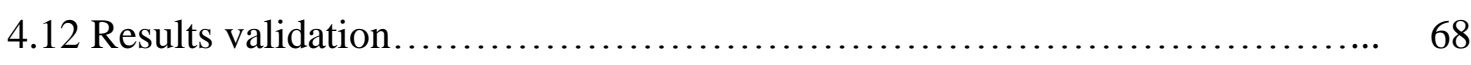

4.13 Summary and conclusions................................................ 69

5 Design and experimental verification of a high efficiency small wind energy portable turbine.................................................................... $\quad 71$

5.1 Design specifications.................................................. 71

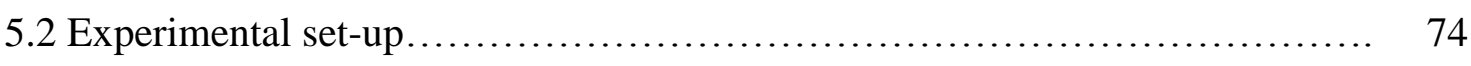

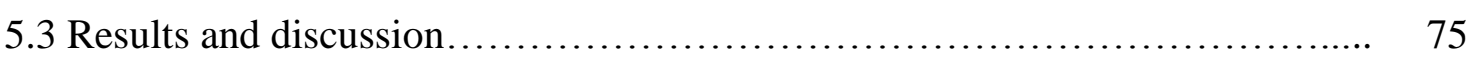

5.3 .1 Torque measurement.......................................... 75

5.3.2 Mechanical power and power coefficient.............................. $\quad 76$

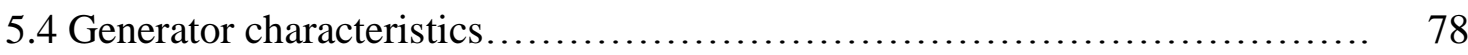

5.5 Power output and overall efficiency..................................... 81

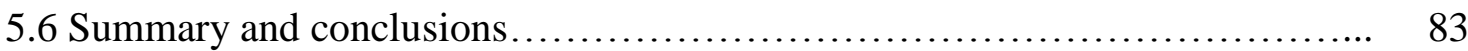

6 Direct-drive small-scale wind energy portable turbine for ultra-low wind speed

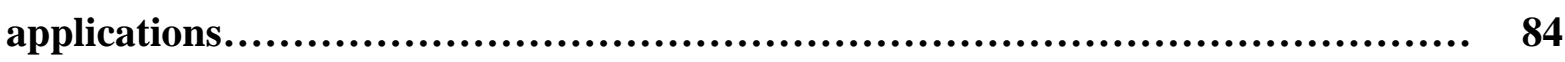

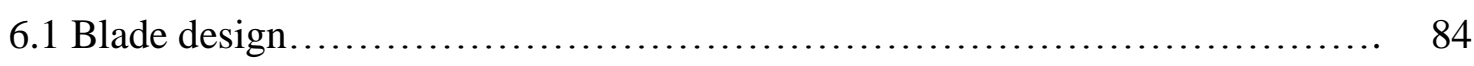

6.2 Generator design........................................................... 84 


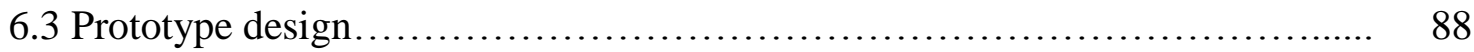

6.4 Experimental set-up........................................... 89

6.5 Results and discussion................................................. 90

6.5.1 Generator characteristics................................... 90

6.5.2 Wind turbine performance..................................... 95

6.6 Summary and conclusions......................................... 98

7 Ultra-low wind speed piezoelectric windmill................................... 99

7.1 Windmill design and experimental set-up............................... 100

7.2 Results and discussion................................................. 102

7.2.1 Power coefficient........................................... 102

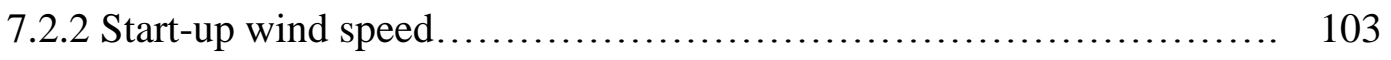

7.2.3 Power output................................................ 104

7.3 Summary and conclusions .......................................... 105

8 Summary and conclusions.................................................... 106

9 Fundamental scientific achievements........................................ 109

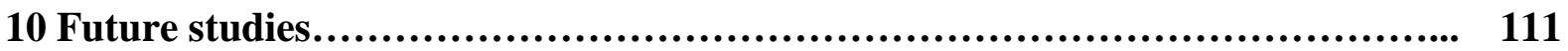

REFERENCES.............................................................. 113

Appendices....................................................................... 116

A NACA 0012 airfoil..................................................... 116

B Inverse design and optimization tool for small scale wind turbines: Part I............ 119

C Inverse design and optimization tool for small scale wind turbines: Part II........ 121

D CAD models............................................................ 124

E List of supplies...................................................... 125 


\section{List of Figures}

Figure 1.1. Some of the world's oldest windmills; (a) Ruins of a vertical axis windmill in Afghanistan, approx. 700 AD (picture taken in 1977); (b) Persian windmill; (c) Chinese windmill with flapping sails, approx. 1000 AD; (d) Vertical axis windmills with flapping sails, France 1719; (e) Vertical axis windmills with bodies driven by drag forces, Italy, approx. 1600; (f) Mediterranean tower mill with sails

Figure 1.2. American windmills (Western windmills): (a) an advertisement by U.S. Wind Engine \& Pumping Co., developer of the American windmills; (b) A wind farm utilizing the American windmills for water pumping

Figure 1.3. Total installed wind power capacity (MW) and world wind power market growth rate (\%) 1996-2012.

Figure 1.4. Vertical Axis Wind Turbines (a) Savonius rotor, (b) Curved-blade Darrieus rotor, and (c) Straight-blade Darrieus rotor.

Figure 1.5. Siemens Horizontal Axis Wind Turbine (model: SWT-2.3-82 VS)....... 7

Figure 1.6. Typical configuration of a modern large scale HAWT.................. 9

Figure 1.7. Drag and Lift components of the aerodynamic force.................... 11

Figure 1.8. Simplified model for Savonius Wind turbine......................... 11

Figure 1.9. Some basic terminologies related to an airfoil.......................... 14

Figure 1.10. The stream-tube representing wind flow through the actuator disc........ 16

Figure 1.11. Influence of Reynolds number on airfoil behavior (NACA-0012)....... 21

Figure 2.1. Blade design configuration with all dimensions in $\mathrm{cm} \ldots \ldots \ldots \ldots \ldots \ldots \ldots \ldots .28$

Figure 2.2. First generation small-scale windmill prototype "SWEPT"

Figure 2.3. Experimental set-up with the schematic diagram....................... 29

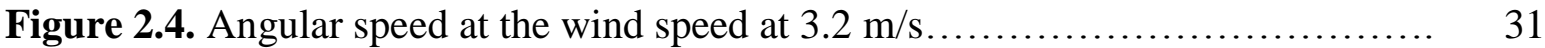

Figure 2.5. Torque and rpm relationship .................................... 32

Figure 2.6. Mechanical power of SWEPT at different wind speed.................. 32

Figure 2.7. Coefficient of Performance vs. Tip speed ratio...................... 33

Figure 2.8. Angular speed as a function of load resistance ....................... 34

Figure 2.9. Electrical power of SWEPT at different load and wind speed............. 35

Figure 3.1. An initial design of diffuser modeled using CFD $\ldots \ldots \ldots \ldots \ldots \ldots \ldots \ldots \ldots . \quad 38$

Figure 3.2 Two-dimensional computational domain with boundary conditions........ 39

Figure 3.3. Two-dimensional grid system...................................... 39 
Figure 3.4. Mesh independency test.

Figure 3.5(a). Effect of converging section length $L_{1}$ and half cone angle $\theta_{1}$ on velocity augmentation factor $\mathrm{U} / \mathrm{U}_{\mathrm{o}}\left(\mathrm{L}_{2}=1.0 \mathrm{D}\right.$ and $\left.\theta_{2}=10^{\circ}\right)$.

Figure 3.5(b). Effect of converging section length $L_{1}$ and half cone angle $\theta_{1}$ on velocity augmentation factor $\mathrm{U} / \mathrm{U}_{\mathrm{o}}\left(\mathrm{L}_{2}=1.5 \mathrm{D}\right.$ and $\left.\theta_{2}=10^{\circ}\right)$.

Figure 3.6. Effect of diverging section length $L_{2}$ and half cone angle $\theta_{2}$ on velocity augmentation factor $\mathrm{U} / \mathrm{U}_{\mathrm{o}}\left(\mathrm{L}_{1}=0.125 \mathrm{D}\right.$ and half cone angle $\left.\theta_{1}=15^{\circ}\right)$

Figure 3.7. Velocity contours at different $\theta_{2}\left(\mathrm{~L}_{2}=1.0 \mathrm{D}, \mathrm{L}_{1}=0.125 \mathrm{D}, \theta_{1}=15^{\circ}\right) \ldots \ldots \ldots$.

Figure 3.8. Velocity contours at different $L_{2}\left(\theta_{2}=12^{\circ}, L_{1}=0.125 D, \theta_{1}=15^{\circ}\right) \ldots \ldots \ldots \ldots .43$

Figure 3.9. Diffuser made up of (a) metal sheet and (b) fiber reinforced plastics...... 44

Figure 3.10. Comparison of velocity augmentation factor obtained numerically and experimentally....

Figure 3.11. Schematic diagram of wind tunnel experimental set-up used to test the performance of the diffuser augmented wind turbine

Figure 3.12. Power output of diffuser augmented SWEPT at different load and wind speed

Figure 3.13. Power augmentation of SWEPT with diffuser over SWEPT without diffuser

Figure 4.1. Flow Chart showing iterative scheme for the numerical model based on BEM theory.

Figure 4.2. Lift and Drag coefficients of NACA 0012 airfoil.

Figure 4.3. Power Coefficient vs. Tip Speed Ratio at various constant angles of attack

Figure 4.4. Blade twist angle at various constant angles of attack 58

Figure 4.5(a). Power Coefficient vs. Tip Speed Ratio at solidity $\sigma=10 \%$ 60

Figure 4.5(b). Power Coefficient vs. Tip Speed Ratio at solidity $\sigma=20 \%$. 61

Figure 4.5(c). Power Coefficient vs. Tip Speed Ratio at solidity $\sigma=30 \%$. 61

Figure 4.5(d). Power Coefficient vs. Tip Speed Ratio at solidity $\sigma=40 \%$. 62

Figure 4.6. Torque Coefficient vs. Tip Speed Ratio at different values of solidity...

Figure 4.7(a). Power Coefficient vs. Tip Speed Ratio at different positive tapering angles.

Figure 4.7(b). Power Coefficient vs. Tip Speed Ratio at different negative tapering angles 
Figure 4.8. Wind turbine rotor manufactured using rapid prototyping machine

Figure 4.9. Blade design configurations with all dimensions in $\mathrm{cm} \ldots \ldots \ldots \ldots \ldots \ldots \ldots . \quad 66$

Figure 4.10. Schematic of the experimental set-up.......................... 67

Figure 4.11. Angular speed of the wind turbine at the wind speed of $4.0 \mathrm{~m} / \mathrm{s} \ldots \ldots \ldots \ldots$

Figure 4.12. Mechanical power output of the wind turbine at various wind speeds.... 68

Figure 4.13. Comparison of numerical and experimental results for torque and power coefficients....

Figure 5.1. Blade twist angle.............................................. 72

Figure 5.2. A second generation prototype of SWEPT........................ 73

Figure 5.3. Set-up and schematic diagram of wind tunnel experiment............... 74

Figure 5.4. Torque-rpm-time characteristics of the wind turbine.................... 76

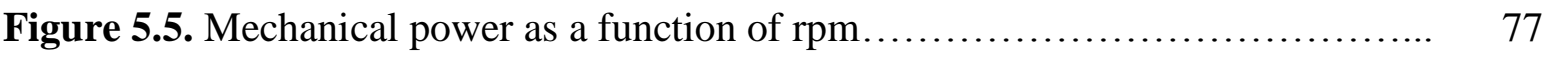

Figure 5.6. Power Coefficient as a function of tip speed ratio...................... 77

Figure 5.7. Torque coefficient as a function of tip speed ratio..................... 78

Figure 5.8. Power output vs. Shaft rpm of generator........................... 79

Figure 5.9. Torque vs. Shaft rpm of generator.............................. 80

Figure 5.10. Shaft rpm vs. Load resistance of generator........................ 81

Figure 5.11. Electrical power of the wind turbine vs. Load resistance............... 82

Figure 5.12. Overall efficiency of the wind turbine vs. Load resistance.............. 82

Figure 5.13. Generator's efficiency vs. Load resistance.......................... 83

Figure 6.1. A CAD model of the "double rotor-single stator slotless axial flux generator" without fixtures

Figure 6.2. Contours showing the magnetic field strength at the mid-plane between two rotors.

Figure 6.3. Axial flux generator design for SWEPT: (a) fabricated stator and rotor parts showing the shapes of the magnets and coils; (b) axial flux generator inside the nacelle box....

Figure 6.4. An experimental prototype of SWEPT.

Figure 6.5. Schematic diagram of the experimental set-up....................... 90

Figure 6.6. Output voltage profiles at various loading conditions (wind speed $=3.2$ $\mathrm{m} / \mathrm{s}$ )

Figure 6.7. Variation of generator voltage with current at different constant rpm conditions 
Figure 6.8. Voltage vs. current at various loading conditions and wind speeds

Figure 6.9. Voltage vs. angular speed at various loading conditions and wind speeds

Figure 6.10. Power vs. angular speed at various loading conditions and wind speeds.

Figure 6.11. Angular speed vs. load resistance at various wind speeds 95

Figure 6.12. Power output vs. load resistance at different wind speeds. 96

Figure 6.13. Peak electrical power vs. wind speed.............................. 97

Figure 6.14. Net efficiency of the wind turbine vs. load resistance at various wind speeds

Figure 7.1. (a) Picture of the piezoelectric wind turbine fabricated in this study with all dimensions (in $\mathrm{mm}$ ); (b) Schematic of experimental set-up used for quantifying 101 the performance of the windmill

Figure 7.2. (a) Angular speed of the wind turbine at wind speed of $3.9 \mathrm{mph}$; (b) Power coefficient as a function of tip speed ratio

Figure 7.3. (a) Induced voltage profile at $2.9 \mathrm{mph}$; (b) Induced voltage profile at 4.2 $\mathrm{mph}$; (c) Variation of open circuit voltage and oscillation frequency as function of wind speed; (d) Electrical power as a function of resistive load...................... 104

Figure 8.1. Overall efficiency of some of the small and mid-scale wind turbines...... 108

Figure A. Airfoil NACA 0012 used to design SWEPT blades..................... 118

Figure D1. CAD model of SWEPT wind turbine rotor........................... 124

Figure D2. CAD model of SWEPT Nacelle box............................... 124 


\section{List of Tables}

Table 1.1. Cumulative wind power capacity outlook from 2008 to $2012 \ldots \ldots \ldots \ldots \ldots \ldots$

Table 1.2. Main differences between vertical and horizontal axis wind turbines........ 10

Table 1.3. Some of the currently available small-to-mid scale horizontal axis wind

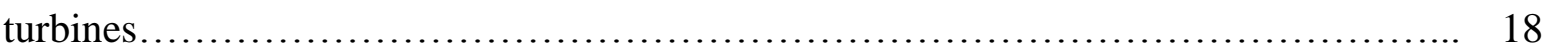

Table 3.1. Diffuser design parameters...................................... 44

Table 4.1. Chord length $(\mathrm{cm})$ at different solidity and number of blades............... 59

Table 5.1. SWEPT's design specifications..................................... 73

Table 6.1. Major design specifications of the axial flux generator developed for

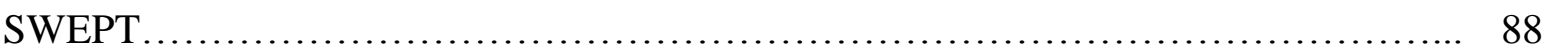

Table A. Coordinates of NACA 0012 airfoil 116 


\section{CHAPTER 1}

\section{Introduction}

\subsection{Historical development of wind turbines}

Wind energy is one of the most abundant renewable energy resource on the earth and has been targeted for centuries. It's predicted that human beings have been using wind energy in their daily work for about 4,000 years [1]. As early as 1,700 B.C., King Hammurabi of Babylon used wind powered scoops to irrigate the plains of Mesopotamia [2]. Wind was also used to grind grain and that's the reason why we still speak of "windmills", even though they are now hardly used for grinding grains [1]. Figure 1.1 displays some of the primitive windmills used by early human civilizations [2].

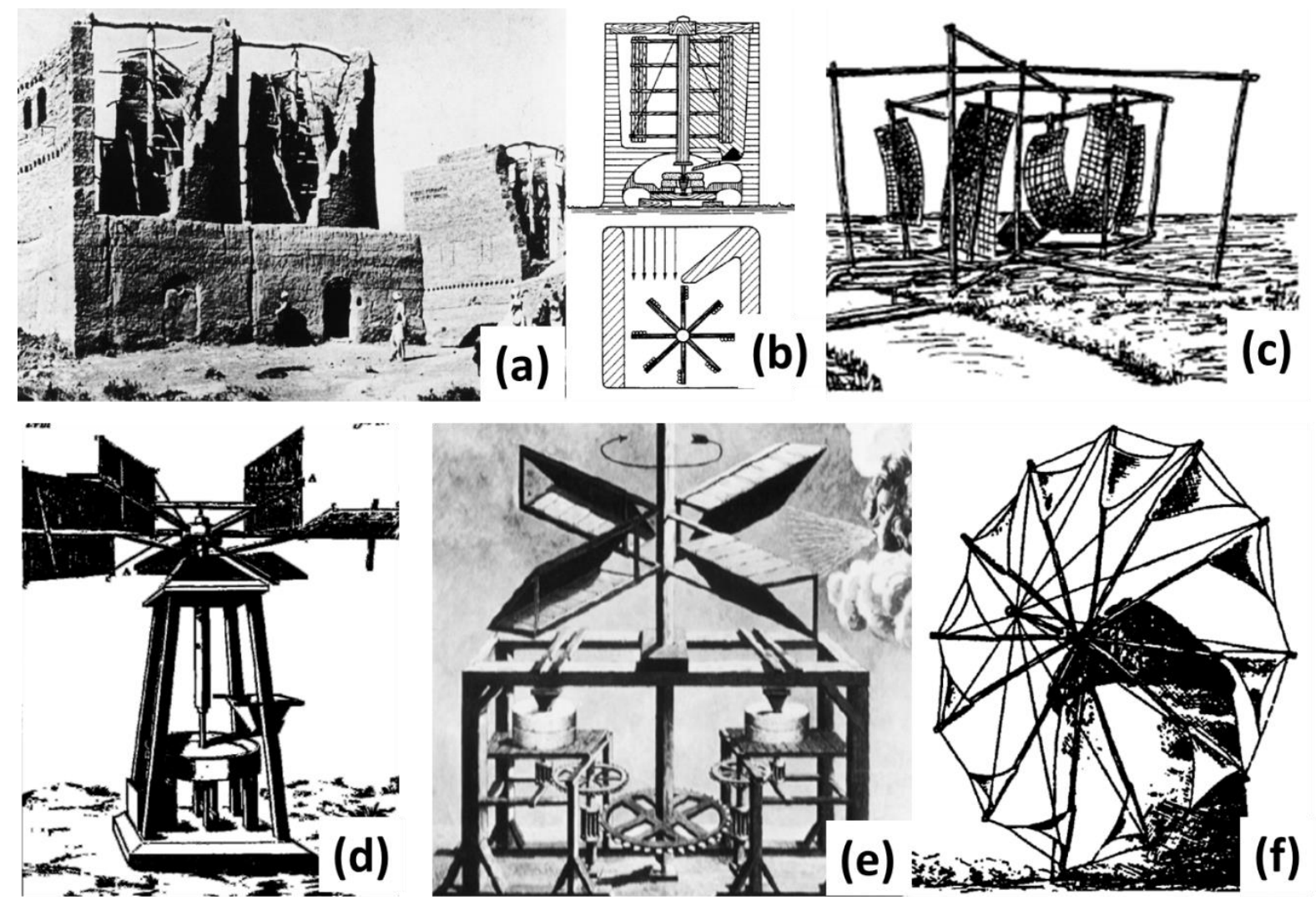

Figure 1.1. Some of the world's oldest windmills; (a) Ruins of a vertical axis windmill in Afghanistan, approx. 700 AD (picture taken in 1977); (b) Persian windmill; (c) Chinese windmill with flapping sails, approx. 1000 AD; (d) Vertical axis windmills with flapping 
sails, France 1719 AD; (e) Vertical axis windmills with bodies driven by drag forces, Italy, approx. $1600 \mathrm{AD}$; (f) Mediterranean tower mill with sails. All pictures are adapted from Ref. [2].

It can be noted that most of the world's oldest windmills had vertical axis of rotation. Initial designs (Figures 1.1(a)-(c)) were very simple, especially from construction point of view. Braided mats or sails were utilized to generate drag and thus to rotate the windmills about the central axis. The vertical axis windmills had another operational advantage that they were independent of wind direction. Figure 1.1(d) and (e) show some later versions of vertical axis mills developed in France and Italy, respectively. In Figure 1.1(d), the millstone is attached directly to the vertical drive shaft without any intermediate gear or other mechanism to redirect the rotational movement. Figure 1.1(e) shows one of the advanced windmills created by Fausto Veranzio in Italy [2]. It can be seen that this windmill is engineered with cup-shaped rotor blades which improves the efficiency of the device. Veranzio also developed a gearing mechanism for his windmills which allows millstones to run at much higher speed, even though the rotors were design for low tip speed ratio [2].

The horizontal axis wind mills are a relatively newer invention than the vertical axis windmills. Though the first documentation of the horizontal axis windmills dates back to the $12^{\text {th }}$ century, the theoretical descriptions regarding the driving power of horizontal axis devices, i.e. lift forces on the blades, was investigated only during the beginning of the $20^{\text {th }}$ century [2]. One of the most popular early horizontal axis wind turbine was the tower mills, shown in Figure 1.1(f), which existed in southern Europe. The first written evidence of such windmills dates back to the $13^{\text {th }}$ century [2]. There were some other types of horizontal axis windmills which existed in different parts of the world (mainly in the Occident) during different periods of time: Post windmill (1100s), Wipmolen Dutch (1400s), Dutch smock mill (1500s), Paltrock mill (1600s) and Gallery smock mill (1700s). Brief description about these windmills can be found in Ref. [2]. However, none of the historical horizontal axis wind turbines gained as much popularity as the American farm windmill (sometimes also called Western mill). These windmills were developed in the mid $-19^{\text {th }}$ century mainly to provide drinking water to people and cattle in North America. Moreover, it was used to assure the water supply for the steam locomotives of the new railways expanding into the West [2]. Figure 1.2(a) shows an early advertisement for the American windmills by U.S. Wind Engine \& Pumping Co., the company who developed this windmill [3]. The most important component of this windmill is the rotor, which is also called "rotor rosette" because of its 
structural design. Its diameter varies between $3 \mathrm{~m}$ and $5 \mathrm{~m}$ and has more than 20 metal sheet blades. It also consists of a tail which allows the rotor to turn automatically so that it always faces the incident wind. It uses a crank shaft to drive a piston pump. The American mills are still in existence and several of them are installed with a nearly unchanged design in Australia, Argentina and the USA [3]. Figure 2(b) depicts one of such wind farms utilizing the American mills for water pumping [4].

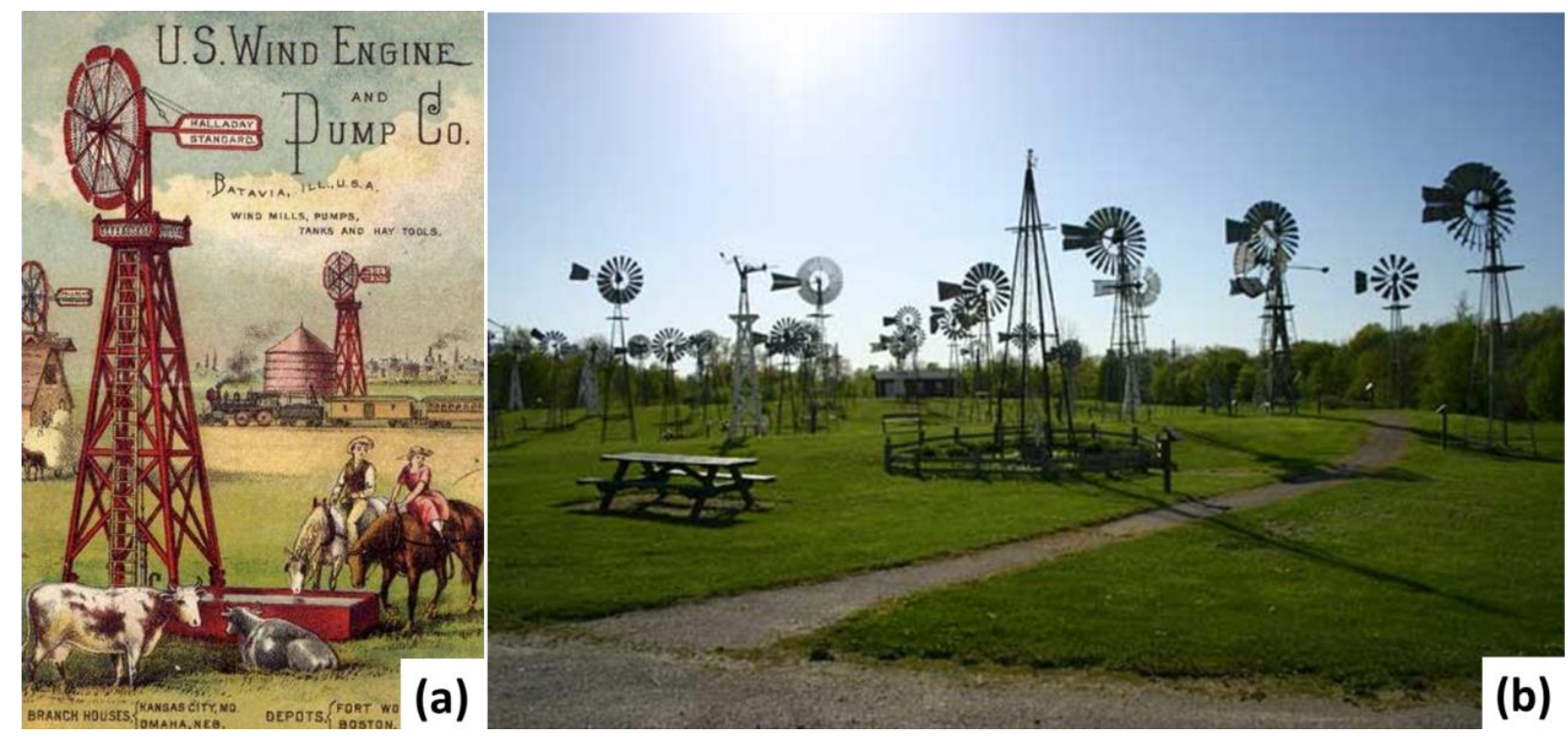

Figure 1.2. American windmills (Western windmills): (a) an advertisement by U.S. Wind Engine \& Pumping Co., developer of the American windmills [3]; (b) A wind farm utilizing the American windmills for water pumping [4].

\subsection{Current status of wind energy}

The fourth edition of the Global Wind Energy Outlook released on Nov 14, 2012 at Beijing by Greenpeace International and the Global Wind Energy Council states that wind power currently shares about $3.5 \%$ of global electricity demand and it is expected that the share could reach up to $12 \%$ by 2020 [5]. Figure 1.3 shows global cumulative installed wind power capacity over last 17 years [6]. At the end of year 2012, the world-wide total wind power capacity was 282 gigawatts (GW), showing a growth of about $18.7 \%$ (44 GW) over the preceding year. It is important to note that although the year 2012 created a new record in total installed wind power capacity, the wind market has cooled down in relative terms. If we look at the annual growth rate, it had continued to increase since the year 2004, peaking at $32.1 \%$ in year 2009. However, since then the growth has decreased substantially. In 2012, 
the global growth went down to $18.7 \%$, which is the lowest rate in the last two decades, according to a report by the World Wind Energy Association (WWEA) [7].

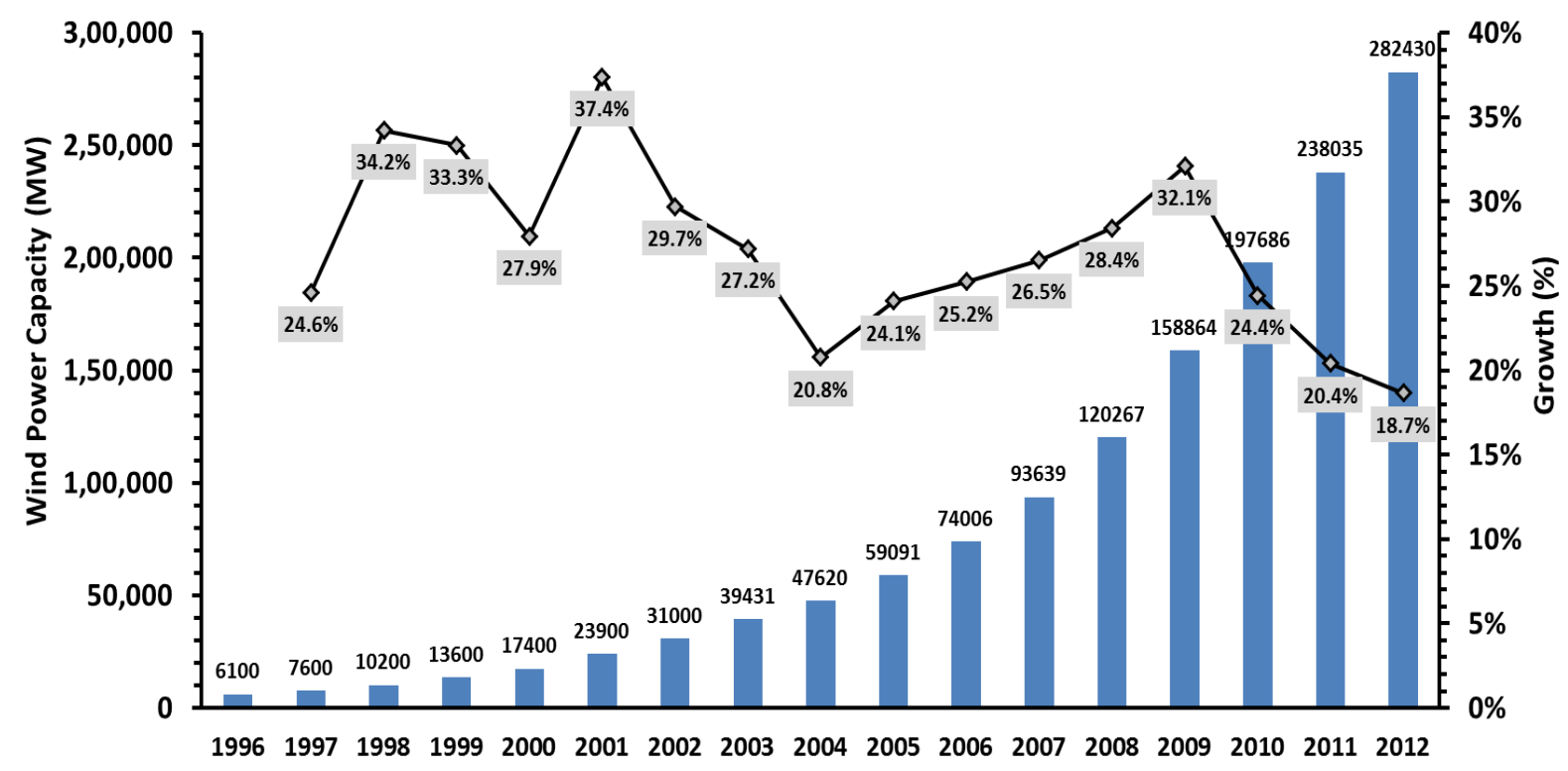

Figure 1.3. Total installed wind power capacity (MW) and world wind power market growth rate (\%) 1996-2012. Information taken from [6].

Table 1.1 presents cumulative wind power capacity from year 2008 to 2012 in top 10 countries and the same variable worldwide $[6,7]$. The data indicates that even though the global wind power capacity exhibited the low growth rate (18.7\%) in year 2012, it increased over $133.5 \%$ during the last five years. It is also very interesting to note that $73.7 \%$ of the total power capacity $(282,430 \mathrm{MW})$ in 2012 was contributed by 5 countries i.e. China, USA, Germany, Spain and India. China's wind power capacity continued to grow at the rate of over $21 \%$ in 2012. The United States has also gained the momentum and displayed the annual growth rate of $27.9 \%$ in 2012, which is the highest growth rate in last three consecutive years. The installed wind power capacity in USA has reached up to 60,007 megawatts by the end of year 2012. In 2012, the electricity produced from wind power in the United States totaled to about 140 terawatt-hours, which is around $3.5 \%$ of net electricity generation by all the energy sources [8]. The U.S. Department of Energy (DOE) has launched 'the wind and water power program' to accelerate the deployment of wind power sources. The federal government has issued several tax-based policy incentives to stimulate the public acceptance of wind energy. According to a report by the U.S. Department of Energy's Wind and Water Power Program published in May 2011, the federal government allows owners of the qualified renewable energy facilities to receive tax credits of 2.2 cents for each kilowatt-hour 
(kWh) of electricity generated by the facility over a ten year period [9]. Several incentives have been provided to promote the deployment of small scale wind power generation. The owners of small wind turbines (100 kW or less) are eligible to receive tax credits worth $30 \%$ of the value of the facility [9]. In addition, DOE offers loan guarantees to help the wind power firms to deploy innovative, clean energy technologies that reduce, avoid or sequester carbon dioxide and other emissions. The information about the policy incentives and other benefits related to wind energy can be found in detail at the website of U.S. Department of Energy: Energy Efficiency and Renewable energy (www.eere.energy.gov/informationcenter). The U.S. Department of Energy envisions supplying $20 \%$ of all U.S. electricity from wind power by 2030 [10].

Table 1.1. Cumulative wind power capacity outlook from 2008 to 2012 [6, 7]

\begin{tabular}{lcccccc}
\hline \multirow{2}{*}{ Country } & \multicolumn{5}{c}{ Total Capacity (Megawatt) } & Growth Rate \\
\cline { 2 - 5 } & $\mathbf{2 0 0 8}$ & $\mathbf{2 0 0 9}$ & $\mathbf{2 0 1 0}$ & $\mathbf{2 0 1 1}$ & $\mathbf{2 0 1 2}$ & $\mathbf{2 0 1 2}$ \\
\hline China & 12210 & 25810 & 44733 & 62364 & 75564 & $21.2 \%$ \\
\hline USA & 25237 & 35159 & 40180 & 46919 & 60007 & $27.9 \%$ \\
\hline Germany & 23897 & 25777 & 27215 & 29075 & 31332 & $7.8 \%$ \\
\hline Spain & 16689 & 19149 & 20676 & 21673 & 22796 & $5.2 \%$ \\
\hline India & 9587 & 11807 & 13065 & 15880 & 18421 & $16.0 \%$ \\
\hline UK & 3195 & 4092 & 5203 & 6018 & 8445 & $40.3 \%$ \\
\hline Italy & 3736 & 4850 & 5797 & 6737 & 8144 & $20.9 \%$ \\
\hline France & 3404 & 4574 & 5660 & 6640 & 7196 & $8.4 \%$ \\
\hline Canada & 2369 & 3319 & 4008 & 5265 & 6200 & $17.8 \%$ \\
\hline Portugal & 2862 & 3357 & 3702 & 4093 & 4525 & $10.6 \%$ \\
\hline Worldwide & 120986 & 159837 & 197040 & 238035 & 282482 & $18.7 \%$ \\
\hline
\end{tabular}

\subsection{Classification of wind turbines}

There are broadly three ways to classify the wind turbines: (i) on the basis of the orientation of axis of rotation (vertical or horizontal), (ii) on the basis of the component of aerodynamic forces (lift or drag) that powers the wind turbine, and (iii) on the basis of energy generating capacity (micro, small, medium, or large). 


\subsubsection{Vertical axis vs. horizontal axis wind turbines}

There are essentially two kinds of wind turbines, when they are categorized on the basis of their orientation of the axis of rotation: Vertical Axis Wind Turbines (VAWTs) and Horizontal Axis Wind Turbines (HAWTs). As the name suggests, the rotor of VAWTs rotates perpendicular to the ground while that of HAWTs spins parallel to the ground. It was explained in the previous section that most of the early wind turbines were vertical axis because they were relatively simple to construct (especially for the milling purpose) and they also didn't require any mechanism to orient themselves in the direction of wind. In spite of these attributes, none of the old designs of VAWTs survived for long time. Currently, there are three most popular designs of VAWTs: (a) Savonius VAWT, (b) Curved-blade Darrieus VAWT, and (c) Straight-blade VAWT [11]. Figure 1.4(a)-4(c) show Savonius, curved-blade Darrieus, and straight-blade Darrieus VAWT rotors, respectively [12]. Savonius turbines are drag-type while Darrieus turbines are lift-type. More details about these designs will be discussed in the next section. In principle, Savonius rotors normally have two cups or half drums attached to a central shaft in opposing directions, as shown in Fig. 1.4(a). The drum, which is against the wind flow, catches the wind and creates a moment along the axis. The aerodynamic torque by the first drum rotates the rotor and brings the opposing drum against the wind flow. The second drum now catches the wind and causes the rotor to rotate even further and thus completes a full rotation. This process continues until there is sufficient wind to turn the axial shaft which is normally connected to a pump or a generator [11]. Savonius turbines generally have poor efficiency (less than $25 \%$ ) and that's why they are not so commercially successful but there are some advantages such as simple construction with low cost, high static and dynamic moment, wind acceptance from any direction, low noise and angular velocity in operation, and reduced wear on moving parts which justifies their operation for low power applications [13].

The Darrieus-type VAWTs consists of two or more blades which are attached to a vertical central shaft. These blades can be curved (as shown in Fig. 1.4(b)) or they can be straight (as shown Fig. 1.4(c)). Irrespective of the curvature, the blades always have airfoil profile which creates aerodynamic lift, when they are exposed to the incident wind. This phenomenon creates moment along the axis and causes the central shaft to rotate, which ultimately runs the generator to produce electricity. The curved-blade Darrieus VAWTs have lower bending stress in the blades as compared to straight-blade Darrieus VAWTs and therefore former is more commercially successful [11]. However, on the small-scale power production, the straight-bladed Darrieus VAWTs are more popular because of their simple 
blade design [13]. The straight-bladed Darrieus VAWTs sometimes may have variable pitch angle. It has been found that constant pitch straight-bladed Darrieus VAWTs don't have selfstart ability [14]. The variable pitch configuration of the blades allows Darrieus VAWTs to overcome the starting torque problem but it is overly complicated, making them quite impractical for small scale power generation [11].

At present, horizontal axis wind turbines (HAWTs) are the most popular among all windmill designs. This is primarily because HAWTs generally have much higher efficiency than VAWTs. The maximum power coefficient of a modern HAWT has been reported up to $45 \%$ to $50 \%$ while that of an efficient VAWT normally lies below 40\% [15] (power coefficient of a Savonius-type VAWT is even lower, normally below $25 \%$ [13]). Figure 1.5 shows a HAWT commercialized by SIEMENS (model: SWT-2.3-82 VS) [16].
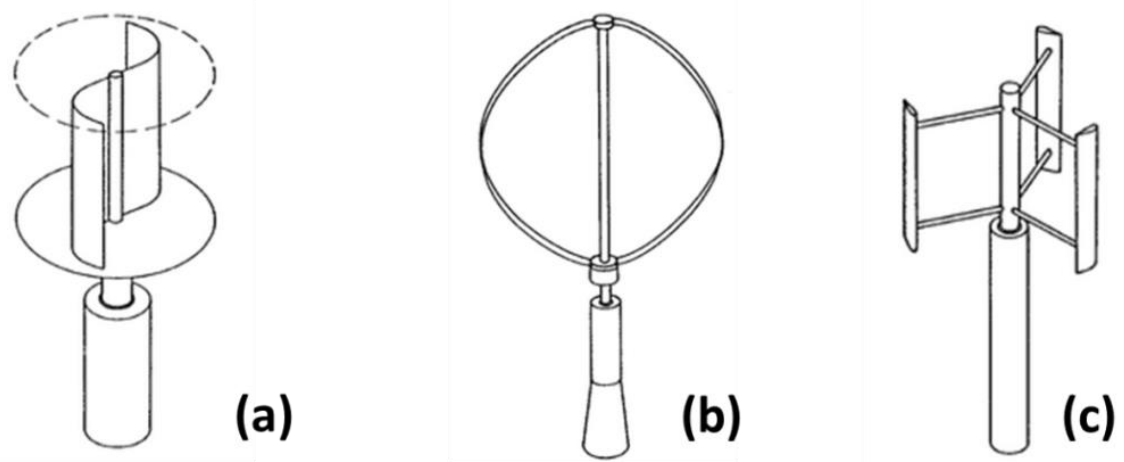

Figure 1.4. Vertical Axis Wind Turbines: (a) Savonius rotor, (b) Curved-blade Darrieus rotor, and (c) Straight-blade Darrieus rotor [12].

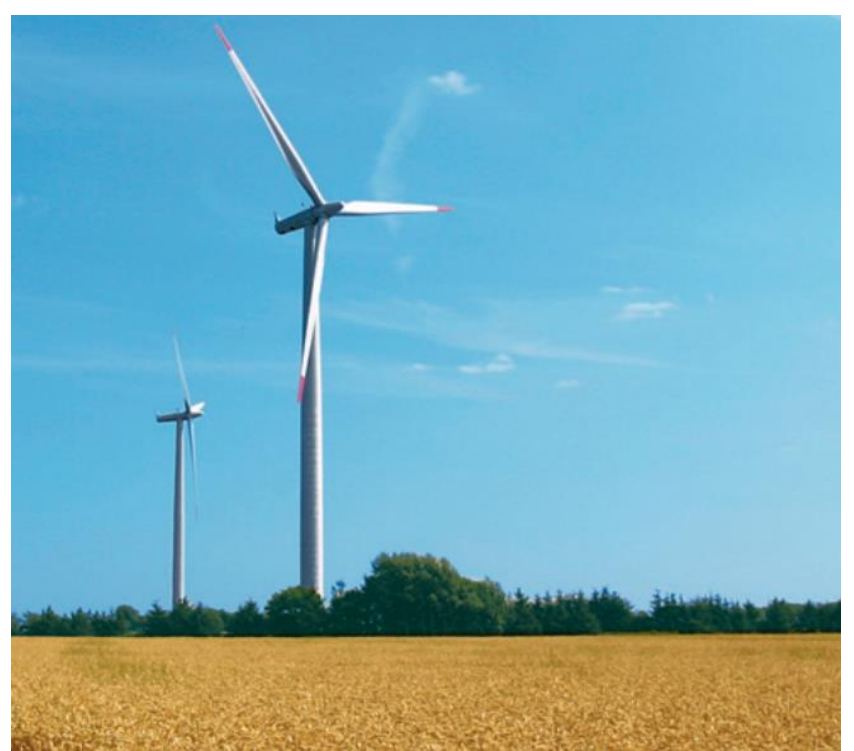

Figure 1.5. Siemens Horizontal Axis Wind Turbine (model: SWT-2.3-82 VS) [16]. 
As explained in the previous section, the rotor shaft of a HAWT is positioned in horizontal direction i.e. parallel to the ground. The electric generator that is connected to the turbine rotor via the primary and secondary shafts is stored inside a nacelle box at the top of the tower. HAWTs are lift-type wind turbines and are very sensitive to changes in blade profile, design, and surface roughness. Another limitation with HAWTs is that they can't catch the wind from all direction. They need a special mechanism to turn the rotor so that it always faces the wind. This was probably one of the main reasons why none of the historical HAWTs were so successful. In fact, the American windmill was the first HAWT which had a fully automatically controlled yaw system. Yaw system of a HWAT is basically a component which is responsible for the orientation of the wind turbine rotor towards the wind. In small size HAWTs, the yaw system comprises of a simple roller bearing connected between the tower and the nacelle. A tail with a fin at the end is mounted on the back of nacelle which produces corrective moment to turn the wind turbine rotor into the wind. This type of yaw system is called 'passive yaw system'. The large scale (megawatt) HAWTs however needs an active yaw mechanism. The active yaw systems are normally equipped with a wind sensor which senses the direction of wind, and a servo motor which produces required torque to rotate the nacelle of the wind turbine against the stationary tower. This study is primarily focused on HAWT, so more details about this kind of turbines will be given in later sections/chapters. A HAWT, in general, consists of a rotor, a gear box, a generator, and a yaw system. The rotor of a HAWT includes two to three blades connected together with a hub. The hub is attached to a main shaft (sometimes also called primary shaft or low speed shaft), which passes through bearings and connects to a gear-train. The gear train amplifies the rotational speed and provides higher rpm to a secondary shaft (sometimes also called high speed shaft). The secondary shaft drives a generator which produces electricity. The gearbox, the primary and secondary shafts, and the generator are contained inside a nacelle box. The nacelle box also contains a yaw system to orient the rotor, and a heat exchanger to cool down the generator. Figure 1.6 demonstrates all the major components of a large scale modern HAWT [17]. A brief description has been also provided explaining the basic necessity of these components.

Table 1.2 summarizes some of the most important differences between vertical and horizontal axis wind turbines [15]. 


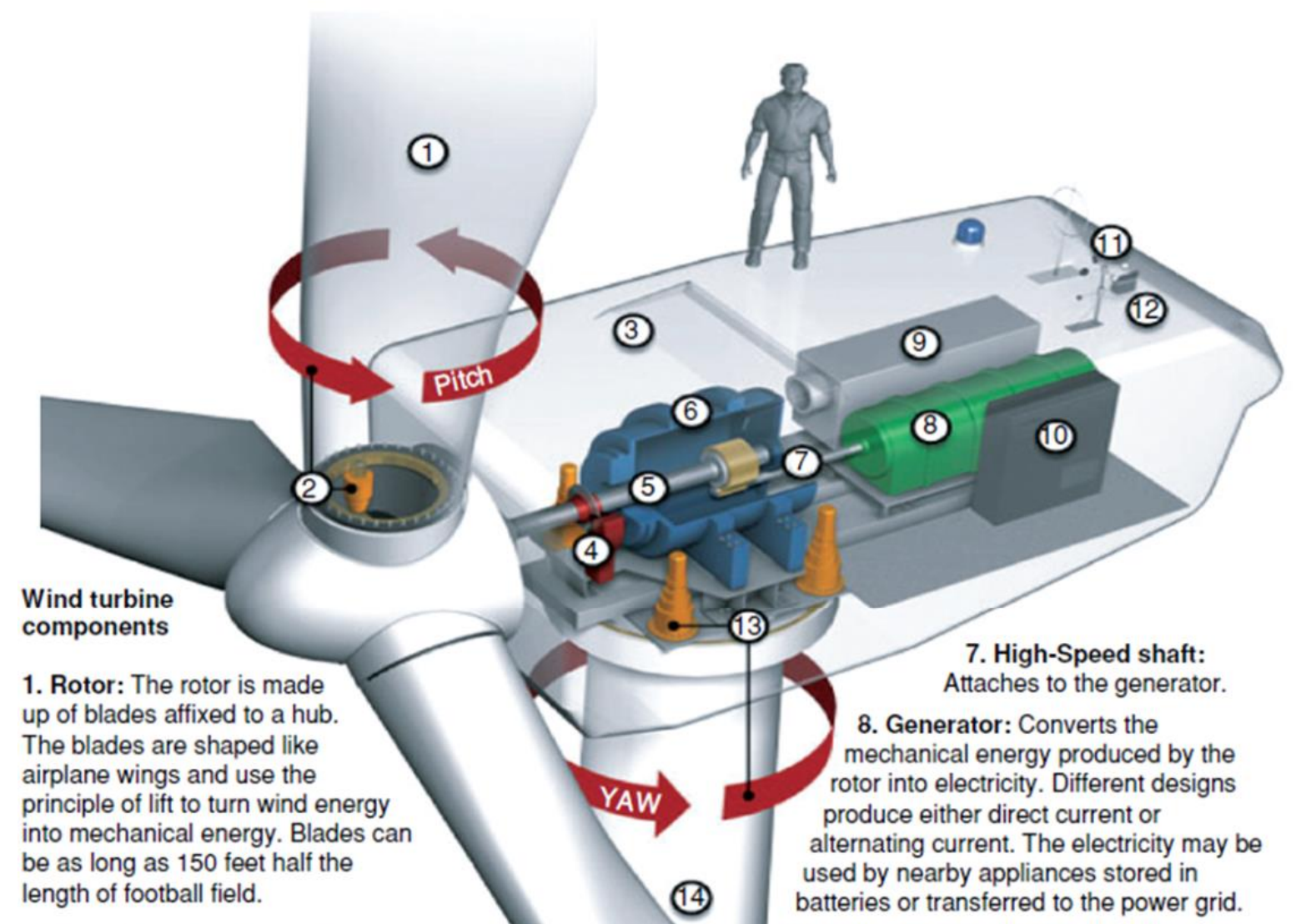

2. Pitch Drive: Blades can be rotated to reduce the amount of lift when wind speeds become too great.

3. Nacelle: The rotor attaches to the nacelle, which sits atop the tower and encloses the various components.

4. Brake: A mechanical brake acts as a back up to the braking effects of the blade pitch drives or as a parking brake for maintenance.

\section{Low-Speed Shaft: Attaches to the rotor.}

6. Gear Box: The rotor turns the low-speed shaft at speeds ranging from 20 revolutions per minute (rpm) on large turbines to $400 \mathrm{rpm}$ on residential units. Transmission gears increase the speed to the $1,200-1,800 \mathrm{rpm}$ required by most generators to produce electricity. Some small-scale turbines use a direct-drive system, eliminating the need for a gear box.

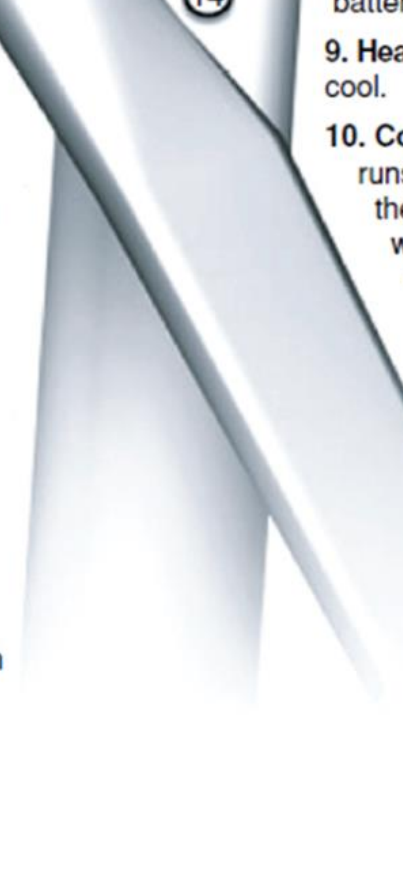

9. Heat exchanger: Keeps the generator cool.

10. Controller: A comouter system runs self-diagnostic tests, starts and stops the turbine, and makes adjustments as wind speed vary. A remote operator can run system checks and enter new parameters via modem.

11. Anemometer: Measures wind speed and passes it along to the controller.

12. Wind Vane: Detects wind direction and passes it along to the controller, which adjusts the "yaw," or heading, of the rotor and nacelle.

13. Yaw Drive: Keeps the rotor facing into the wind.

14. Tower: Because wind speed increases with height, taller towers allow turbines to capture more energy.

Figure 1.6. Typical configuration of a modern large scale HAWT [17]. 
Table 1.2. Main differences between vertical and horizontal axis wind turbines [15].

\begin{tabular}{llll}
\hline & Straight-blade & Curved-blade & HAWT \\
& Darrieus VAWT & Darrieus VAWT & \\
\hline Blade Profile & Simple & Complicated & Complicated \\
\hline Need for Yaw Mechanism & No & No & Yes \\
\hline Possibility of Pitch Mechanism & Yes & No & Yes \\
\hline Tower & Yes & No & Yes \\
\hline Guy Wires & Optional & Yes & No \\
\hline Noise & Low & Moderate & High \\
\hline Blade Area & Moderate & Large & Small \\
\hline Generator position & On ground & On ground & On ground \\
\hline Blade load & Moderate & Low & High \\
\hline Self-start & No & No & Yes \\
\hline Tower interference & Small & Small & Large \\
\hline Foundation & Moderate & Simple & Extensive \\
\hline Overall Structure & Simple & Simple & Complicated \\
\hline
\end{tabular}

\subsubsection{Drag type and lift type wind turbines}

When a flat object is exposed to an incident wind, it encounters a surface force, commonly known as aerodynamics force (Fig. 1.7). The component of the aerodynamic force that is parallel to the flow direction is called drag while the one, perpendicular to the direction of wind, is called lift. Magnitude of the drag force $D$ and the lift force $L$ are determined by following expressions:

$$
\begin{aligned}
& D=C_{D} \frac{\rho}{2} a u_{\infty}^{2} \\
& L=C_{L} \frac{\rho}{2} a u_{\infty}^{2}
\end{aligned}
$$

where $a$ is the planform area (projected area perpendicular to the flow velocity) of the object, $\rho$ is density of the air, and $u_{\infty}$ is the upstream wind speed and, $C_{D}$ and $C_{L}$ are proportional constants called drag and lift coefficients respectively. The constants depend on the 'aerodynamic quality' of the object: the better the aerodynamic quality of the object, the higher is the lift coefficient $C_{L}$ but lower is the drag coefficient $C_{D}$, and thus higher the lift force but lower drag force. 


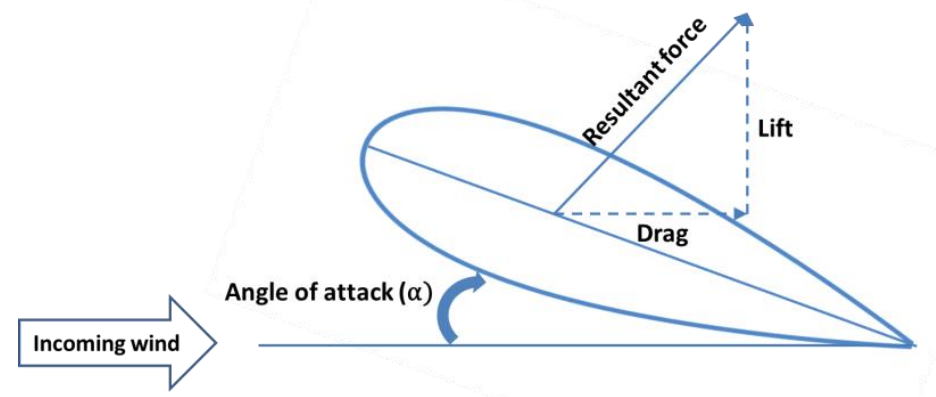

Figure 1.7. Drag and Lift components of the aerodynamic force.

As discussed earlier, Savonius type rotor is a drag-based wind turbine because it's the drag component of the aerodynamic force that powers the Savonius turbine to rotate. We can estimate the torque, and mechanical power output of a Savonius rotor using a simplified model, Figure 1.8. This simplified model however neglects the effect of rotor on the wind flow characteristics.

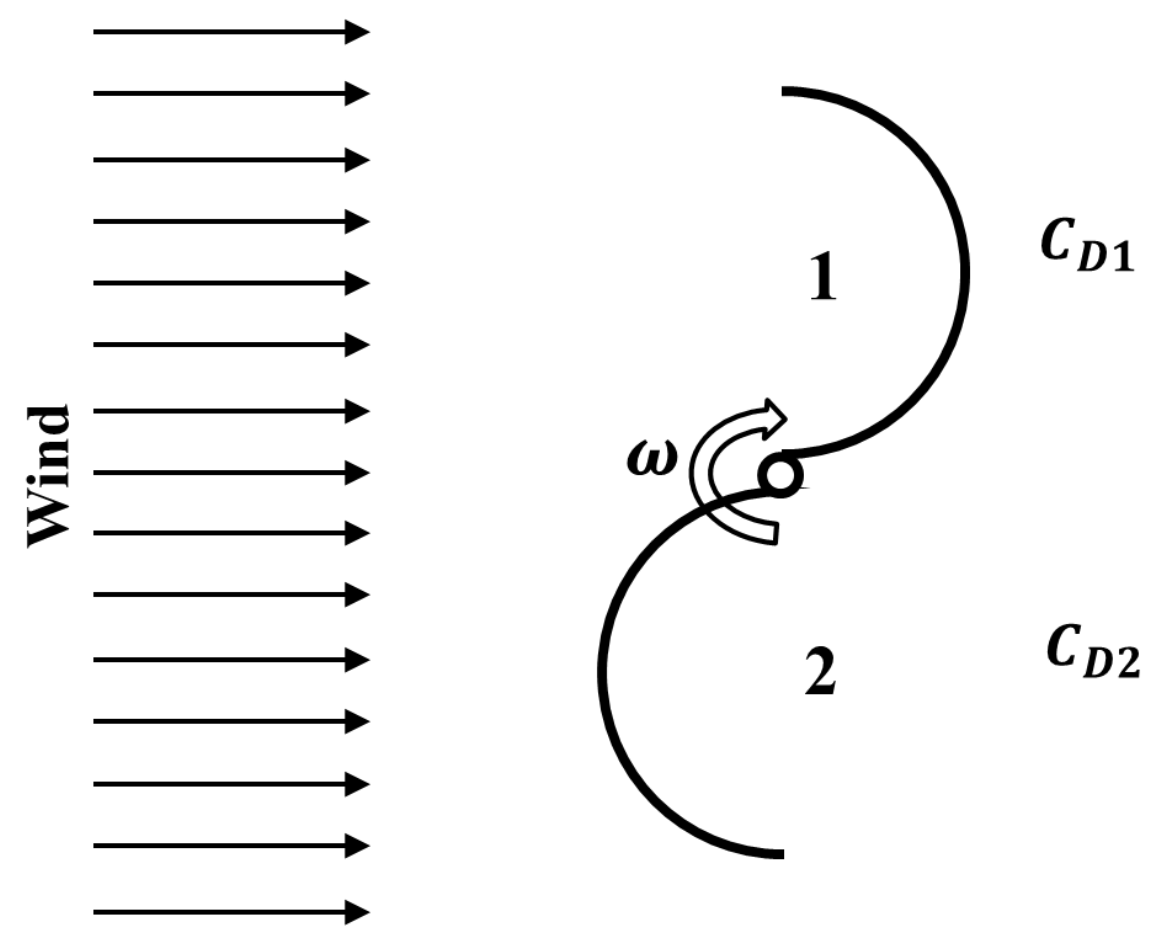

Figure 1.8. Simplified model for Savonius Wind turbine.

Let's assume that the rotor has mean radius $\mathrm{R}$ and it is rotating with an angular speed $\omega$. The circumferential velocity of the rotor at the mean radius is equal to:

$u=\omega R$ 
The average relative velocities of the wind $u_{r 1}$ and $u_{r 2}$ at the first and second rotating drums are given by following expressions, respectively.

$$
\begin{aligned}
& u_{r 1}=u_{\infty}-u \\
& u_{r 2}=u_{\infty}+u
\end{aligned}
$$

The resulting drag forces $D_{1}$ and $D_{2}$ on the rotating drums are given as:

$$
\begin{aligned}
& D_{1}=C_{D 1} \frac{1}{2} a u_{r 1}^{2}=C_{D 1} \frac{\rho}{2} a\left(u_{\infty}-u\right)^{2}=C_{D 1} \frac{\rho}{2} a u_{\infty}^{2}\left(1-\frac{u}{u_{\infty}}\right)^{2} \\
& D_{2}=C_{D 2} \frac{1}{2} a u_{r 2}^{2}=C_{D 2} \frac{\rho}{2} a\left(u_{\infty}+u\right)^{2}=C_{D 2} \frac{\rho}{2} a u_{\infty}^{2}\left(1+\frac{u}{u_{\infty}}\right)^{2}
\end{aligned}
$$

where, $a$ denotes projected area of the drums. The aerodynamic torque along the central axis is calculated as:

$$
\tau=\left(D_{1}-D_{2}\right) * R=\frac{\rho}{2} a u_{\infty}^{2} R\left(C_{D 1}\left(1-\frac{u}{u_{\infty}}\right)^{2}-C_{D 2}\left(1+\frac{u}{u_{\infty}}\right)^{2}\right)
$$

The mechanical power by the turbine can be then determined using the following equation.

$P=\tau * \omega=\frac{\rho}{2} a u_{\infty}^{2} \omega R\left(C_{D 1}\left(1-\frac{u}{u_{\infty}}\right)^{2}-C_{D 2}\left(1+\frac{u}{u_{\infty}}\right)^{2}\right.$

$P=\tau * \omega=\frac{\rho}{2}(2 a) u_{\infty}^{3}\left\{\frac{1}{2} \frac{u}{u_{\infty}}\left(C_{D 1}\left(1-\frac{u}{u_{\infty}}\right)^{2}-C_{D 2}\left(1+\frac{u}{u_{\infty}}\right)^{2}\right\}=C_{P} \frac{\rho}{2} a u_{\infty}^{3}\right.$

The expression $\left\{\frac{1}{2} \frac{u}{u_{\infty}}\left(C_{D 1}\left(1-\frac{u}{u_{\infty}}\right)^{2}-C_{D 2}\left(1+\frac{u}{u_{\infty}}\right)^{2}\right\}\right.$ is defined as power coefficient $C_{P}$. It can be noted from equation (1.7) that the mechanical power produced by a Savonius turbine is directly proportion to the total projected area by the rotor and the cube of upstream wind speed $u_{\infty}$.

Darrieus VAWTs and HAWTs are the lift-based wind turbines i.e. they extract power from the wind by utilizing mainly the lift component of the aerodynamic force on their blades. The analytical model to predict the power by a Darrieus wind turbine is quite complex. Normally, people use Computational Fluid Dynamics (CFD) to analysis the characteristics of a Darrieus rotor. There are however several analytical theories and models for HAWTs. Some of the major models, which are currently in practice, are Actuator Disc theory, Rotor Disc Theory, Vortex Cylinder Model of the Actuator Disc, and Rotor Blade Theory [18]. We will discuss some of these theories briefly in Chapter 4.

\subsubsection{Large scale vs. small scale wind turbines}

The definition of "small" and "large" scale windmill has remained vague in the literature of wind energy. Small wind turbine was initially defined on the basis of its capability to produce 
electrical power sufficient enough to cover individual household electricity demands [19]. But the problem lies in the fact that the consumption of electricity by a household itself is very debatable because it varies with time and place. For example, an average American family needs a $10 \mathrm{~kW}$ turbine to cover their full consumption, while a European household requires a $4 \mathrm{~kW}$ turbine, which further reduces to a $1 \mathrm{~kW}$ turbine for an average Chinese household [19]. Lacking any credible unanimous definition, the range for the rated power capacity of small scale wind turbines vary from few watts to few hundred kilowatts. To bring consistency in discussion, we define a nomenclature in this report based on the size of the horizontal axis wind turbine rotors as follows [20]:

(i) Micro-scale wind turbine $(\mu \mathrm{SWT})$ : rotor diameter $\leq 10 \mathrm{~cm}$,

(ii) Small-scale wind turbine (SSWT): $10 \mathrm{~cm}<$ rotor diameter $\leq 100 \mathrm{~cm}$,

(iii) Mid-scale wind turbine (MSWT): $1 \mathrm{~m}<$ rotor diameter $\leq 5 \mathrm{~m}$, and

(iv) Large-scale wind turbine (LSWT): rotor diameter $>5 \mathrm{~m}$

\subsection{Some terminologies}

Before we move any further in our discussion, let's introduce some basic terminologies that we shall often use in this thesis. Figure 1.9 demonstrates the various terms related to the nomenclature of an airfoil.

- Leading edge: It's the point at the front of an airfoil, which has the maximum curvature.

- Trailing Edge: It's the point at the rear of an airfoil, which has the maximum curvature.

- Chord Line: It's the straight line that connects the leading edge and trailing edge of an airfoil

- Chord Length $(c)$ : It's the length of the chord line.

- Suction Surface: It is the upper surface of an airfoil and is generally associated with higher velocity and lower static pressure than the pressure surface.

- Pressure Surface: It is the lower surface of an airfoil and is generally associated with lower velocity and higher static pressure than the suction surface.

- Mean Camber Line: It is the locus of a set of points that lie midway between the upper and lower surfaces.

- Maximum Thickness: It's the maximum thickness of an airfoil when measured perpendicular to the camber line. 


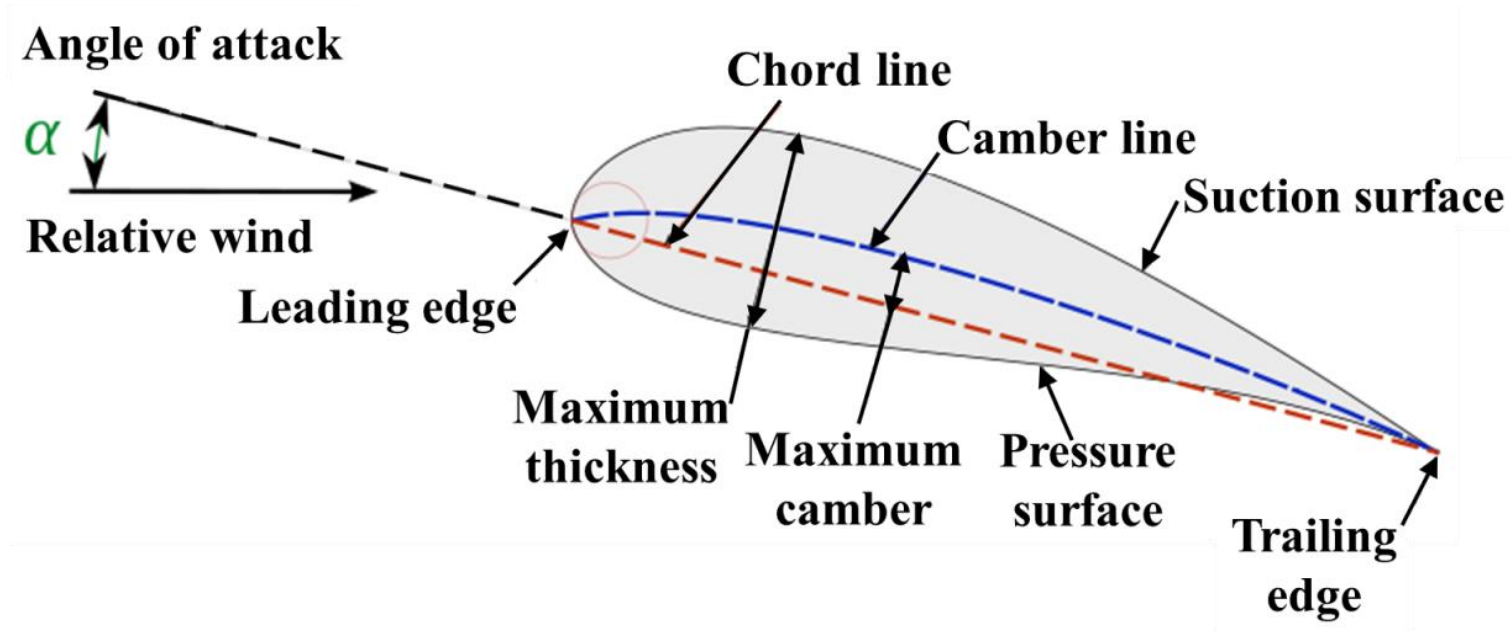

Figure 1.9. Some basic terminologies related to an airfoil [21].

Apart from the nomenclature of the airfoil, we shall also use few terms that are often used to indicate and characterize the performance of a wind turbine, particularly a HAWT.

- Power coefficient: It is defined as the amount of mechanical power produced by a wind turbine against the total available wind power. Sometimes, it's also called coefficient of performance and mathematically it is calculated using following expression [18].

$$
C_{P}=\frac{P_{m e c h}}{\frac{1}{2} \rho \pi r_{t}^{2} u_{\infty}^{3}}
$$

where $P_{\text {mech }}$ is the mechanical power generated by the wind turbine, $\rho$ is the density of the wind, $r_{t}$ is the tip radius by the rotor and $U_{\infty}$ is the free wind speed. The denominator term $\left(\frac{1}{2} \rho \pi r_{t}^{2} u_{\infty}^{3}\right)$ of equation (1.20) denotes the total available wind power passing across the swept area of the wind turbine rotor.

- Betz' Law: It calculates the maximum mechanical power produced by a wind turbine in an open wind flow. According to Betz's law, any turbine cannot extract more than $16 / 27(59.3 \%)$ of the kinetic energy in wind. The factor $16 / 27(0.593)$ is the maximum value of the power coefficient of a wind turbine and it is most commonly known as Betz's coefficient or Betz's limit.

- Torque Coefficient: This parameter is used to assess the shaft torque produced by a wind turbine rotor. High value of torque coefficient allows wind turbine to start and operate at lower wind speed. Also, there are some specific applications like water pumping where the shaft torque by the wind turbine is more important variable than the power output. For such cases, the torque coefficient becomes the prime 
characteristics of the wind turbine. Mathematically, torque coefficient $C_{Q}$ is given as [22]:

$$
C_{Q}=\frac{C_{P}}{\lambda}
$$

where $\lambda$ denotes tip speed ratio of the turbine.

- Tip Speed Ratio: Tip speed ratio $(\lambda)$ is the most commonly and conveniently used scaling parameter, which integrates the principle aerodynamic effect of the wind speed, rotor size and rotor's angular speed with the power coefficient of the wind turbine rotor. It evaluates the tangential speed of the turbine's blade with respect to the free wind speed and is given as [18]:

$$
\lambda=\frac{r_{t} \omega}{u_{\infty}}
$$

where $u_{\infty}$ is free wind speed, $r_{t}$ and $\omega$ denote tip radius and angular speed of the wind turbine rotor.

- Overall Efficiency: Power and torque coefficients characterize the performance of wind turbine rotor only. They don't account for the losses due to the other components of wind turbine such as electric generator, bearings, and gearbox. The third parameter, overall efficiency is defined as the net electric power produced against the total available wind power. It is given as [20]:

$$
\eta=\frac{P_{\text {elec }}}{\frac{1}{2} \rho \pi r_{t}{ }^{2} u_{\infty}^{3}}
$$

where $P_{\text {elec }}$ is the electric power produced by the wind turbine and term $\left(\frac{1}{2} \rho \pi r_{t}^{2} u_{\infty}^{3}\right)$ is the maximum available wind power as defined previously.

- Cut-in Speed: The cut-in speed of a wind turbine is defined as the minimum wind speed at which the wind turbine starts on its own and generates some usable power.

- Rated Speed: The rated speed of a wind turbine is defined as the minimum wind speed at which the wind turbine generates its indicated rated power.

- Cut-out Speed: The cut-out speed of a wind turbine is the maximum wind speed up to which the wind turbine should operate. This is required as a safety feature to protect the wind turbine from being damaged at the high wind speed.

\subsection{Betz' law}

Betz' law defines the maximum power that can be extracted from the wind by a wind turbine in an open flow. This law can be derived using principles of conservation of mass and 
momentum of the airflow flowing through an idealized "actuator disc" that emulates the wind turbine. Let's consider a stream-tube of air stream flowing through the actuator disc as shown in Figure 1.10. The stream-tube has upstream wind speed equal to $u_{1}$ and cross-sectional area equal to $A_{1}$. The actuator disc extracts the kinetic energy of the wind and thus causes it to slow down to speed $u_{2}$. Since air flowing within the stream-tube does not get compressed (assuming incompressible flow), the cross-sectional area of the stream-tube must expand to area $A_{2}$ in order to accommodate the slower moving air. Also, due to the static pressure drop $\left(p^{+}-p^{-}\right)$across the actuator disc, the downstream wind continues to expand till the point where static pressure of the flow returns to atmospheric level $p_{\infty}$ and equilibrium is achieved. The far downstream flow has cross-sectional area $A_{3}$ and wind speed equal to $u_{3}$.

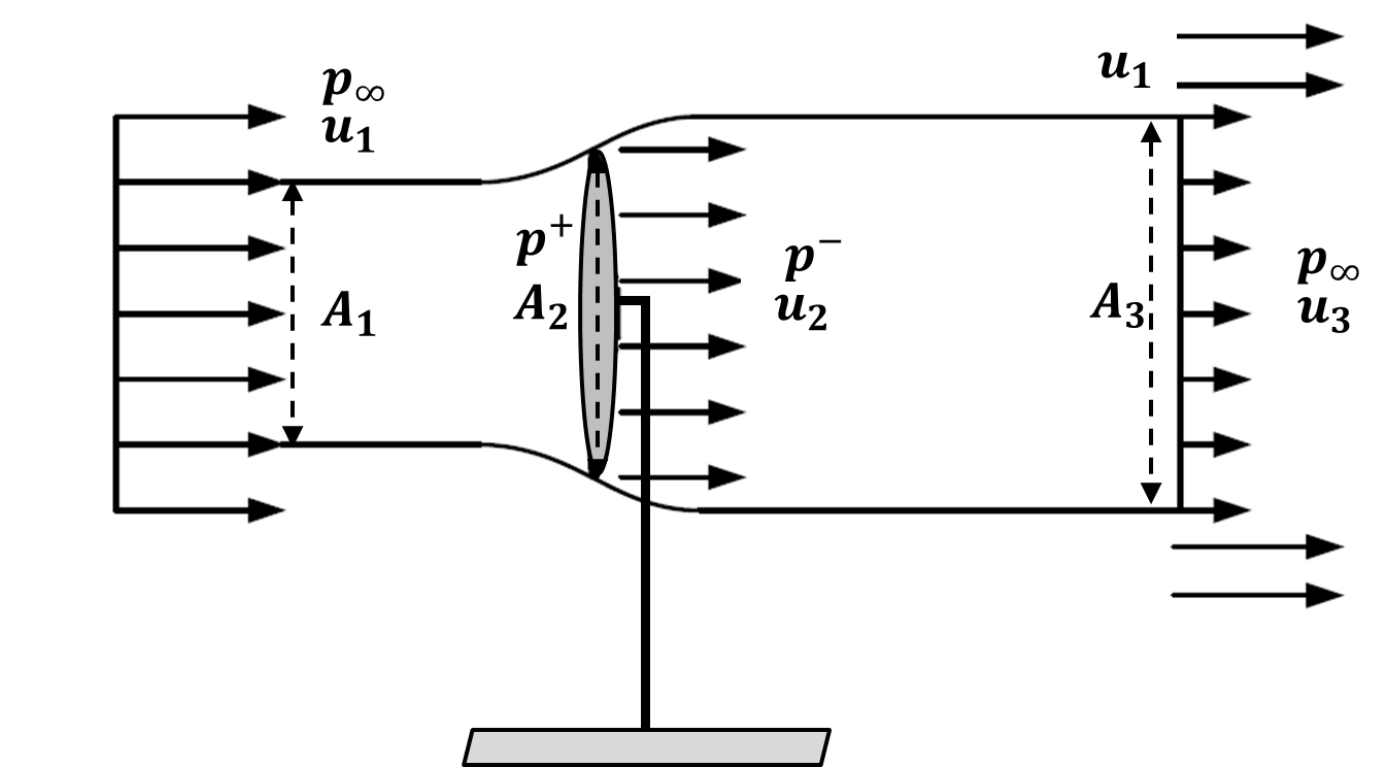

Figure 1.10. The stream-tube representing wind flow through the actuator disc.

Let the mass flow rate of the wind flow through the stream-tube is equal to $\dot{m}$. Using continuity equation, we can write:

$$
\dot{m}=\rho u_{1} A_{1}=\rho u_{2} A_{2}=\rho u_{3} A_{3}
$$

where $\rho$ denotes the density of air.

The total available wind power at wind speed $u_{1}$, passing through the cross-sectional area $A_{2}$ equal to the swept area of the actuator disc, is given by:

$$
P_{\text {max }}=\frac{1}{2} \dot{m}_{2} u_{1}^{2}=\frac{1}{2}\left(\rho A_{2} u_{1}\right) u_{1}^{2}=\frac{1}{2} \rho A_{2} u_{1}^{3}
$$

This is the maximum available wind power to the wind turbine. The extracted power by the wind turbine can be calculated as: 


$$
P_{\text {ext }}=\frac{1}{2} \dot{m} u_{1}^{2}-\frac{1}{2} \dot{m} u_{3}^{2}=\frac{1}{2} \rho A_{2} u_{2}\left(u_{1}^{2}-u_{3}^{2}\right)
$$

Also, using Bernoulli's equation, we can write:

$$
\begin{aligned}
& \frac{1}{2} \rho u_{1}^{2}+p_{\infty}=\frac{1}{2} \rho u_{2}^{2}+p^{+} \\
& \frac{1}{2} \rho u_{2}^{2}+p^{-}=\frac{1}{2} \rho u_{3}^{2}+p_{\infty}
\end{aligned}
$$

From equations (1.27) and (1.28), it can be derived that

$$
p^{+}-p^{-}=\frac{1}{2} \rho u_{1}^{2}-\frac{1}{2} \rho u_{3}^{2}
$$

Using momentum equation, we know that the net axial thrust $F=\left(p^{+}-p^{-}\right) A_{2}$ exerted by the turbine mounting on the wind flow is equal to its rate of change in momentum.

$$
\begin{aligned}
& \left(p^{+}-p^{-}\right) A_{2}=\dot{m}\left(u_{1}-u_{3}\right) \\
& \text { or }\left(p^{+}-p^{-}\right) A_{2}=\rho A_{2} u_{2}\left(u_{1}-u_{3}\right)
\end{aligned}
$$

From equations (1.29) and (1.31),

$$
\rho A_{2} u_{2}\left(u_{1}-u_{3}\right)=A_{2}\left(\frac{1}{2} \rho u_{1}^{2}-\frac{1}{2} \rho u_{3}^{2}\right)
$$

This implies, $u_{2}=\frac{1}{2}\left(u_{1}+u_{3}\right)$

As explained in the previous section, power coefficient $C_{P}$ is defined as:

$$
\begin{aligned}
C_{P} & =\frac{P_{\text {ext }}}{P_{\max }}=\frac{\frac{1}{2} \rho A_{2} u_{2}\left(u_{1}^{2}-u_{3}^{2}\right)}{\frac{1}{2} \rho A_{2} u_{1}^{3}} \\
C_{P} & =\frac{\frac{1}{4} \rho A_{2}\left(u_{1}+u_{3}\right)\left(u_{1}^{2}-u_{3}^{2}\right)}{\frac{1}{2} \rho A_{2} u_{1}^{3}} \\
C_{P} & =\frac{1}{2}\left(1+\frac{u_{3}}{u_{1}}\right)\left(1-\frac{u_{3}^{2}}{u_{1}^{2}}\right)
\end{aligned}
$$

Let, $\frac{u_{3}}{u_{1}}=y$

$C_{P}=\frac{1}{2}(1+y)\left(1-y^{2}\right)$

The maximum value of power coefficient occurs when

$$
\begin{aligned}
& \frac{d C_{P}}{d y}=0 \\
& \frac{d C_{P}}{d y}=\frac{1}{2}\left(1-y^{2}\right)+\frac{1}{2}(1+y)(-2 y) \\
& \frac{1}{2}(1+y)(1-3 y)=0
\end{aligned}
$$

Since, $y=\frac{u_{3}}{u_{1}} \neq-1$

$$
y=\frac{1}{3}
$$

This gives maximum value of power coefficient as:

$$
C_{P, \max }=C_{P}\left(y=\frac{1}{3}\right)=\frac{16}{27}
$$




\subsection{Need and applications of small scale wind turbines (SSWTs)}

The recent advancements in the field of microelectronics have not only miniaturized the wireless devices but have also decreased their power requirement by an order of magnitude. Wireless sensors nodes, for example, now need power less than $1 \mathrm{~mW}$ [23]. Such nodes are used in variety of applications such as gas and chemical sensors, temperature, pressure and humidity monitoring, motion detector, structural health monitoring, and explosives detection [23]. The over-expanding usage of wireless devices however has brought challenges in terms of finding a suitable power source, especially for the remote applications. In majority of such cases, currently lithium cell batteries are used, which presents maintenance challenge because these batteries need to be regularly monitored and replaced. One of the most convenient methods of supplying the required power to the miniature electronic devices is by harvesting the wind energy. The conventional large scale wind turbines (LSWTs) are efficient and the modern mega-watt wind turbines have power coefficient up to $40 \%-45 \%$ [24]. However, they need high wind speed to operate; typical rated wind speed is around $12 \mathrm{~m} / \mathrm{s}-14 \mathrm{~m} / \mathrm{s}$. Further, their installations are limited to areas far from the city or township due to some practical concerns related to safety hazards and noise emission. In comparison, small scale wind turbines (SSWTs) can operate at low wind speed, generate minimal noise and there are no known safety hazards. In spite of several advantages, very few small-scale wind turbine models have been developed. Table 1.3 shows some of the currently available small to midscale wind turbines [25-35]. It is interesting to note that most of these wind turbines are in mid-scale range. The rated wind speed is typically above $10 \mathrm{~m} / \mathrm{s}$. None of the wind turbines except micro-wind turbine can operate efficiently at the wind speed condition below $5 \mathrm{~m} / \mathrm{s}$. The micro-wind turbine which operates in range of $2 \mathrm{~m} / \mathrm{s}-7 \mathrm{~m} / \mathrm{s}$ has optimal power coefficient of $18 \%$ which is quite low. $\mu$ F500 is the only SSWT which has good overall efficiency value of $25 \%$, but its rated wind speed is $12 \mathrm{~m} / \mathrm{s}$. The current status of the SSWTs essentially emphasizes the lack of suitable SSWT models that can operate near ground level at wind speeds of the order of few meters per second.

Table 1.3. Some of the currently available small-to-mid scale horizontal axis wind turbines

\begin{tabular}{ccccc}
\hline Sr. & Description & $\begin{array}{c}\text { Rotor } \\
\text { Diameter } \\
\text { No. }\end{array}$ & $\begin{array}{c}\text { Rated } \\
\text { Wind } \\
\text { Speed } \\
(\mathbf{m} / \mathbf{s})\end{array}$ & $\begin{array}{c}\text { Overall } \\
\text { Efficiency } \\
\text { a }\end{array}$ \\
\hline 1 & $\begin{array}{l}\text { NE-100 S } \\
\text { (http://www.wxnaier.com/ProductShow.asp?ID=790) }\end{array}$ & 120 & 10 & $14 \%$ \\
\hline
\end{tabular}




\begin{tabular}{|c|c|c|c|c|}
\hline 2 & $\begin{array}{l}\text { NE-200 S } \\
\text { (http://www.wxnaier.com/ProductShow.asp?ID=790) }\end{array}$ & 130 & 11 & $18 \%$ \\
\hline 3 & $\begin{array}{l}\text { NE-300 S } \\
\text { (http://www.wxnaier.com/ProductShow.asp?ID=790) }\end{array}$ & 130 & 13 & $17 \%$ \\
\hline 4 & $\begin{array}{l}\text { Energy Ball V100(http://www.home- } \\
\text { energy.com/int/ebv100technical.htm) }\end{array}$ & 110 & 10 & $17 \%$ \\
\hline 5 & Micro Wind Turbine [35] & 23.4 & $2-7^{b}$ & $18 \%^{\mathrm{c}}$ \\
\hline 6 & $\begin{array}{l}\text { TAOS } 600 \\
\text { (www.taoswind.com/TAOS600SPEC.pdf) }\end{array}$ & 180 & 12.5 & $20 \%$ \\
\hline 7 & $\begin{array}{l}\text { Chinook } 200 \\
\text { (www.chinookturbines.com/Products.html) }\end{array}$ & 100 & 12.5 & $21 \%$ \\
\hline 8 & $\begin{array}{l}\text { EP-220 } \\
\text { (www.electricpinwheels.com/Wind_Turbine.html) }\end{array}$ & 137 & 12.5 & $12 \%$ \\
\hline 9 & $\begin{array}{l}\text { Bornay } 600 \text { (www.bornay.com/eolica/en/wind- } \\
\text { turbines/4/models/17/bornay-600/1/specs) }\end{array}$ & 200 & 11 & $23 \%$ \\
\hline 10 & $\begin{array}{l}\text { AC } 120 \text { (www.aerocraft.de/downloads/AeroCraft- } \\
\text { Systems_gb.pdf) }\end{array}$ & 120 & 9 & $24 \%$ \\
\hline 11 & $\begin{array}{l}\text { AC } 240 \text { (www.aerocraft.de/downloads/AeroCraft- } \\
\text { Systems_gb.pdf) }\end{array}$ & 165 & 9 & $25 \%$ \\
\hline 12 & $\mu \mathrm{F} 500[34]$ & 50 & 12 & $25 \%$ \\
\hline 13 & $\begin{array}{l}\text { Alladin } 400 \\
\text { (www.taoswind.com/Alladin400SPEC.pdf) }\end{array}$ & 130 & 12.5 & $25 \%$ \\
\hline 14 & $\begin{array}{l}\text { Superwind } 350 \\
\text { (www.superwind.com/swe/index.htm) }\end{array}$ & 120 & 12.5 & $26 \%$ \\
\hline
\end{tabular}

\subsection{Research scope}

It is clear from the discussion in the previous section that the developments in the wind energy harvesting technology as of now have been mainly concentrated towards the large scale power production. This is mainly due to the economy of scale that justifies the installation and operational costs of LSWTs. The two main reasons for the low adaptability of the SSWTs are their poor aerodynamic performance and the low power output. The aerodynamic performance of a wind turbine is primarily influenced by Reynolds number of the airfoil used for the turbine blades. Reynolds number of an airfoil is given by:

$$
R e=\frac{\rho c u_{r e l}}{\mu}
$$

where $\rho$ and $\mu$ are density and dynamic viscosity of the flowing fluid respectively, c denotes the chord length of the airfoil and $u_{r e l}$ is the relative wind speed. Relative wind speed $\left(\vec{u}_{r e l}\right)$ is vector sum of free wind speed and the blade speed at mid-radius of the rotor. Mathematically, it is given as:

$$
\overrightarrow{\boldsymbol{u}}_{\boldsymbol{r e l}}=\overrightarrow{\boldsymbol{u}}_{\infty}+r_{m} \overrightarrow{\boldsymbol{\omega}}
$$


where, $u_{\infty}$ is the upstream free wind speed, $r_{m}$ and $\omega$ denote the mid-radius and the angular speed of the wind turbine rotor, respectively.

The Reynolds number of a wind turbine is proportional to the chord length and the wind speed. For the small scale wind turbines, these two factors have very small value and therefore they operate at much lower Reynolds number as compared to the large scale wind turbines. Figure 1.10 depicts the effect of Reynolds number on the aerodynamic parameters (lift and drag coefficients) for NACA 0012 airfoil [20, 36]. It is very interesting to note that the maximum lift coefficient decreases with decrease in Reynolds number while the drag coefficient increases when Reynolds number is reduced. This implies that the lift to drag ratio reduces sharply with decrease in Reynolds number, which results in poor performance of the small scale wind turbines. There are myriad kinds of airfoil available that have been developed for different purposes. Each of these airfoils has specific range of flow Reynolds number where it performs efficiently. The selection of an appropriate airfoil, which is suitable for the operating range of given Reynolds number, is the first and foremost step for achieving acceptable performance of a small scale wind turbine.

The power $P$ generated by a wind turbine is given by following expression [18].

$$
P=\frac{1}{2} \eta \rho \pi r^{2} u_{\infty}^{3}
$$

where $r$ is the radius of the wind turbine, $u_{\infty}$ is the speed of the wind and $\eta$ is the overall efficiency of the system whose maximum value is equal to $\frac{16}{27}$ (defined by Betz's limit). The power output is proportional to the square of the radius of wind turbine and cube of the wind velocity. As the size of the wind turbine and the wind speed decrease, the power decreases drastically and below certain limit its magnitude is too low to justify the construction and operational cost. Therefore, achieving maximum possible efficiency should not be the only objective in the development of SSWTs. The structural factors such as modularity, portability and reliability can excessively broaden the scope of application of the device and thus justify the cost-effectiveness of the technology. 


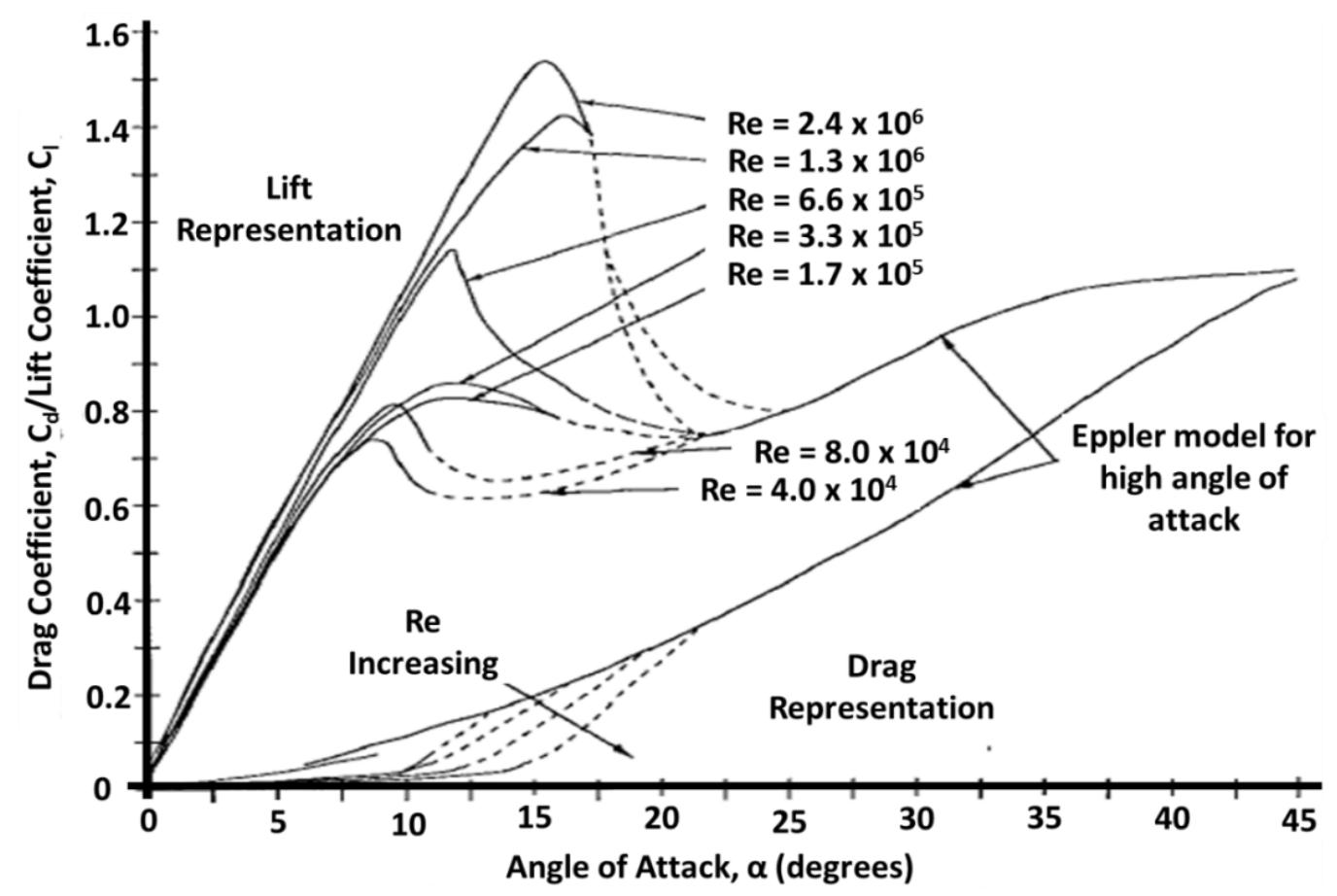

Figure 1.11. Influence of Reynolds number on airfoil behavior (NACA-0012) [20, 36].

Another important metric while working on the small scale is the cut-in speed. This represents the undisturbed upstream speed of the wind at which the turbine starts producing power. It depends on the total inertia and the internal friction of the system including the rotor, ball bearings, gear train, and generator. The smaller the wind turbine the lower is cut-in speed due to lower inertia but the problem lies in the fact that decrease in the size of wind turbine blades reduces the aerodynamic torque and thus increases the cut-in speed. These two opposing factors should be optimized to design a wind turbine of small size but of the desired cut-in speed and power-output. The cut-in speed and the efficiency of the wind turbine may also be improved by reducing the frictional losses from the bearings and the gear train. The gear train and bearing can be avoided if the generator is directly connected to the wind turbine. However, this presents challenge in terms of achieving desired revolutions per minute (rpm) of the rotor shaft. Therefore, choosing a small size generator with the low starting torque and high voltage-to-rpm ratio is a key step. Determining the gear ratio is another important step which needs to be done when the power transmitting gearbox is unavoidable. Gear ratio depends on the range of speed and torque needed by the generator to perform most efficiently. Sometimes, size of the nacelle also restricts the size of the gear box and thus the gear ratio. Cost, noise and reliability in operation are the three main factors which should also be taken into account while finalizing the type and configuration of gearing system. 
Apart from the factors discussed above, there are some geometrical parameters of the wind turbine blades which are needed to be optimized. The most important among them are the twist angle, blade angle, tapering angle, chord length, solidity, and number of blades. There are numerous design tools and programs available commercially and in literature which a designer can use to optimize the geometrical parameters of the wind turbine blades. However, the problem is that the majority of these design tools have been developed for LSWTs and unfortunately currently, SSWTs are also being designed using the same design tools. The SSWTs have quite different aerodynamic behavior than their large scale counterparts because of few fundamental differences. First, they are much smaller in size and thus many assumptions, which are made at larger scale, do not remain valid entirely at the small scale. Second, the SSWTs operate at much lower wind speed than the LSWTs. Thus, the main design goal for SSWTs is not only to achieve the highest possible power output but also high starting torque and thus low cut-in wind speed. Finally, the application requirements and the operating conditions of the small scale wind turbines are near the ground where wind is not fully developed but weak and turbulent due to the presence of surrounding obstacles like buildings, trees etc. Therefore, there is critical need to develop a design tool for SSWTs that takes into account their operating conditions and local application requirements.

\subsection{Literature review}

A small scale wind turbine consists of three main components: (i) wind turbine rotor which includes turbine blades and hub, (ii) transmission system which consists of connecting shafts, bearings and the gear train, and (iii) electric generator. Since the power output of SSWTs is quite low, even a small loss in efficiency due to any of these components may largely affect the overall performance and utility of the turbine. Each of these components should be designed, optimized and mutually synchronized in such a fashion that they operate at their rated operating condition. There are very few attempts available in literature that study the performance characteristics of SSWTs. Vardar and Alibas [37] compared the rotation rates and power coefficients of various $31 \mathrm{~cm}$ diameter wind turbine rotor models. They were manufactured using four different NACA profiles (NACA 0012, NACA 4412, NACA 4415, and NACA 23012). Various geometric parameters such as blade angle, twist angle and blade number of these turbine models were investigated at different wind speeds. It was observed that the rotor with NACA 4412 profiles having $0^{\circ}$ twisting angle, $5^{\circ}$ blade angle, and two blades had the highest rotation rate while the one with NACA 4415 profiles with $0^{\circ}$ twisting 
angle, $18^{\circ}$ blade angle, and 4 blades had the highest power coefficient. A numerical study using blade element momentum (BEM) theory and lifting line based wake theory was conducted by Duquette and Visser [22] to assess the effects of blade number and solidity on the performance of $2 \mathrm{~m}$ diameter wind turbine. The study suggested that by increasing the solidity from the conventional range of $5 \%-7 \%$ to $15 \%-25 \%$ one can achieve better power coefficient values. Leung et al. [35] optimized different blades parameters of a $23.4 \mathrm{~cm}$ diameter wind turbine using Computational Fluid Dynamics (CFD). The wind turbine used in this study had fan-type, mono-thick (constant thickness along the radius) and multiple numbers of blades instead of conventional airfoil type tapered blades. This study supported the fact that the higher solidity gives better performance to SSWTs, however it was also suggested that the blades should not fully occupy the swept area of the rotor to avoid blockage. It can be observed that all of these studies primarily focus on designing and optimizing the wind turbine rotor, more specifically the turbine blades. They lack the overall comprehensiveness addressing all the components together to develop a complete small scale wind turbine. Probably, the first attempt to make a complete SSWT was performed by Hirahara et al. [34]. They developed a 4-bladed $50 \mathrm{~cm}$ diameter small wind turbine called $\mu$ F500 using NACA 2404 airfoil. This turbine exhibited very good performance with power coefficient of 0.36 and overall efficiency of 0.25 in the wind speed range of $8-12 \mathrm{~m} / \mathrm{s}$.

Some researchers [38-42] have also proposed the idea of diffuser augmented wind turbines. It has been suggested that a duct in the form of diffuser around a wind turbine augments the wind speed near the turbine blade and thus increases the overall power output of the wind turbine. Further, it also improves the cut-in wind speed of the wind turbines and thus allows them to operate at lower wind speed. Different kinds of diffusers have been developed over the period of time and the power augmentation up to 4-5 times has been reported with the flanged diffuser [42]. However, incorporation of diffuser makes the wind turbine quite bulky, which increases the overall aerodynamic drag and thus requires strong mounting.

\subsection{Objectives of the thesis}

Considering the lack of any suitable design tool for modeling the small scale wind turbines, the primary objective of this thesis is to develop a reliable numerical model to design an efficient SSWT. Using the proposed design tool, a small-scale wind energy portable turbine (SWEPT) will be designed and fabricated, which will operate near ground level where wind speed is below $5 \mathrm{~m} / \mathrm{s}$. SWEPT should not only be efficient and small in size but it should also 
be simple, compact, and portable. It needs to produce at least 1 watt of electrical power output at the wind speed below $5 \mathrm{~m} / \mathrm{s}$. The efficacy of the design tool will be tested by comparing the performances of two similar size SSWTs, one designed using the current design tool and other designed using a commercial program. To investigate the possibility of diffuser-augmented SSWT, a diffuser will be designed for SWEPT using Computational Fluid Dynamics (CFD). Wind Tunnel experiments will be then carried out to compare the performances of SWEPT with and without the diffuser. The study also aims to develop a piezoelectric wind turbine which will operate below the cut-in wind speed of SWEPT.

\subsection{Layout of the thesis}

This thesis has been divided into ten chapters. Chapter 1 is 'Introduction', which covers a brief account of the historical background of wind turbines, the current status of wind energy worldwide and in the United States, various classifications of the wind turbines along with their configurations, and the main components of a HAWT with their needs and working principles. A short note addressing some basic terminologies used in wind turbine literature has been also provided in this chapter. This chapter also summarizes the major differences between large and small scale wind turbines followed by a discussion on needs and applications areas of SSWTs, the current status of SSWTs, and the prospective research scope in this field. Finally, a section on literature review is included followed by a brief note on the main objectives of this thesis.

Chapter 2 aims to design and develop a small-scale wind turbine portable turbine (SWEPT), targeted to operate near ground level, using a commercial software. This chapter covers design and fabrication process of the wind turbine, its main design specifications, the experimental set-up for wind tunnel experimentation, and the experimentation procedure. It also highlights a novel torque measurement technique for small scale wind turbines, which does not require any torque sensor or transducer. Finally, the result and discussion section of this chapter provides an exhaustive discussion on the mechanical and electrical performances of the wind turbine obtained using wind tunnel experimentation.

Chapter 3 intends to develop a diffuser-augmented small-scale wind energy portable turbine. Computational fluid dynamics (CFD) studies have been conducted to optimize the geometrical parameters of a diffuser in order to achieve maximum possible wind velocity augmentation factor, keeping into account the size and cost constraints of the device. This chapter covers the solution strategy and procedure for CFD studies, optimization process, diffuser construction and fabrication techniques, and the experimental set-up for wind tunnel 
experimentation. The numerical results predicted by the CFD model have been verified with experimental data. The wind tunnel experiments have been also conducted to determine the power augmentation factor of SWEPT with diffuser over the one without diffuser.

In Chapter 4, we propose a novel inverse design and optimization tool for SSWTs. This chapter first covers a brief discussion on blade element momentum (BEM) theory followed by an iterative scheme used to develop the design tool. A systematic design procedure has been described that discusses the approach and steps required to optimize various geometrical parameters of a SSWT. This chapter also covers the manufacturing process of the optimized wind turbine blades, the experimental set-up and procedure for the wind tunnel experiment. Finally, the power and torque coefficients predicted by the design tool have been compared with the experimental results to check the sanctity and efficacy of the design tool.

Chapter 5 provides experimental study on the second generation small-scale wind energy portable turbine (SWEPT). A high efficiency SWEPT has been developed having power coefficient of $32.3 \%$ and overall efficiency of $21 \%$ at the rated wind speed of $4.0 \mathrm{~m} / \mathrm{s}$. This chapter describes the design specifications of the high efficiency SWEPT followed by the experimental set-up and the testing procedure. The exhaustive discussion on the torque and power characteristics of SWEPT, including the turbine blade and the generator, has been given in 'results and discussion' section.

Chapter 6 concludes the discussion on small-scale wind energy portable turbine (SWEPT). A $3^{\text {rd }}$ generation SWEPT prototype has been proposed in this chapter. Unlike the previous designs, this prototype is direct-drive, which allows the wind turbine to operate in much wider range of wind speeds than the previous generation prototypes. An axial flux generator is developed, which is suitable for small-scale wind turbines at low wind speed applications. Using wind tunnel experiments, it was found that the $3^{\text {rd }}$ generation SWEPT has cut-in speed of $1.7 \mathrm{~m} / \mathrm{s}$; it operates between $1.7 \mathrm{~m} / \mathrm{s}-10 \mathrm{~m} / \mathrm{s}$ of wind speed and produces rated electrical power of 1 watt at $4.0 \mathrm{~m} / \mathrm{s}$. The electrical power of the wind turbine however increased to 9.3 watts at wind speed of $10 \mathrm{~m} / \mathrm{s}$.

Chapter 7 of this thesis is dedicated to the development of a novel piezoelectric wind turbine which operates at wind speeds below the cut-in wind speed of SWEPT. An ultra-low wind speed piezoelectric wind energy harvester has been developed which operates in the range of wind speeds between $1.0 \mathrm{~m} / \mathrm{s}$ to $2.2 \mathrm{~m} / \mathrm{s}$. The chapter first covers the needs and applications of such wind energy harvester, followed by the design procedure and main design specifications of the piezoelectric wind turbine. The experimental set-up and the 
power performance of the wind turbine obtained using wind tunnel experiments have been described in-depth in the next sections.

In Chapter 8, we summarize the major findings of this research. Chapter 9 highlights the some of the main fundamental scientific achievements of this work. Chapter 10 suggests some future studies required to modify the existing SWEPT prototype to make it suitable for the deployment. 


\section{CHAPTER 2}

\section{First generation small-scale wind energy portable turbine}

This chapter presents design and characterization of the first generation small-scale wind energy portable turbine (SWEPT) targeted to operate near ground level (wind speed: below 5 $\mathrm{m} / \mathrm{s}$ ). The wind turbine was designed using a commercial software, Blade Designer [43]. Wind tunnel experiments were then conducted to characterize its performance in the range of wind speeds between $1.5 \mathrm{~m} / \mathrm{s}$ and $5.0 \mathrm{~m} / \mathrm{s}$. An alternative method for the mechanical power calculation is also discussed which does not require any torque measurement device and thus is highly useful for common laboratory measurements.

\subsection{SWEPT design specifications and construction}

Blade Designer uses various input parameters such as rotor diameter, tip-speed-ratio, number of blades, and some airfoil properties, and estimates the performance of a wind turbine. It also provides various geometrical parameters of the blade, such as blade angle, chord length, and maximum thickness at increments down the length of blade. Using these blade parameters, the blade geometry can be created using a computer-aided design (CAD) software, which can then be used for manufacturing and fabrication. After performing several initial iterations, a design having predicted power output of 1 watt at the wind speed of 10 $\mathrm{mph}(4.47 \mathrm{~m} / \mathrm{s})$ was finalized. The selected design was slightly modified later on to simplify the manufacturing.

The final design of SWEPT has three blades, and its rotor diameter is equal to 39.4 $\mathrm{cm}$. Its blades are linearly twisted by $32^{\circ}$ from root to tip and their connection angle to the hub is $3^{\circ}$. The airfoil used is symmetrical along the camber line and had maximum thickness of about $6.5 \mathrm{~mm}$ throughout the span of the blades. Figure 2.1 shows the details of the blade profile with all dimensions in centimeters. Blades are connected to the aerodynamically shaped hub using dove-tail joints. SWEPT has a gear train of gear-ratio 80:10 which are needed to amplify the rotational speed of the driving shaft of the generator. The permanent magnet direct current motor has been used as the generator as there was no suitable generator/alternator readily available of the desired size. A $24 \mathrm{~V}$ permanent magnet DC motor manufactured by Mabuchi Motor Co. Ltd. (model \# 14415) was selected as the generator. Blades and hub of SWEPT were casted to ensure the reliability of manufacturing 
process and also to reduce the cost associated with fabrication. The casting material used was 'Feather Lite' low density urethane casting resin produced by Smooth-on, Inc. 'Feather Lite' has low weight-to-strength ratio so that the rotating components have low inertia but high strength. Carbon fiber rods were incorporated in the mid-plane of the blades while casting as an additional reinforcement. Figure 2.2 shows a fully assembled SWEPT prototype.

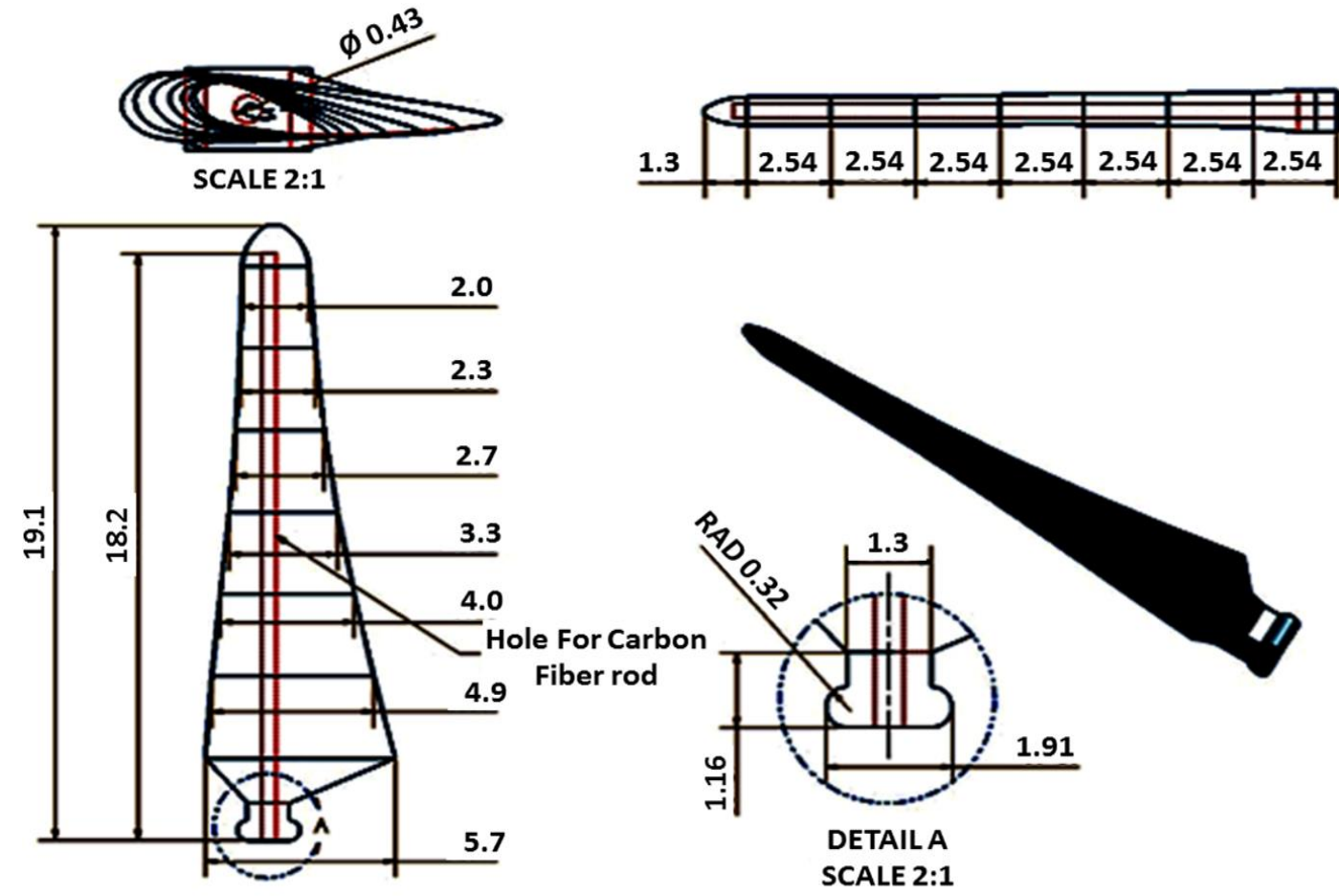

Figure 2.1. Blade design configuration with all dimensions in $\mathrm{cm}$.
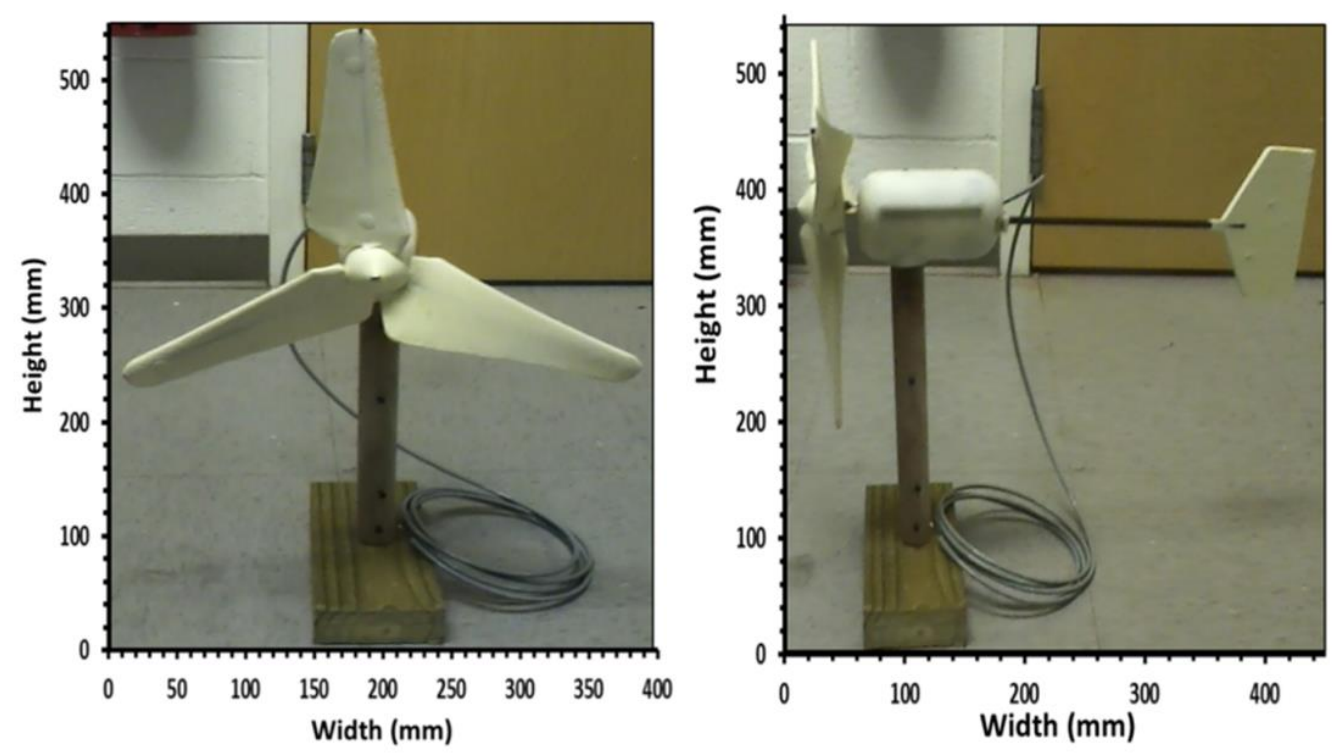

Figure 2.2. First generation small-scale windmill prototype "SWEPT". 


\subsection{Experimental set-up}

All the experiments were conducted using the Subsonic Open Jet Wind Tunnel facility available in the Department of Aerospace and Ocean Engineering at Virginia Tech. This is $0.7 \mathrm{~m}$ long, blower type, open circuit wind tunnel which is known for its high quality flow. It is powered by a $30 \mathrm{hp} \mathrm{BC-SW}$ size 365 Twin City centrifugal fan. The air flow discharged by the fan first passes through a $6^{\circ}-4 \mathrm{~m}$ long diffuser, which is then directed into a $1.47 \times 1.78 \mathrm{~m}^{2}$ settling chamber followed by a combination of $0.01 \mathrm{~m}$ cell size, $0.09 \mathrm{~m}$ long honeycomb and three turbulence reduction screens which ensure a uniform flow with low turbulence, less than $2 \%$. The flow is finally discharged in the atmosphere through a 5.5:1 contraction nozzle based on a $5^{\text {th }}$ degree polynomial profile. The maximum obtainable wind speed of the wind tunnel is $28 \mathrm{~m} / \mathrm{s}$. The wind tunnel is also equipped with a jet catcher, which is located $1.2 \mathrm{~m}$ downstream of the contraction exit, to minimize the impact of the flow on the lab environment.
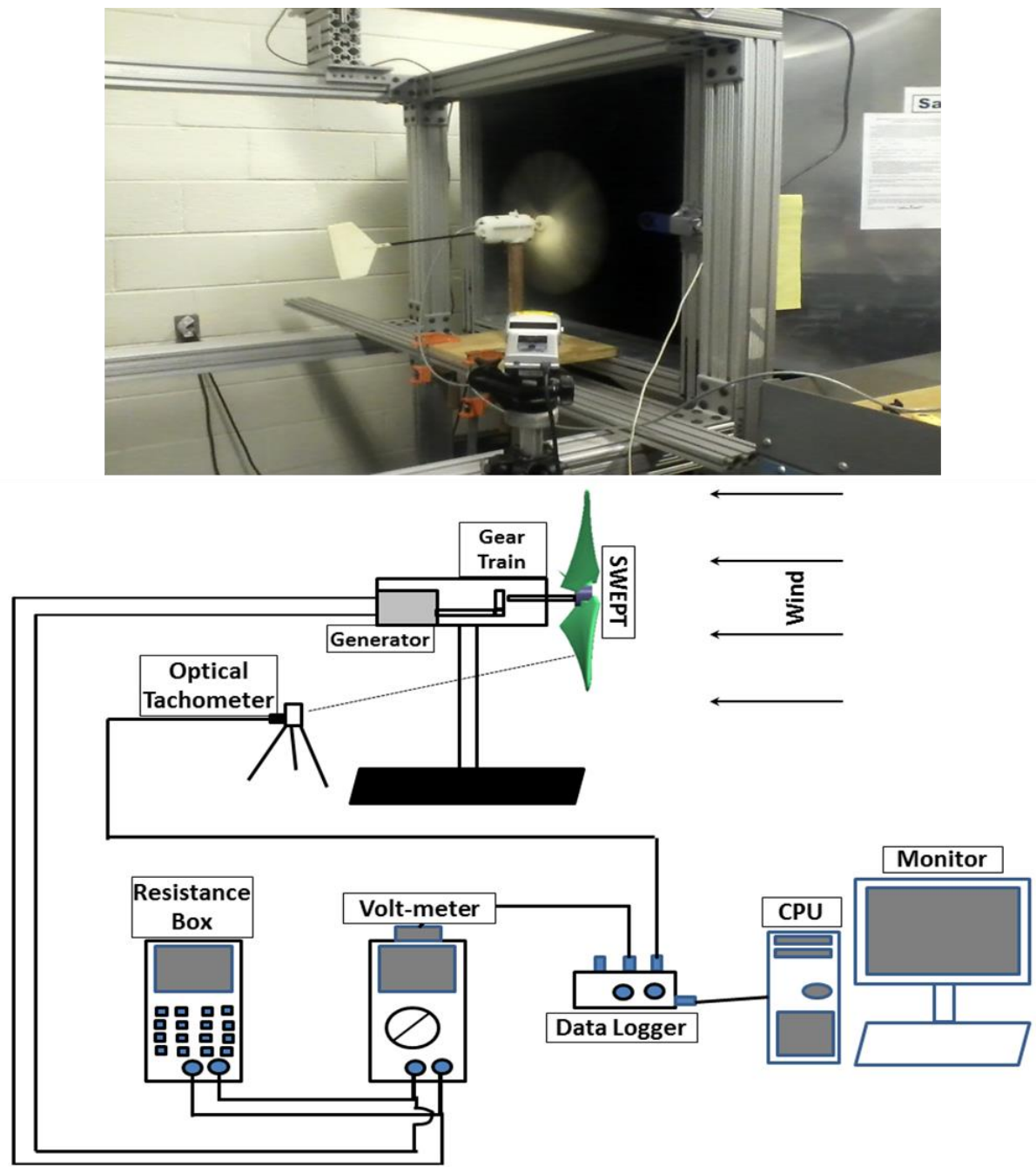

Figure 2.3. Experimental set-up with the schematic diagram. 
The angular velocity of the wind turbine was measured using non-contact type optical, digital Tachometer "DT-209X" (SHIMPO Instruments, USA). Anemometer used in the experiments was PASPORT, Model PS-2174 (PASCO, USA). The output voltage of the wind turbine generator was measured using "RadioShack Digital Multi-meter". The resistance box used to study the performance of the wind turbine at various loading conditions was an electronically controlled resistance box named "ohmSOURCE Model OS260" by IET Labs, Inc. Figure 2.3 shows the experimental set-up and schematic diagram of the wind tunnel experimentation. The generator of the wind turbine was connected to the voltmeter which was connected to the resistance box in parallel. At a fixed wind velocity, the load resistance can be varied using the resistance box and corresponding output voltage can be recorded. The experiment was repeated several times for a given set of conditions and arithmetic mean of the voltage and the angular velocity recorded was taken as the representative value. Wind tunnel experiments were conducted at 8 different wind speed conditions between $1.8 \mathrm{~m} / \mathrm{s}$ and $5.0 \mathrm{~m} / \mathrm{s}$. The method for mechanical power calculation is explained in the next section.

\subsection{Results and discussion}

\subsubsection{Mechanical power by SWEPT}

The mechanical power is defined as the product of torque and angular speed and it can be easily calculated for a wind turbine if we can accurately determine the torque and rpm of the rotor when wind turbine is running without any external load. Torque transducer, which is generally used to measure the shaft torque, is quite expensive device therefore an alternative method was developed in this study. This method is based on the basic relationship which defines torque as:

$$
\Gamma=\mathrm{J} \frac{d \omega}{d t}
$$

where $\Gamma$ is the torque generated by the wind turbine, $\mathrm{J}$ is the moment of inertia of the rotor

(including blades) about the axis of rotation and $\frac{d \omega}{d t}$ is the time rate of change of angular speed called angular acceleration. The moment of inertia $J$ was determined using the commercial software SolidWorks. The angular acceleration was calculated using the wind tunnel experimentation. The blade of the wind turbine was held stationary until wind speed in the wind tunnel was stabilized and then it was allowed to rotate and accelerate freely to its maximum constant speed. The rpm of the turbine blade, while it was accelerating, was recorded at the time interval of $100 \mathrm{~ms}$ using the optical tachometer. The curve fitting method 
was then employed to find the $6^{\text {th }}$ degree polynomial equation which describes the rpm as function of time. Figure 2.4 shows the angular speed of the wind turbine at the wind speed of $3.2 \mathrm{~m} / \mathrm{s}$. The time derivative of the velocity gives the acceleration which multiplied by the moment of inertia provides the torque.

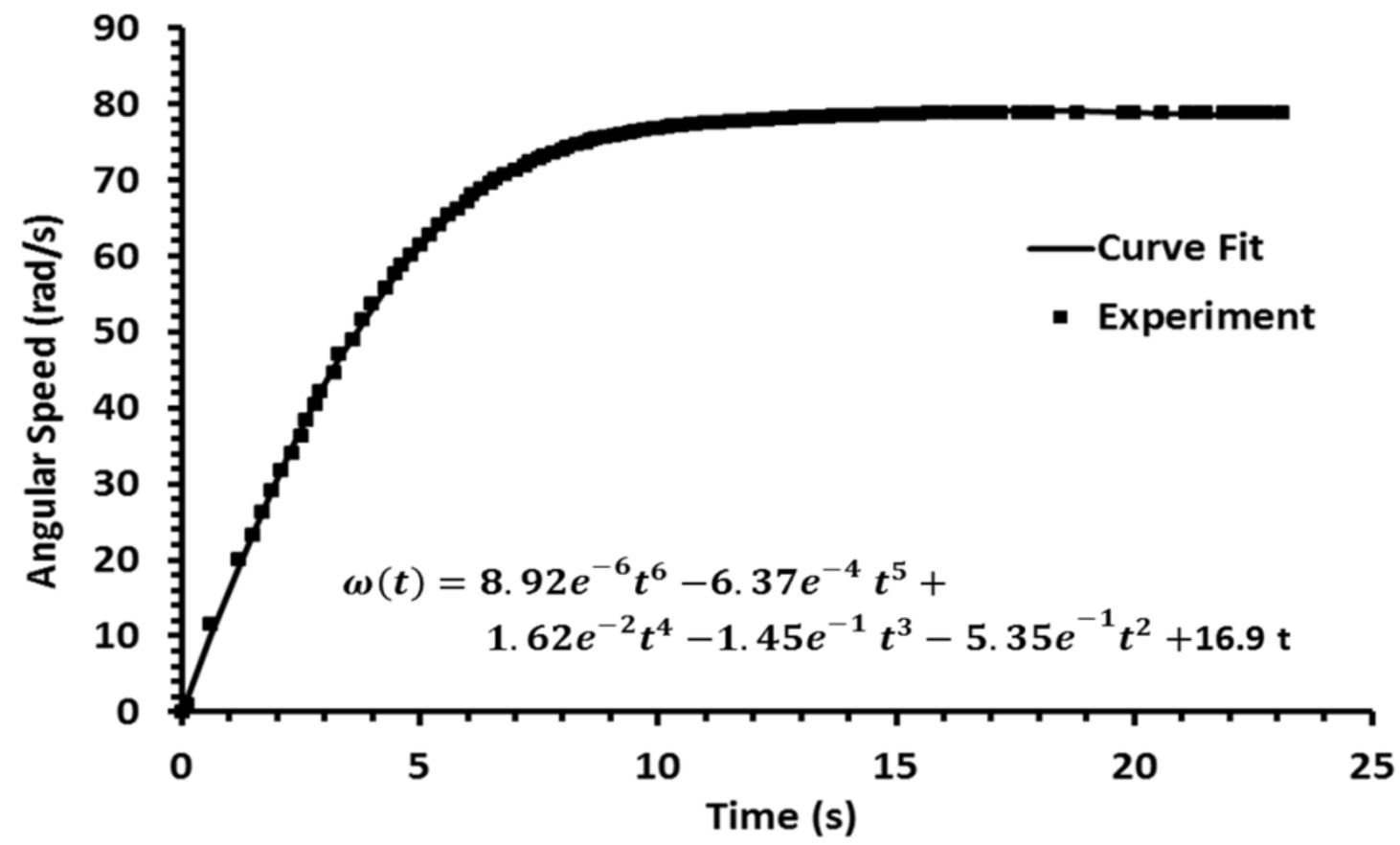

Figure 2.4. Angular speed at the wind speed at $3.2 \mathrm{~m} / \mathrm{s}$.

Figure 2.5 shows the variation of torque and the angular speed as a function of time at four different wind speeds. Torque is highest when the wind turbine is stationary and it slowly decreases to zero as the wind turbine speeds up to its maximum rpm. The mechanical power is zero at $\mathrm{t}=0$ because $\mathrm{rpm}$ is zero. It reaches maximum at time interval where the product of torque and rpm is maximum and then again decreases to zero because torque is zero. The intersection point of torque and rpm curves moves up and leftward as wind speed is increased which implies that not only the magnitude of the maximum mechanical power is higher but also the response of the wind turbine is better. The angular speed at which a wind turbine generates the maximum power is called its optimal $\mathrm{rpm}$. The mechanical power as a function of angular speed is shown in Figure 2.6. It's interesting to note that although the optimal rpm increases with increase in the wind speed, it is always near about $60 \%$ of the maximum rpm. The best possible overall output power from a wind turbine can't be achieved unless and until the rated rpm of the generator is well synchronized with the turbine's optimal rpm. 


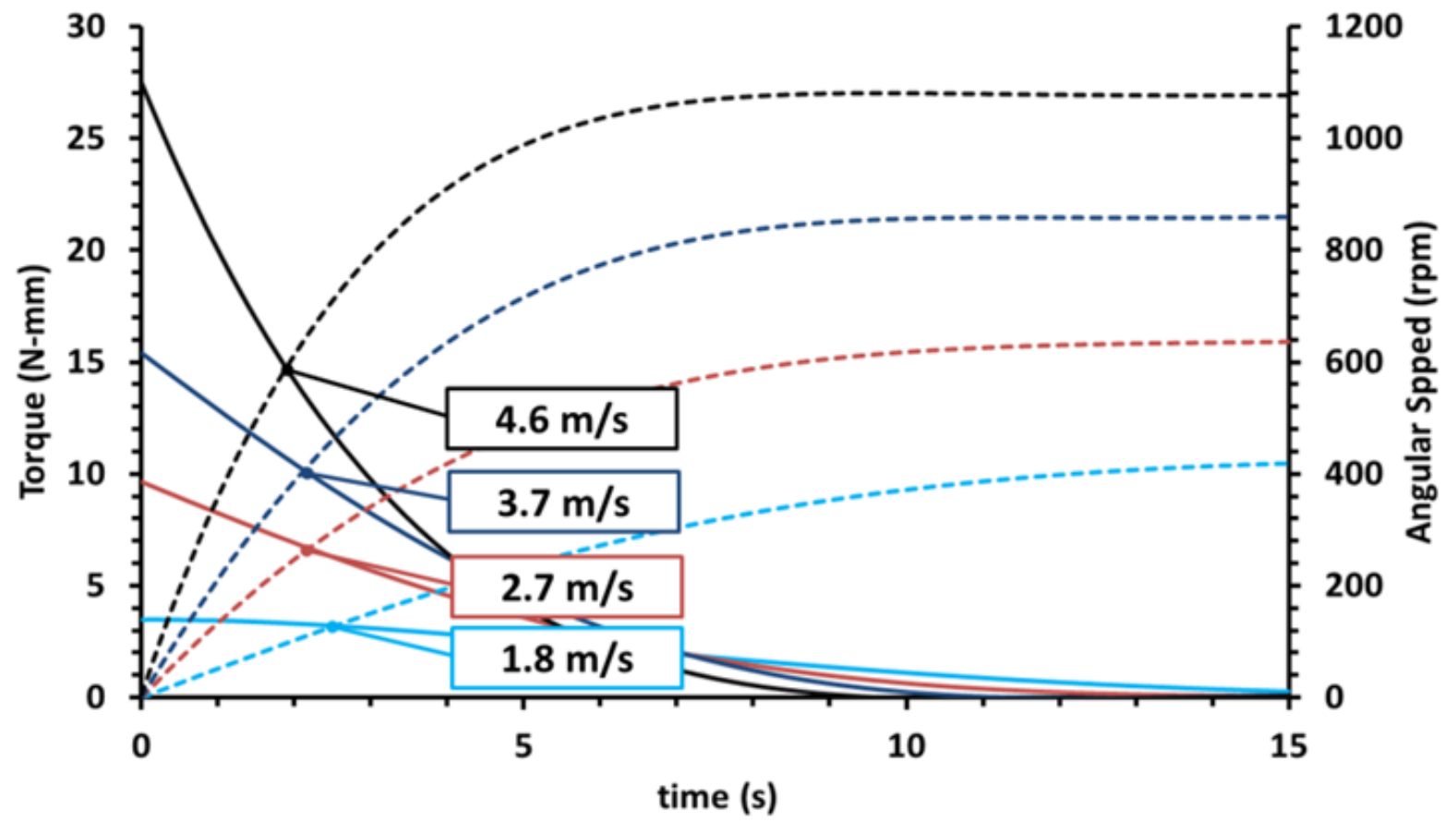

— Torque $(1.8 \mathrm{~m} / \mathrm{s})$ —Torque $(2.7 \mathrm{~m} / \mathrm{s})$-Torque $(3.7 \mathrm{~m} / \mathrm{s})$-Torque $(4.6 \mathrm{~m} / \mathrm{s})$ ----rpm $(1.8 \mathrm{~m} / \mathrm{s}) \quad$----rpm $(2.7 \mathrm{~m} / \mathrm{s}) \quad$----rpm $(3.7 \mathrm{~m} / \mathrm{s}) \quad$----rpm $(4.6 \mathrm{~m} / \mathrm{s})$

Figure 2.5. Torque and rpm relationship.

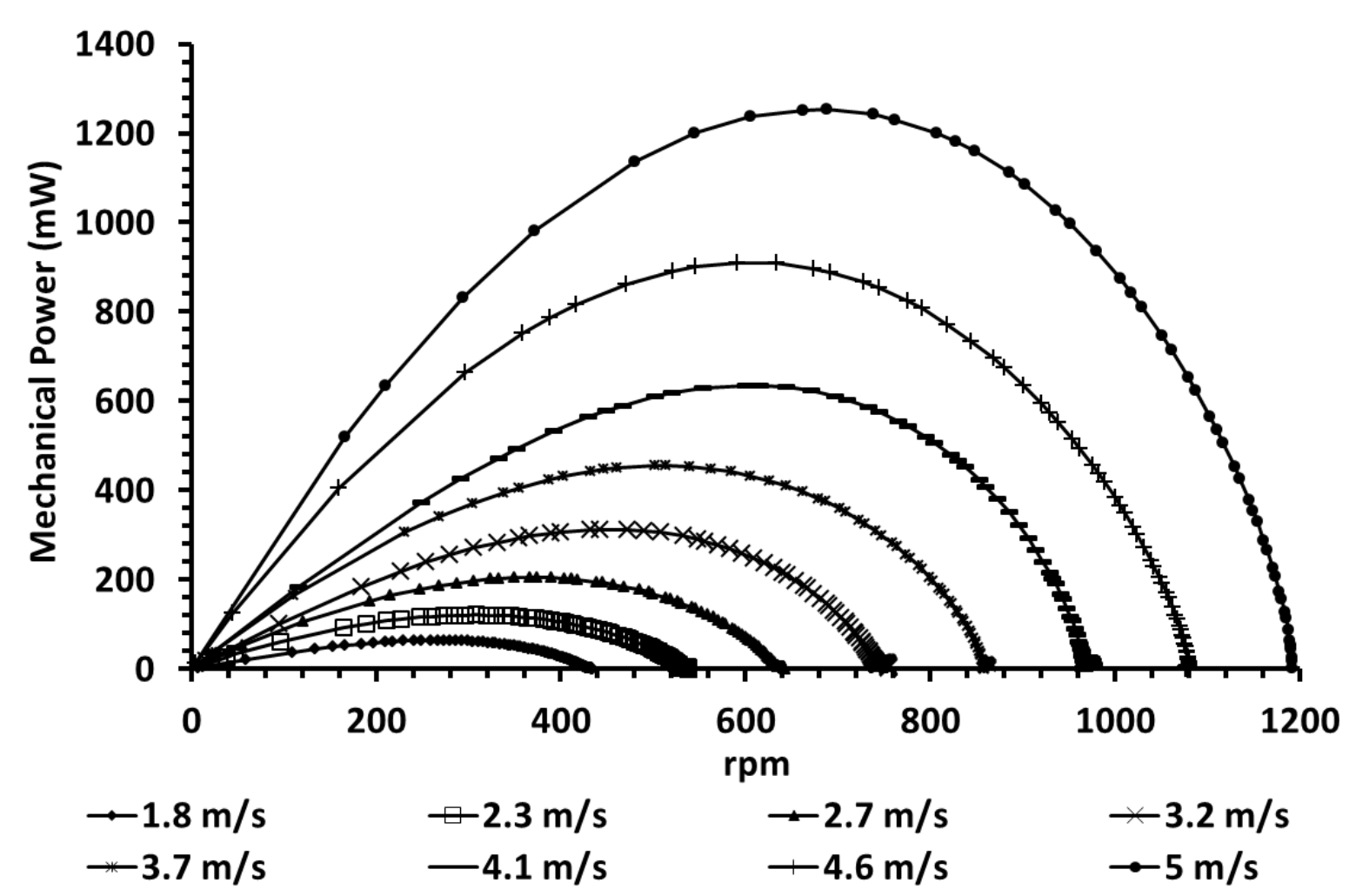

Figure 2.6. Mechanical power of SWEPT at different wind speed. 


\subsubsection{Coefficient of performance}

Figure 2.7 shows coefficient of performance vs. tip speed ratio of SWEPT at various wind speeds between $1.8 \mathrm{~m} / \mathrm{s}$ and $5.0 \mathrm{~m} / \mathrm{s}$. It can be observed that the coefficient of performance initially increases with the increase in the value of tip speed ratio, reaches maxima, and then decreases. This can be explained by noticing that when tip speed ratio is small it corresponds to a situation when the wind turbine is rotating very slowly and almost all the wind passes across the blades without much power transfer. On the other hand, when tip speed ratio is too large, the fast moving blades appear like a solid disc and thus the coefficient of performance decreases. Tip speed ratio directly affects the power output of a wind turbine and thus it's very crucial to assess its optimal value. The tip speed ratio of the large scale wind turbines is normally between 7 and 10, however for the small-scale wind turbines, low TSR in the range of 2 to 4 has been suggested for achieving reliability and noiseless driving [36]. Figure 2.7 depicts that the maximum value of the power coefficient of SWEPT is around 14\% at the tipspeed ratio of 2.9 which is well within the desirable limits.

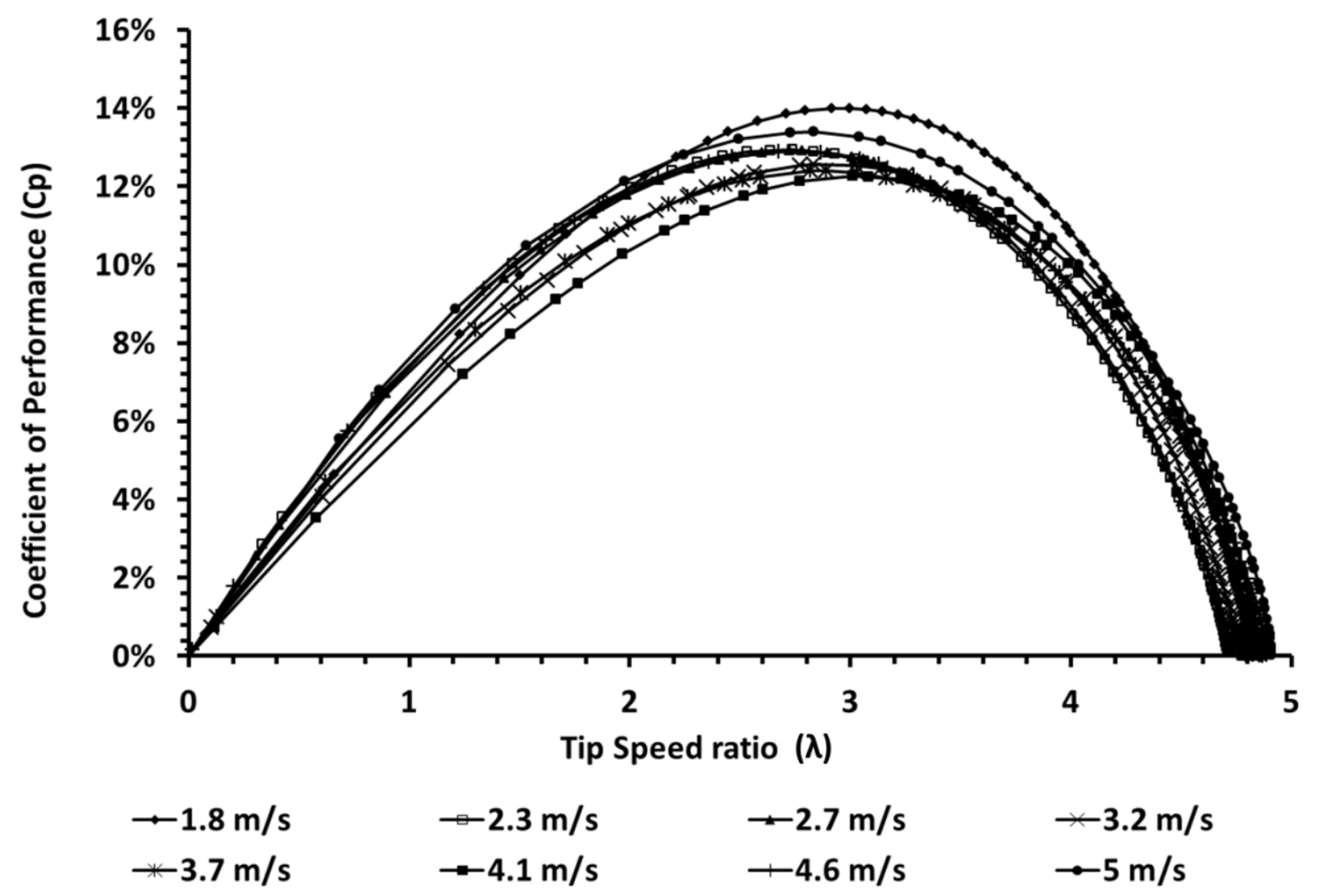

Figure 2.7. Coefficient of Performance vs. Tip speed ratio. 


\subsubsection{Overall performance of SWEPT}

The overall performance of a small-scale wind turbine is dependent upon all its components. Figure 2.8 shows the rpm of the turbine blades under different loading conditions at six different wind speeds. It can be seen that SWEPT starts at very low wind speed of $2.7 \mathrm{~m} / \mathrm{s}$. It runs between $300 \mathrm{rpm}$ and $800 \mathrm{rpm}$ under the normal loading condition. The gear train has gear ratio of 80:10 and it thus allows the generator rotor to run in the range of 2400 to 6400 rpm which is reasonable speed for a motor working as a generator to produce good output voltage. At a fixed wind speed, initially the rpm of the wind turbine increases with the increase in the load resistance and it saturates after some point when load resistance is too large. This characteristic of the wind turbine arises due to a typical behavior, called motor reaction, of an electric generator. Basically, when load is applied to a running generator, it delivers current which creates a magnetic force that opposes the rotation of the armature. The strength of the reacting magnetic force depends on the armature current which is ultimately determined by the magnitude of the load resistance. Decrease in the resistive load increases the armature current and thus increases the motor reaction which eventually slows down the speed of the rotor. However, at the given loading condition, the angular speed increases with the increase in the wind speed. Higher wind speed causes larger aerodynamic torque on the turbine blades which increases the rotor's rpm, provided the wind speed is below stall limit.

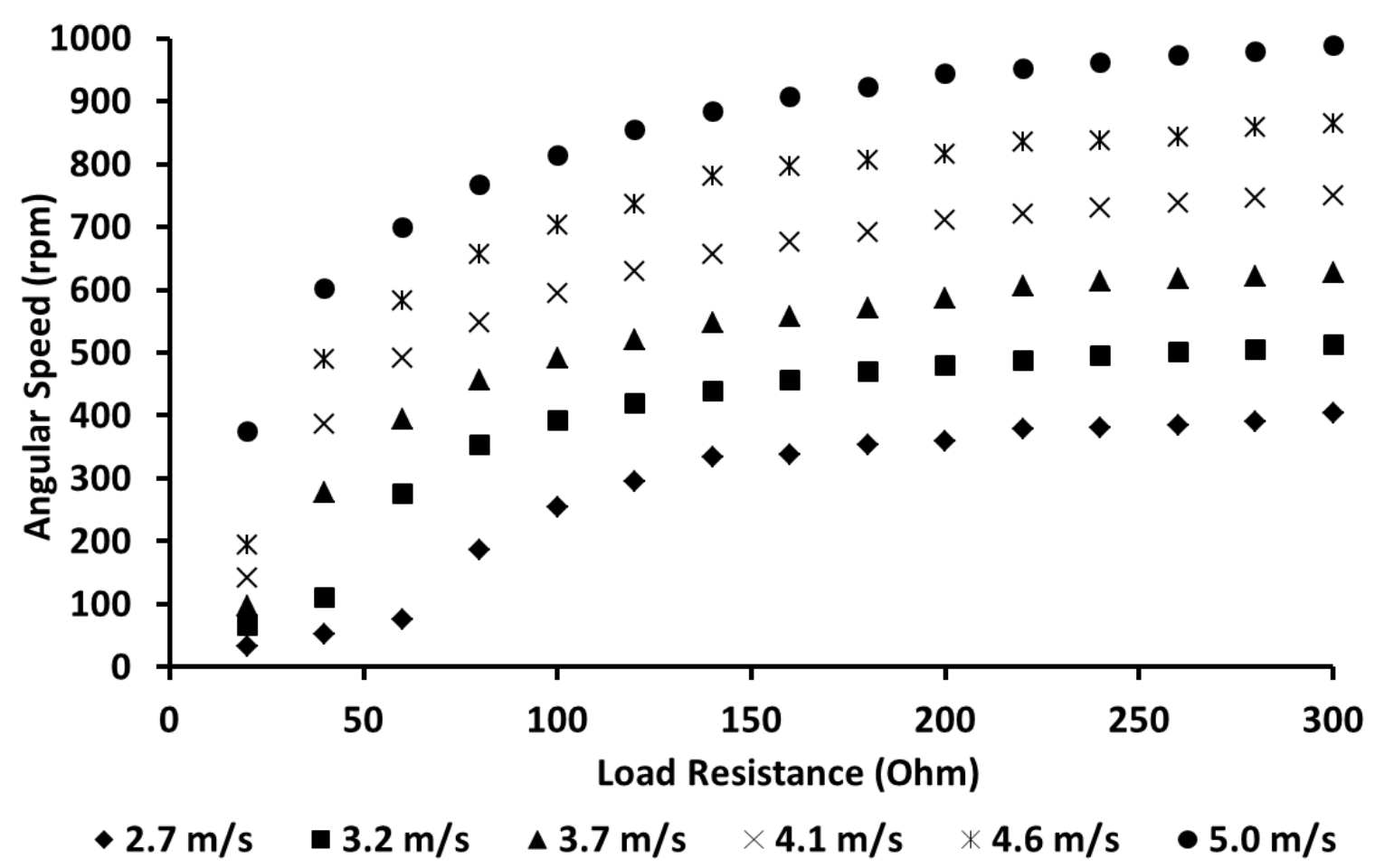

Figure 2.8. Angular speed as a function of load resistance. 
Figure 2.9 shows the electrical behavior of SWEPT at different loading conditions. The optimal load lies between $60 \mathrm{ohm}$ and $120 \mathrm{ohm}$ and it decreases as the wind speed increases. At a fixed loading condition, the electrical power output increases with increase in wind speed. However, at a fixed wind speed, the electrical power first increases with increase in the resistive load, reaches its maximum value at a certain point, and then it decreases again when the load is increased further. The wind turbine produces the maximum power output of $830 \mathrm{~mW}$ at the optimal load of $60 \mathrm{ohm}$ when wind speed is $5.0 \mathrm{~m} / \mathrm{s}$.

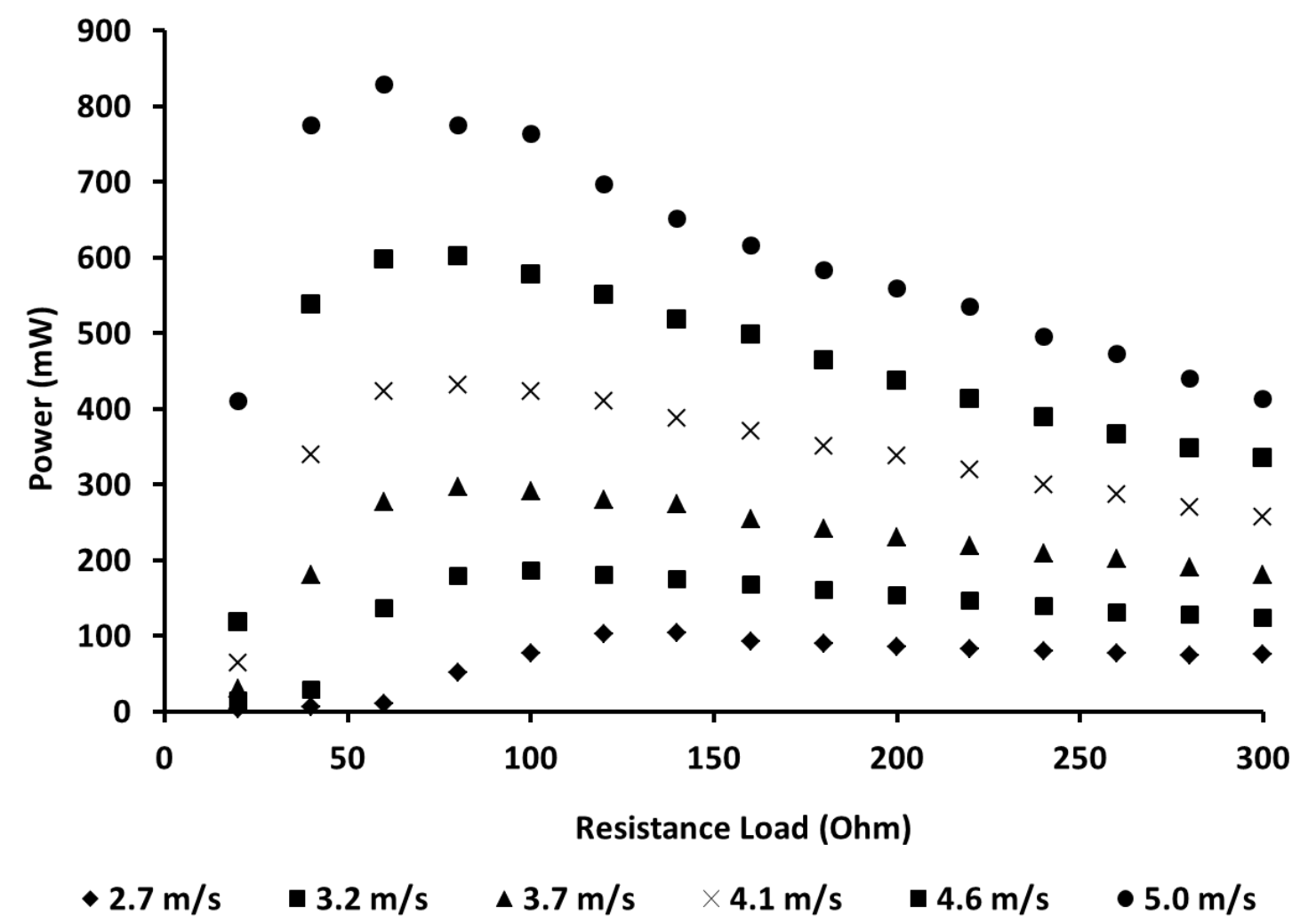

Figure 2.9. Electrical power of SWEPT at different load and wind speed.

\subsection{Summary and conclusions}

This chapter reported the design and development of the first generation prototype of a smallscale wind energy portable turbine (SWEPT) which operates at wind speeds below $5.0 \mathrm{~m} / \mathrm{s}$. The wind turbine was designed using commercial software and wind tunnel experiments were conducted to characterize its performance. It was found that SWEPT has maximum coefficient of performance of $14 \%$ at the optimal tip speed ratio of 2.9. It had very low cut-in wind speed of $2.7 \mathrm{~m} / \mathrm{s}$ and it could generate mechanical power of $1.25 \mathrm{~W}$ and electrical power of up to $0.83 \mathrm{~W}$ at the wind speed of $5 \mathrm{~m} / \mathrm{s}$. This chapter also highlighted a novel torque 
measurement technique for SSWTs, which doesn't require any torque measurement instruments like torque sensor or torque transducer. Lastly, it is important to note that the actual power performance of the wind turbine found experimentally was much lower than its predicted value proposed by the design software. This study thus reiterates the fact that the low wind speed SSWTs cannot be designed using the design tools that have been developed for conventional high wind speed large-to-mid scale wind turbines. 


\section{CHAPTER 3}

\section{Diffuser augmented small-scale wind energy portable turbine}

Theoretically, the power output by a wind turbine is proportional to cube of the wind speed. It implies that any method, which can increase the wind speed around the turbine even by small factor, can largely improve its power output. It has been recently found that a duct in the form of a diffuser around the wind turbine can augment the wind speed near the turbine blades. The diffuser essentially allows turbine's exhaust flow to expand and thus produces subatmospheric pressure in the region near to turbine exit. The low pressure region draws more wind and causes it to accelerate. This is the reason why a ducted wind turbine with a diffuser exhibits higher power output than a wind turbine without diffuser [40].

As noted in the previous chapter, the first generation SWEPT was found to have very low power output. This chapter investigates the possibility of augmenting the power output of SWEPT using an optimized diffuser. Computational fluid dynamics (CFD) studies were conducted to optimize the geometrical parameters of the diffuser in order to achieve maximum possible wind velocity augmentation, keeping into account the size and cost constraints of the device. The numerical results predicted by the CFD model have been then verified with the experimental data obtained from wind tunnel experiments.

\subsection{Diffuser: design optimization and construction}

Considering the 3D manufacturing processes, it was decided to simplify the diffuser geometry. As shown in Figure 3.1, the diffuser consisted of three parts: a converging section, a 1-inch $(25.4 \mathrm{~mm})$ long throat and a diverging section. There are essentially four geometrical parameters which needed to be optimized, namely (a) converging section length $L_{1}$, (b) converging section half cone angle $\theta_{1}$, (c) diverging section length $L_{2}$ and (d) diverging section half cone angle $\theta_{2}$. Computational fluid dynamics (CFD) has been used in literature $[38,39,44]$ to model the diffuser design. In this study we utilized commercial fluids package fluent (ANSYS Inc., USA) to study the flow field through and around the diffuser. The effect of each geometrical parameter on the velocity augmentation was extensively examined and an optimal geometry was derived. Wind tunnel experiment was conducted to verify the numerical results. 

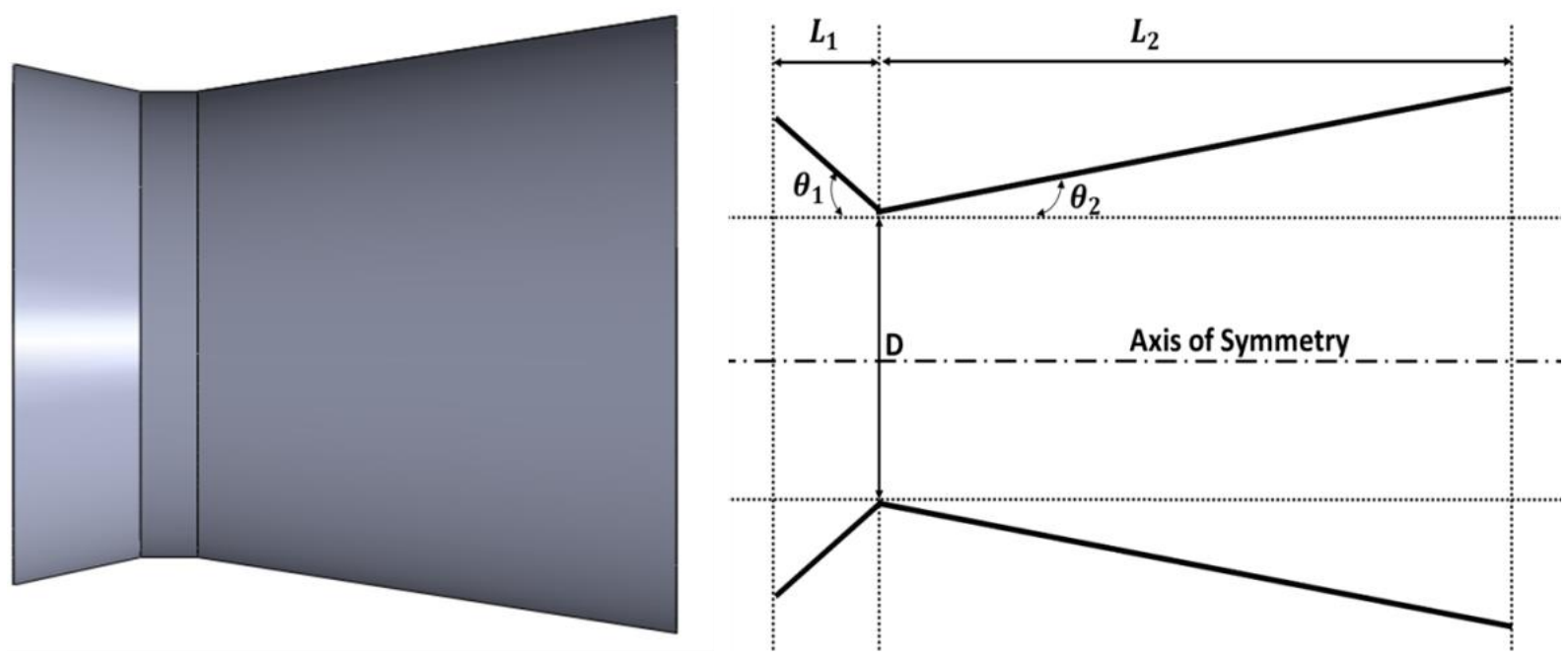

Figure 3.1. An initial design of diffuser modeled using CFD.

\subsection{Solution strategy}

The flow inside the diffuser is axis symmetrical, therefore, 2-dimensional model was considered to reduce the simulation time. Figure 3.2 shows the computational domain of the diffuser along with the area inside a hypothetical wind tunnel. The wind tunnel has diameter 20 times that of diffuser throat diameter. Entrance and exit lengths before and after the diffuser were approximately 8 and 10 times of the diffuser throat diameter respectively. Such a large wind tunnel around the diffuser will ensure that the boundary layer effect of the walls of the tunnel does not affect the flow inside the diffuser. Also, relatively bigger fluid domain around the diffuser mitigates the effects of obstruction and blockage to the free stream [39, $41,44]$. Velocity-inlet and pressure outlet boundary conditions were specified at the entrance and exit of the fluid domain respectively. Turbulence intensity as $10 \%$ with length scale as 1 $\mathrm{m}$ has been assumed at the velocity-inlet boundary condition. The walls of the wind tunnel and the diffuser were assigned no slip boundary condition. As mentioned later in the manuscript that we have used SST $k-\omega$ turbulence model, which provides "enhanced wall treatments" to the wall boundary conditions i.e. all the boundary conditions for the coarse meshes are treated as the wall function approach, while for the fine meshes, the appropriate low-Reynolds-number boundary conditions are applied [45]. Symmetry boundary condition was specified for the axis, as the system was symmetrical about it. The free stream velocity of $4.1 \mathrm{~m} / \mathrm{s}$ was taken for all the numerical calculations. Figure 3.3 shows the 2-dimensional grid system generated using ICEM CFD (ANSYS Inc., USA) commercial software. Total number of elements was 26500 with very fine meshing in the region inside the diffuser and relatively coarser mesh outside. The element counts inside the diffuser were about 4000 with 
approximately 100 nodes in axial direction and 40 nodes along radial direction. Mesh independency test was performed to ensure that variation in number of elements does not affect the solution. The simulations were run at different number of elements between 6000 and 60000 and it was found that the variation in result from element count of 26500 to 59500 was less than $0.5 \%$. Figure 3.4 shows the effect of element count on the velocity augmentation factor $U / U_{o}$ by one of the diffuser model at the wind speed of $U_{o}=4.1 \mathrm{~m} / \mathrm{s}$.

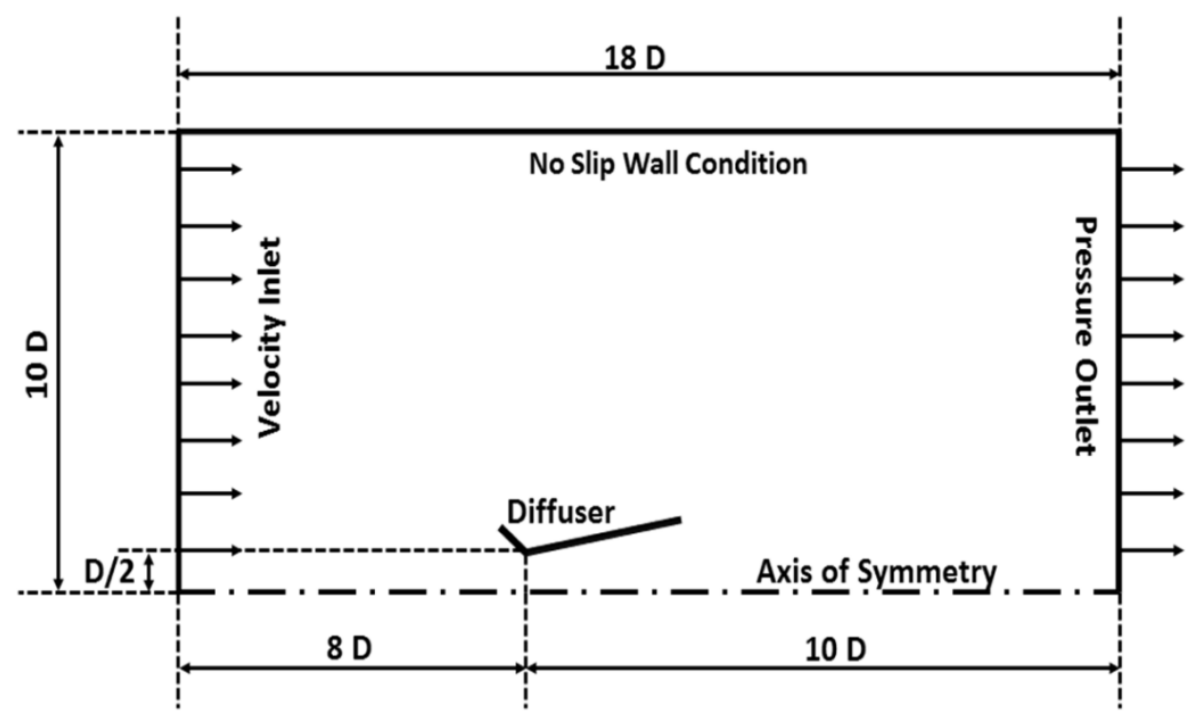

Figure 3.2. Two-dimensional computational domain with boundary conditions.

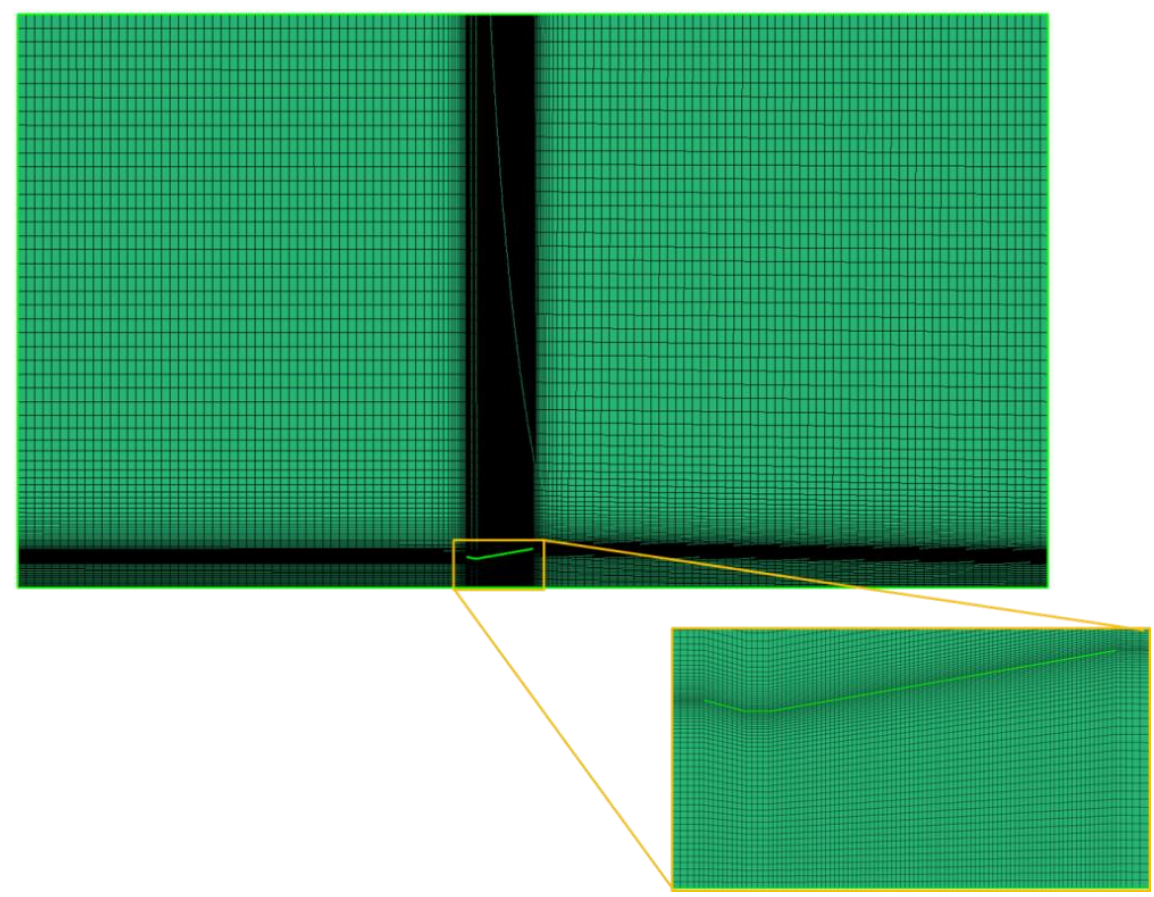

Figure 3.3. Two-dimensional grid system. 
The shear-stress transport (SST) $k$ - $\omega$ model has been used as the turbulence model for all the numerical simulations in this study. The advantage of using SST $k$ - $\omega$ over the standard turbulence models like $k-\omega$ and $k-\varepsilon$ is that it effectively blends the robustness and accurate formulation of the $k$ - $\omega$ model in the near-wall region with the free-stream independency of the $k$ - $\varepsilon$ model in the far field [45]. It is believed that the use of SST $k$ - $\omega$ model provides better results for the flow-field predictions with the adverse pressure gradient. The areaweighted average velocity across a cross-sectional area near the throat of the diffuser has been used to calculate the velocity amplification factor. Each diffuser design parameter discussed in the previous section was varied individually by keeping other variables constant to understand its effect on the velocity augmentation.

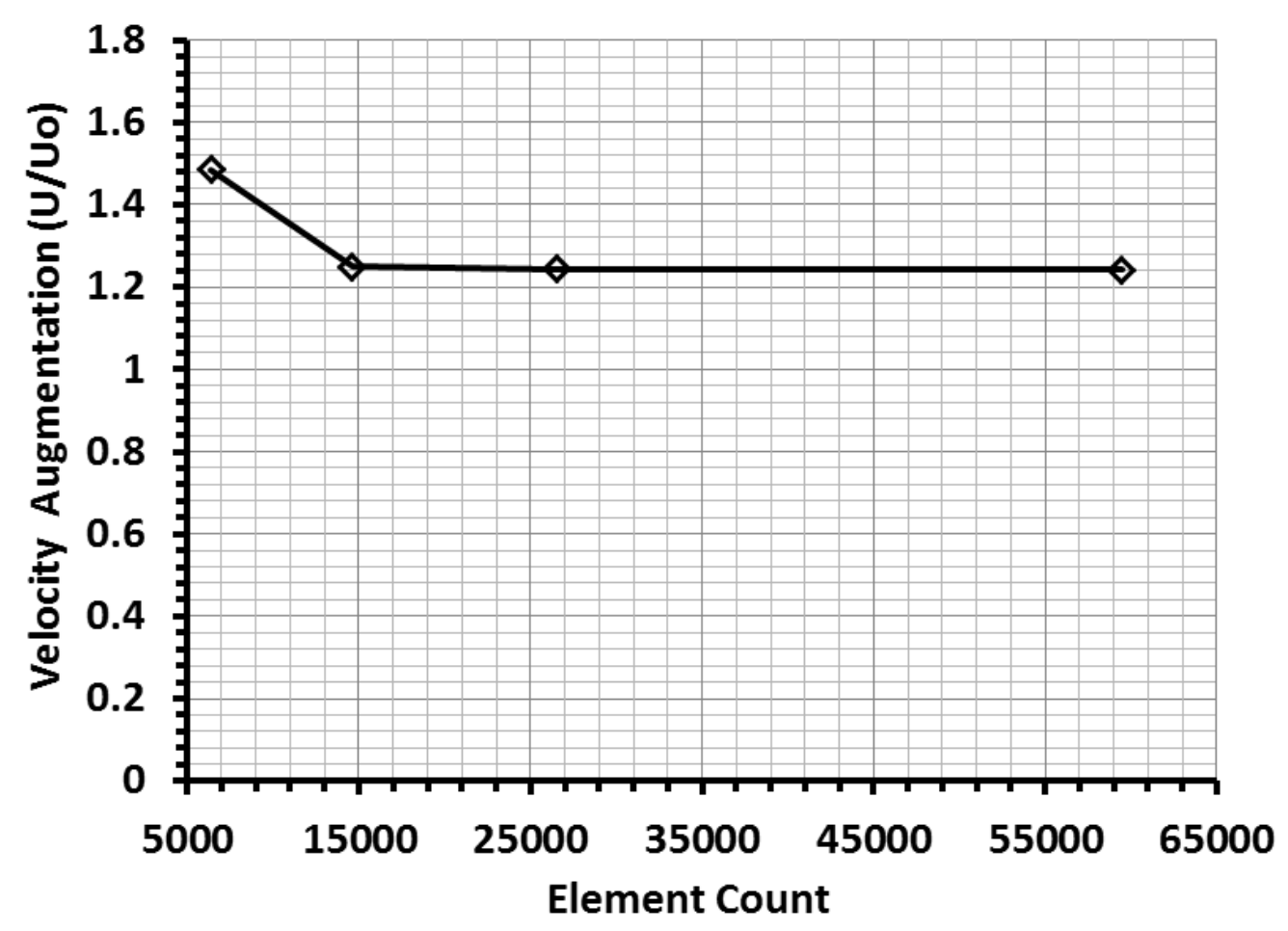

Figure 3.4. Mesh independency test.

\subsection{Diffuser design optimization}

Figure 3.5 (a) and (b) show the effect of converging section length $L_{1}$ and half cone angle $\theta_{1}$ on the velocity amplification factor of the diffuser. The numerical simulations were conducted at four different values of converging section length $L_{1}$ varying from $0.125 \mathrm{D}$ to $0.5 \mathrm{D}$ and eight different values of converging section half cone angle ranging from $0^{\circ}$ to $21^{\circ}$. At the given values of diverging section length $L_{2}=1.0 \mathrm{D}$ (Figure $3.5(\mathrm{a})$ ) and $L_{2}=1.5 \mathrm{D}$ 
(Figure 3.5(b)), and half cone angle $\theta_{2}=10^{\circ}$, the velocity augmentation factor $U / U_{o}$ increases with increase in converging section length $L_{1}$, when $\theta_{1}$ is fixed. However, the effect is not so prominent and therefore the smallest value $L_{1}=0.125 \mathrm{D}$ has been selected considering the size constraint and to minimize the cost of material. It can also be noted in these figures that when $L_{1}$ is fixed, the velocity augmentation factor $U / U_{o}$ slowly increases with increase in the value of $\theta_{1}$ from $0^{\circ}$ to $15^{\circ}$ but saturates beyond this range.

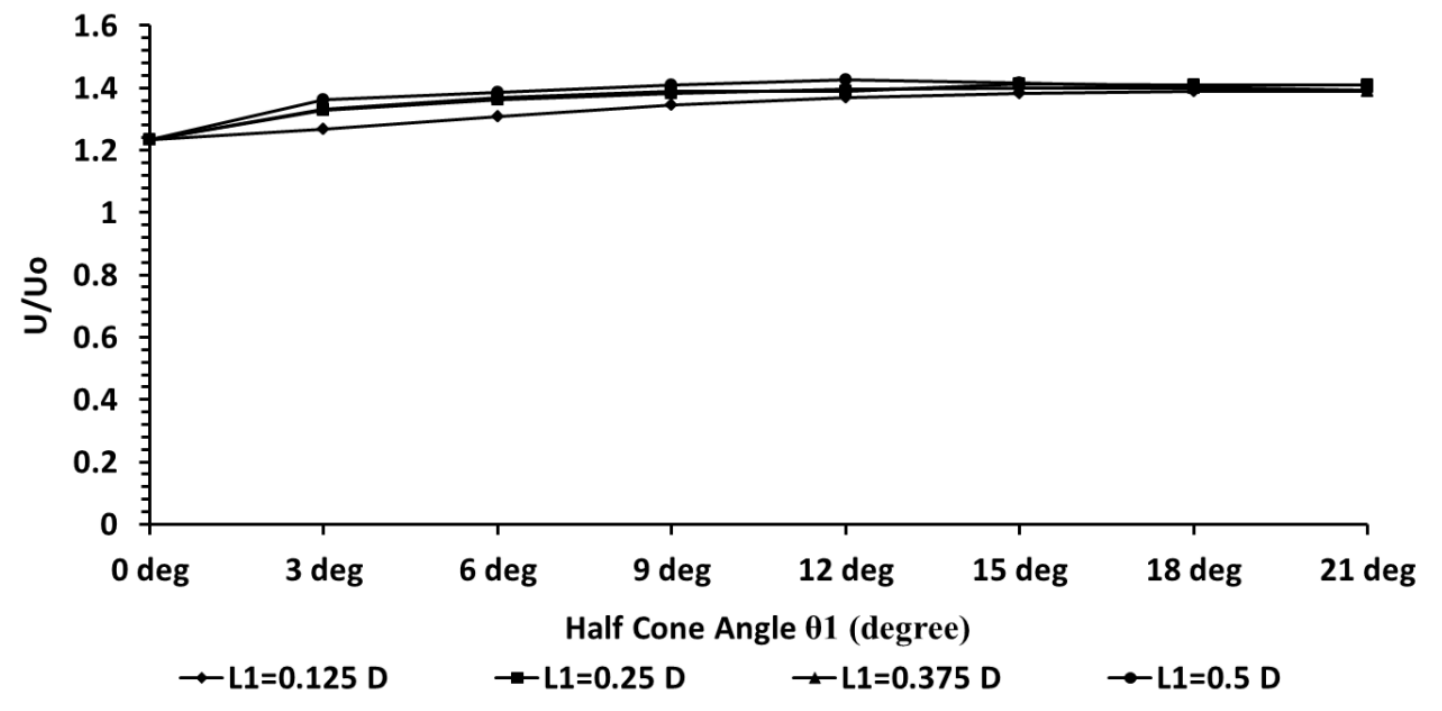

Figure 3.5(a). Effect of converging section length $L_{1}$ and half cone angle $\theta_{1}$ on velocity augmentation factor $\mathrm{U} / \mathrm{U}_{\mathrm{o}}\left(\mathrm{L}_{2}=1.0 \mathrm{D}\right.$ and $\left.\theta_{2}=10^{\circ}\right)$.

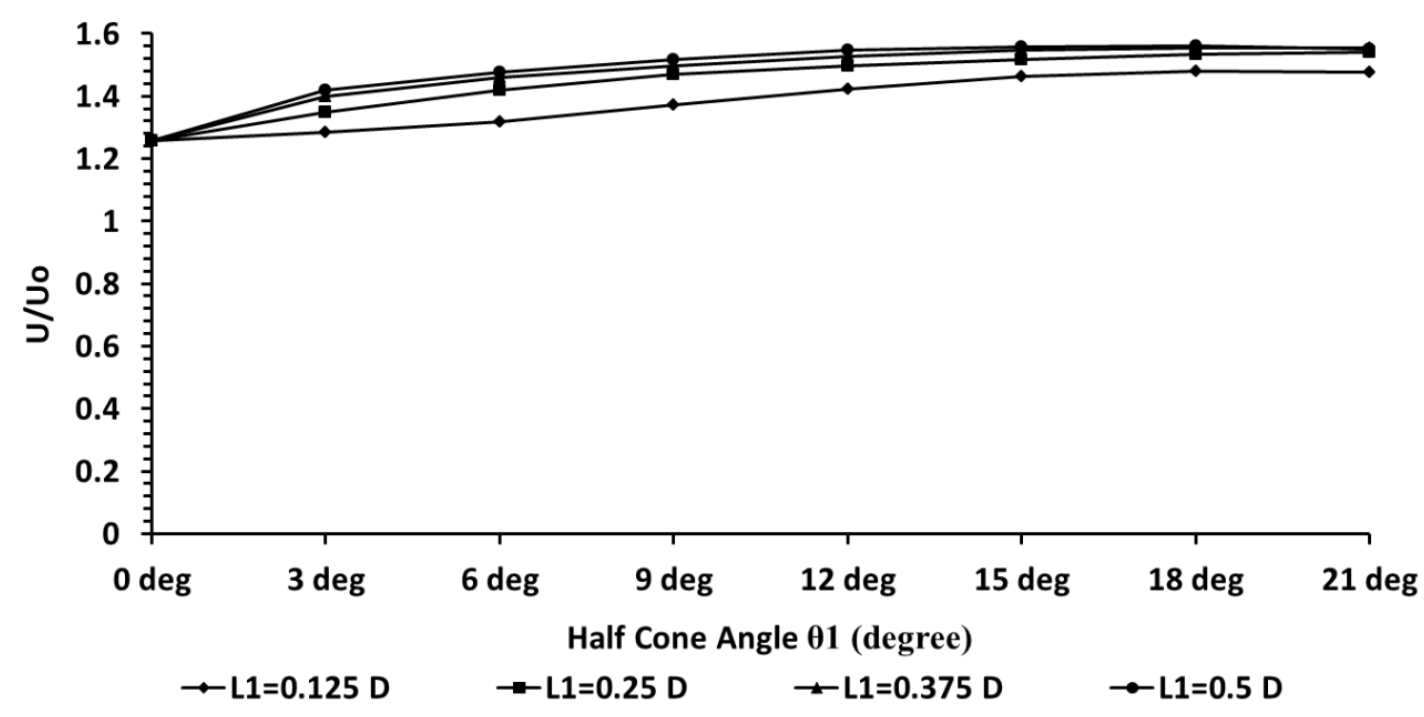

Figure 3.5(b). Effect of converging section length $\mathrm{L}_{1}$ and half cone angle $\theta_{1}$ on velocity augmentation factor $\mathrm{U} / \mathrm{U}_{\mathrm{o}}\left(\mathrm{L}_{2}=1.5 \mathrm{D}\right.$ and $\left.\theta_{2}=10^{\circ}\right)$. 
Figure 3.6 represents the effect of diverging section length $L_{2}$ and half cone angle $\theta_{2}$ at the fixed values of converging section length $L_{1}=0.125 \mathrm{D}$ and half cone angle $\theta_{1}=15^{\circ}$. It can be seen that the velocity augmentation factor $U / U_{o}$ increases continuously with increase in the value of $\theta_{2}$ from $0^{\circ}$ to $16^{\circ}$ when $L_{2}=0.5 \mathrm{D}$. However, when $L_{2}=1.0 \mathrm{D}$ and $1.5 \mathrm{D}$, factor $U / U_{o}$ has a maxima at $\theta_{2}=10^{\circ}$. Also, $U / U_{o}$ increases continuously with increase in the value of $L_{2}$ when other variables are fixed.

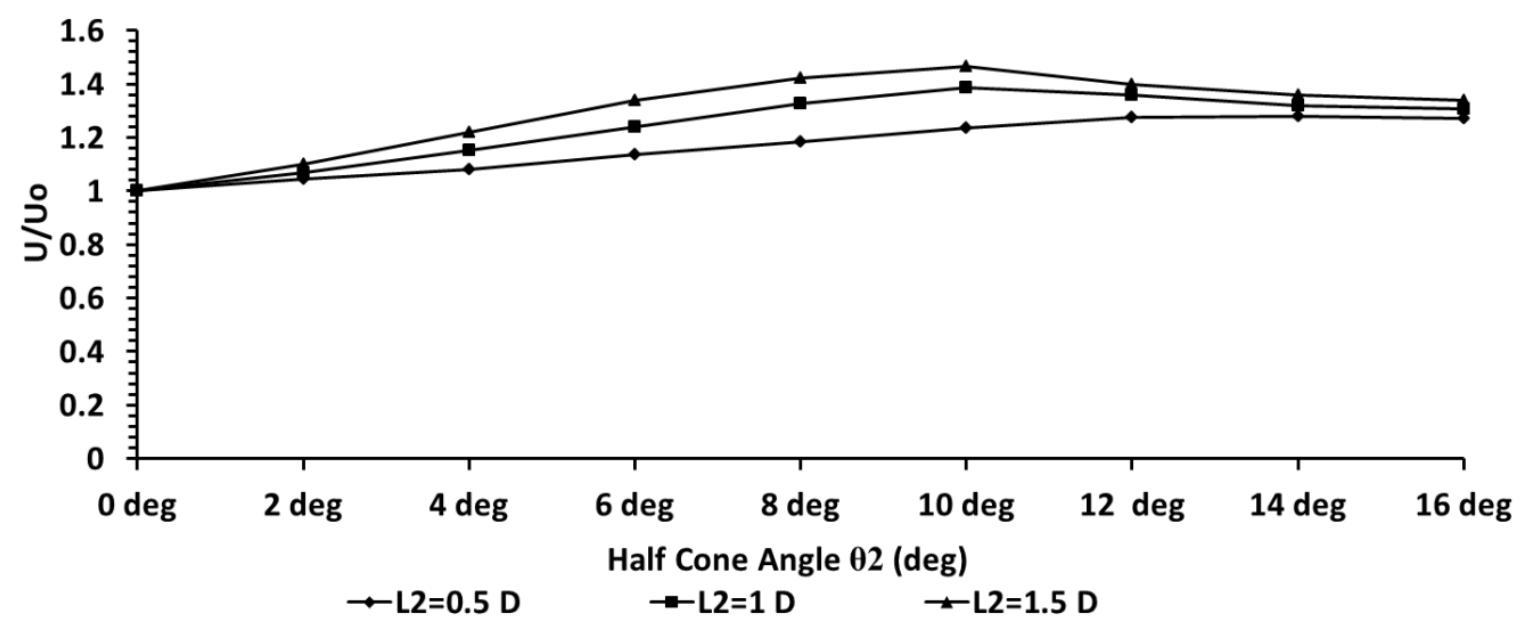

Figure 3.6. Effect of diverging section length $L_{2}$ and half cone angle $\theta_{2}$ on velocity augmentation factor $\mathrm{U} / \mathrm{U}_{\mathrm{o}}\left(\mathrm{L}_{1}=0.125 \mathrm{D}\right.$ and half cone angle $\left.\theta_{1}=15^{\circ}\right)$.

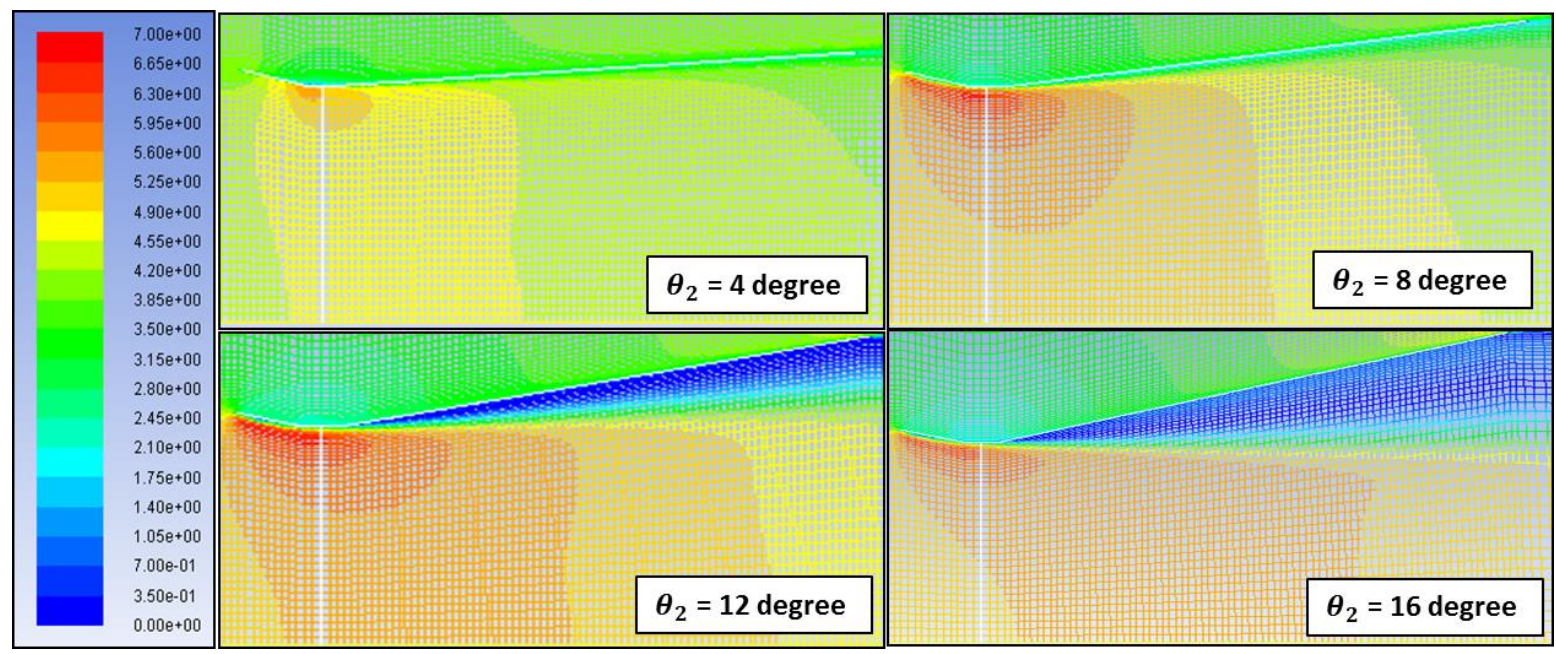

Figure 3.7. Velocity contours at different $\theta_{2}\left(\mathrm{~L}_{2}=1.0 \mathrm{D}, \mathrm{L}_{1}=0.125 \mathrm{D}, \theta_{1}=15^{\circ}\right)$.

It can be concluded from this analysis that the diverging section has very strong effect on the velocity augmentation by the diffuser. Higher value of expansion angle $\theta_{2}$ allows 
flow-field to expand. However, flow tends to separate from the wall of diffuser when expansion angle is too large. Separation of the flow is generally not desirable because it deteriorates the performance of the device. The attachment and detachment of the flow are not only controlled by the expansion angle but also by the length of the diverging section. Flow may remain attached even at larger expansion angle, if length of the diverging section is smaller. Figure 3.7 and Figure 3.8 show the velocity contours obtained during postprocessing of CFD results. Violet region near the wall of the diffuser in some of the contours show flow separation. All the contours of Figure 3.7 have been obtained for $L_{1}=0.125 \mathrm{D}$, $\theta_{1}=15^{\circ}$ and $L_{2}=1.0 \mathrm{D}$ at the wind speed of $4.1 \mathrm{~m} / \mathrm{s}$. It can be seen that flow is attached when $\theta_{2}=4^{\circ}$ and $\theta_{2}=8^{\circ}$, it detaches at $\theta_{2}=12^{\circ}$ and separation region is much bigger at $\theta_{2}=16^{\circ}$. This explains the reason as to why velocity augmentation factor $U / U_{o}$ is maximum at $\theta_{2}=10^{\circ}$ when $\mathrm{L}_{2}=1.0 \mathrm{D}$ in Figure 3.6.

Contours of Figure 3.8 show the effect of diverging section length on flow separation. At $\theta_{2}=12^{\circ}$, flow separates when $L_{2}=1.0 \mathrm{D}$ but it is still attached to the wall of diffuser when $\mathrm{L}_{2}=0.5 \mathrm{D}$. The consequence of this effect is clear in Figure 3.6, velocity augmentation factor $U / U_{o}$ decreases when $\theta_{2} \geq 12^{\circ}$ at $\mathrm{L}_{2}=1.0 \mathrm{D}$ but it continues to increase for the case $\mathrm{L}_{2}=0.5 \mathrm{D}$. As stated above, the effect of converging section on the velocity augmentation is not so strong, but it makes the flow more concentrated before it starts to expand in diverging section.

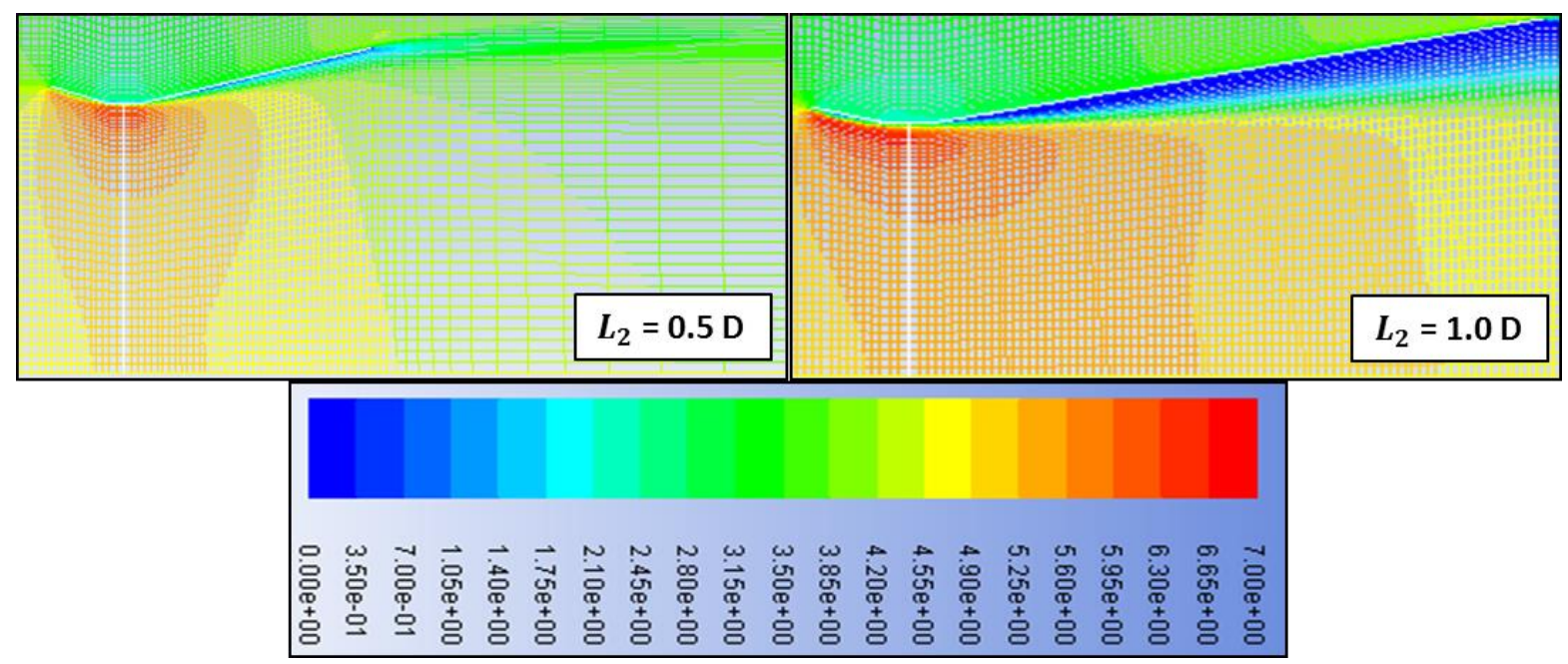

Figure 3.8. Velocity contours at different $\mathrm{L}_{2}\left(\theta_{2}=12^{\circ}, \mathrm{L}_{1}=0.125 \mathrm{D}, \theta_{1}=15^{\circ}\right)$. 
Table 3.1 summaries the range of various variables studied and their optimal value selected on the basis of velocity augmentation factor $U / U_{o}$ and size constraint of the diffuser.

Table 3.1. Diffuser design parameters

\begin{tabular}{lccc}
\hline \multicolumn{1}{c}{ Parameters } & Symbol & Range & Optimal value \\
\hline Converging section length & $L_{1}$ & $0.125 \mathrm{D}-0.5 \mathrm{D}$ & $0.125 \mathrm{D}$ \\
\hline Converging section half cone angle & $\theta_{1}$ & $0^{\circ}-21^{\circ}$ & $15^{\circ}$ \\
\hline Diverging section length & $L_{2}$ & $0.5 \mathrm{D}-1.5 \mathrm{D}$ & $1.0 \mathrm{D}$ \\
\hline Diverging section half cone angle & $\theta_{2}$ & $0^{\circ}-16^{\circ}$ & $10^{\circ}$ \\
\hline
\end{tabular}

\subsection{Diffuser construction}

The main challenge before constructing the diffuser was to make it as light in weight as possible while keeping the manufacturing process compatible with $3 \mathrm{D}$ molding and casting. The diffuser construction was completed in two steps. First, a prototype was constructed using metallic sheet and then this prototype was used as mold to make actual diffuser using fiber reinforced plastics by hand lay-up process. The composite consists of three layers of fibers: one layer of glass fiber sandwiched between two layers of carbon fiber with epoxy resin as the bonding agent. Figure 3.9 shows the diffuser mold constructed from metal sheet and the final product made up of carbon and glass fiber reinforced plastics.

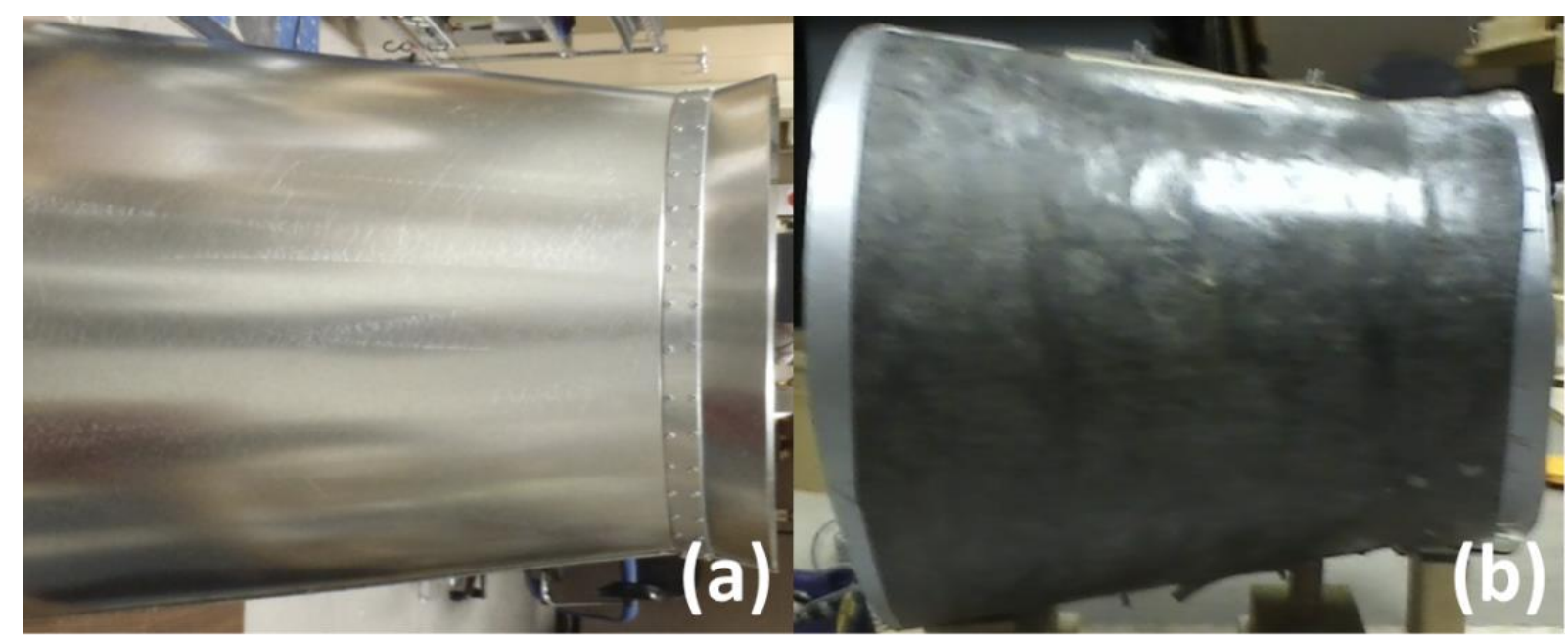

Figure 3.9. Diffuser made up of (a) metal sheet and (b) fiber reinforced plastics. 


\subsection{Velocity augmentation}

Wind tunnel experiment was conducted on diffuser without turbine inside to know the actual velocity augmentation. The details of the experimental set-up and wind tunnel experiment will be discussed in the next section. In this section, we will compare the numerical data on the velocity augmentation factor with the experimental performance. Figure 3.10 depicts the velocity augmentation factor at the center of the throat of the diffuser found experimentally and calculated numerically. It can be seen that the velocity augmentation factor $U / U_{o}$ is almost constant with the wind speed. Numerical results are, however, slightly higher than the experimental data. One of the reasons for this difference in numerical and experimental results can be related to the blockage effect. While in computational modeling, we purposely defined much larger fluid domain around the diffuser in order to avoid blockage to the flow, however, during experimentation, we didn't have availability of such wind tunnel with large cross-sectional area. Next, the wind tunnel experiment was re-conducted to know the performance and power augmentation factor of ducted-SWEPT over normal SWEPT at various wind speeds. These results will be described in Results and Discussion section.

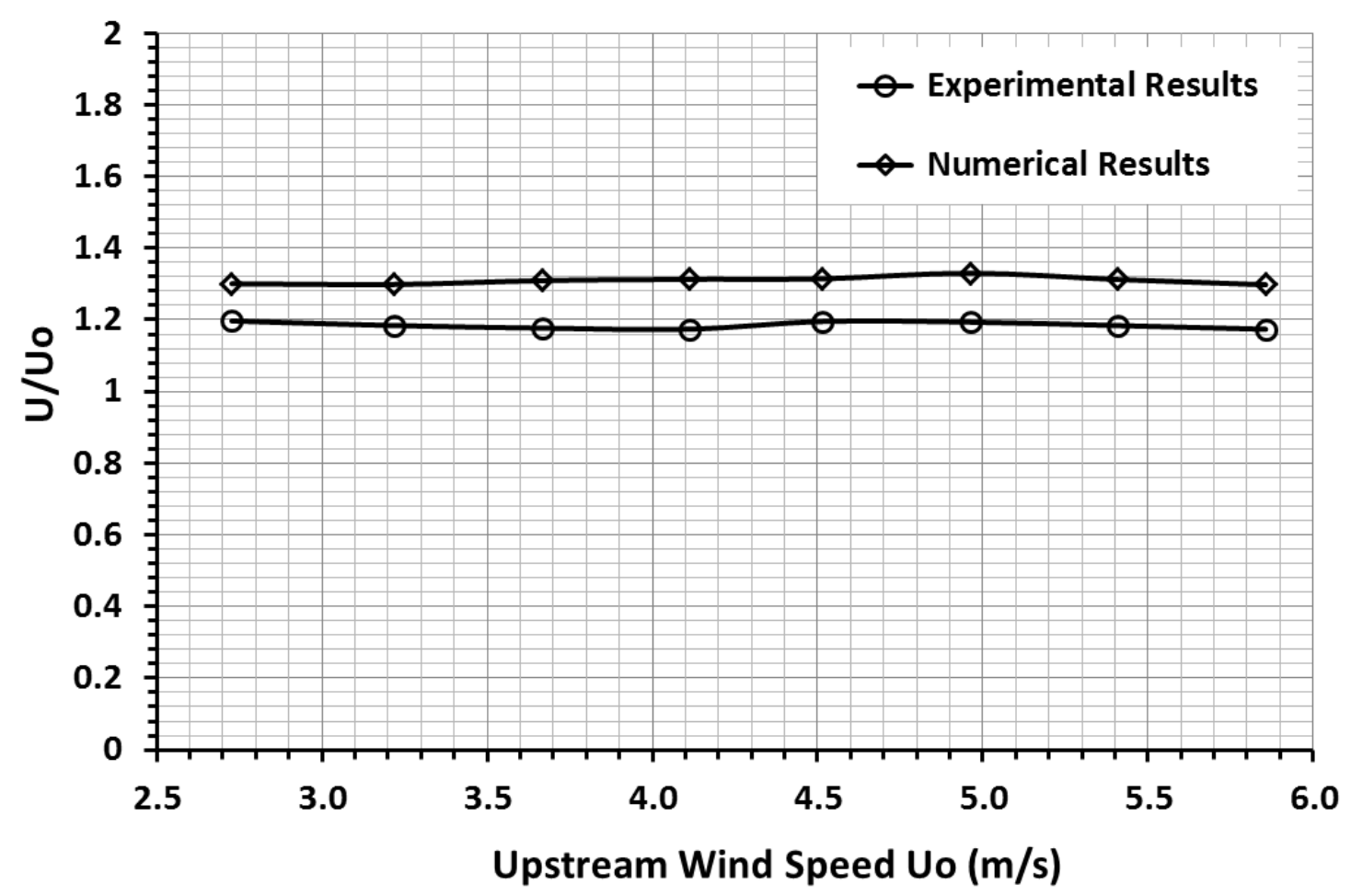

Figure 3.10. Comparison of velocity augmentation factor obtained numerically and experimentally. 


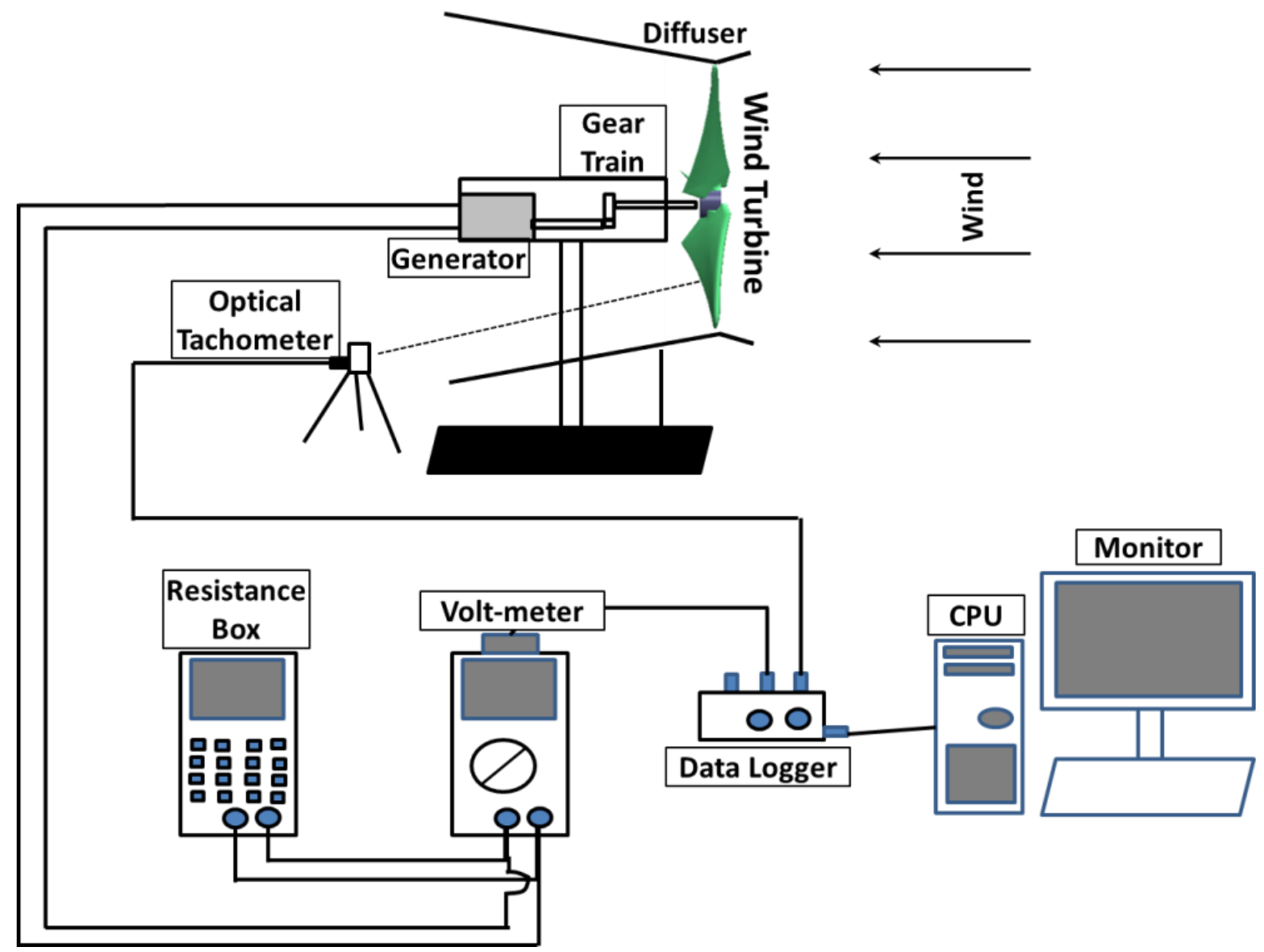

Figure 3.11. Schematic diagram of wind tunnel experimental set-up used to test the performance of the diffuser augmented wind turbine.

\subsection{Experimental set-up}

Figure 3.11 shows the schematic of experimental set-up of the wind tunnel experimentation used to test the power output by the ducted-wind turbine at various wind speeds. It's quite similar to the experimental set-up described in chapter 2, except there is a diffuser around the wind turbine. The experiments were conducted using the Subsonic Open Jet Wind Tunnel facility available in the Department of Aerospace and Ocean Engineering at Virginia Tech. The specifications of all the instruments used in this experiment are same as those stated in the previous chapter. To determine the velocity amplification by duct, the wind turbine was first removed and then wind speeds inside the duct at various locations were measured using the anemometer.

\subsection{Power by ducted-SWEPT}

As explained earlier, a diffuser is essentially a wind acceleration system which, by virtue of its shape, creates sub-atmospheric pressure near exit and thus induces greater mass flow rate 
through the turbine. Figure 3.10 shows that the optimized diffuser has velocity augmentation factor of about 1.2. Theoretically, power output of a horizontal axis wind turbine is proportional to cube of upstream wind speed, which entails that the power output of ducted SWEPT should be around 1.7 times the power by SWEPT without a diffuser. Figure 3.12 shows the power output of the ducted SWEPT at various wind speeds and load resistances. It can be seen that the power out of the wind turbine with duct is greater than the one without duct at the same wind speeds. The ducted SWEPT can produce the electrical power up to $1.15 \mathrm{~W}$ compared to $0.83 \mathrm{~W}$ by a SWEPT without duct at the wind speed of $5.0 \mathrm{~m} / \mathrm{s}$.

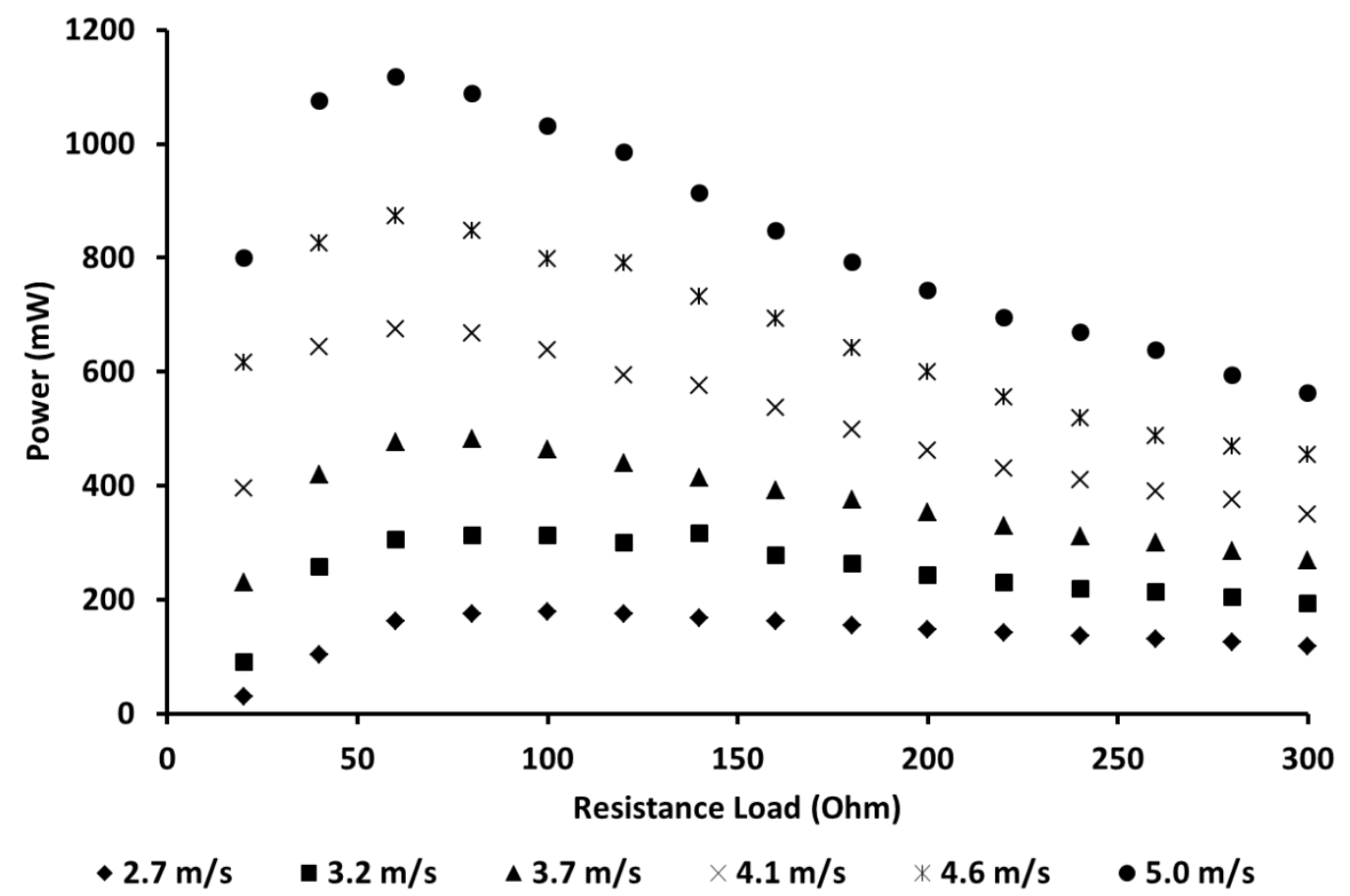

Figure 3.12. Power output of diffuser augmented SWEPT at different loads and wind speeds.

Lastly, the optimal power output of SWEPT with and without diffuser at various wind speeds has been compared in Figure 3.13. It can be noted that the power augmentation factor $\mathrm{P} / \mathrm{P}_{\mathrm{o}}$ is in the range of 1.4-1.6, which is lower than the expected value of 1.7. The main reason for the lower than expected performance of diffuser is the wind turbine itself. The presence of wind turbine in the diffuser exerts resistance to the wind flow and thus it creates loading effect. The loading factor $\mathrm{C}_{\mathrm{t}}$ of a wind turbine depends on many variables such as geometric parameters (like rotor diameter, blade twist angle, chord length and number of blades), aerodynamic properties (like lift and drag coefficients) and operating conditions (like wind speed and rpm of the rotor). Abe and Ohya [39] determined the value of $\mathrm{C}_{\mathrm{t}}$ using disk loading 
method and showed that the acceleration factor $\mathrm{U} / \mathrm{U}_{\mathrm{o}}$ decreases with increase in value of $\mathrm{C}_{\mathrm{t}}$. Besides loading, there are some other factors, mainly the aerodynamic losses associated with nacelle drag, hub/tip losses and blockage to flow because of diffuser, which can be the reason for the poorer performance of the ducted SWEPT at higher wind speed than expected.

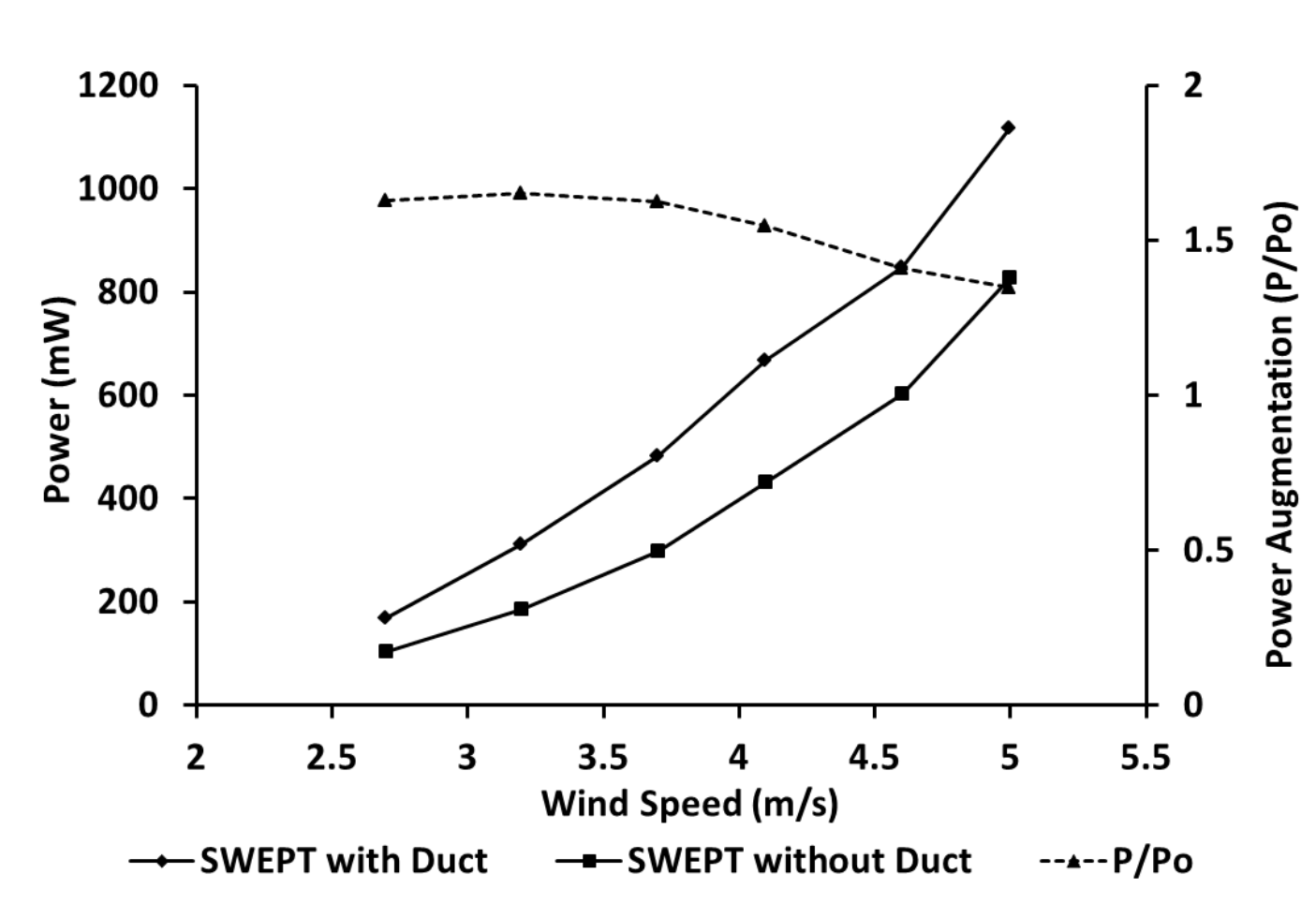

Figure 3.13. Power augmentation of SWEPT with diffuser over SWEPT without diffuser.

\subsection{Summary and conclusions}

This chapter presented the design, fabrication, and characterization of a diffuser augmented small-scale wind energy portable turbine (SWEPT). The diffuser was designed and optimized using computational fluid dynamics (CFD). The CFD studies revealed that the diverging section of diffuser is the stronger parameter in comparison to its converging section, which influences the performance of the wind turbine. The optimal diffuser design has converging section length of 0.125 times throat diameter and half cone angle of $15^{\circ}$ while the length of diverging section is equal to the throat diameter with half cone angle of $10^{\circ}$. It produces velocity augmentation of about 1.2 times the upstream wind speed. It was observed that the diffuser-augmented SWEPT of length approximately the same as the turbine's diameter could produce 1.4 to 1.6 times higher power output than a SWEPT without diffuser. The diffuser, however, makes the device very bulky and adds an extra mass over the mounting rod. Moreover, during wind tunnel experiments, it was noticed that the diffuser augmented wind 
turbine has higher structural vibration than the bare wind turbine, and this problem increases with increase in the wind speed. In summary, it can be stated that even though the diffuser increases the power output of a small scale wind turbine, it raises various practical concerns which questions the simplicity of the device. 


\section{CHAPTER 4}

\section{An inverse design and optimization tool for small scale wind turbines}

It was noted in chapter 3 that even though the power output target of 1 watt was achieved at $5.0 \mathrm{~m} / \mathrm{s}$ with the diffuser augmented SWEPT, the device was too bulky to be deployed in real environment. It's not only the power output, but also the simplicity, compactness, and portability of the device are the other design considerations. Also, it was shown in chapter 2 that currently available design tools for mid-to-large scale wind turbines were not effective towards designing small scale wind turbine for low wind speed applications. This chapter aims to develop a novel design tool for SSWTs, which will provide a systematic procedure for optimizing various blade parameters for developing a high efficiency small scale portable turbine (SWEPT). First, a brief discussion on blade element momentum (BEM) theory will be provided, followed by the iterative scheme used to develop the design tool. A systematic design procedure will be then described in the next section, which discusses the approach and steps required to optimize various geometrical parameters of a SSWT. This chapter will also cover the manufacturing process of the optimized wind turbine blades, the experimental setup and procedure for the wind tunnel experiment. Finally, the power and torque coefficients predicted by the design tool will be compared with the experimental results to check the sanctity and efficacy of the design tool.

\subsection{Blade element momentum theory}

Blade Element momentum theory is based on assumption that the rate of change of momentum of the air passing across the wind turbine is equal to the force on the turbine blades. The details of the theory can be found in the literature $[18,46]$ and here we briefly outline the method for calculation of power coefficient.

a. The turbine blade is divided into number of span-wise elements. Rate of change of axial and angular momentum of wind which passes through the annulus swept by a blade element is equal to the total aerodynamic force (lift and drag) on that element. It is assumed that there is no radial interaction between the flows through two neighboring annuli.

b. Even though upstream wind is axial, the flow passing through the annulus has both axial and angular velocity components. The axial wind velocity component $u_{z}$ and angular wind 
velocity component $u_{\theta}$ at the mid-plane of annulus were expressed in terms of free stream velocity $u_{\infty}$ and rotational rate $\omega$ of wind turbine rotor as:

$$
\begin{aligned}
& u_{z}=(1-a) u_{\infty} \\
& u_{\theta}=\omega r a^{\prime}
\end{aligned}
$$

where $a$ and $a^{\prime}$ are axial and tangential flow induction factors respectively and $\mathrm{r}$ is the distance of annulus from the center of rotation.

c. The relative wind speed $u_{\text {rel }}$ and relative inflow angle $\phi$ with respect to the rotating element can be given as:

$$
\begin{aligned}
& u_{r e l}=\sqrt{\left[(1-a) u_{\infty}\right]^{2}+\left[\left(1+a^{\prime}\right) \omega r\right]^{2}} \\
& \tan \phi=\frac{(1-a) u_{\infty}}{\left(1+a^{\prime}\right) \omega r}
\end{aligned}
$$

d. The angle of attack $\alpha$ is then calculated by:

$$
\alpha=\phi-\beta
$$

where $\beta$ is the local twist angle of the element.

e. The axial force $d N$ and torque $d Q$ acting on the blades element of radius $r$ and length $d r$ can be calculated by axial momentum and angular momentum conservation equations.

$$
\begin{aligned}
& d N=\frac{\rho}{2} \frac{u_{\infty}^{2}(1-a)^{2}}{\sin ^{2} \phi} B\left(C_{L} \cos \phi+C_{D} \sin \phi\right) c d r \\
& d Q=\frac{\rho}{2} \frac{u_{\infty}(1-a)}{\sin \phi} \frac{\omega \mathrm{r}\left(1+a^{\prime}\right)}{\cos \phi} B\left(C_{L} \sin \phi-C_{D} \cos \phi\right) c r d r
\end{aligned}
$$

where $C_{L}$ and $C_{D}$ are lift and drag coefficient respectively, $\rho$ denotes density of air, $B$ is number of blades and $c$ is chord length at radius $r$.

f. The power produced $d P$ by each of the annulus is given by $d P=\omega d Q$. Total power $\mathrm{P}$ can be calculated by integrating $d P$ for all the elements from hub to tip. The power coefficient $C_{P}$ can be then expressed as:

$$
C_{P}=\frac{\int_{r_{h}}^{r_{t}} \omega d Q}{\frac{1}{2} \rho \pi r_{t}^{2} u_{\infty}^{3}}
$$

where $r_{h}$ and $r_{t}$ are hub and tip radii respectively.

g. The power coefficient $C_{P}$ is more often expressed in terms of tip speed ratio $\lambda$ and local tip speed ratio $\lambda_{r}$. Tip speed ratio $\lambda$, local tip speed ratio $\lambda_{r}$ and power coefficient $C_{P}$ are given as [46] :

$$
\begin{aligned}
\lambda & =\frac{\omega r_{t}}{u_{\infty}} \\
\lambda_{r} & =\frac{\omega r}{u_{\infty}}
\end{aligned}
$$




$$
C_{P}=\frac{8}{\lambda^{2}} \int_{\lambda_{r}}^{\lambda} \sin ^{2} \phi\left(\cos \phi-\lambda_{r} \sin \phi\right)\left(\sin \phi+\lambda_{r} \cos \phi\right)\left[1-\left(\frac{C_{D}}{C_{L}}\right) \cot \phi\right] \lambda_{r}^{2} d \lambda_{r}
$$

h. Equation (4.11) does not account for the effect of number of blades on the power coefficient. Further, it does not consider any type of losses that reduce the torque and power of the wind turbine. Out of many mathematical models, Prandtl method is the most frequently used, which expresses tip and hub loss factors as [22]:

$$
\begin{aligned}
& F_{\text {tip }}=\left(\frac{2}{\pi}\right) \cos ^{-1}\left[e^{-\frac{B\left(r_{t}-r\right)}{2 r \sin \phi}}\right] \\
& F_{\text {hub }}=\left(\frac{2}{\pi}\right) \cos ^{-1}\left[e^{-\frac{B\left(r-r_{h}\right)}{2 r_{h} \sin \phi}}\right]
\end{aligned}
$$

The overall blade loss factor is given as

$$
\mathrm{F}=F_{\text {tip }} * F_{\text {hub }}
$$

i. Equation (4.11) with blade loss factor modifies to:

$$
C_{P}=\frac{8}{\lambda^{2}} \int_{\lambda_{r}}^{\lambda} F \sin ^{2} \phi\left(\cos \phi-\lambda_{r} \sin \phi\right)\left(\sin \phi+\lambda_{r} \cos \phi\right)\left[1-\left(\frac{C_{D}}{C_{L}}\right) \cot \phi\right] \lambda_{r}^{2} d \lambda_{r}
$$

\subsection{Iterative scheme}

The calculation of power coefficient is not so straight forward as it appears in the previous section. The problem lies in the fact that one doesn't know the values of axial and tangential flow induction factors $\left(a\right.$ and $\left.a^{\prime}\right)$. Thus it requires an iterative procedure to calculate the values of induction factors for each of the elements. The main steps of the iterative method used in this study are as following:

a. Divide the blades into 15-20 numbers of span-wise elements.

b. Start with some guess values of $a$ and $a^{\prime}$ (e.g. $a=0$ and $a^{\prime}=0$ ).

c. Calculate relative wind speed $u_{r e l}$ and relative inflow angle $\phi$ using Equations (4.3) and (4.4) for all the elements.

d. Determine the value of angle of attack $\alpha$ using Equation (4.5) for the given local twist angle $\beta$ of each element.

e. Calculate Reynolds number for each of the element using equation (1.42):

$$
R e=\frac{\rho c u_{r e l}}{\mu}
$$

f. Look up the values of lift and drag coefficients $\left(C_{L}\right.$ and $\left.C_{D}\right)$ for the given airfoil at the calculated values of angle of attack and Reynolds number. $C_{L}$ and $C_{D}$ for a given airfoil at 
various Reynolds number and angle of attack can be found in published literature. When angle of attack is within 'Attached flow' and 'Dynamic stall' regimes, import the values of $C_{L}$ and $C_{D}$ directly from the data base. For "Flat plate, fully stalled" regime, use following equations [47-49]-

$$
\begin{aligned}
& C_{L}=2 C_{\text {Lmax }} \sin \alpha \cos \alpha \\
& C_{D}=C_{\text {Dmax }} \sin ^{2} \alpha
\end{aligned}
$$

where $C_{\text {Lmax }}$ and $C_{D \max }$ are defined as:

$$
\begin{aligned}
& C_{\text {Lmax }}=C_{L} \text { at } \alpha=45^{\circ} \\
& C_{D \max }=C_{D} \text { at } \alpha=90^{\circ}
\end{aligned}
$$

g. Calculate the blade loss factor F using Equations (4.12), (4.13) and (4.14).

h. Calculate the value of $a$ using following equations.

$$
\begin{aligned}
& \text { If } a<0.4 ; a=\frac{1}{\left[1+\frac{4 F \sin ^{2} \phi}{\frac{c B}{2 \pi r}\left(C_{L} \cos \phi+C_{D} \sin \phi\right)}\right]} \\
& \text { If } a \geq 0.4 ; a=\frac{18 F-20-3 \sqrt{C_{T}(50-36 F)+12 F(3 F-4)}}{36 F-50}
\end{aligned}
$$

where $C_{T}$ is called the thrust coefficient and is given as:

$$
C_{T}=\frac{8}{9}+\left(4 F-\frac{40}{9}\right) a+\left(\frac{50}{9}-4 F\right) a^{2}
$$

i. Calculate the value of $a^{\prime}$ using following equation:

$$
a^{\prime}=\frac{1}{2}\left[-1+\sqrt{1+\frac{4}{\lambda_{r}^{2}} a(1-a)}\right]
$$

j. Repeat the steps from (c) to (i) until convergence has been reached.

k. Finally calculate the power coefficient using Equation (4.15).

\subsection{Design procedure}

There are essentially five blade parameters which influence the power coefficient of a wind turbine. These parameters are: (1) airfoil, (2) twist angle, (3) chord length, (4) tapering angle, and (5) number of blades. Each of these parameters needs to be optimized to achieve the best possible power coefficient. The complete design procedure is divided into two parts, as shown in Figure 4.1. Part I is used to optimize the blade parameters. Once, the turbine blades are optimized, Part II of the model checks the consistency of turbine's performance in the entire range of operating wind speed. A wind turbine may perform very efficiently at its design point but its power coefficient may drop sharply when wind speed is increased. The numerical model was next applied to design a SSWT which is intended to produce $1 \mathrm{~W}$ output power at very low wind speed in the range of 7-10 mph (approx. 3.1-4.5 m/s). We will 
explain the formulation and working of the model using the design procedure of this wind turbine.
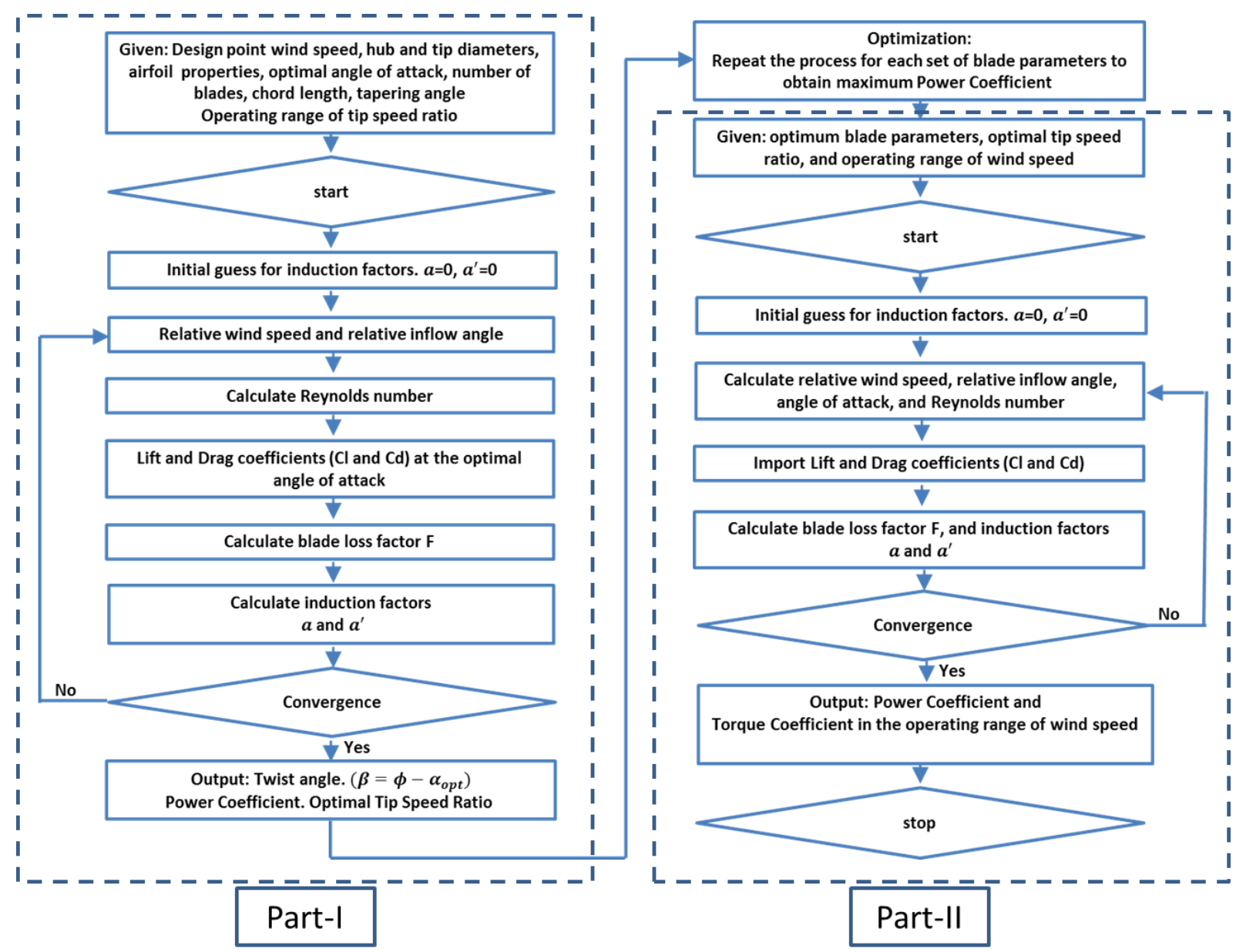

Figure 4.1. Flow Chart showing iterative scheme for the numerical model based on BEM theory.

\subsection{Size of the wind turbine}

Before starting to design a wind turbine, two pieces of information are required to estimate the size of prospective wind turbine. First, the required power output and secondly, the average wind speed of the region where it will be installed. The diameter D of the wind turbine can be calculated using the following expression:

$$
D=\sqrt{\frac{8 P}{\eta \rho \pi u_{\infty}^{3}}}
$$

where $\eta$ is the overall efficiency of the system (including generator). The value of $\eta$ can be assumed to be in the range $20-25 \%$ as an initial value. Thus, for $1 \mathrm{~W}$ wind turbine operating at an average wind speed of $8.5 \mathrm{mph}(3.8 \mathrm{~m} / \mathrm{s})$, the required size of wind turbine will be $40 \mathrm{~cm}$. 


\subsection{Airfoil selection}

As explained in section 1.7, the lift over drag ratio of an airfoil decreases drastically with decrease in flow Reynolds number. Therefore, correct estimation of flow Reynolds number is the first and foremost step of the design process. Reynolds number can be calculated using Equation (1.42). It's important to notice that the expression contains relative wind speed and not the absolute wind speed. Also, there are many variables whose values are not known at the beginning, such as induction factors $a$ and $a^{\prime}$, rotation rate $\omega$ and the chord length $c$. Each of these variables needs to be wisely guessed. We assume induction factors $a$ and $a^{\prime}$ equals to zero. Rotation rate $\omega$ can be calculated using Equation (4.9), but tip speed ratio $\lambda$ is unknown. For the LSWTs, the optimal tip speed ratio lies in the range of 8 to 10, whereas, for SSWTs, the value in the range of 2 to 4 has been suggested for the better reliability of performance and lower noise level [34]. The tip speed ratio was assumed to be $\lambda=3.0$, mean of 2 and 4 as a reliable initial guess. Chord length $c$ should be estimated by considering the structural rigidity. The value of $15 \%$ of the diameter was taken as the average chord length as an initial guess. For a wind turbine having diameter of $40 \mathrm{~cm}$ and tip speed ratio of 3, the Reynolds number can be calculated to be 40,000 .

Once the flow Reynolds number has been estimated, the next step was to determine an appropriate airfoil which performs well at the given Reynolds number. Thickness of airfoil is an important feature that should be kept in mind while finalizing the airfoil. The airfoil should be thick enough to provide sufficient rigidity to the turbine blades. There are various kinds of airfoils that have been developed for low Reynolds number operation. One of such airfoils is NACA 0012 which has been extensively investigated and reliably used for various applications at low Reynolds numbers [37, 50-54]. We selected this airfoil primarily because it is symmetrical and thus it will be relatively easier to manufacture the blades. Figure 4.2 shows the lift and drag coefficients $(\mathrm{Cl}$ and $\mathrm{Cd})$ and lift over drag ratio $(\mathrm{Cl} / \mathrm{Cd})$ of NACA 0012 at Reynolds number $\mathrm{Re}=40000$ obtained using program XFLR5 v6.06 [55], an analysis tool for the airfoils at low Reynolds number. NACA 0012 airfoil has maximum lift over drag ratio of 22 at the angle of attack $\alpha=6^{\circ}$. 


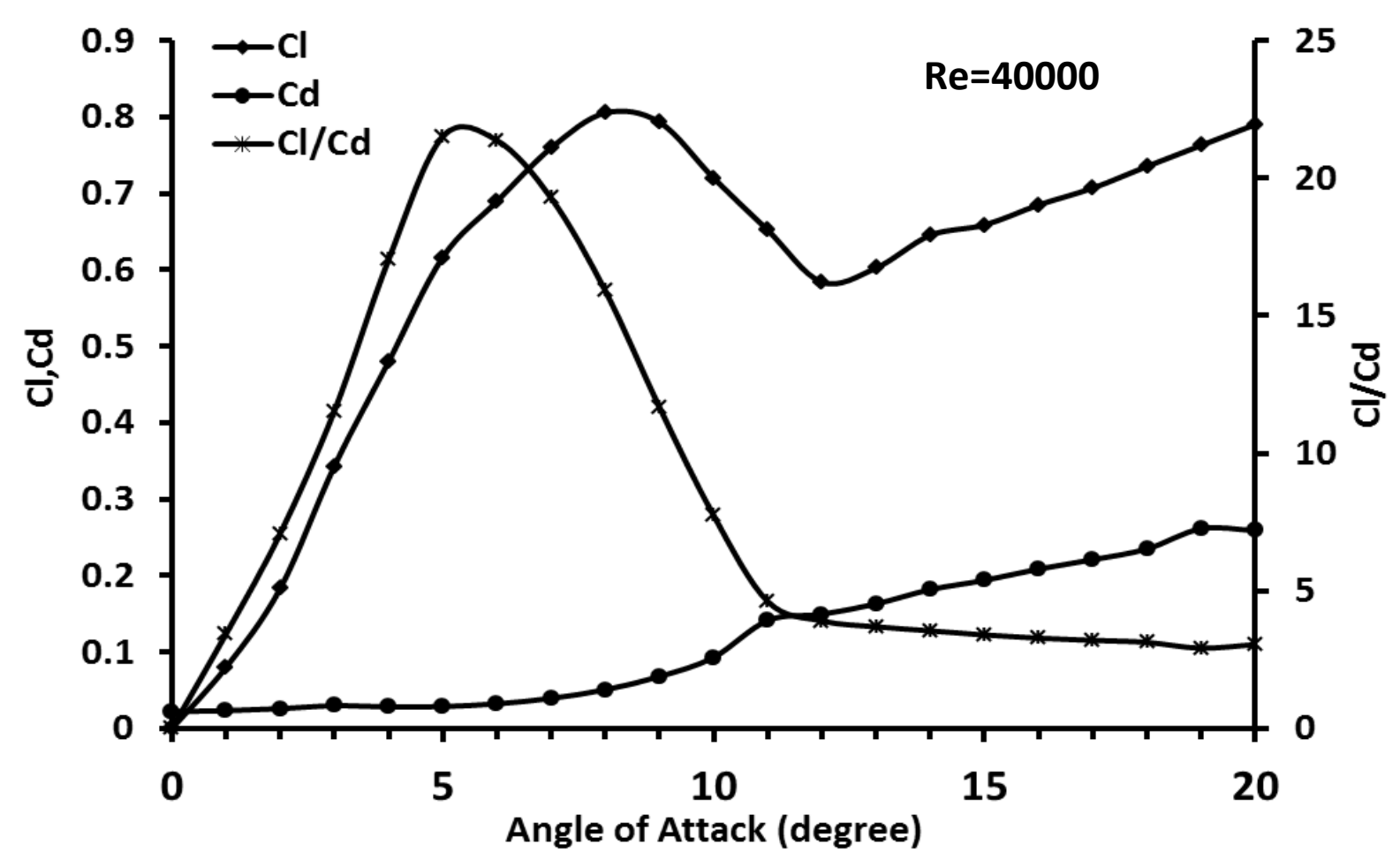

Figure 4.2. Lift and Drag coefficients of NACA 0012 airfoil.

\subsection{Blade twist angle}

It can be seen from Equation (4.4) that the relative inflow angle $\phi$ of the wind with respect to rotating turbine blades is inversely proportional to radius of the wind turbine. This implies that the inflow angle has higher value near the hub and it decreases from hub to tip. The blades of the wind turbines need to be twisted in such a way that the wind should always strike the turbine blades at the optimal angle of attack. Iterative method discussed in section 4.2 can be modified to estimate the twist angle of the turbine blade. The modified iterative method is given below:

i. Divide the blades into 15-20 numbers of span-wise elements

ii. Start with some guess values of $a$ and $a^{\prime}$ (e.g. $a=0$ and $a^{\prime}=0$ )

iii. Calculate relative wind speed $u_{r e l}$ and relative inflow angle $\phi$ using Equations (4.3) and (4.4) for all the elements

iv. Calculate Reynolds number for each of the element using Equation (1.42)

v. Look up the values of lift and drag coefficients $\left(C_{L}\right.$ and $\left.C_{D}\right)$ at the constant value of optimal angle of attack $\alpha_{o p t}$

vi. Calculate the blade loss factor F using Equations (4.12), (4.13) and (4.14)

vii. Calculate the induction flow factors $a$ and $a^{\prime}$ using Equations (4.18) to (4.21)

viii. Repeat the steps from (iii) to (vii) till convergence is reached 
ix. The local twist angle $\beta$ of each of the elements can be calculated using the expression:

$$
\beta=\phi-\alpha_{\text {opt }}
$$

x. $\quad$ Power coefficient can also be calculated using Equation (4.15)

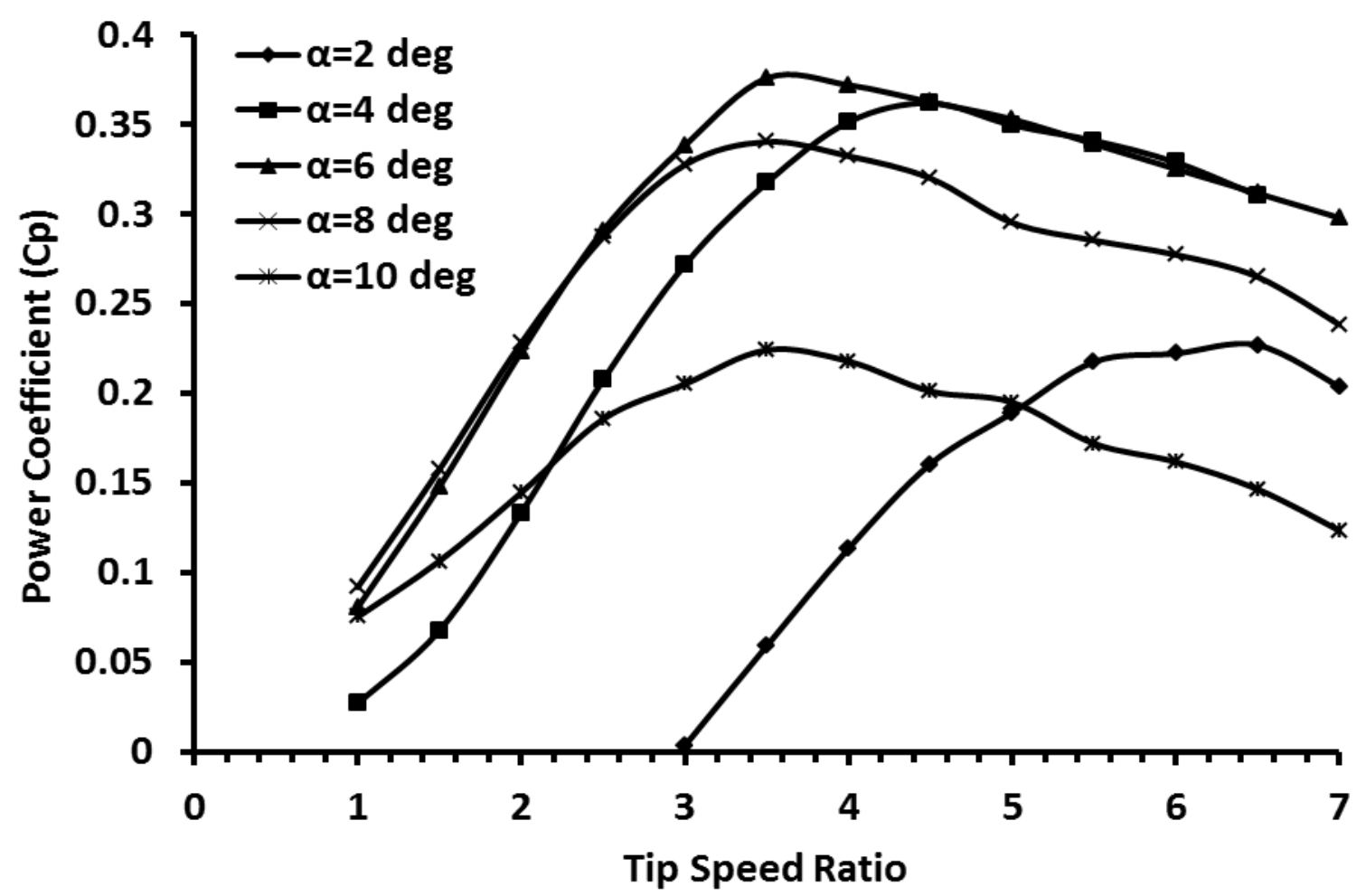

Figure 4.3. Power Coefficient vs. Tip Speed Ratio at various constant angles of attack.

Figure 4.3 shows the variation of power coefficient $\left(C_{P}\right)$ as a function of tip speed ratio $(\lambda)$ at different values of constant angle of attack $\left(\alpha=2^{\circ}, 4^{\circ}, 6^{\circ}, 8^{\circ}, 10^{\circ}\right)$. All the simulations were run at the wind speed of $4 \mathrm{~m} / \mathrm{s}$ and at constant chord length of $6 \mathrm{~cm}$ from hub to tip. The maximum value of power coefficient first increases with increase of $\alpha$ from 2 to 4 degree, reaches maximum at $\alpha=6$ degree and then decreases with further increase in $\alpha$. Also, optimal tip speed ratio $\lambda_{\text {opt }}$ decreases with increase in the value of $\alpha$ from 2 to 6 degree and then remains almost constant at $\lambda_{\mathrm{opt}}=3.5$. This behavioral variation of optimal power coefficient with constant values of angle of attack is directly related to change in lift and drag forces with the angle of attack. It can be seen from Figure 4.2 that lift to drag ratio has maxima at around $\alpha=6^{\circ}$ for the given airfoil. Therefore, optimal power coefficient also has the highest value at $\alpha=6^{\circ}$ and it decreases with the change in $\alpha$ in either direction.

Figure 4.4 shows the blade twist angle at different values of constant angle of attack for its optimal power coefficient. It can be seen that the variation in the twist angle is non- 
linear from hub to tip and blade is highly twisted near the hub. This is a special feature of a SSWT blade. Large twist angle near the root generates high starting torque which helps the wind turbine rotor to start at low wind speed. Negative twist angle at the tip of the blade can be seen at $\alpha=10^{\circ}$, this is not desirable as it creates inverse tangential force and leads to decrease in power coefficient [49]. At $\alpha=6^{\circ}$, the local twist angle varies from $44^{\circ}$ at the hub to $3.5^{\circ}$ at the tip of the blade.

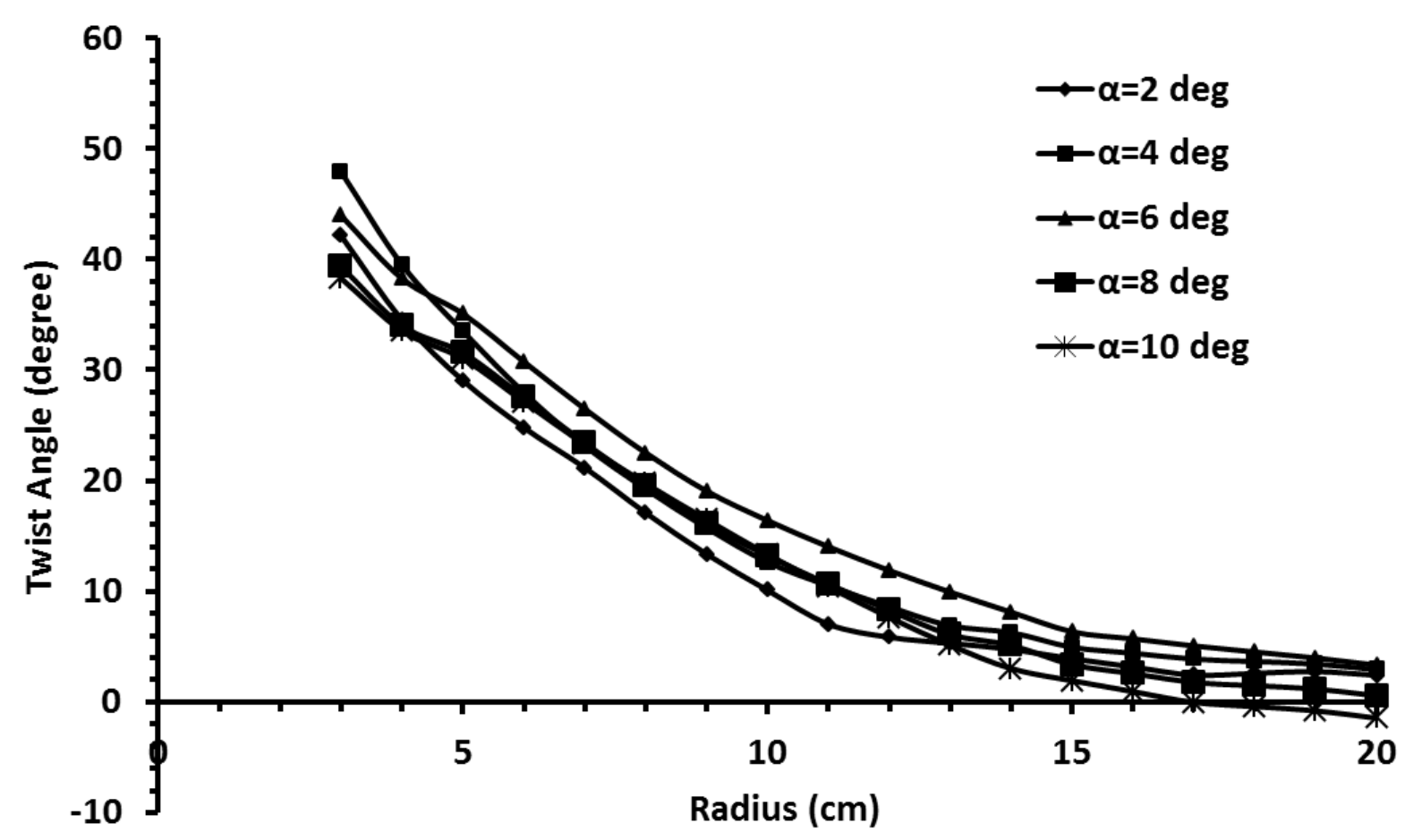

Figure 4.4. Blade twist angle at various constant angles of attack.

\subsection{Solidity of the wind turbine}

Solidity of a wind turbine is defined as the ratio of surface area of the blades to its total swept area and is given by expression [22] :

$$
\sigma(r)=\frac{B c(r)}{2 \pi r}
$$

It is very important parameter which influences the power coefficient of a wind turbine. Its value lies in the range of 5\%-7\% for the conventional LSWT. However, for the SSWTs, much higher solidity has been reported at the maximum power coefficient. The optimal solidity in the range of $15 \%-25 \%$ has been suggested by Duquette and Visser [22] for the wind turbine of $2 \mathrm{~m}$ diameter. This figure increased up to $50 \%$ as the diameter decreased to $\sim 23.5 \mathrm{~cm}$ [35]. These two studies show that there is very large variation in the optimal solidity depending on the size of SSWTs and any wrong assumption may lead to wrong 
design. The optimal solidity of the $40 \mathrm{~cm}$ diameter wind turbine was determined using the proposed numerical model. For the time being, let's assume the turbine has constant chord length for the entire span of the turbine blade. The effect of tapering angle will be discussed in the next section. Average solidity of a constant chord wind turbine is given by following expression:

$$
\sigma=\frac{B c\left(r_{t}-r_{h}\right)}{\pi r_{t}^{2}}
$$

Equation (4.25) has two variables that influence the solidity: chord length and number of blades. Table 4.1 shows matrix for the calculation of chord length (in $\mathrm{cm}$ ) at different solidity and number of blades. The tip and hub radii of the given turbine were $20 \mathrm{~cm}$ and $3 \mathrm{~cm}$ respectively.

Table 4.1. Chord length $(\mathrm{cm})$ at different solidity and number of blades

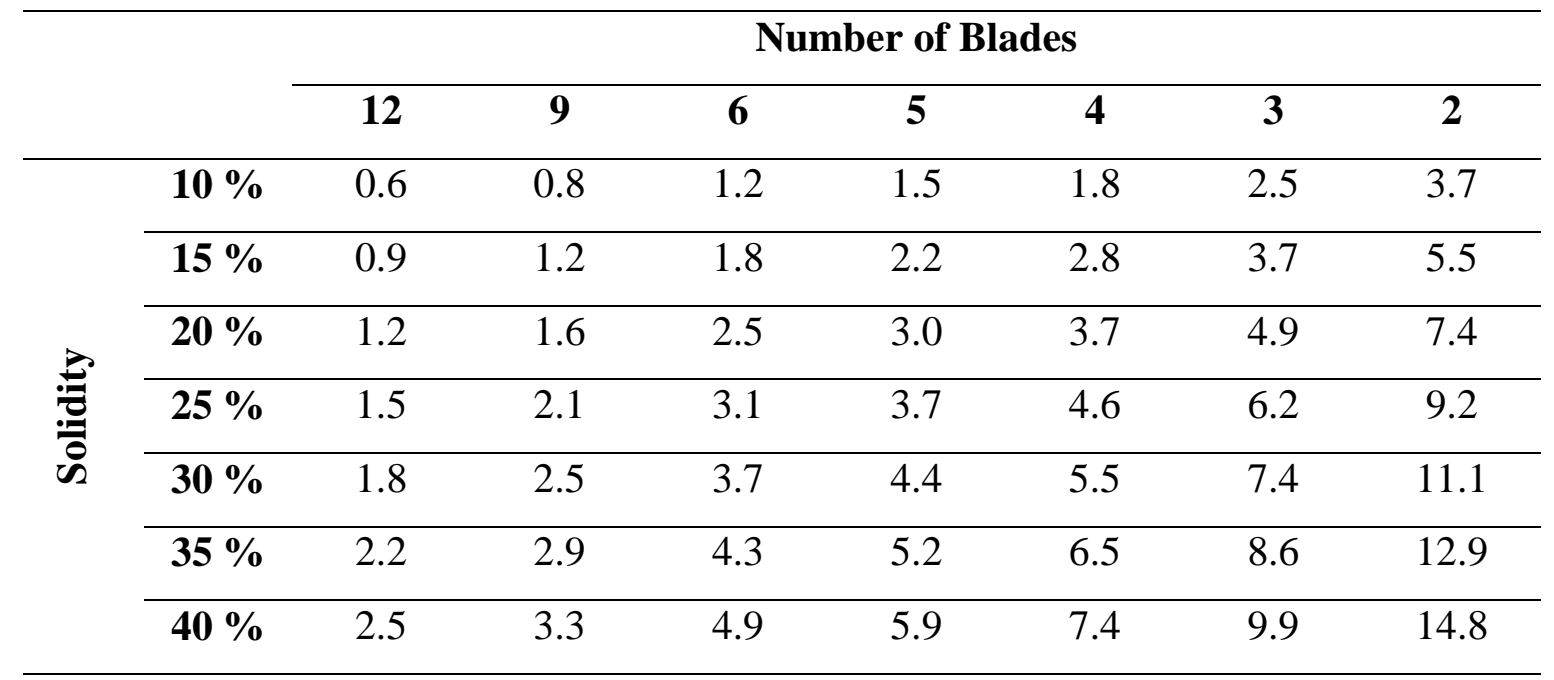

Figure 4.5 (a) to (d) show the power coefficient vs. tip speed ratio at four different values of solidity $(10 \%, 20 \%, 30 \%$ and $40 \%)$ obtained using the proposed numerical model at constant angle of attack $\alpha=6^{\circ}$. When $\sigma=10 \%$, the optimal power coefficient $C_{P}=31 \%$ occurs at $\mathrm{c}=3.7 \mathrm{~cm}, \mathrm{~B}=2$ and $\lambda=6$. When $\sigma=20 \%$, the power coefficient increases to $36 \%$ at $\mathrm{c}=7.4 \mathrm{~cm}, \mathrm{~B}=2$ and $\lambda=4.5$. When $\sigma=30 \%$, the maximum power coefficient $C_{P}=38 \%$ can be seen at $\mathrm{c}=7.4 \mathrm{~cm}, \mathrm{~B}=3$ and $\lambda=3.5$ whereas when $\sigma=40 \%$, the higher power coefficient $C_{P}=39 \%$ is found at $\mathrm{c}=7.4 \mathrm{~cm}, \mathrm{~B}=4$ and $\lambda=3$. This implies that the optimal power coefficient increases with increase in solidity, though the rate of increase is higher at lower solidity (10\%-20\%) and becomes slower at higher solidity (30\%-40\%). Increase in solidity affects the aerodynamics of the wind turbine in two different ways. Higher solidity provides greater blade surface area to the wind and thus it increases the aerodynamic torque. However, 
drag induced losses also increase with increase in solidity. When solidity is low $(\sigma<20 \%)$, the former effect dominates which is favorable towards turbine's performance and thus the power coefficient increases sharply with increase in solidity. As the solidity increases beyond $20 \%$, the influence of drag induced losses increase and optimal power coefficient starts to saturate. It was found that when solidity increased more than $50 \%$, the power coefficient decreased. Also, the optimal number of blades increases from 2 to 4 when solidity is raised from $10 \%$ to $40 \%$. It is interesting to note that the optimal chord length remains almost constant when solidity is increased. It's the number of blades which controls the optimal power coefficient. The optimal tip speed ratio, however, decreases with increase in solidity. Thus, higher the solidity better is the power coefficient. Also, higher solidity has lower optimal tip speed ratio, thus lower rpm and lower centrifugal stress on blades. Since there is not much gain in terms of power coefficient, when $\sigma>30 \%$, very high solidity should be avoided due to two main reasons. First, increase in solidity means increase in cost of material of the blades. Secondly, higher solidity may block the flow and thus blades need to be highly twisted near the hub to avoid flow blockage which may cause manufacturing difficulties.

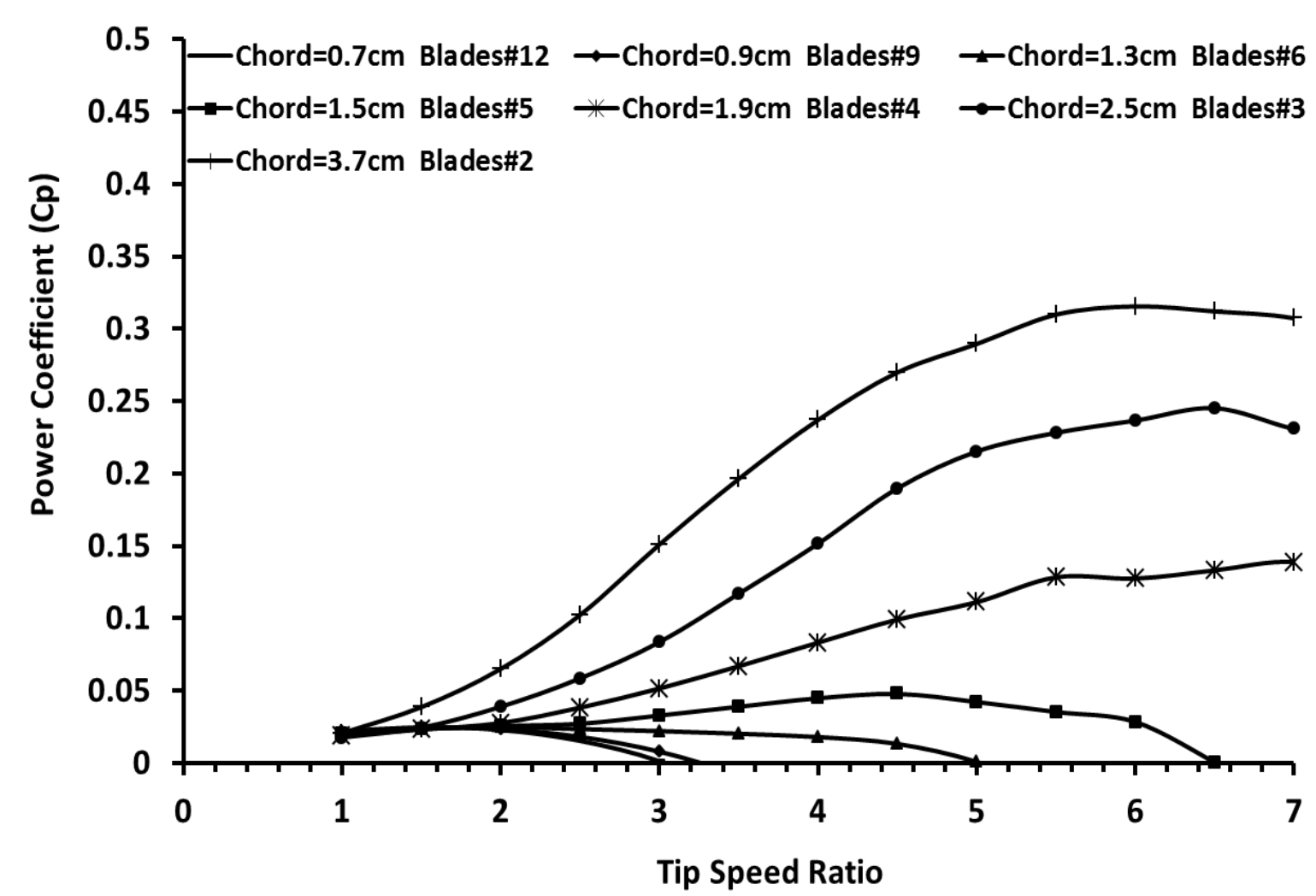

Figure 4.5(a). Power Coefficient vs. Tip Speed Ratio at solidity $\sigma=10 \%$. 


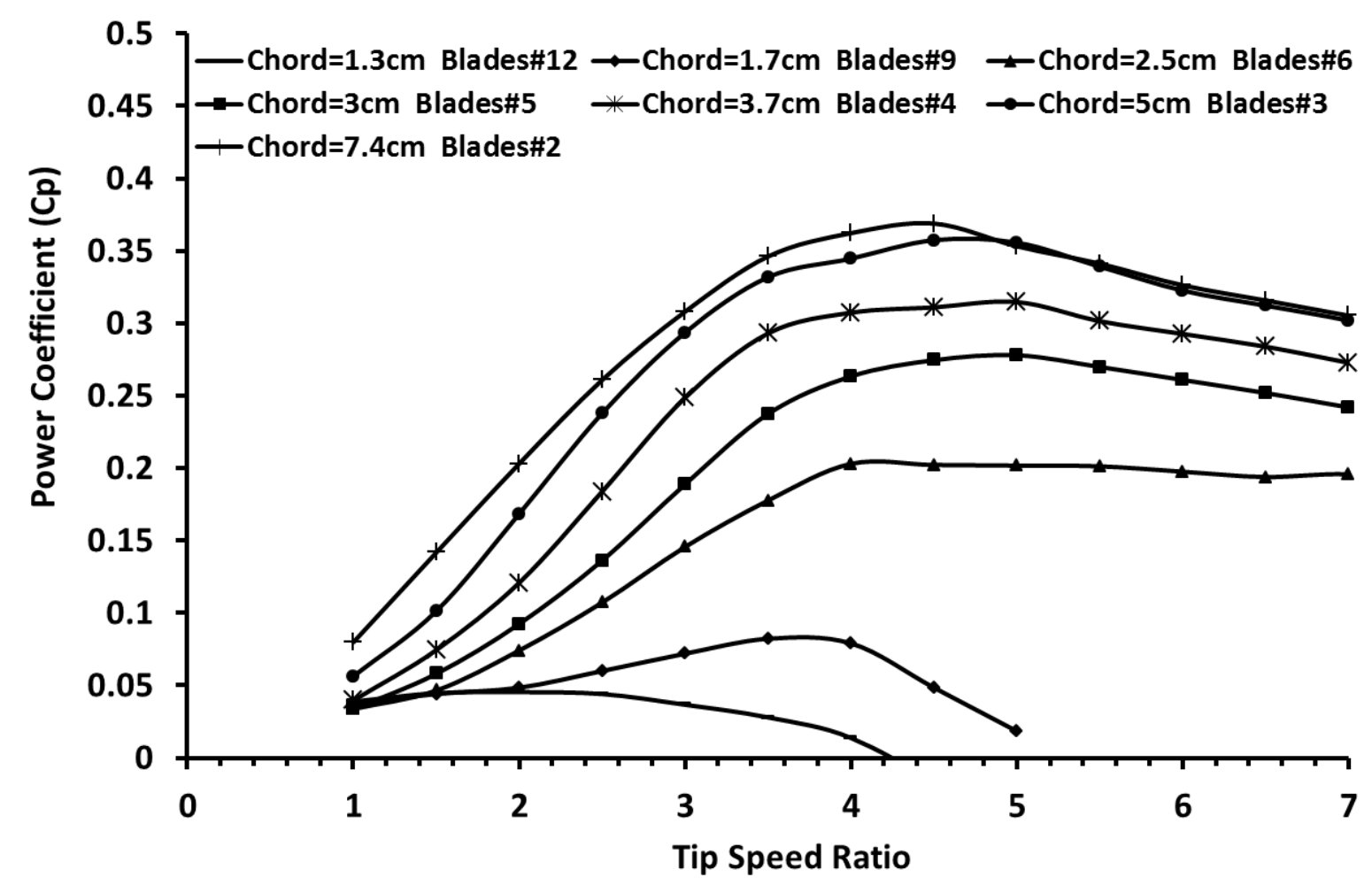

Figure 4.5(b). Power Coefficient vs. Tip Speed Ratio at solidity $\sigma=20 \%$.

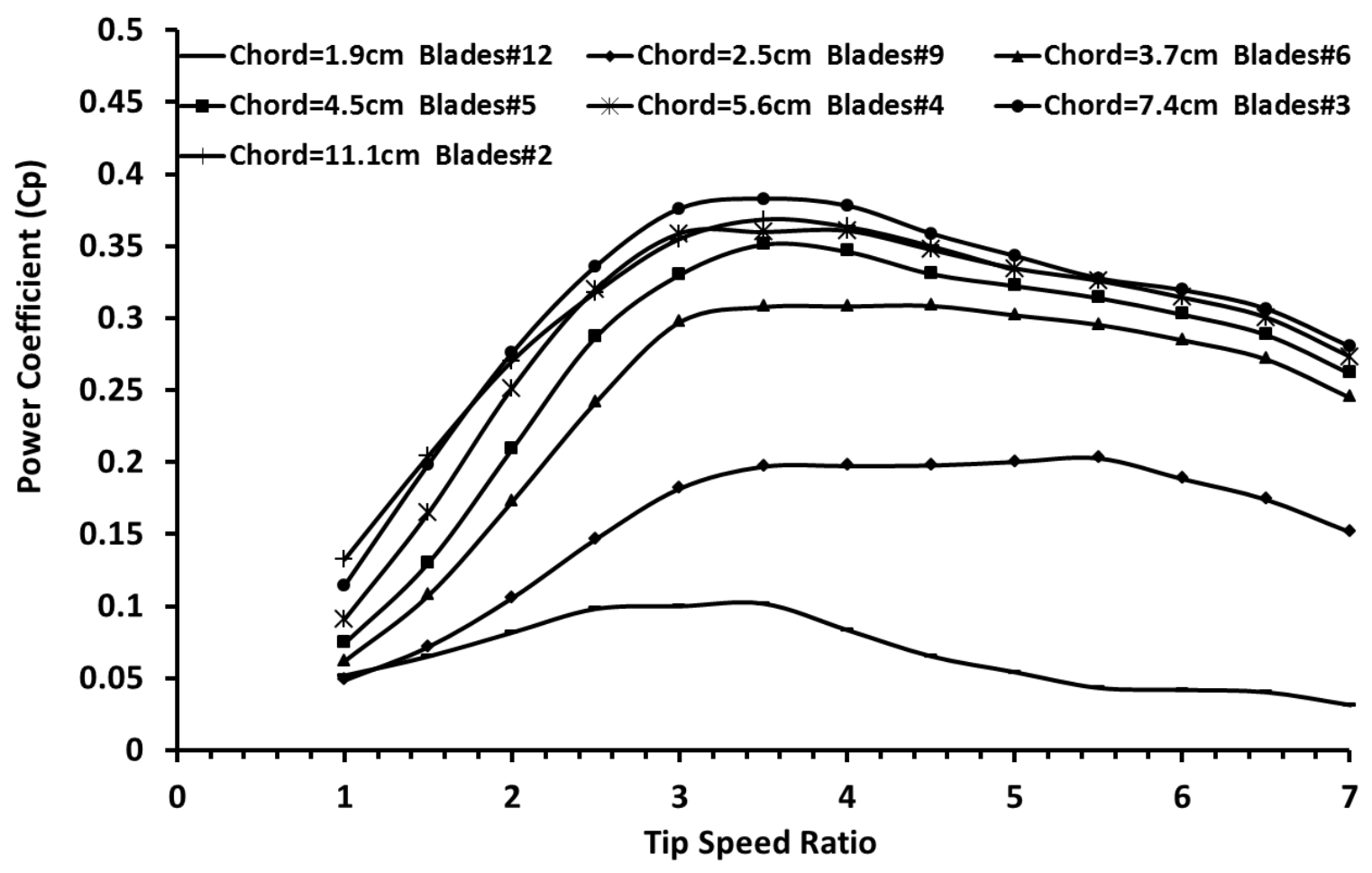

Figure 4.5(c). Power Coefficient vs. Tip Speed Ratio at solidity $\sigma=30 \%$. 


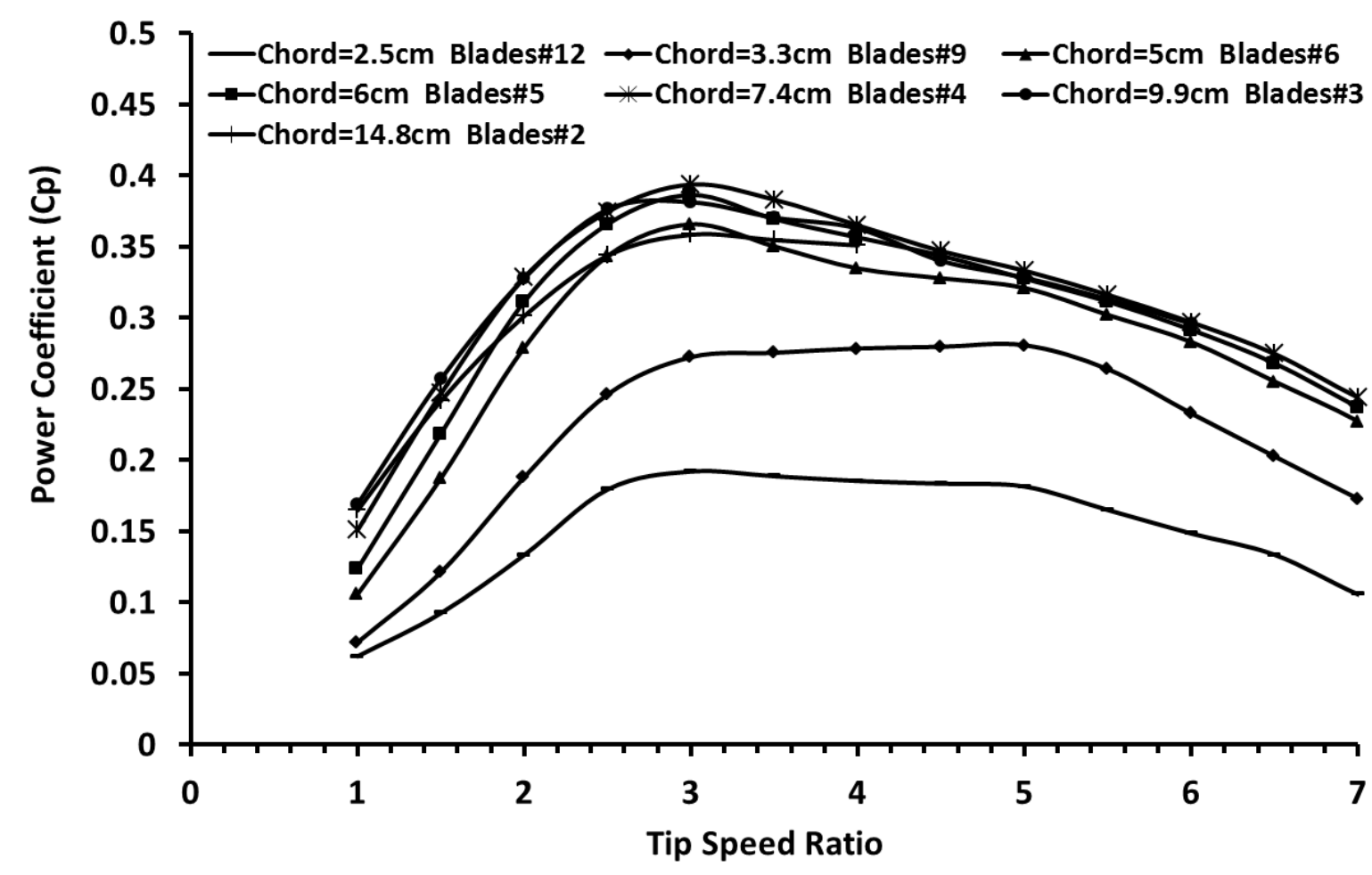

Figure 4.5(d). Power Coefficient vs. Tip Speed Ratio at solidity $\sigma=40 \%$.

Figure 4.6 shows the torque coefficient vs. tip speed ratio of the wind turbine at different solidity with its corresponding optimal chord length and blade number. It is interesting to note that the peak of torque coefficient curve is located at lower tip speed ratio than that of power coefficient curve. Further, the torque coefficient increases with increase in solidity, while the tip speed ratio corresponding to maximum value of torque coefficient decreases. At very high solidity $\sigma \geq 50 \%$, the optimal tip speed ratio for the torque coefficient occurs when the wind turbine is almost stalled and power coefficient is too low. This is another reason why solidity $\sigma \geq 50 \%$ should be avoided in case of SSWTs. For the $1 \mathrm{~W}$ wind turbine under study, we have opted solidity $\sigma=30 \%$ with chord length $c=7.5 \mathrm{~cm}$ and number of blades $B=3$. Blades of the wind turbine are non-linearly twisted, $40^{\circ}$ at the hub to $3^{\circ}$ at the tip. 


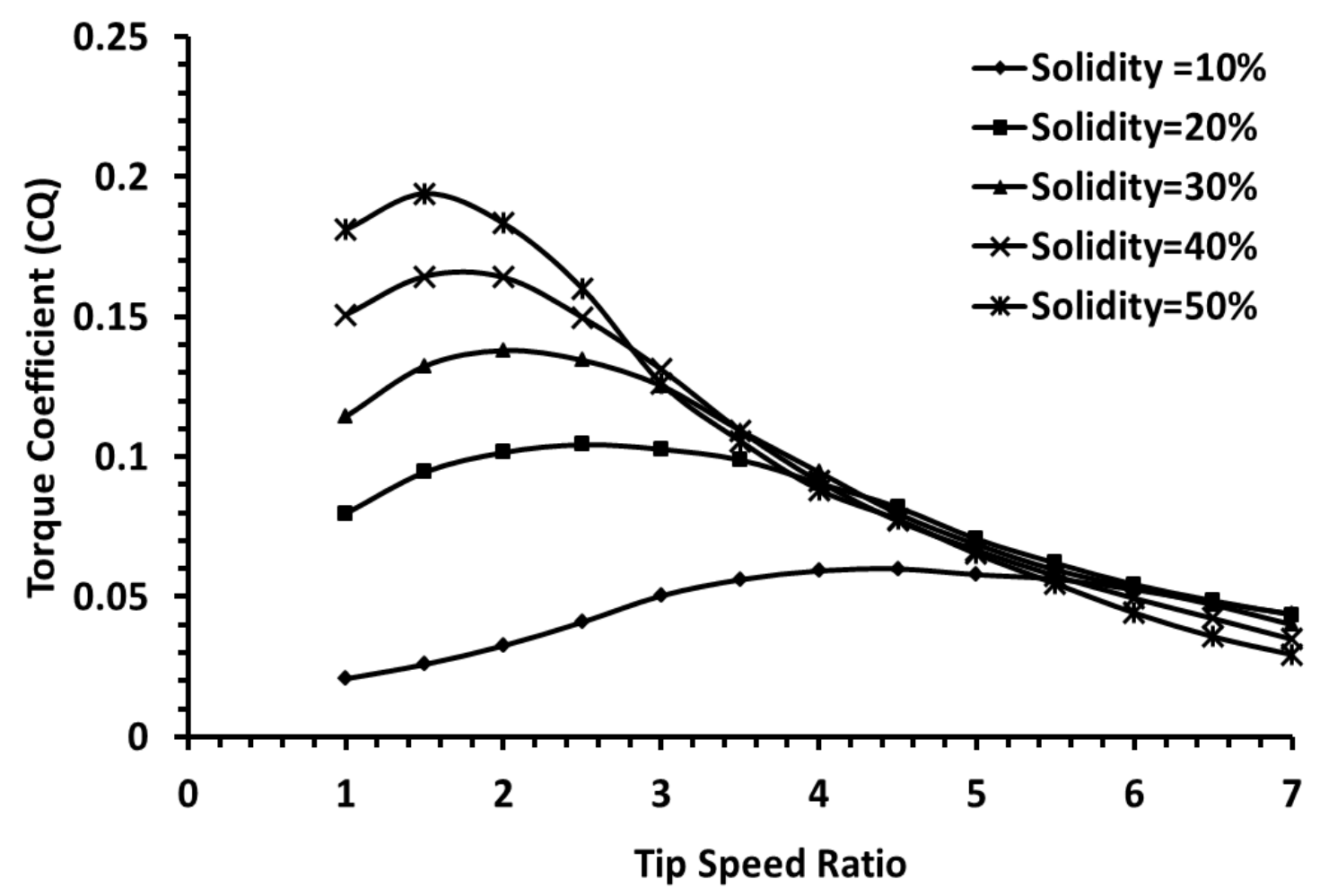

Figure 4.6. Torque Coefficient vs. Tip Speed Ratio at different values of solidity.

\subsection{Tapering angle}

Blades of a wind turbine are generally tapered from hub to tip to minimize centrifugal stresses. However, the problem of centrifugal stress is generally low in case of SSWTs due to smaller size. This is the reason why some of the SSWTs have been constructed with constant chord length. Tapering can be either linear or non-linear. In this study, the effect of linear tapering angle of the given wind turbine was examined. Figure 4.7(a) and (b) show the effect of positive and negative tapering angle on power coefficient. Positive tapering means the blade has maximum chord length near the hub and it decreases to the tip. On the other hand, chord length of the negative tapered blades (fan type blades) increases from hub to tip. 


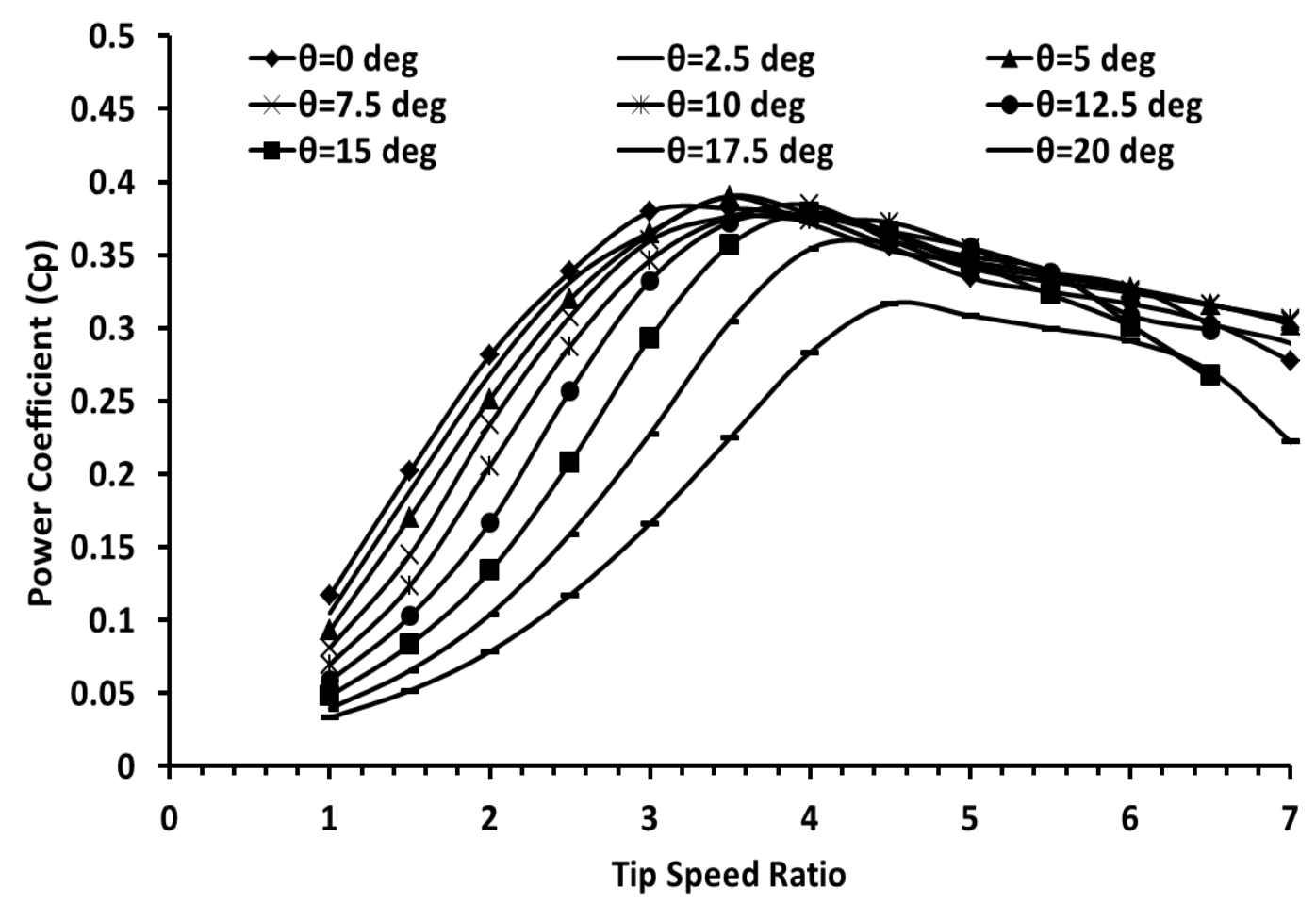

Figure 4.7(a). Power Coefficient vs. Tip Speed Ratio at different positive tapering angles.

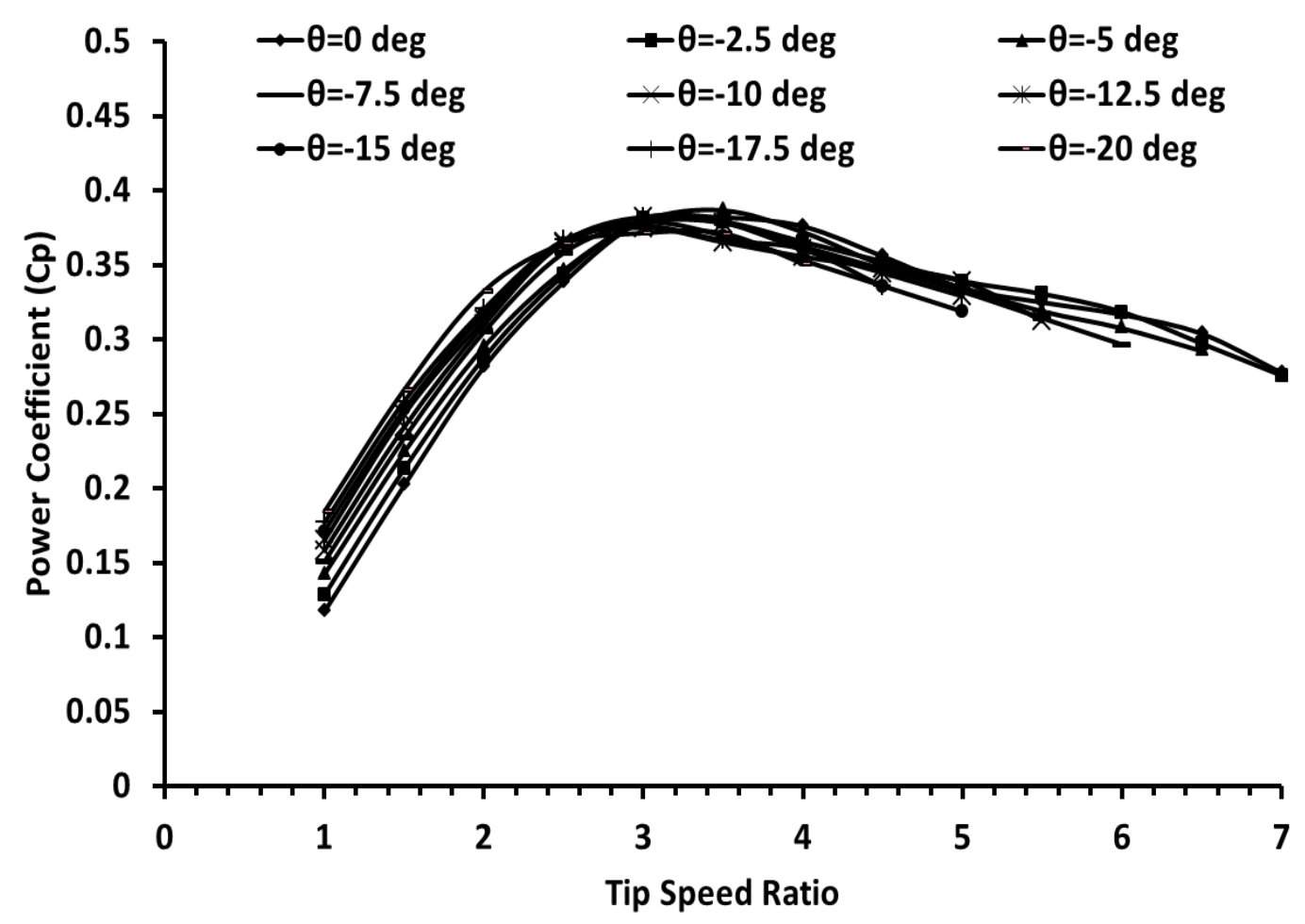

Figure 4.7(b). Power Coefficient vs. Tip Speed Ratio at different negative tapering angles.

Figure 4.7(a) shows that the maximum power coefficient remains almost constant till $\theta \leq 5^{\circ}$ and then it decreases with increase in positive tapering angle. Also, it can be seen 
from Figure 4.7(b) that the negative tapering angle has almost no effect on the maximum power coefficient. It implies that the blades of SSWTs should have constant chord length or small positive tapering angle in the range of $0^{\circ}-5^{\circ}$.

\subsection{Blade construction}

The optimized blade of the wind turbine has following features:

(i) Tip Radius: $40 \mathrm{~cm}$; Hub Radius: $3 \mathrm{~cm}$

(ii) Airfoil: NACA 0012

(iii) Twist Angle: $37^{\circ}$; Non-linearly twisted, $40^{\circ}$ at the hub to $3^{\circ}$ at the tip

(iv) Chord Length: $7.5 \mathrm{~cm}$ uniform along the entire span of the blade

(v) Number of Blades: 3

Blades were constructed using a 3-D printer (Objet Inc., USA). The printer material used was VeroWhite plastic. Figure 4.8 shows the actual wind turbine rotor. Figure 4.9 shows the blade design configuration of the wind turbine with all dimensions in $\mathrm{cm}$.

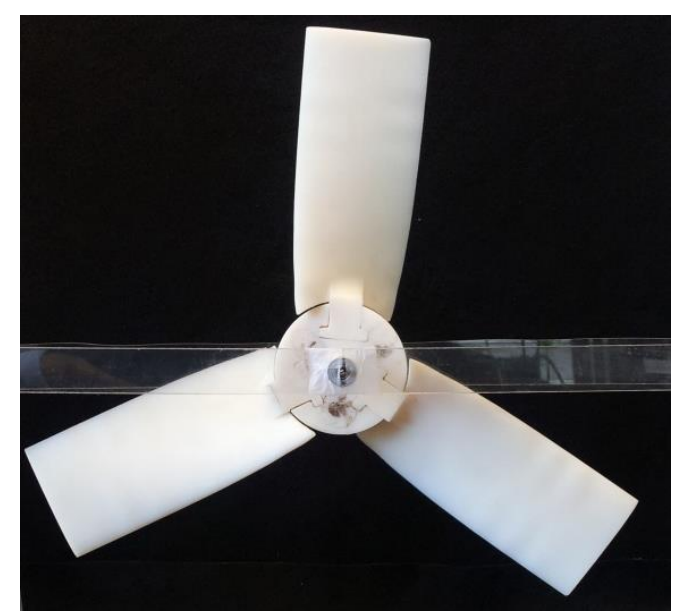

Figure 4.8. Wind turbine rotor manufactured using rapid prototyping machine.

\subsection{Experimental set-up}

The wind tunnel experiments were conducted using the Subsonic Open Jet Wind Tunnel facility available in the Aerospace and Ocean Engineering Department at Virginia Tech. Figure 4.10 shows the experimental set-up. The angular velocity of the wind turbine was measured using non-contact type optical, digital Tachometer "DT-209X" (SHIMPO Instruments, USA). Anemometer used in the experiments was "Xplorer GLX" (PASCO, 
USA). The experiment was repeated several times for a given set of conditions and the arithmetic mean of recorded data was taken as the representative value.
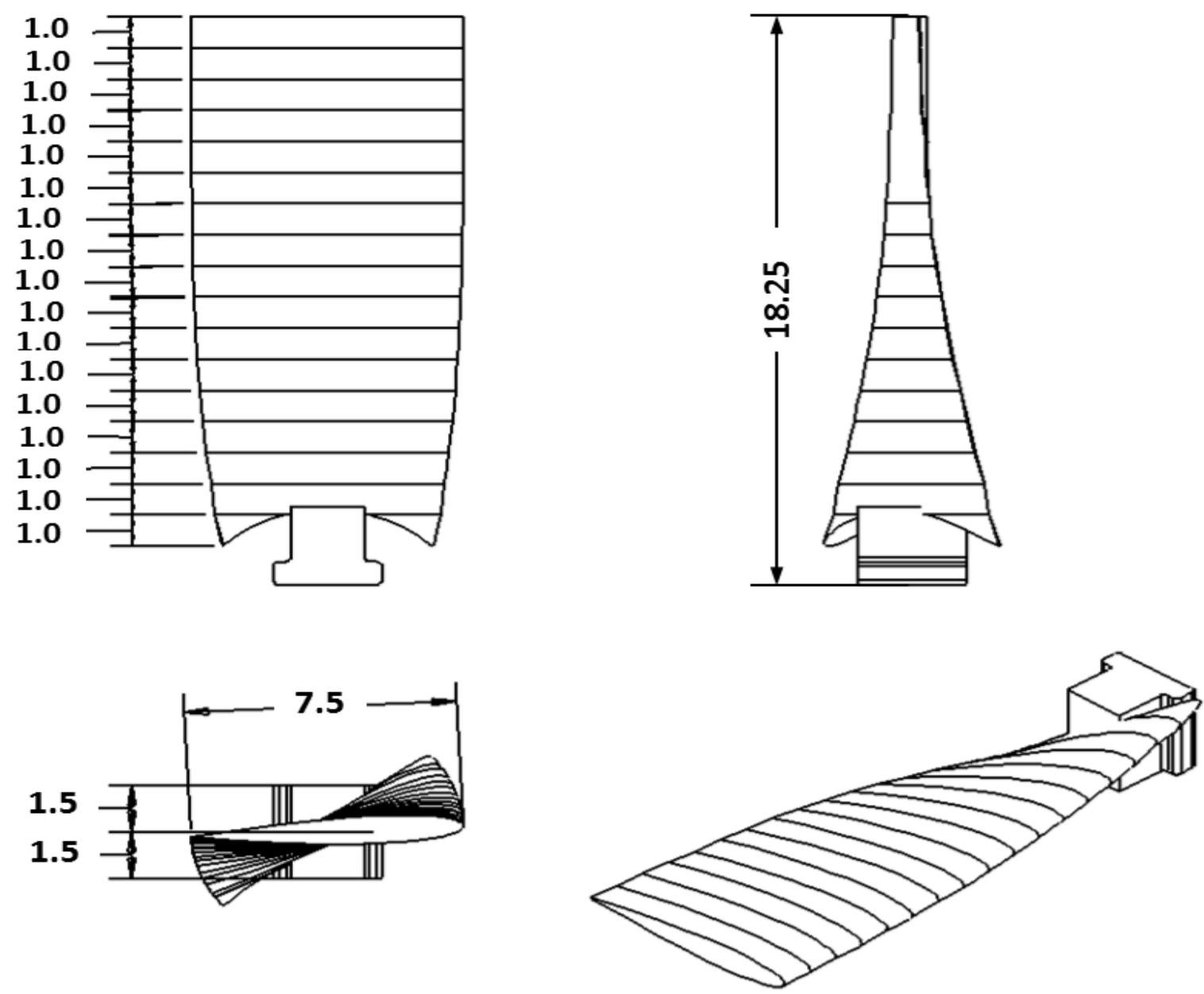

Figure 4.9. Blade design configurations with all dimensions in $\mathrm{cm}$.

\subsection{Power output of the wind turbine}

To measure the mechanical power output of the wind turbine, the same method that was described in section 2.3.1 was used. The blade of the wind turbine was held stationary until wind speed in the wind tunnel was stabilized and then it was allowed to rotate and accelerate freely to its maximum constant speed. The angular speed of the turbine blade, while it was accelerating, was recorded at the time interval of $100 \mathrm{~ms}$ using the optical tachometer. The curve fitting method was then employed to find the $6^{\text {th }}$ degree polynomial equation which describes the rpm as function of time. Figure 4.11 shows the angular speed plot of the wind turbine at the wind speed of $4.0 \mathrm{~m} / \mathrm{s}$. The time derivative of the velocity was calculated to determine the acceleration which was then multiplied with the moment of inertia to calculate 
torque. Once torque was known, it was multiplied with angular speed to calculate the mechanical power.

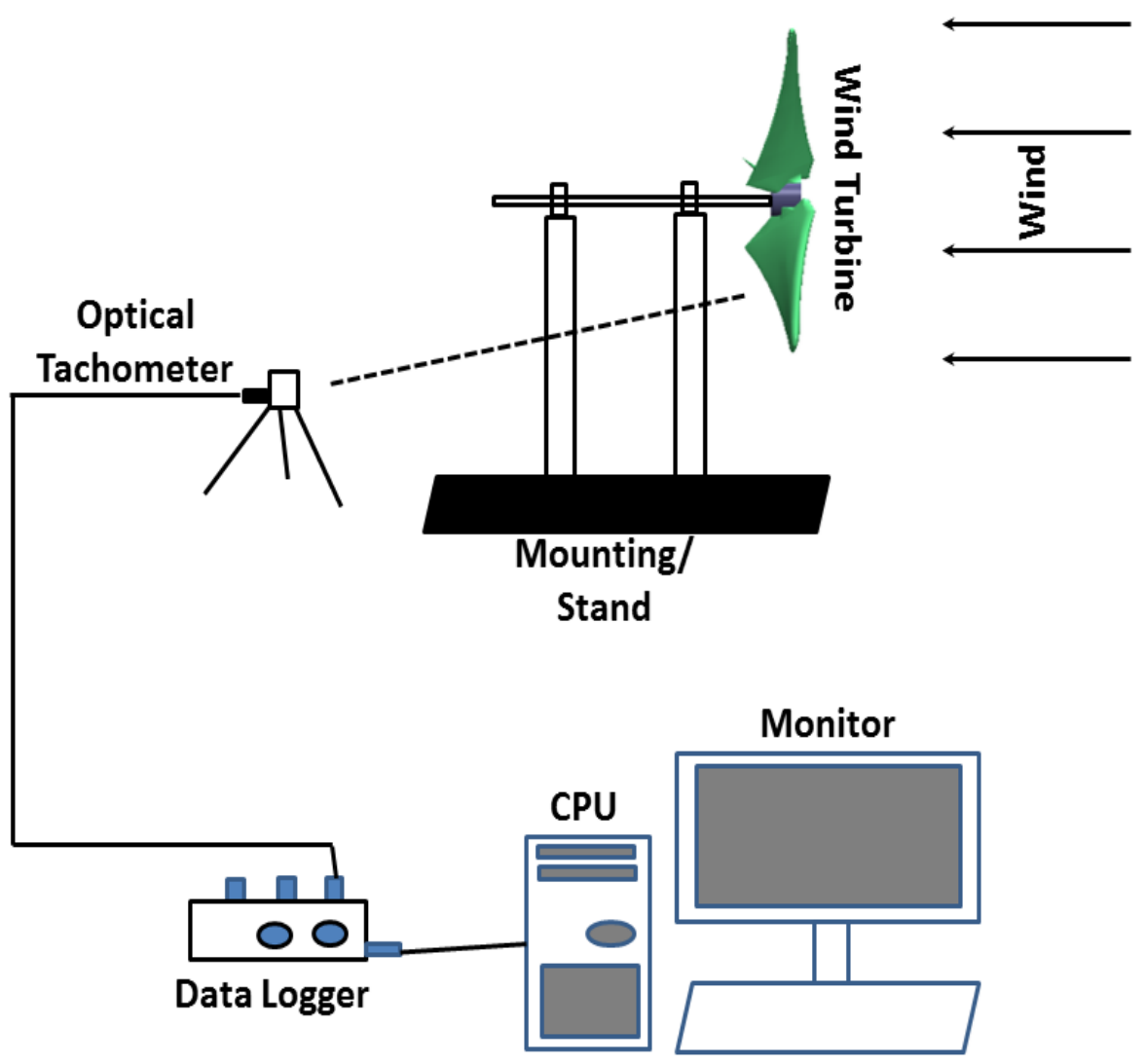

Figure 4.10. Schematic of the experimental set-up.

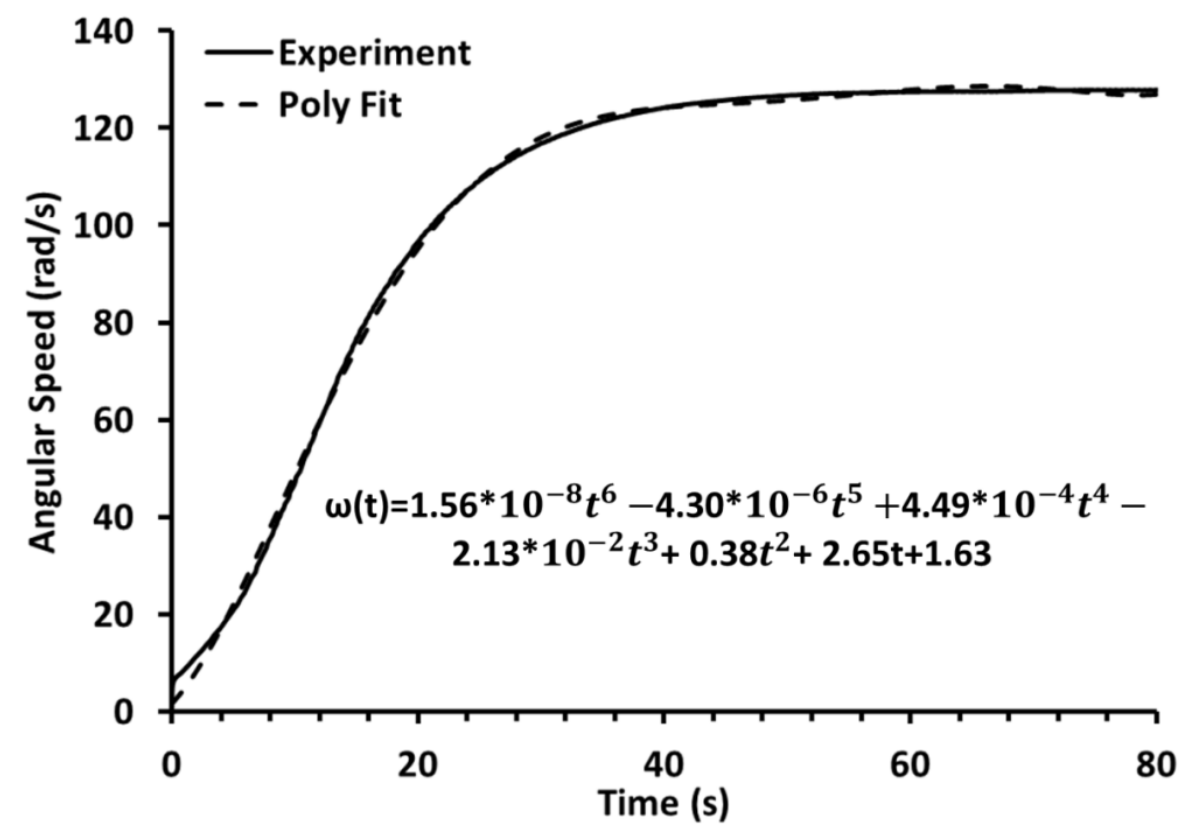

Figure 4.11. Angular speed of the wind turbine at the wind speed of $4.0 \mathrm{~m} / \mathrm{s}$. 
Figure 4.12 shows the mechanical power of the wind turbine obtained experimentally at different wind speeds. The wind turbine produced mechanical power in the range $0.2 \mathrm{~W}-3.1$ $\mathrm{W}$ when it was operated in the wind speed between $2.0 \mathrm{~m} / \mathrm{s}$ and $5.5 \mathrm{~m} / \mathrm{s}$. The power coefficient can also be calculated using Equation (1.20). The wind turbine was found to exhibit consistent performance in its entire range of operating wind speed conditions. The maximum power coefficient was found to be in the range of $32 \%$ to $34 \%$ depending upon the wind speed. The experimental optimal tip speed ratio was around 4.1 which was little higher than its predicted value of 3.5 .

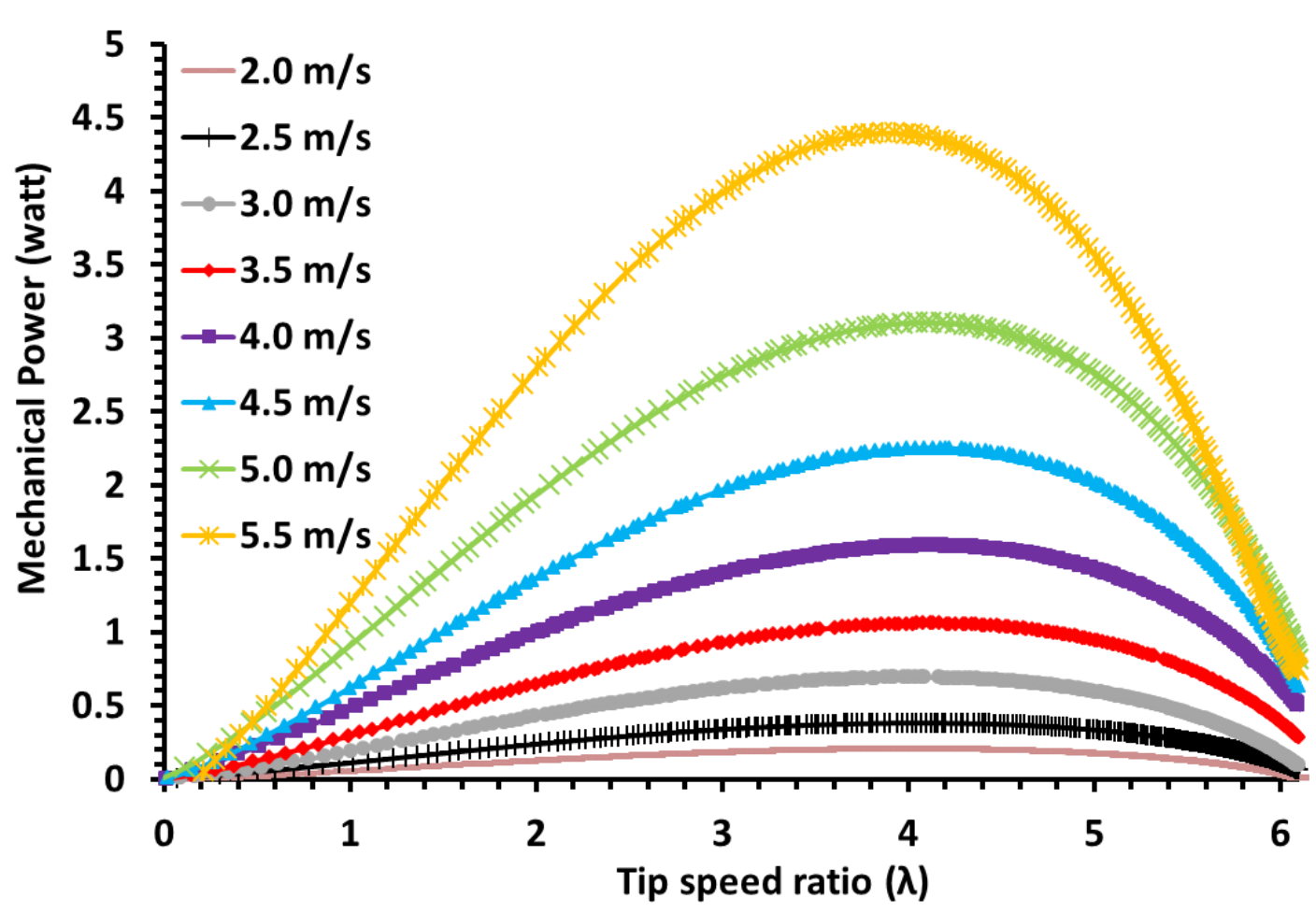

Figure 4.12. Mechanical power output of the wind turbine at various wind speeds.

\subsection{Results validation}

A numerical study is incomplete unless and until the predicted results by the model are validated against some experimental or analytical results. Figure 4.13 shows a comparative plot between the experimental and numerical results for the power and torque coefficients. It can be seen that the numerical model under-predicts the power coefficient when wind speed is below $2.5 \mathrm{~m} / \mathrm{s}$ but over-predicts the power coefficient when wind speed is greater. On the other hand, if we compare the values of torque coefficient obtained experimentally and numerically, we can see that results are close at the lowest wind speed but at higher wind speeds, the predicted results by numerical model are greater than the experimental values. 
The accuracy of the numerical model based on Blade Element Momentum theory is mainly dependent on the accuracy of lift and drag coefficient data. The main concern while using BEM Theory for low Reynolds number applications is the availability of reliable data for lift and drag coefficients. The program XFLR5 v6.06 [55] was used to obtain all the data related to lift and drag coefficients needed in this study. The simulated data from XFLR5 can't be considered as realistic as the experimental data and some disparity in results is obvious. Nonetheless, the excellent performance with power coefficient of $32.2 \%$ from a small wind turbine of rotor diameter $40 \mathrm{~cm}$ at such a low rated wind speed of $4.0 \mathrm{~m} / \mathrm{s}$, confirms both utility and efficacy of the current numerical model.

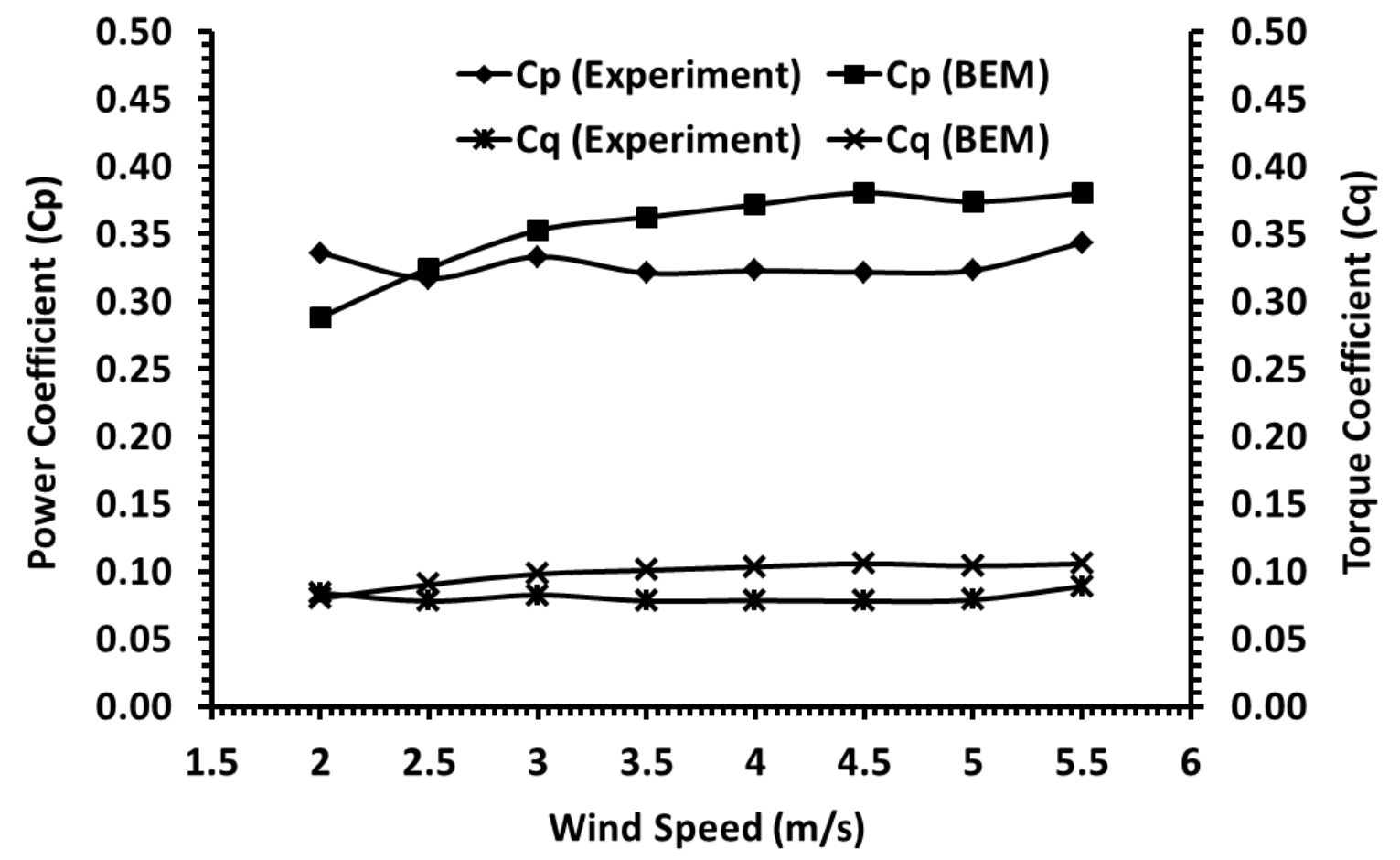

Figure 4.13. Comparison of numerical and experimental results for torque and power coefficients.

\subsection{Summary and conclusions}

An inverse design and optimization tool based on Blade Element Momentum (BEM) theory was developed specifically for the SSWTs. It will not only help a designer to optimize one or more parameters of a SSWT but also provide a systematic design procedure based on inverse logic starting from the desired power output to the optimal blade design configuration of the wind turbine. The complete design process is divided into two parts. Part I aims to optimize 
all the blade parameters of the wind turbine, such as number of blades, chord length, solidity, twist angle and tapering angle. Part II checks the consistency of wind turbine performance in the entire range of operating wind speed. This design tool was used to develop a $40 \mathrm{~cm}$ diameter wind turbine having very low operating wind speed in the range of $2 \mathrm{~m} / \mathrm{s}-5 \mathrm{~m} / \mathrm{s}$. The wind turbine was found be very efficient with power coefficient of about $32.2 \%$ at its design point wind speed of $4.0 \mathrm{~m} / \mathrm{s}$. Wind tunnel experiments were then conducted to verify the numerical predictions. It was found that the numerical and experimental values of power and torque coefficients were close to each other with some disparities at higher wind speeds. The major findings of the study are listed below:

(a) The blades of SSWTs should be constructed with an airfoil applicable for low Reynolds number operation. Correct estimation of flow Reynolds number is the vital step of the design process.

(b) The SSWT blades should be non-linearly twisted with higher angle of twist near the root. This provides higher starting torque coefficient to the wind turbine and thus helps it to start at lower wind speed.

(c) The study revealed that the power coefficient of SSWT increased with increase in solidity. The optimal solidity was found in the range of $30 \%-50 \%$ which is quite higher than the conventional large scale wind turbines which have solidity of around $5 \%-10 \%$.

(d) Various possible combinations of chord length and number of blades at the given values of solidity were examined and it was found that the optimal number of blades existed in the range of 2-4. Furthermore, the blade number was found to be more dominating feature of a small scale wind turbine than the chord length which influenced solidity in regards to higher power coefficient.

(e) Torque coefficient was found to be increasing with increase in solidity and the tip speed ratio corresponding to the peak torque coefficient at very high solidity was found to occur in stall regime of the wind turbine. This is one of the reasons why the solidity greater than $50 \%$ should be avoided.

(f) The blades of small scale wind turbine should have constant chord length or small positive tapering angle in the range of $0^{\circ}-5^{\circ}$. 


\section{CHAPTER 5}

\section{Design and experimental verification of a high efficiency small wind energy portable turbine}

In chapter 4, a novel design tool based on Blade Element Momentum (BEM) theory was developed specifically to design SSWTs for low wind speed applications. The predicted values of power and torque coefficients of the blades were verified with the experimental results. However, the study in the previous chapter was limited to the blade characterization as the blades were not attached with any electric generator. Thus, the overall performance of the wind turbine was not determined. The study in this chapter is more comprehensive where the behavior of the complete wind turbine will be investigated. This is the second generation prototype of small-scale wind energy portable turbine (SWEPT) and it is termed as high efficiency SWEPT.

\subsection{Design specifications}

SWEPT is a 3-bladed horizontal axis wind turbine. The average flow Reynolds number of the turbine, as defined by equation (1.42), calculated at mid-radius under the design point operating condition (wind speed $=4.0 \mathrm{~m} / \mathrm{s}$ and tip-speed ratio=4.1) was found to be around 40,000. NACA 0012 airfoil template was selected for the blade design, which is a suitable airfoil for low Reynolds number applications [37, 50-54]. In addition, it is symmetrical along the camber line and thus it provides simplicity from construction point of view and minimizes the chances of manufacturing related defects. Each of the blades has constant chord length which is equal to $7.5 \mathrm{~cm}$. The hub and tip radii are $3 \mathrm{~cm}$ and $20 \mathrm{~cm}$ respectively. The blades are non-linearly twisted by $37^{\circ}$ from hub to tip. Figure 5.1 shows the twist angle of blade along the radius of the turbine. It can be seen that blade is more twisted near the root than the tip. The large twist near the hub essentially provides higher starting torque and thus it helps the turbine to start at lower wind speed.

Besides the twist angle, solidity is another very important parameter which influences the power coefficient of a wind turbine. The conventional LSWT has solidity in the range of $5 \%-7 \%$. However, for the SSWTs, solidity may be as high as $50 \%$, depending upon the size of wind turbine [22, 35]. The solidity of SWEPT was equal to $30 \%$ which is in agreement with the literature. The blades were connected to hub using dove-tail joint. This method not 
only provides required structural rigidity to the rotor but also gives flexibility towards disassembling the turbine blades from the hub when turbine is not in use. The blades and hub were constructed using a 3-D printer (Objet Inc., USA). The printer material used was VeroWhite plastic.

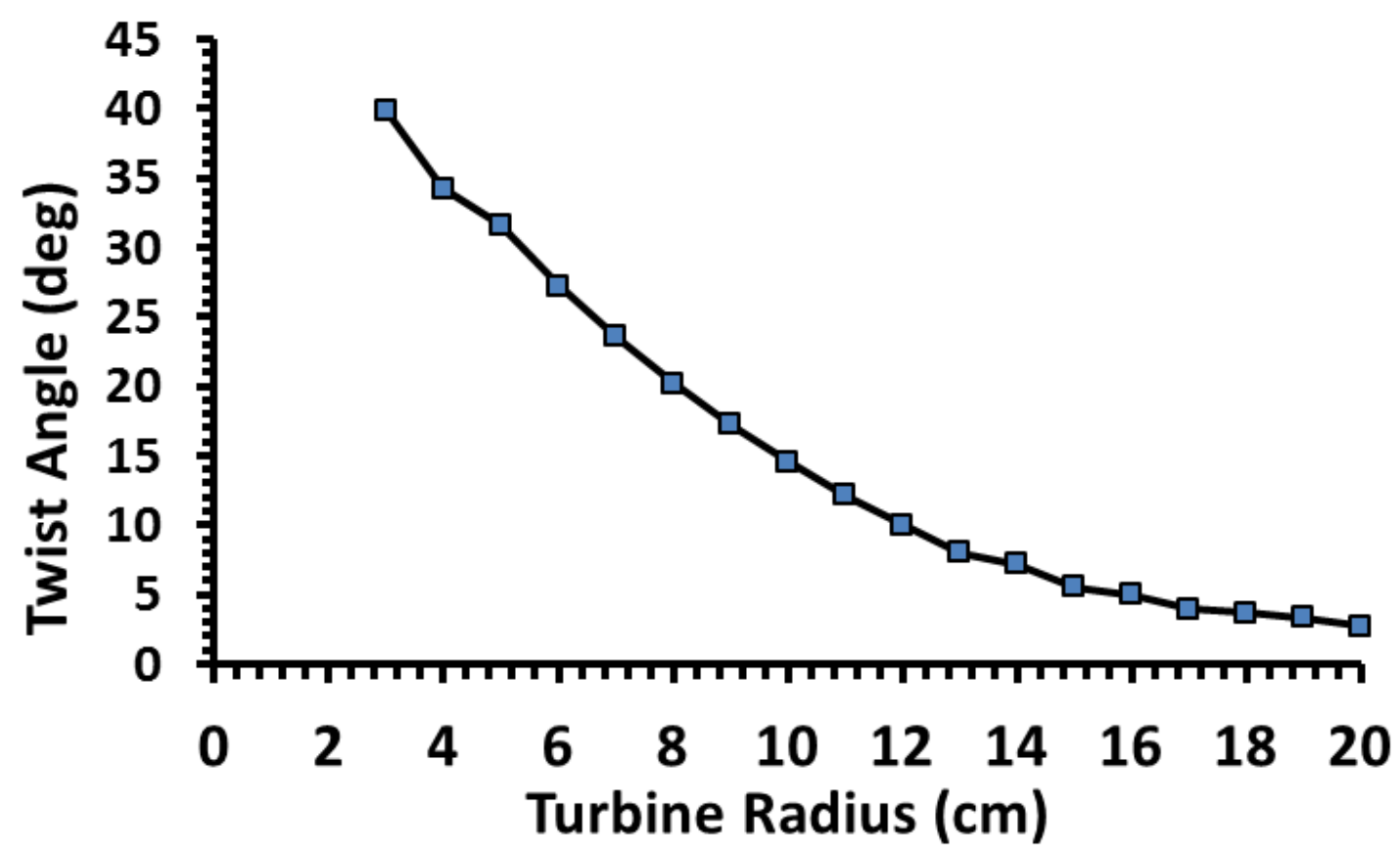

Figure 5.1. Blade twist angle.

SWEPT's nacelle box consists of 2 connecting shafts, four bearings, one gear assembly and a DC generator. The driving shaft is $1 / 8$ inch $(3.175 \mathrm{~mm})$ in diameter while driven shaft has diameter of $1 / 4$ inch $(6.35 \mathrm{~mm})$. The bearings used were high-load steel ball bearings. They were unshielded from both the sides and oil lubricated to minimize the frictional losses. The drive train had gear ratio of 80:10 which was needed to amplify the rotational speed of the generator. The details regarding the calculation of gear ratio will be discussed in the later section. Finding a suitable generator for a small scale wind turbine is challenging. The generator should not only be small in size but also needs to have low starting torque and high voltage-to-rpm ratio. A $24 \mathrm{~V}$ permanent magnet DC motor manufactured by Mabuchi Motor Co. Ltd. (model \# 14415) was used as the generator because there was no suitable generator/alternator readily available with the desired attributes. Table 5.1 summarizes all the design specification of the SWEPT. Figure 5.2 shows the final assembled SWEPT with all dimensions in $\mathrm{cm}$. The modularity and portability are some other features of SWEPT that make it unique. Most of the components including the 
mounting rod and base have been constructed from standard materials. These components can be easily disassembled when the turbine is not in use.

Table 5.1. SWEPT's design specifications

$\begin{array}{ll}\text { Tip Diameter } & 40 \mathrm{~cm} \\ \text { Hun Diameter } & 6 \mathrm{~cm} \\ \text { Airfoil } & \text { NACA } 0012 \\ \text { Number of Blades } & 3 \\ \text { Axis of Rotation } & \text { Horizontal } \\ \text { Twist Angle } & 37^{\circ} \\ \text { Local Twist Angle at Hub } & 40^{\circ} \\ \text { Local Twist Angle at Tip } & 3^{\circ} \\ \text { Tapering Angle } & 0^{\circ}(\mathrm{Constant} \text { chord length }) \\ \text { Chord Length } & 7.5 \mathrm{~cm} \\ \text { Solidity } & 30 \% \\ \text { Gear Ratio } & 80: 10 \\ \text { Generator } & 24 \mathrm{~V} \text { permanent magnet DC motor } \\ \text { Cut-in Wind Speed } & 3.0 \mathrm{~m} / \mathrm{s} \\ \text { Rated Wind Speed } & 4.0 \mathrm{~m} / \mathrm{s}\end{array}$
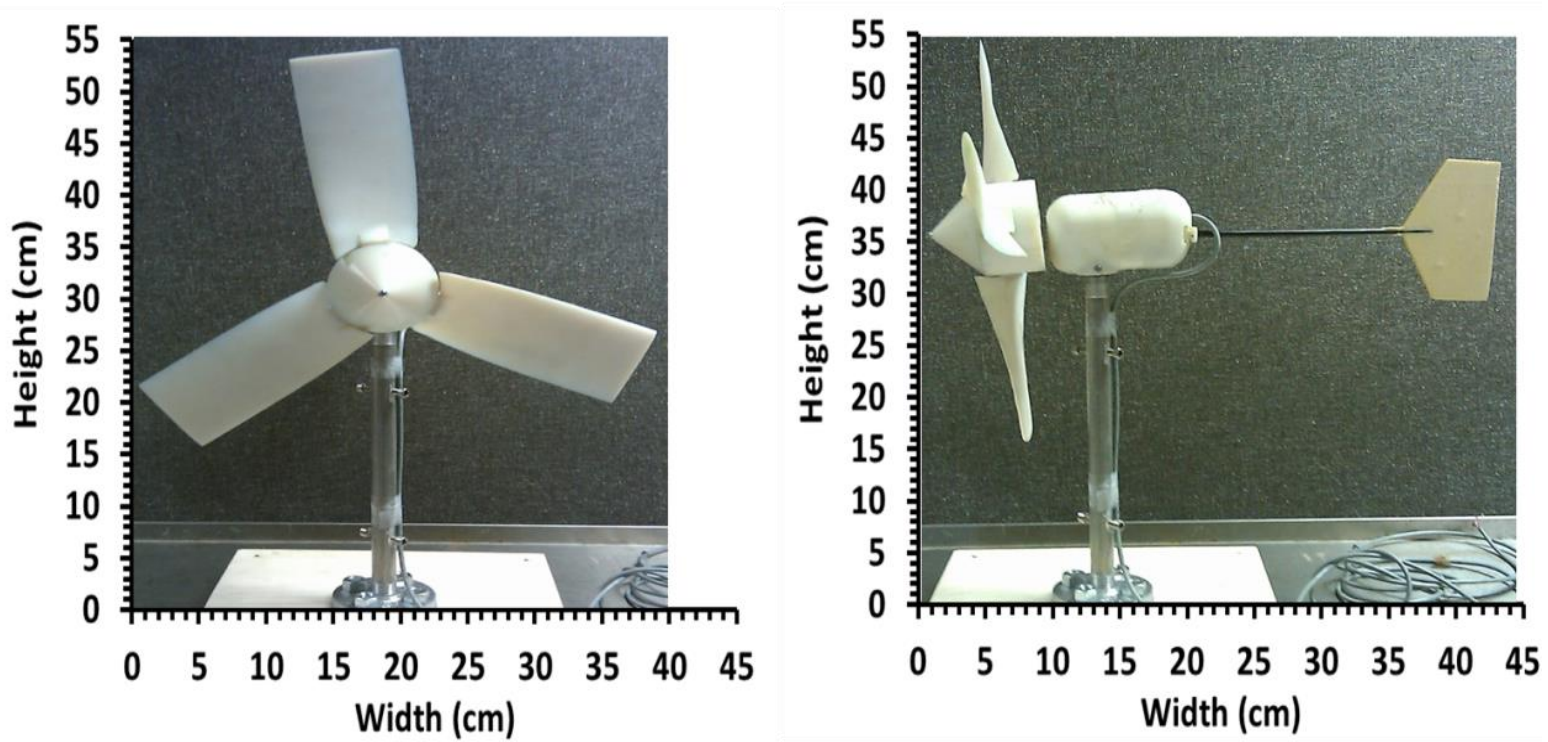

Figure 5.2. A second generation prototype of "SWEPT". 


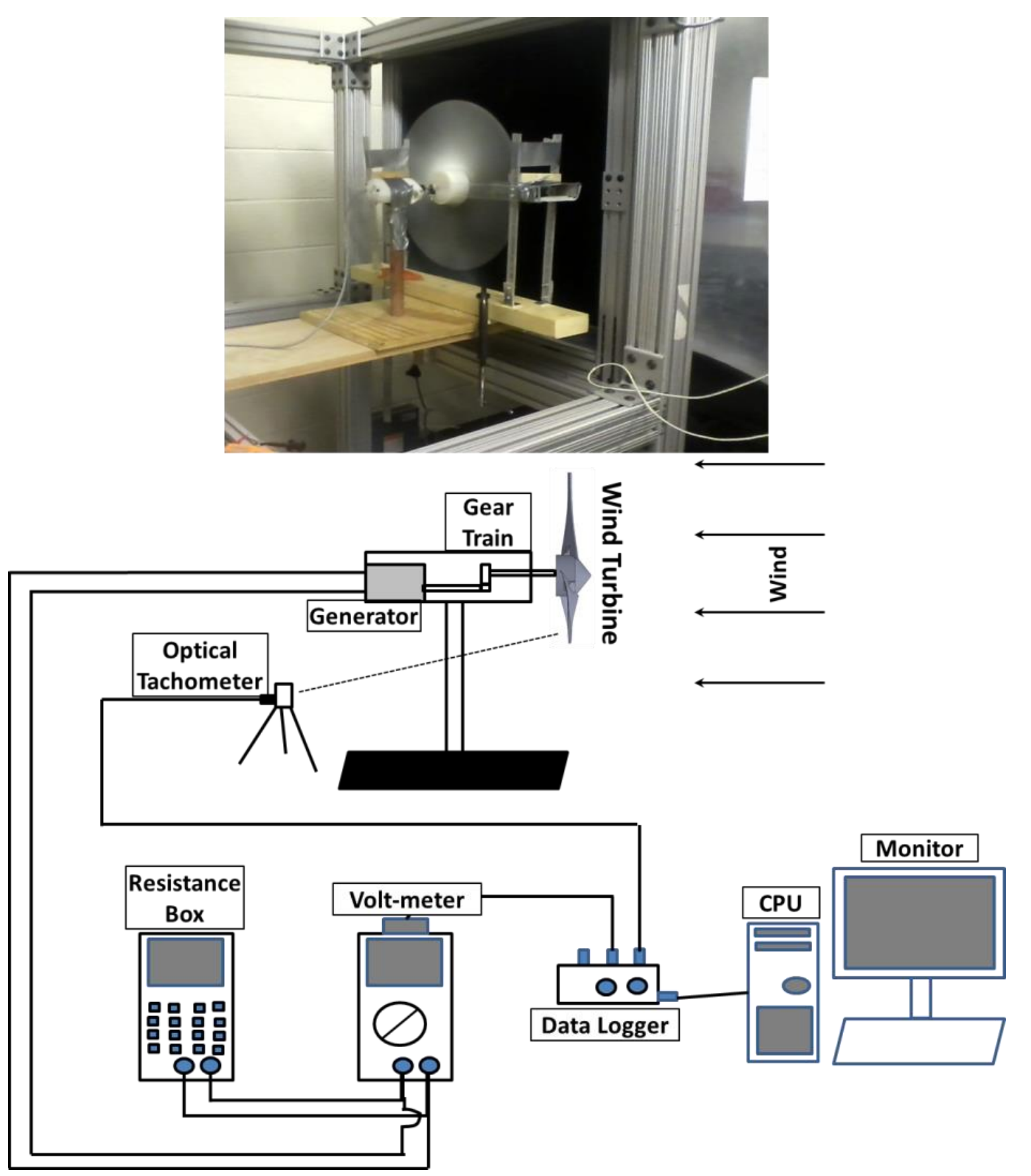

Figure 5.3. Set-up and schematic diagram of wind tunnel experiment

\subsection{Experimental set-up}

Figure 5.3 shows the schematic diagram of the experimental set-up of the wind tunnel experiments that were conducted using the Subsonic Open Jet Wind Tunnel facility available in Aerospace \& Ocean Engineering department at Virginia Tech. It is similar to the one described in chapter 2, section 2.2. The specifications of all the instruments are the same as those described in the previous chapters. As shown in Figure 5.3, the generator of the wind turbine was connected to the resistance box which was further connected to the multi-meter 
to measure the voltage. The load resistance can be varied using the resistance box at the fixed wind velocity and corresponding output voltage can be recorded. The experiments were repeated multiple times at the given loading conditions and wind speeds. Continuous data for voltage and angular velocity was recorded and then the arithmetic mean was calculated as the representative value for the respective variables.

\subsection{Results and discussion}

\subsubsection{Torque measurement}

Section 4.11 describes the method used to determine the rpm and the aerodynamic torque on the SWEPT blades. Figure 5.4 shows the torque-rpm-time curve of the wind turbine at four different wind speeds. There are two important points that can be noted from this graph. First, the starting torque (torque at time $\mathrm{t}=0$ ) increases with increase in wind speed. It is zero when wind speed is equal to $1.9 \mathrm{~m} / \mathrm{s}$. It means, the aerodynamic torque on the blade is too low to overcome the static friction in the bearings and therefore the rotor can't start on its own at this wind speed. However, torque is positive once it starts to spin. This implies that even though the turbine doesn't starts automatically at $1.9 \mathrm{~m} / \mathrm{s}$ but it will continue to operate at $u_{\infty}=1.9 \mathrm{~m} / \mathrm{s}$ if it is already running. The value of starting torque increases to $4.5 \mathrm{mN}-\mathrm{m}$ at $u_{\infty}=3.0 \mathrm{~m} / \mathrm{s}$, which is close to the starting torque of the generator including gear drive. (Similar test were conducted at $u_{\infty}=2.5 \mathrm{~m} / \mathrm{s}$ as well. The rpm and torque profiles at this wind speed are not shown in Fig. 5.4 just to keep the clarity. The starting torque was positive and it started the bare rotor connected with main shaft only. But, when the rotor was connected with nacelle containing gearbox and generator, SWEPT didn't start. The minimum wind speed where the wind turbine consisting of all the components including the gearbox and the generator, started on its own was $3.0 \mathrm{~m} / \mathrm{s}$.) This entails wind speed $u_{\infty}=3.0 \mathrm{~m} / \mathrm{s}$ as the cut-in wind speed of SWEPT because this is the minimum wind speed where it can start on its own. Second important point to note here is the trend of torque curve at a fixed wind speed. It can be observed that at any given wind speed, the torque has certain value at time $t=0$ which is called the starting torque as explained above. Torque increases to certain maximum value as the turbine starts to accelerate and then it decreases and finally becomes zero when the turbine attains its constant maximum angular speed. It means that if one wants the turbine to be used for certain application where torque is more important than the power, then its operating angular speed should have a value such that torque is highest. However, for more generic applications where power is main concern, the optimal angular speed is the point 
where the product of torque and rpm is highest. This is very important information that is required before selecting a generator for the turbine. Ideally the rated rpm of the generator should match with this optimal rpm value of the wind turbine at the design wind speed.

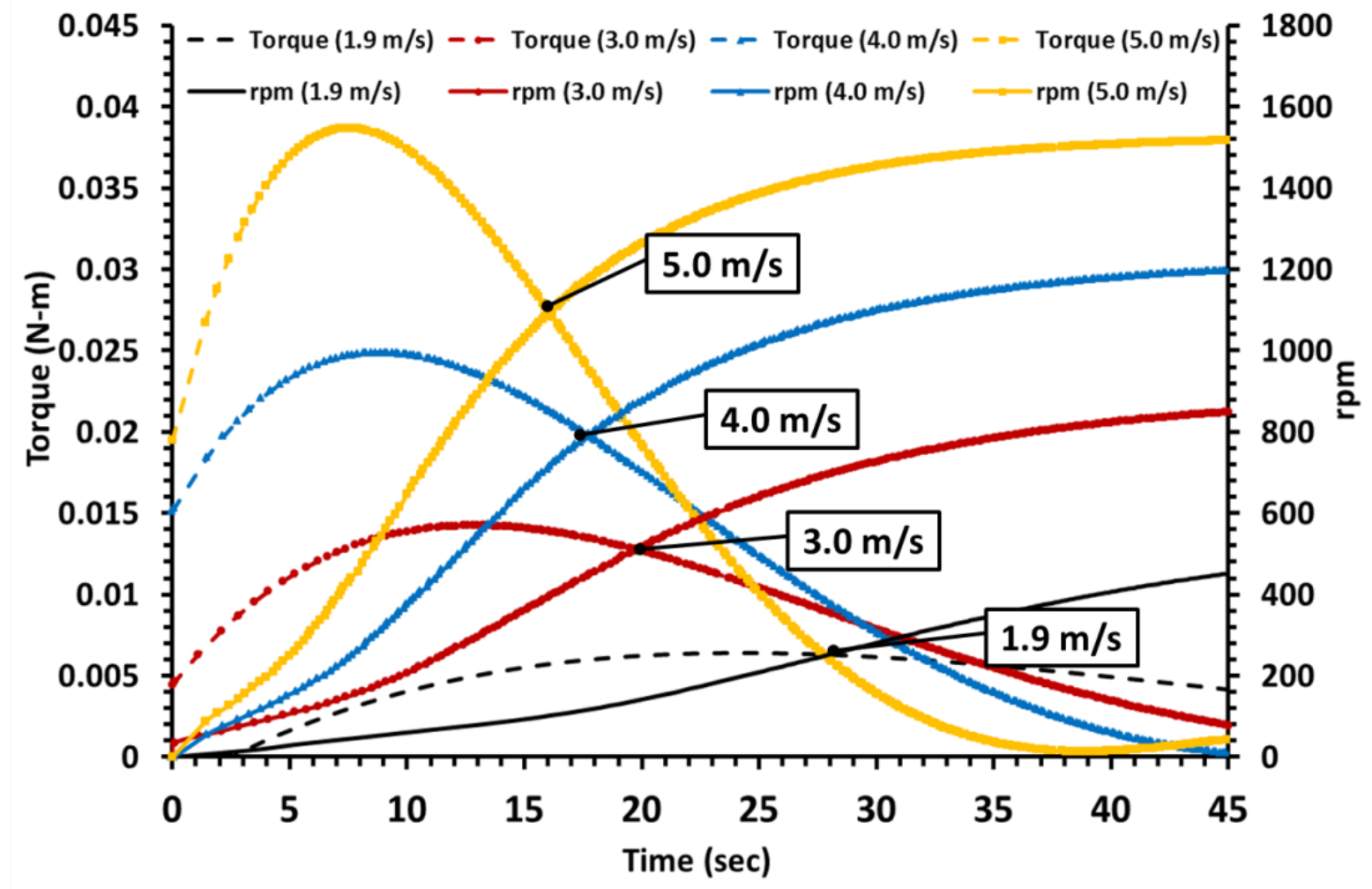

Figure 5.4. Torque-rpm-time characteristics of the wind turbine.

\subsubsection{Mechanical power and power coefficient}

Mechanical power is defined as multiple of torque and angular speed. Torque and angular speed were computed using the method described in the previous section. The mechanical power thus can be easily calculated by multiplying these two variables. Figure 5.5 shows the SWEPT's mechanical power output vs. rpm at various wind speeds. Maximum mechanical power increases with increase in wind speed as expected because it is directly proportional to the cube of wind velocity. The turbine produces $1.7 \mathrm{~W}$ at the design wind speed of $4.0 \mathrm{~m} / \mathrm{s}$. Power increases to $4.4 \mathrm{~W}$ at wind speed of $5.5 \mathrm{~m} / \mathrm{s}$. The optimal rpm at which mechanical power is maximum increases with increase in wind speed. However, it is interesting to note that its value is always about $65 \%$ of the maximum angular speed at any wind speed. 


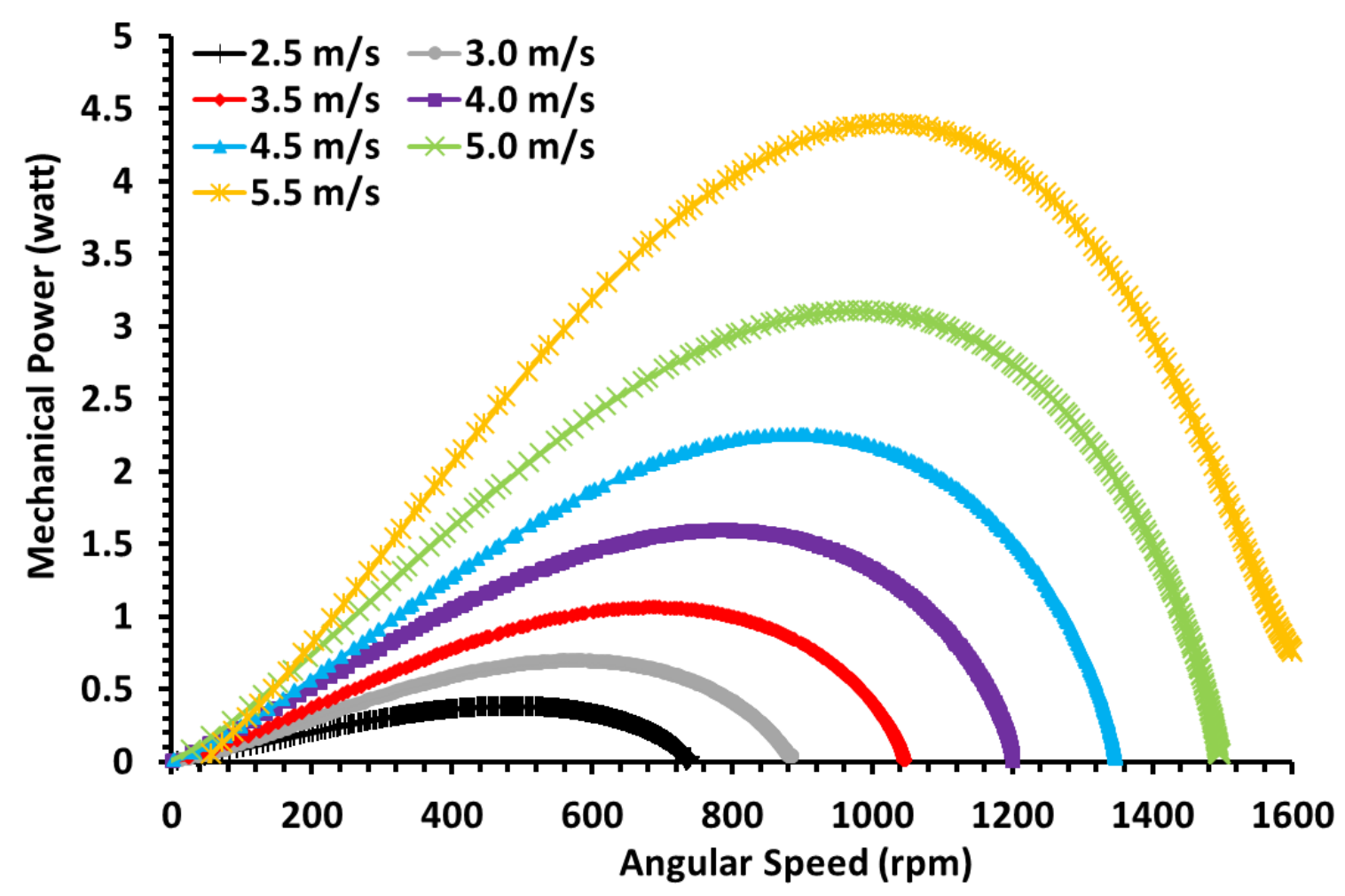

Figure 5.5. Mechanical power as a function of rpm.

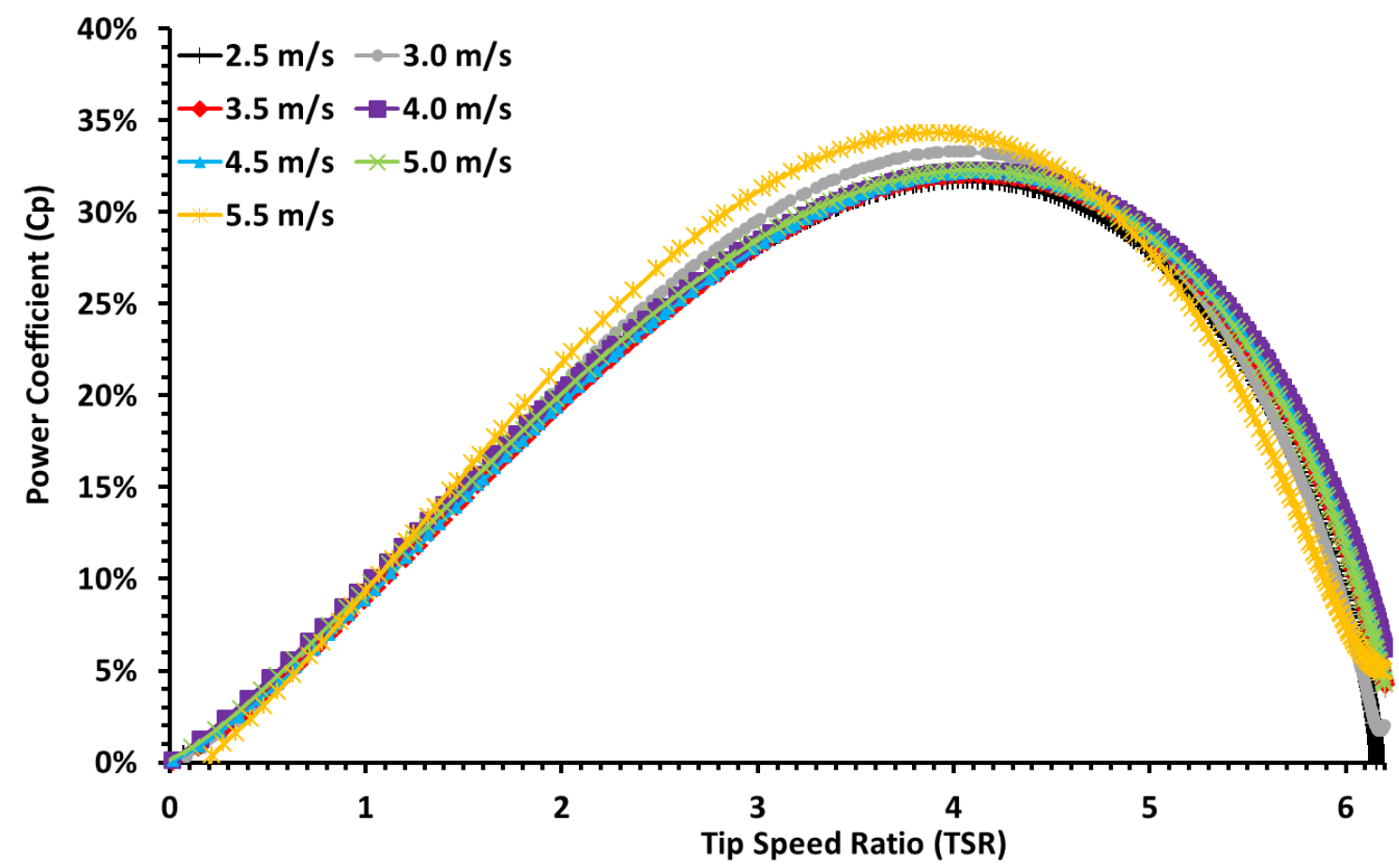

Figure 5.6. Power Coefficient as a function of tip speed ratio.

The power coefficient and torque coefficient of the turbine can be calculated using equations (1.20) and (1.21). Figure 5.6 shows the variation of power coefficient vs. tip speed 
ratio at different wind speeds. It can be observed that the power coefficient lies in the range of $31 \%$ to $34 \%$ when wind speed is varied between $2.5 \mathrm{~m} / \mathrm{s}$ and $5.5 \mathrm{~m} / \mathrm{s}$. SWEPT has power coefficient of $32.3 \%$ at the rated wind speed of $4.0 \mathrm{~m} / \mathrm{s}$. Optimal tip speed ratio is around 4.1 . Torque coefficient of the turbine vs. tip speed ratio is plotted in Figure 5.7. This figure shows that torque coefficient varies between $9 \%$ and $11 \%$ in the given range of operating wind speed. It is important to note here that the optimal tip speed ratio for the torque coefficient is around 2.2, which is much lower than that for power coefficient.

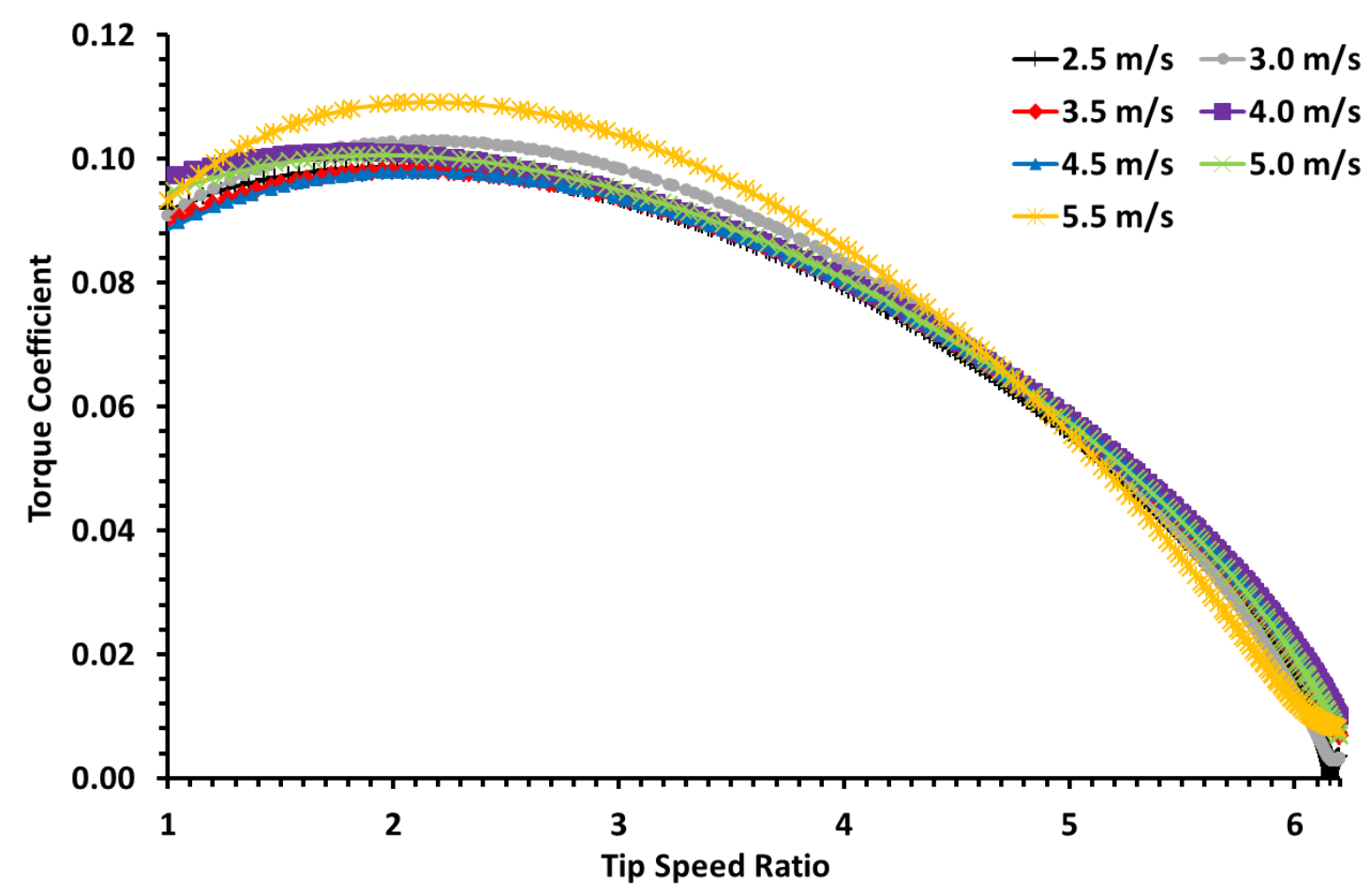

Figure 5.7. Torque coefficient as a function of tip speed ratio.

\subsection{Generator characteristics}

Besides the turbine blades, generator is the second most important component of a wind turbine. In order to achieve excellent overall performance, it is important that the torque-rpm characteristics of the generator must be synchronized with that of the wind turbine. Since a DC motor was used as generator, the characteristics of the generator were not available beforehand. Initially, generator was directly connected to the wind turbine and it was found that the shaft rpm was too low to provide sufficient voltage output. Different trials were conducted at various gear ratios and it was observed that when gear ratio was 80:10, the optimal rpm of the wind turbine and that of the generator were close to each other. Figure 5.8 shows the power-rpm curve of the generator at various loading conditions and wind speeds 
with gear ratio of 80:10. It can be observed that at the given wind speed, the power output is maximum at an optimal load which is $60 \Omega$ at lowest wind speed and $40 \Omega$ when wind speed was higher. The shaft rpm of generator at the optimal loading condition can also be obtained from this figure. It is now worth comparing optimal rpm of the wind turbine rotor obtained from Figure 5.5 and Figure 5.8. It can be seen that the two optimal rpm values of the wind turbine, one without generator and other with generator (at optimal load) at the various wind speeds are quite close. This shows that both the components, i.e., generator and turbine rotor, were properly synchronized and they were running at their optimal conditions. Figure 5.9 shows the torque-rpm characteristics of the generator. Torque on the y-axis is the mechanical torque applied by the wind turbine due to aerodynamic lift. Torque is directly proportional to rpm, so as expected, it increases almost linearly for a given loading condition. Increase in torque with increase in wind speed is expected because the aerodynamic lift acting on turbine blades increases with increase in wind speed. At a given wind speed, however, torque decreases with increase in load resistance.

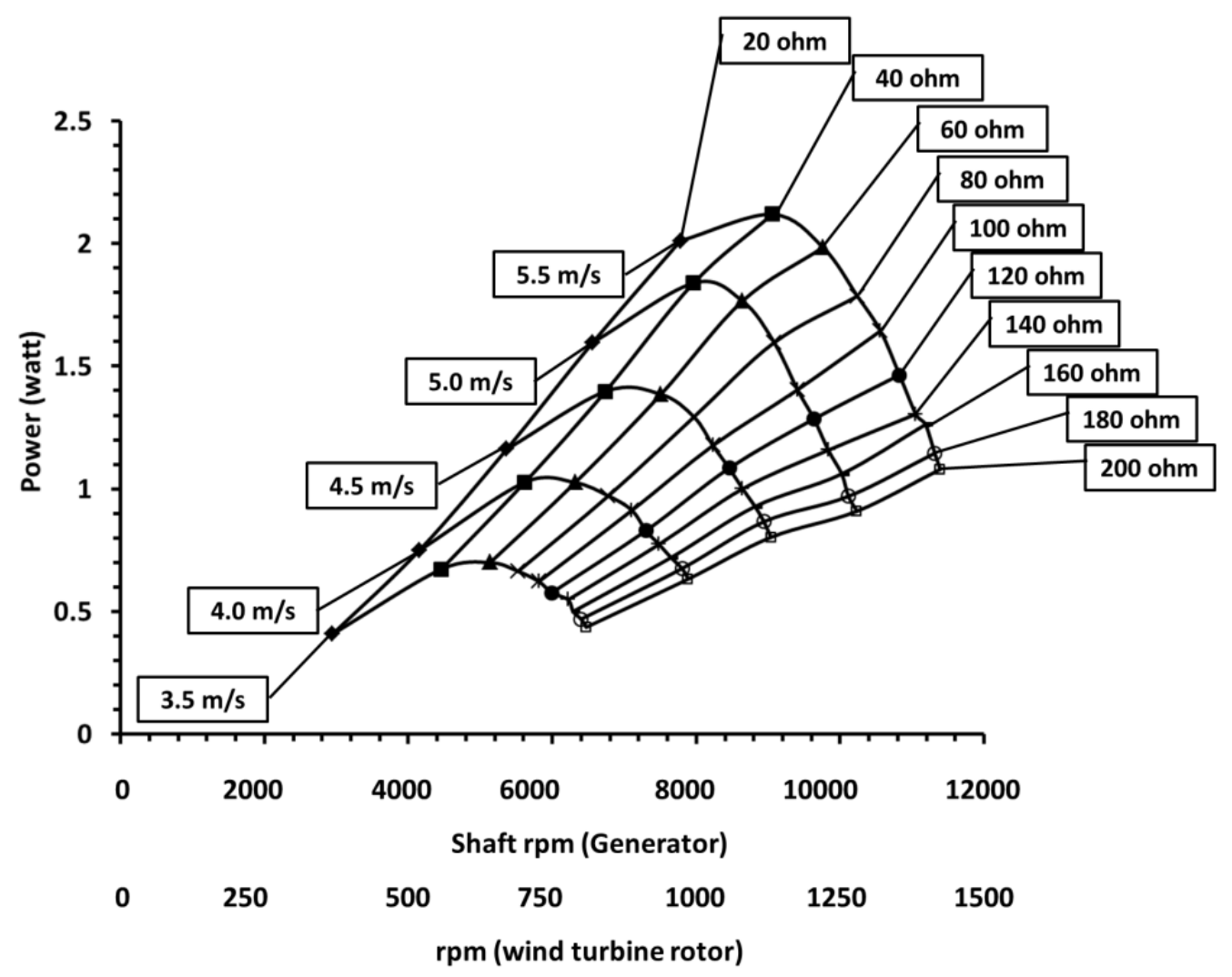

Figure 5.8. Power output vs. Shaft rpm of generator. 


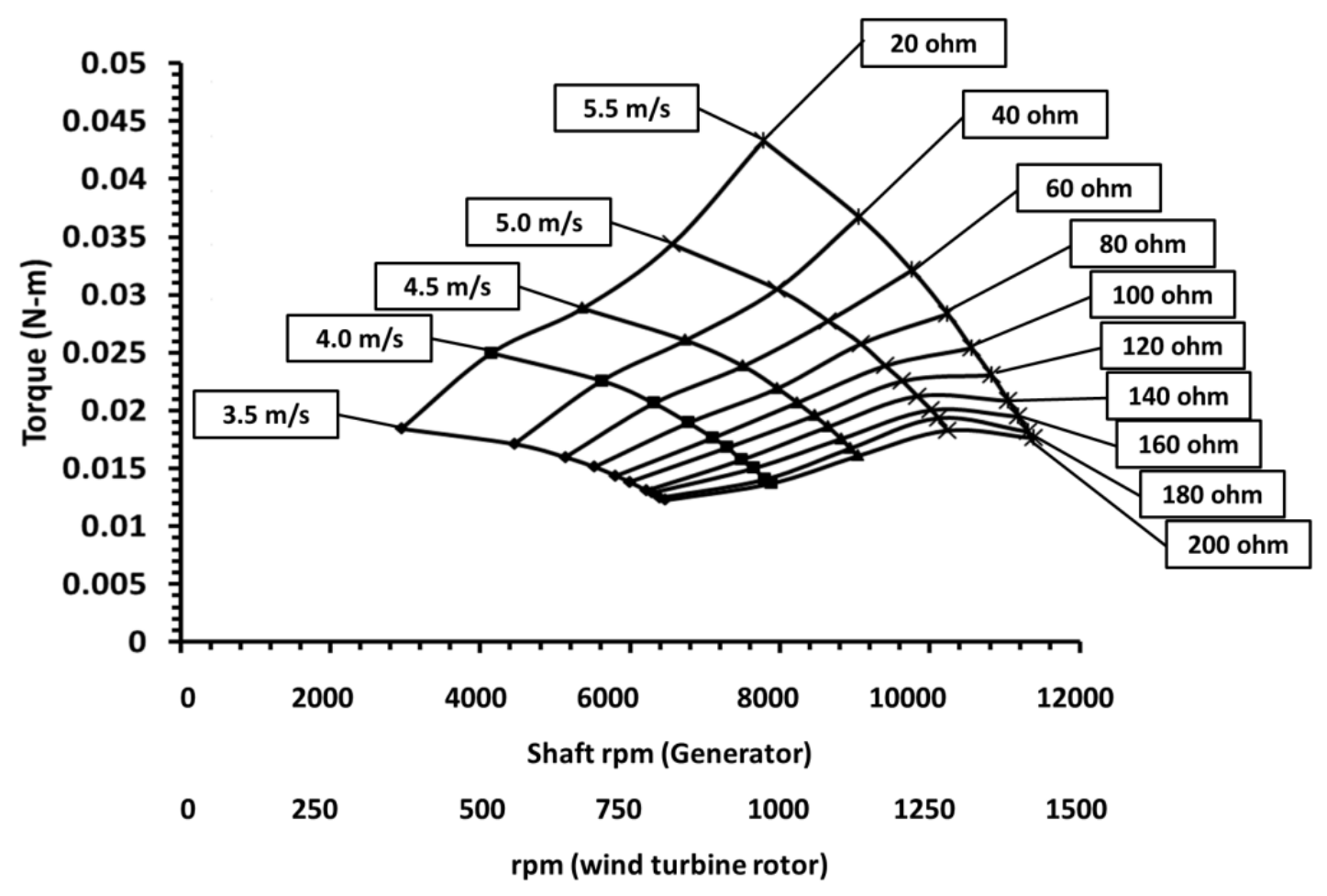

Figure 5.9. Torque vs. Shaft rpm of generator.

Figure 5.10 depicts the relationship between the shaft rpm vs. the external load of the generator at various wind speeds. It can be noted that rpm increases with increase in wind speed at a given load resistance. At fixed wind speed, rpm increases with increase in load resistance, however it starts to saturate when load is too large. This can be explained if we understand the working of a generator with and without the load. When load is applied to a running generator at no load, it delivers current that creates magnetic field around the armature which reacts with the magnetic field of the stator. The strength of the reacting magnetic force depends on the armature current which is ultimately determined by the magnitude of the load resistance. Higher load resistance means lower armature current and lower motor reaction and therefore increase in shaft rpm. 


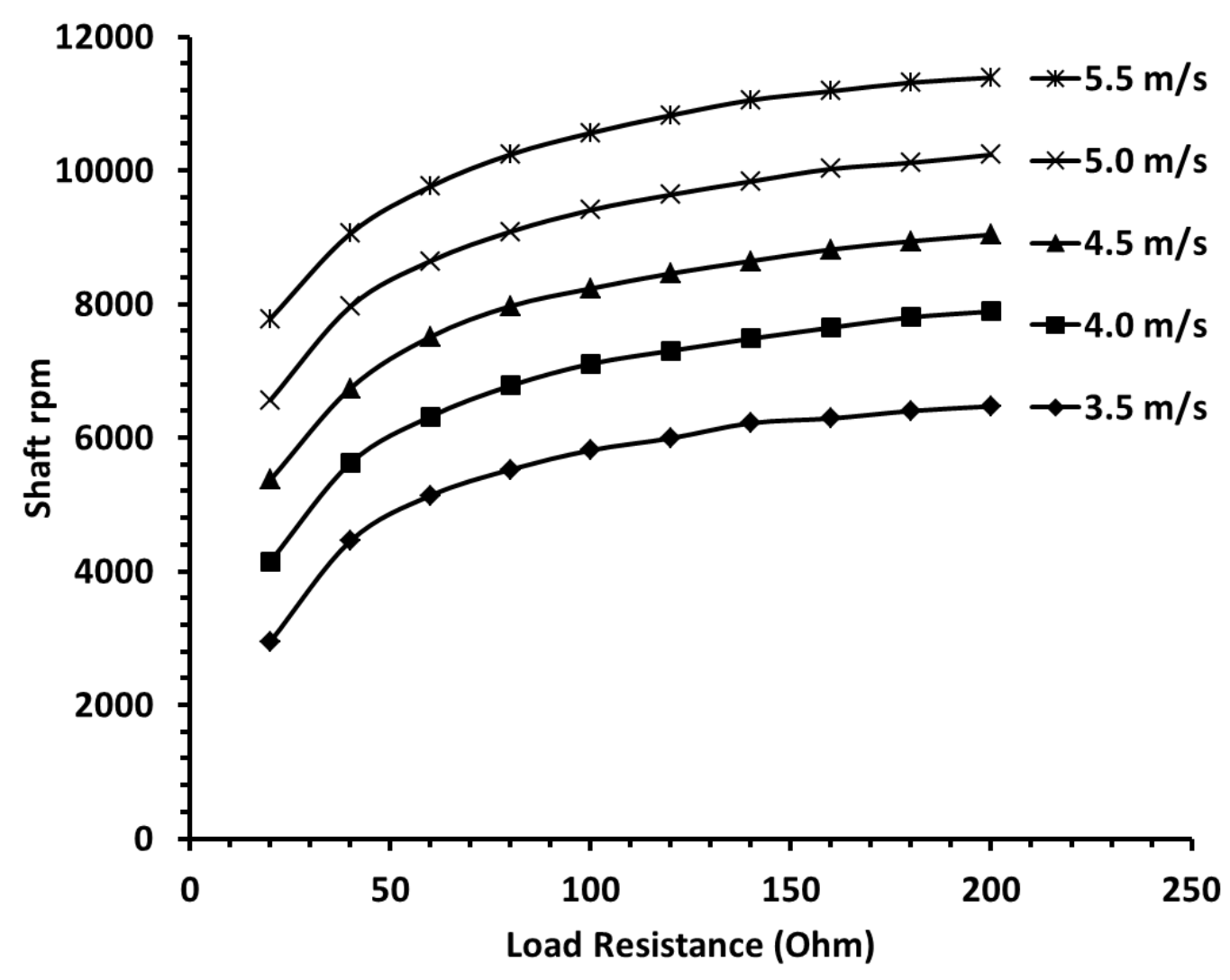

Figure 5.10. Shaft rpm vs. Load resistance of generator.

\subsection{Power output and overall efficiency}

Figure 5.11 shows the electrical power output of the wind turbine at various loading conditions and wind speeds. SWEPT produces $1 \mathrm{~W}$ power at its rated wind speed of $4.0 \mathrm{~m} / \mathrm{s}$ when the optimal external load is around $40 \Omega$. The power output increases with increase in wind speed and it reaches up to $2.2 \mathrm{~W}$ when wind speed is $5.5 \mathrm{~m} / \mathrm{s}$. The optimal load remains constant at $40 \Omega$. Figure 5.12 shows the overall or net efficiency of the wind turbine. It can be seen that the maximum net efficiency is $21 \%$ at the rated wind speed of $4.0 \mathrm{~m} / \mathrm{s}$. Its value decreases with further increase in wind speed. Lastly, Figure 5.13 shows the efficiency of the generator at various loading conditions and wind speeds. It can be seen that generator efficiency is highest at the lowest wind speed and it decreases with increase in wind speed. 


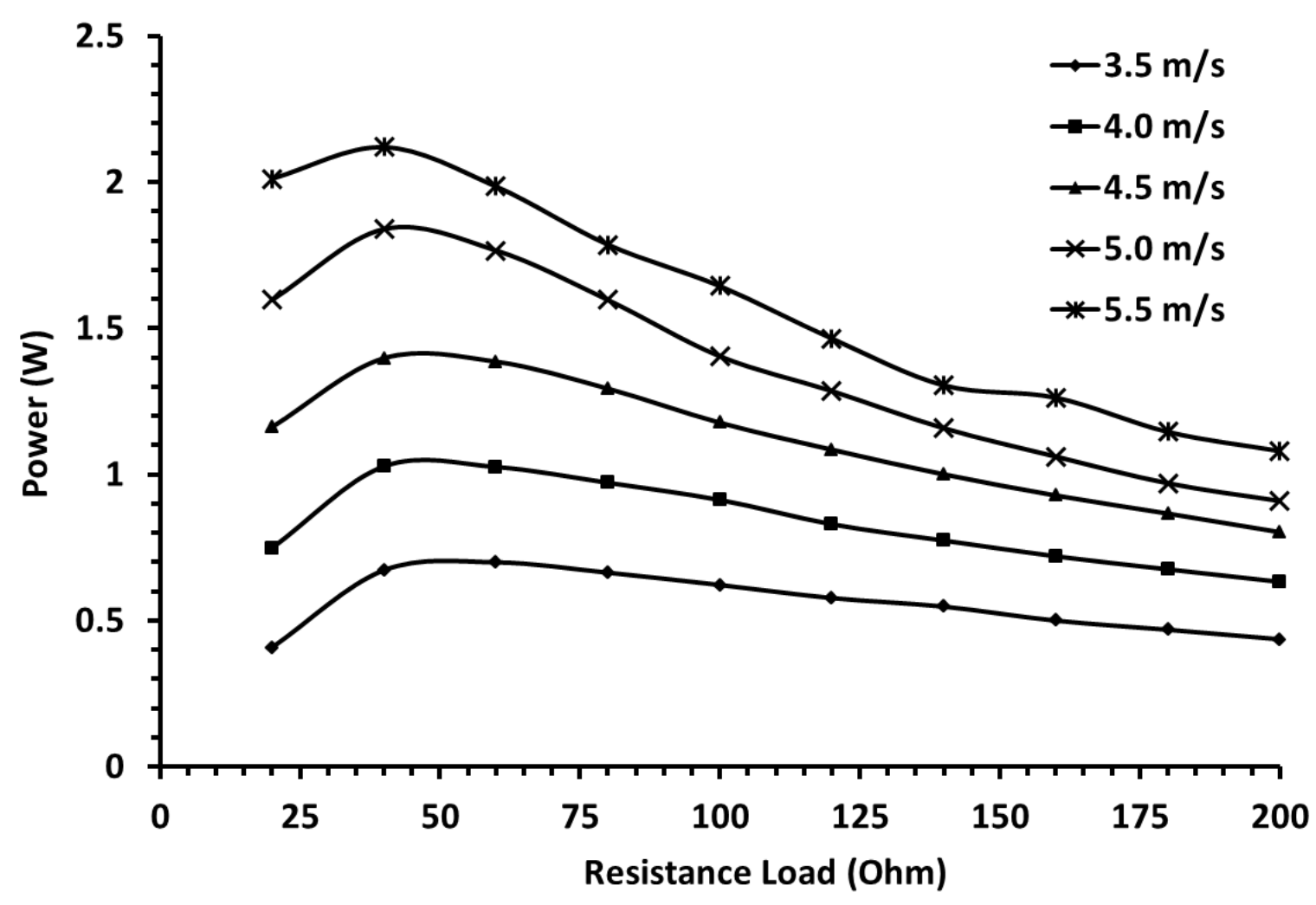

Figure 5.11. Electrical power of the wind turbine vs. Load resistance.

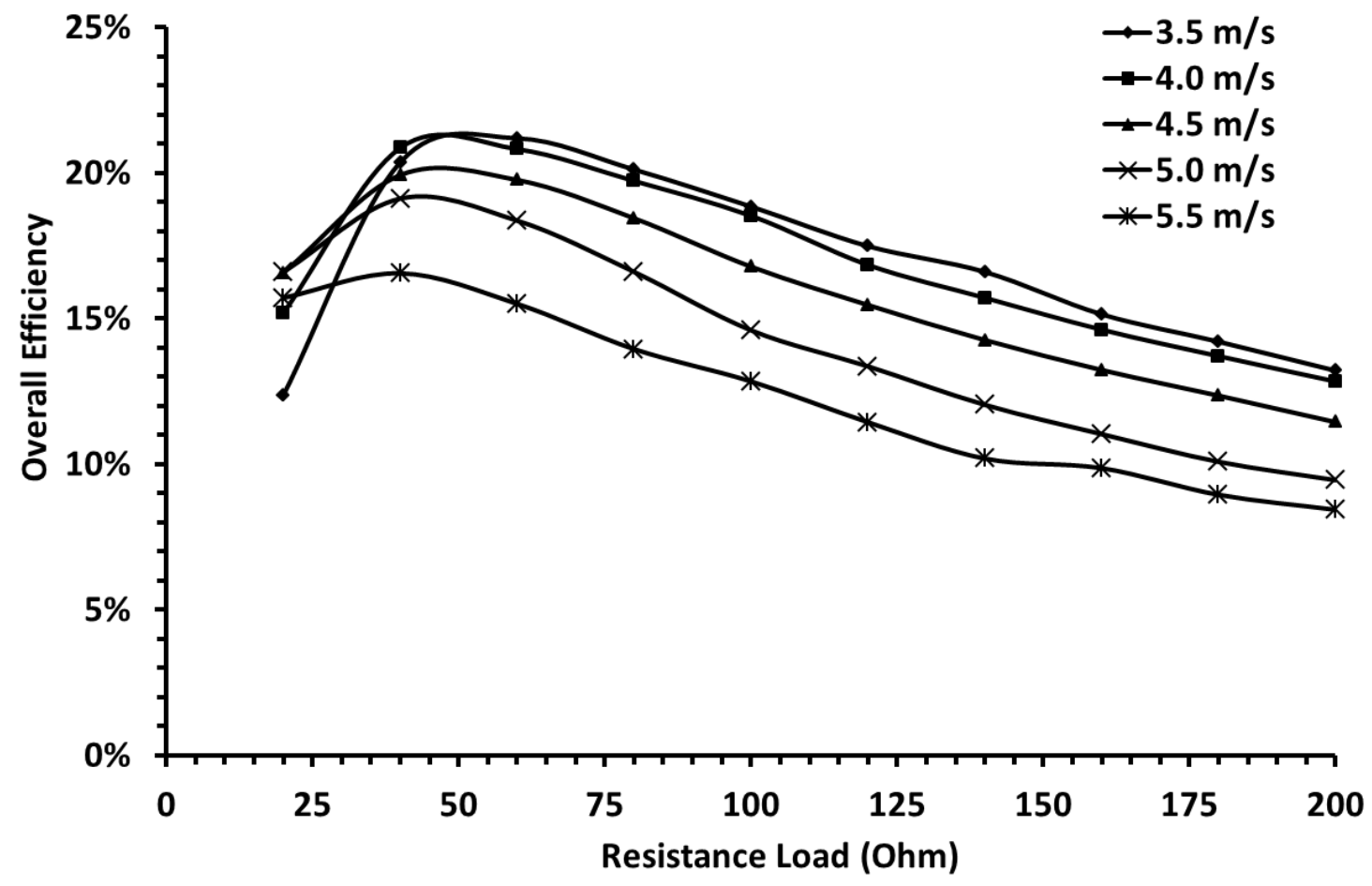

Figure 5.12. Overall efficiency of the wind turbine vs. Load resistance. 


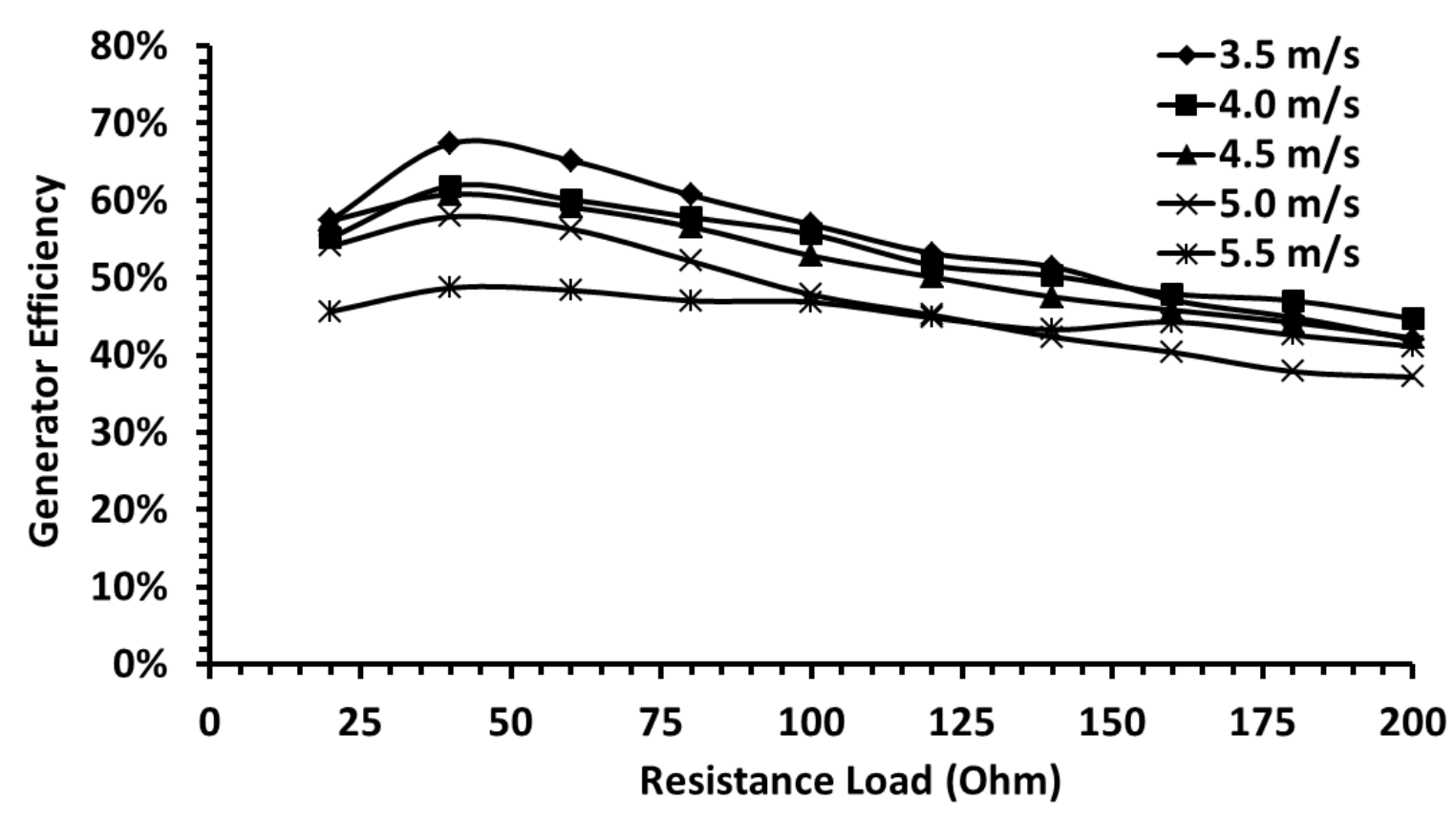

Figure 5.13. Generator's efficiency vs. Load resistance.

\subsection{Summary and conclusions}

A high efficiency small scale wind energy portable turbine (SWEPT) was developed for applications near the ground level where wind speed is below $5 \mathrm{~m} / \mathrm{s}$. SWEPT is not only an highly efficient wind turbine but also compact and portable. It can be used effectively for powering the low power electronic components especially in the remote locations. It can also be used as a convenient carry-on modular windmill that can recharge the batteries of commonly used electronics, such as cellular phones, Global Positioning Systems and pocket radios. The major outcomes of the study obtained by conducting the wind tunnel experiments on the fabricated wind turbine at various loading conditions and wind speeds are summarized below:

(i) SWEPT is a very efficient wind turbine with power coefficient ranging from $31 \%$ to 34 $\%$ in its operating wind speed range of $3.0 \mathrm{~m} / \mathrm{s}$ to $5.5 \mathrm{~m} / \mathrm{s}$. It has power coefficient of about $32 \%$ at its design point wind speed which is equal to $4.0 \mathrm{~m} / \mathrm{s}$.

(ii) The optimal overall efficiency of the wind turbine is $21 \%$ at its rated wind speed of 4.0 $\mathrm{m} / \mathrm{s}$.

(iii) SWEPT has rated power output of $1 \mathrm{~W}$ but it is capable of producing power output up to $2.2 \mathrm{~W}$ at the higher wind speed of $5.5 \mathrm{~m} / \mathrm{s}$. 


\section{CHAPTER 6}

\section{Direct-drive small-scale wind energy portable turbine for ultra-low wind speed applications}

In the previous chapter, it was found that the second generation SWEPT prototype had very good overall efficiency of $21 \%$ at the rated wind speed of $4.0 \mathrm{~m} / \mathrm{s}$. However, it is not a direct drive wind turbine; rather it utilizes a gear train of gear ratio 80:10 to amplify the angular speed so that the generator can be run at its rated rpm. The use of gear train has several limitations: (i) it increases the mechanical losses and thus reduces the overall efficiency of the device, (ii) the static friction between the gears increases the start-up wind speed of the wind turbine, (iii) running gears produce excess noise which is annoying, especially at high wind speed, (iv) at high wind speed, when gears run at very high rpm, they skid and thus limit the cut-out wind speed of the wind turbine, and (v) the wear and tear in the gears reduces the overall reliability and life span of the device. In order to address these problems, it was decided to make a $3^{\text {rd }}$ generation SWEPT which will be direct drive. But, the main problem in accomplishing this task was the unavailability of a small size generator with required attributes (high efficiency, low rated angular speed of around $1000 \mathrm{rpm}$, low starting torque of the order of few $\mathrm{mN}-\mathrm{m}$, and high voltage to rpm ratio). Therefore, it was decided to develop home-built generator which can fulfill the needs without compromising the overall performance of the wind turbine. This chapter addresses the design, fabrication, and testing of a gear-less high efficiency small-scale wind energy portable turbine (SWEPT). Wind tunnel experiments were conducted to characterize the direct-drive wind turbine. Finally, its performance and power output was compared with previous generation prototypes.

\subsection{Blade design}

The blades of second generation prototype were very efficient with the power coefficient of about $32 \%$. Therefore, the same blades were employed for the $3^{\text {rd }}$ generation prototype. The basic design specification of these blades can be found in chapter 4 .

\subsection{Generator design}

There are several kinds of generators that are used for wind turbines: direct or alternating current types, synchronous or asynchronous, with or without permanent magnets, and self or 
external electrical field excited machines. It has been suggested that the generators equipped with permanent magnets (PMs) are more suitable for small size wind turbines because of their higher efficiency compared with other generators [56]. The permanent magnet electric generators are broadly divided into two categories: radial flux and axial flux machines, depending on the direction of magnetic flux in the air gap between stator and rotor. The radial flux generators can be further subdivided into inner rotor radial flux machines or outer rotor radial flux machines, according to the position of rotor with respect to stator. Similarly, axial flux generators can be subcategorized into double stator-single rotor machines or double rotor-single stator machines, basis the number of rotors and stators. Normally for small scale wind turbines, an axial flux generator is preferred because it occupies lesser space in the radial direction than a radial flux generator of the same power rating [56-58]. A recent study by Marin [59] revealed that double rotor-single stator slotless axial flux generator design provides very promising results for micro-scale wind turbines developed for low wind speed applications. The slotless axial flux generator design, in general, has several other advantages over other kinds of generators which makes it most suitable for the small scale wind turbines: (i) The topology of an axial flux machine leads to a short radial length which makes it very compact generator suited for small wind turbines; (ii) due to the slotless air-gap winding, the values of mutual and leakage inductances are low; (iii) the absence of the slots provides noiseless operation with negligible cogging torque. In this study, therefore, the focus was on design and fabrication of a double rotor-single stator slotless axial flux generator suitable for SWEPT.

As shown in Figure 6.1, a double rotor-single stator axial flux generator consists of a stator containing a set of coils, and two rotors on either sides of the stator. Each of the rotors contains a set of permanent magnets. Holding the coils stationary has both functional and operational advantages. It not only reduces the number of moving parts and thus renders a commutator unnecessary, but also decreases the heating losses in the commutator and thus improves the efficiency. The proposed generator design has a slotless stator and the coils were wound around individual coil holders, unlike a typical DC generator where core of the machine consists of metallic slots and teeth around which the coils were wound. This design eliminates cogging torque and thus improves the start-up speed of the wind turbine. Cogging torque is the friction caused by the attraction between permanent magnets and iron core present in a typical DC motor/generator, which increases the startup torque and decreases the electrical efficiency at low wind speed. 
Once the configuration of generator was selected, the next step was to determine and optimize various design parameters which were needed to achieve highest possible efficiency under the given size constraints. Some of the main parameters which affect the performance of an axial flux generator are number of poles, air gap between stator and rotor, shape and size of magnets, and shape of the coils. The number of pole pairs is given by following equation [58]:

$$
p=\frac{120 f_{\text {nom }}}{n_{\text {nom }}}
$$

where $p$ denotes number of pairs of magnetic poles, $f_{\text {nom }}$ is the nominal armature $E M F$ frequency and $n_{\text {nom }}$ represents the nominal angular speed of the rotor in rev/min (rpm). The rpm of rotor essentially depends on the wind speed; normally, it increases as wind speed is increased. We selected the optimal angular speed of the wind turbine at its rated wind speed of $4.0 \mathrm{~m} / \mathrm{s}$, which is around $900 \mathrm{rpm}$, as the nominal rpm to calculate the number of pole pairs. Taking the nominal $E M F$ frequency as $60 \mathrm{~Hz}$, the number of pairs of poles was found to be 8 .

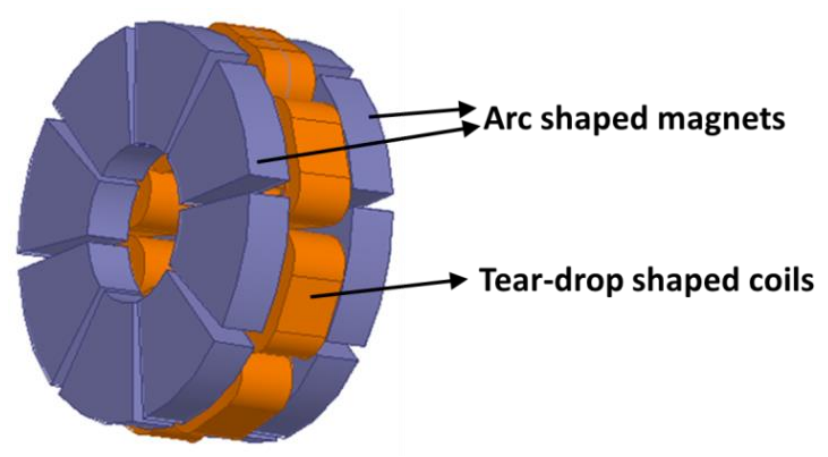

Figure 6.1. A CAD model of the "double rotor-single stator slotless axial flux generator" without fixtures.

The procedure to obtain the optimized values of other three parameters: air gap between stator and rotor, shape and size of magnets, and shape of the coils, are not so straight forward. It requires numerical techniques to solve the equations of rotational dynamics as well as electromagnetic induction mathematics, simultaneously. The details of the optimization process are not covered in this thesis as it has been reported elsewhere, but the summary of results is given here for completeness. Numerical studies revealed that the arc shaped magnets produce more than $60 \%$ higher power than rectangular magnets of the same thickness and size. Considering the size of the generator (about the same diameter as the hub of the wind turbine), arc shaped magnets of dimension $26.4 \mathrm{~mm}$ (or) $\mathrm{x} 10.5 \mathrm{~mm}$ (ir) $\mathrm{x} 6.35 \mathrm{~mm}$ 
(t) $x 40^{\circ}$ were selected, where, 'or' and 'ir' denote outer radius and inner radius, ' $t$ ' denotes thickness, and $40^{\circ}$ is the angle made by inner and outer arc at the center. Figure 6.2 shows the contour for magnetic field strength at the mid-plane between two rotors. Dark red and dark blue indicate the highest field strength in two polarities. It can be noted that the magnetic field is in tear-drop shape, therefore, to match the profile of magnetic field, coils were also designed to have a tear drop shape rather than most common circular shape. Lastly, the numerical simulations predicted that the maximum power output by the generator occurs when the air-gap (distance between the rotors) is 7 to $8 \mathrm{~mm}$. Later on, this distance was increased to $10 \mathrm{~mm}$ during fabrication to provide manufacturing easiness.

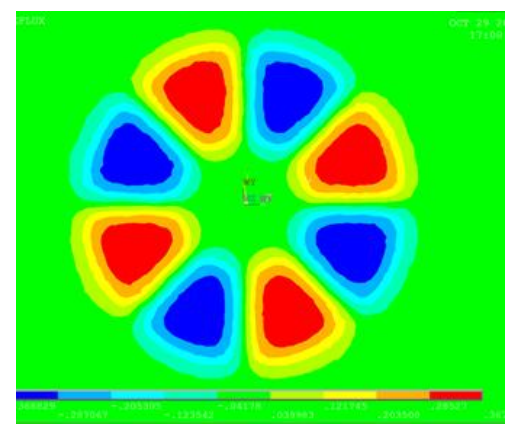

Figure 6.2. Contours showing the magnetic field strength at the mid-plane between two rotors.

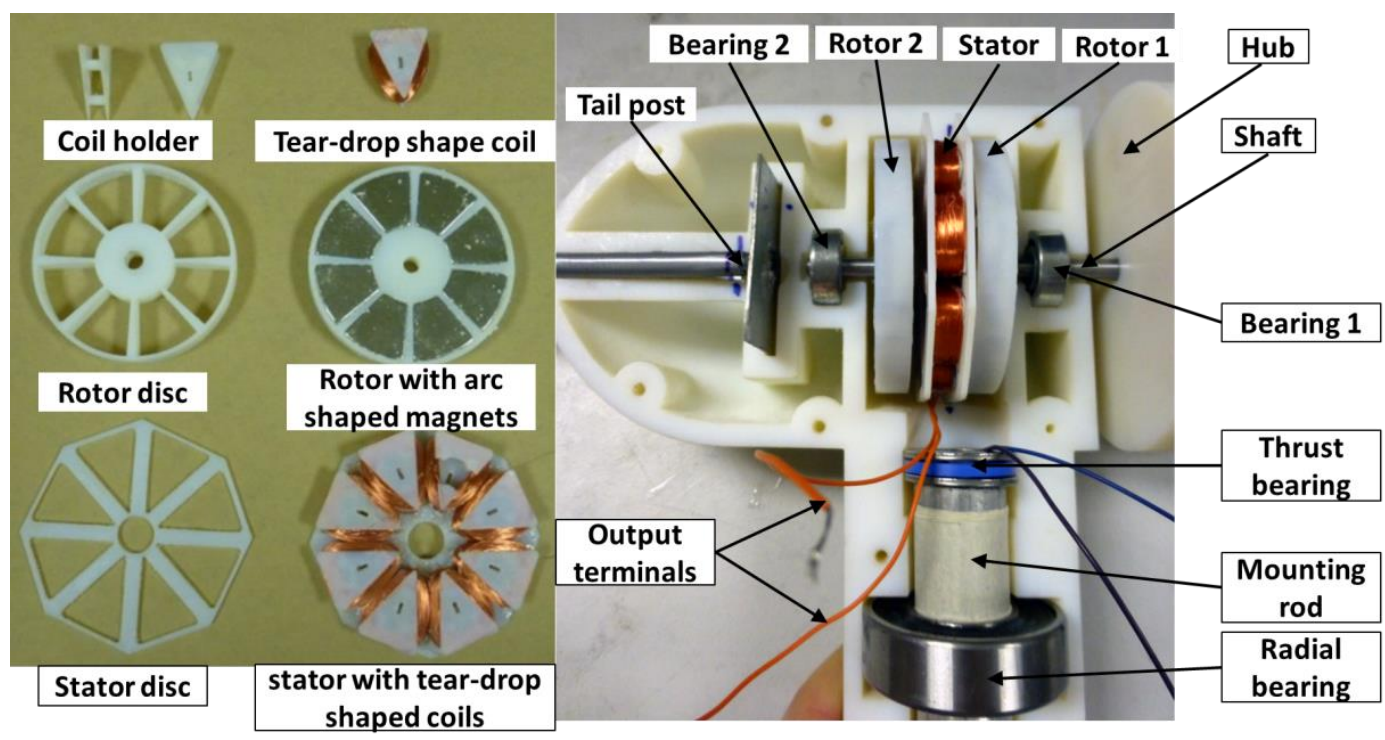

(a)

(b)

Figure 6.3. Axial flux generator design for SWEPT: (a) fabricated stator and rotor parts showing the shapes of the magnets and coils; (b) axial flux generator inside the nacelle box. 
Table 6.1 summarizes the major design specifications of the axial flux generator developed for SWEPT. Figure 6.3(a) depicts the fabricated stator and rotor parts. Figure 6.3(b) demonstrates a fabricated prototype of the axial flux generator set along with other main components assembled inside the nacelle box.

Table 6.1. Major design specifications of the axial flux generator developed for SWEPT

$\begin{array}{ll}\text { Number of pole pairs } & 8 \\ \text { Number of the magnets } & 16 \\ \text { Shape of magnets } & \text { Arc-shaped } \\ \text { Dimension of magnets } & 26.4 \mathrm{~mm}(\text { or }) \times 10.5 \mathrm{~mm}(\text { ir }) \times 6.35 \mathrm{~mm}(\mathrm{t}) \times 40^{\circ} \\ \text { Shape of coils } & \text { Tear drop } \\ \text { Number of coils } & 8 \\ \text { Number of turns per coil } & 150 \\ \text { Coil wire material } & \text { AWG } 30 \text { copper } \\ \text { Stator thickness } & 5 \mathrm{~mm} \\ \text { Air gap between rotors } & 10 \mathrm{~mm} \\ \text { Outer radius } & 3 \mathrm{~cm} \\ \text { Inner radius } & 5 \mathrm{~mm}\end{array}$

\subsection{Prototype design}

Figure 6.4 shows the current generation prototype of SWEPT. As stated earlier, this prototype contains the same blades which were developed in chapter 4. In nutshell, SWEPT is 3-bladed horizontal axis wind turbine. It employs NACA 0012 airfoil template for the blade design. Each of the blades has constant chord length of $7.5 \mathrm{~cm}$ throughout the span. The hub and tip diameters of the wind turbine rotor are $3 \mathrm{~cm}$ and $40 \mathrm{~cm}$, respectively. The blades are nonlinearly twisted by $37^{\circ}$ from hub to tip, and the solidity of the rotor is about $30 \%$. As shown in Fig. 6.3, SWEPT's nacelle box consists of an axial shaft, two bearings, a generator set, and a tail post. The nacelle is mounted over a tower using a thrust bearing and a radial bearing. The central shaft is $3 / 16$ inch $(4.76 \mathrm{~mm})$ in diameter. The bearings used are high-load steel ball bearings, which are oil lubricated and unshielded from both the sides to minimize the frictional losses. The hub was connected with the central shaft using press-fit while the blades are attached with the hub using dove-tail joints. The nacelle box also contains a tail with a fin at the end, which produces corrective moment to orient the wind turbine rotor into the 
direction of wind. The blades, hub, and nacelle box were constructed using a 3-D printer (Objet Inc., USA). The printer material used was VeroWhite plastic.

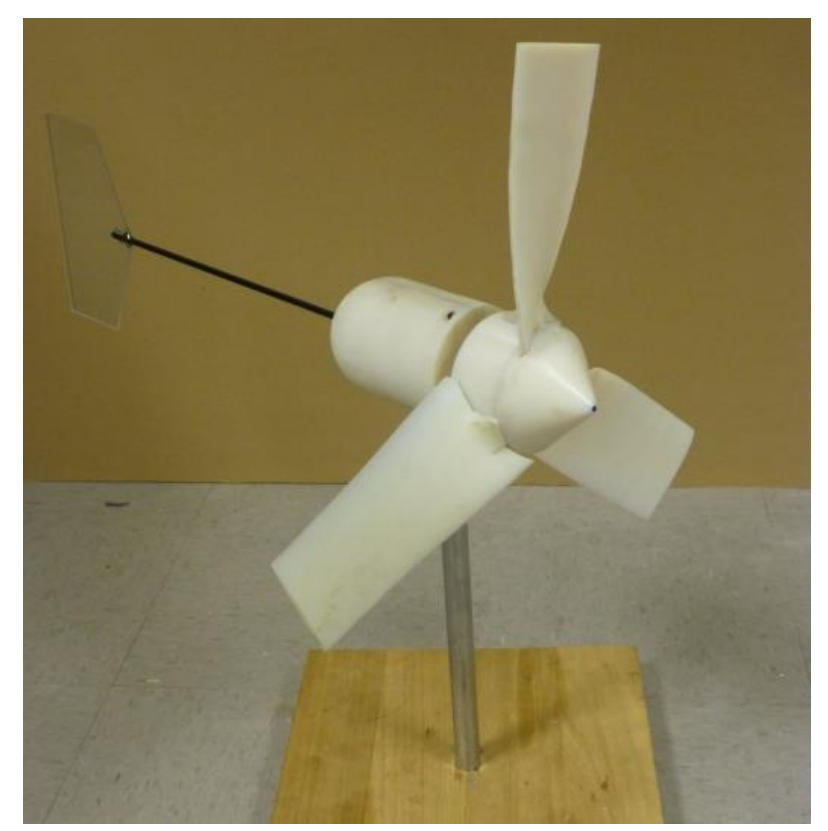

Figure 6.4. An experimental prototype of SWEPT.

\subsection{Experimental set-up}

Figure 6.5 depicts the schematic of experimental set-up used in this study to characterize the wind turbine. All the experiments were conducted in Subsonic Open Jet Wind Tunnel facility available in Aerospace \& Ocean Engineering department at Virginia Tech. The details about the wind tunnel and the quality of flow are given in chapter 2. We used non-contact type optical digital Tachometer "DT-209X" (SHIMPO Instruments, USA) to measure angular speed of the wind turbine. Anemometer used in the experiments was PASPORT, Model PS2174 (PASCO, USA). “OhmSOURCE Model OS-260” by IET Labs, Inc. was used as the resistance box to vary the loading conditions of the wind turbine. The multi-meter used to measure the output voltage of the wind turbine generator was purchased from RadioShack.

It can be seen from Fig. 6.5 that the resistance box and the multi-meter are connected in parallel with the generator of the wind turbine. The load resistance can be varied using the resistance box at any given wind speed and the corresponding output voltage can be recorded. Since the voltage output of this generator was alternating, we measured the root mean square (rms) value to calculate the electrical power. We recorded continuous data for voltage and angular velocity at the given loading conditions and wind speeds, and then the arithmetic 
mean was calculated as the representative value for the respective variables. The experiments were carried out at various wind speeds between $1.5 \mathrm{~m} / \mathrm{s}$ and $10 \mathrm{~m} / \mathrm{s}$.
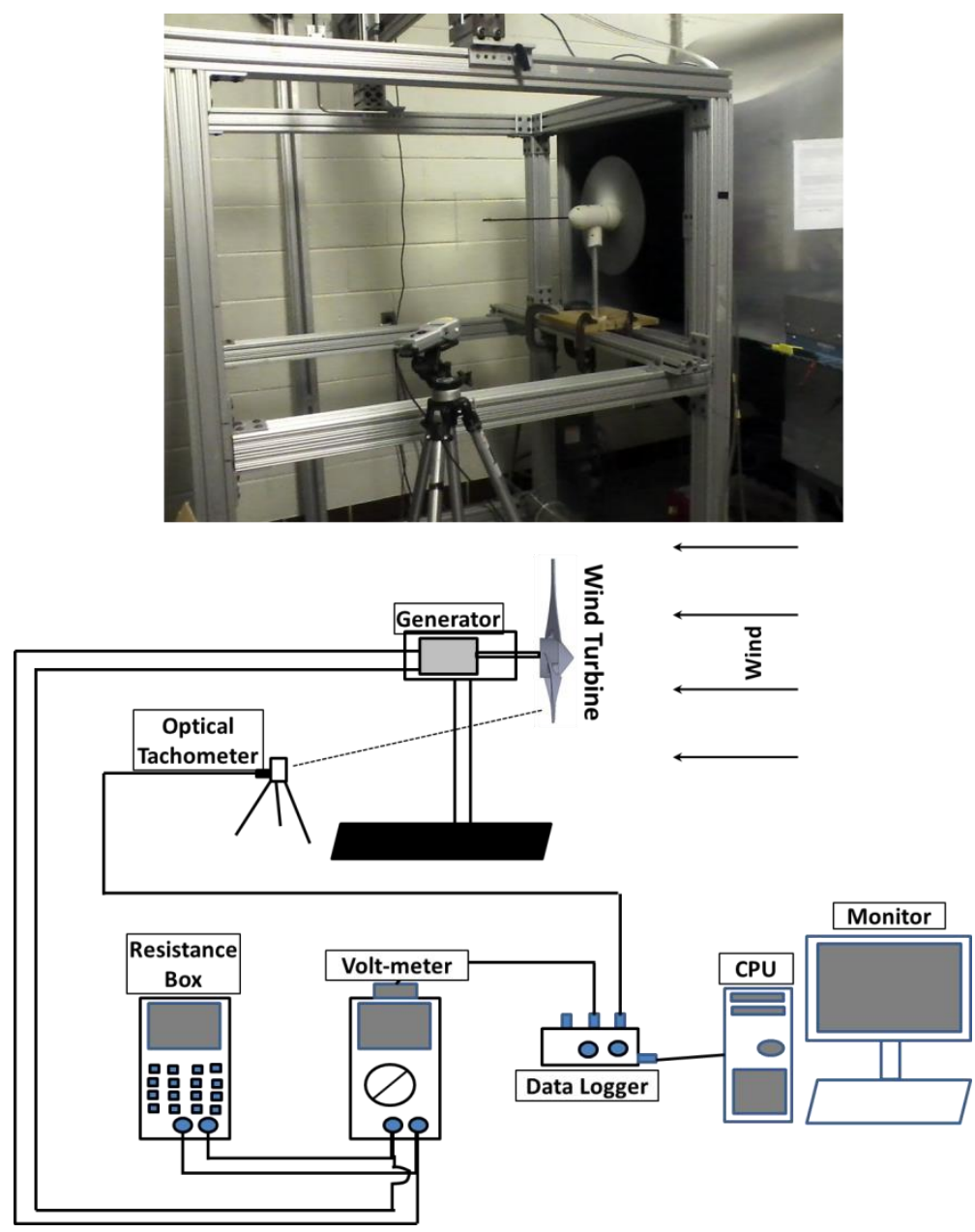

Figure 6.5. Schematic diagram of the experimental set-up.

\subsection{Results and discussion}

\subsubsection{Generator characteristics}

To investigate the performance of a generator in laboratory, normally it is coupled with a dynamometer motor and the wind turbine is emulated by varying the speed of the dynamometer motor. In this study, however, the generator was directly attached to the wind turbine rotor and its characteristics were studied using wind tunnel experiments. Figure 6.6 depicts the output voltage profiles of the generator at various loading conditions and at constant wind speed of $3.2 \mathrm{~m} / \mathrm{s}$. It can be noted that the waveforms are practically sinusoidal. Increase in the load resistance increases both amplitude as well as frequency of the voltage signal. 


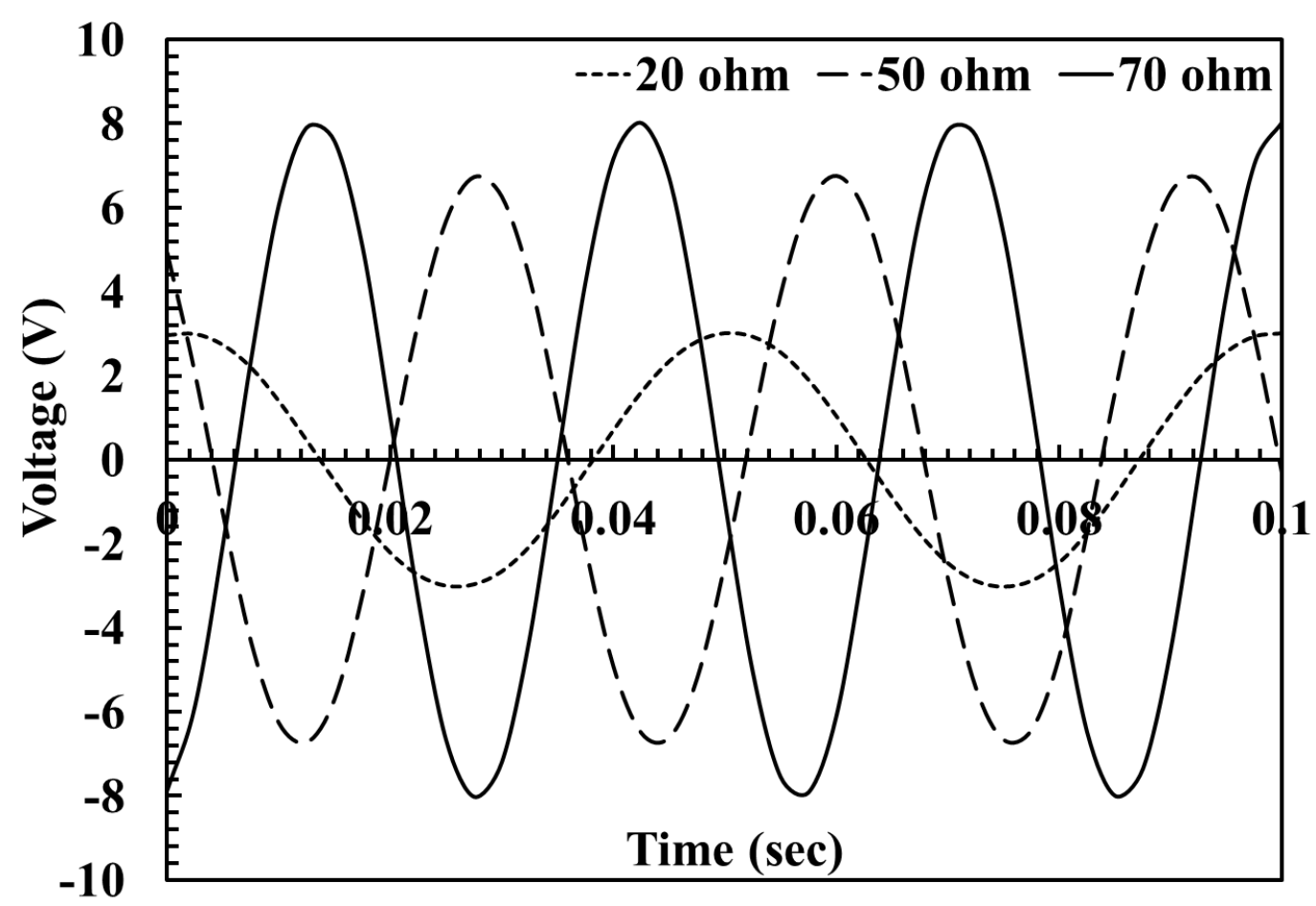

Figure 6.6. Output voltage profiles at various loading conditions (wind speed=3.2 m/s).

The internal impedance of the generator was measured by varying the load resistance and the wind speed in such a manner that the constant rotational speed of the wind turbine rotor is maintained. Figure 6.7 shows the variation of output rms voltage vs. rms current at three different angular speeds. The slope of the curves gives the internal impedance of the generator at different frequencies (rpm). It is to be noted that the value obtained is internal impedance, not internal resistance. The coil resistance of the generator was measured to be $19.6 \mathrm{ohm}$ using a multi-meter. Looking at the slopes of the curves in Fig. 6.7, it can be seen that the internal impedance is around $20.4 \mathrm{ohm}$ at $304 \mathrm{rpm}(20.3 \mathrm{~Hz})$ and it increases slowly with increase in the angular speed of the rotor. The angular speed of the rotor is related to EMF frequency by following equation:

$$
f=\frac{n * p}{120}
$$

where $n$ denotes rpm of the rotor and $p$ represents number of pole pairs. Increase in angular speed increases the EMF frequency which ultimately increases the reactance of the stator coils. However, it can be calculated that the reactance of the generator is very small in comparison to the resistance of the stator coils and therefore the generator's performance will be primarily influenced by internal resistance. 


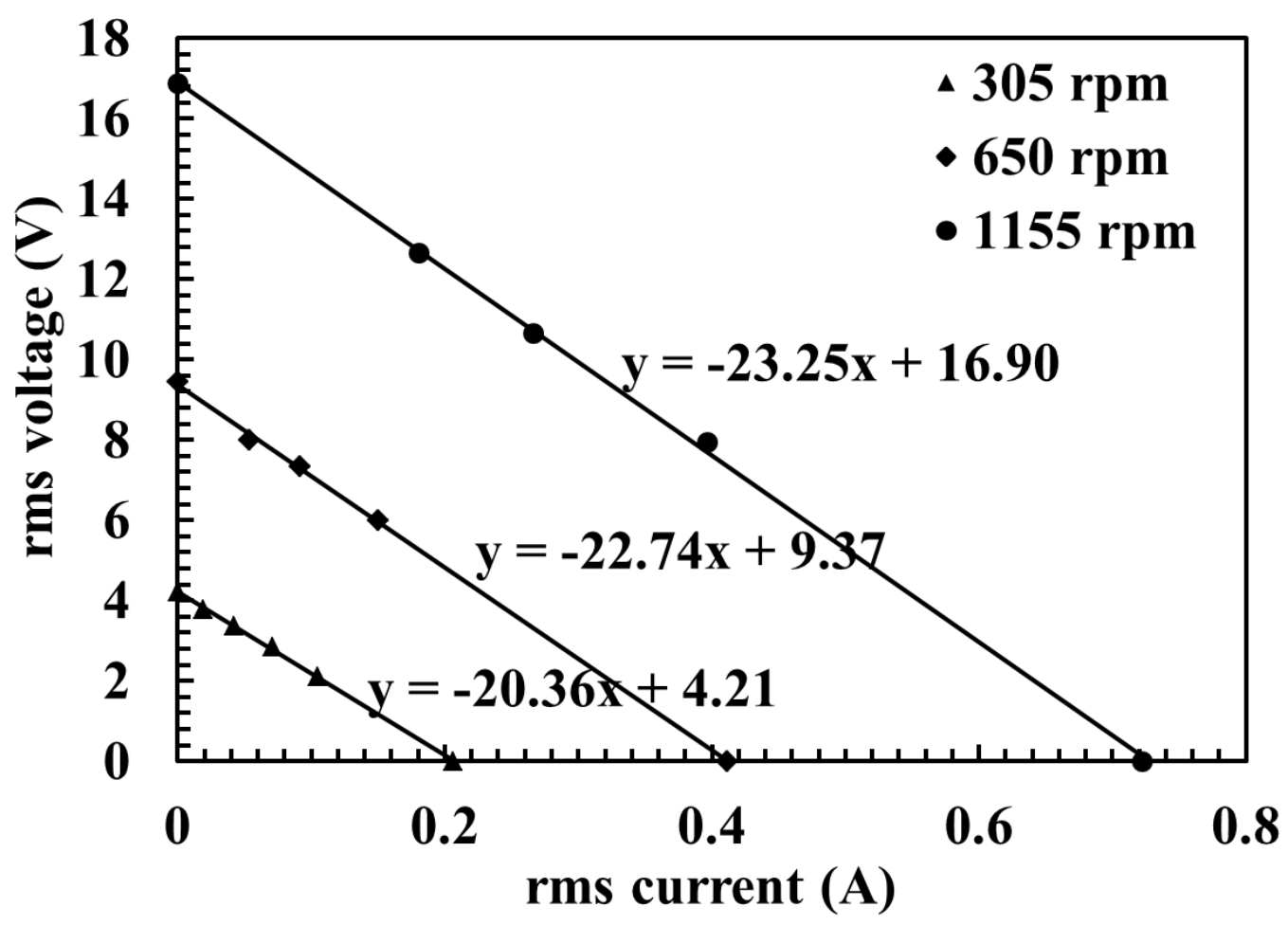

Figure 6.7. Variation of generator voltage with current at different constant rpm conditions.

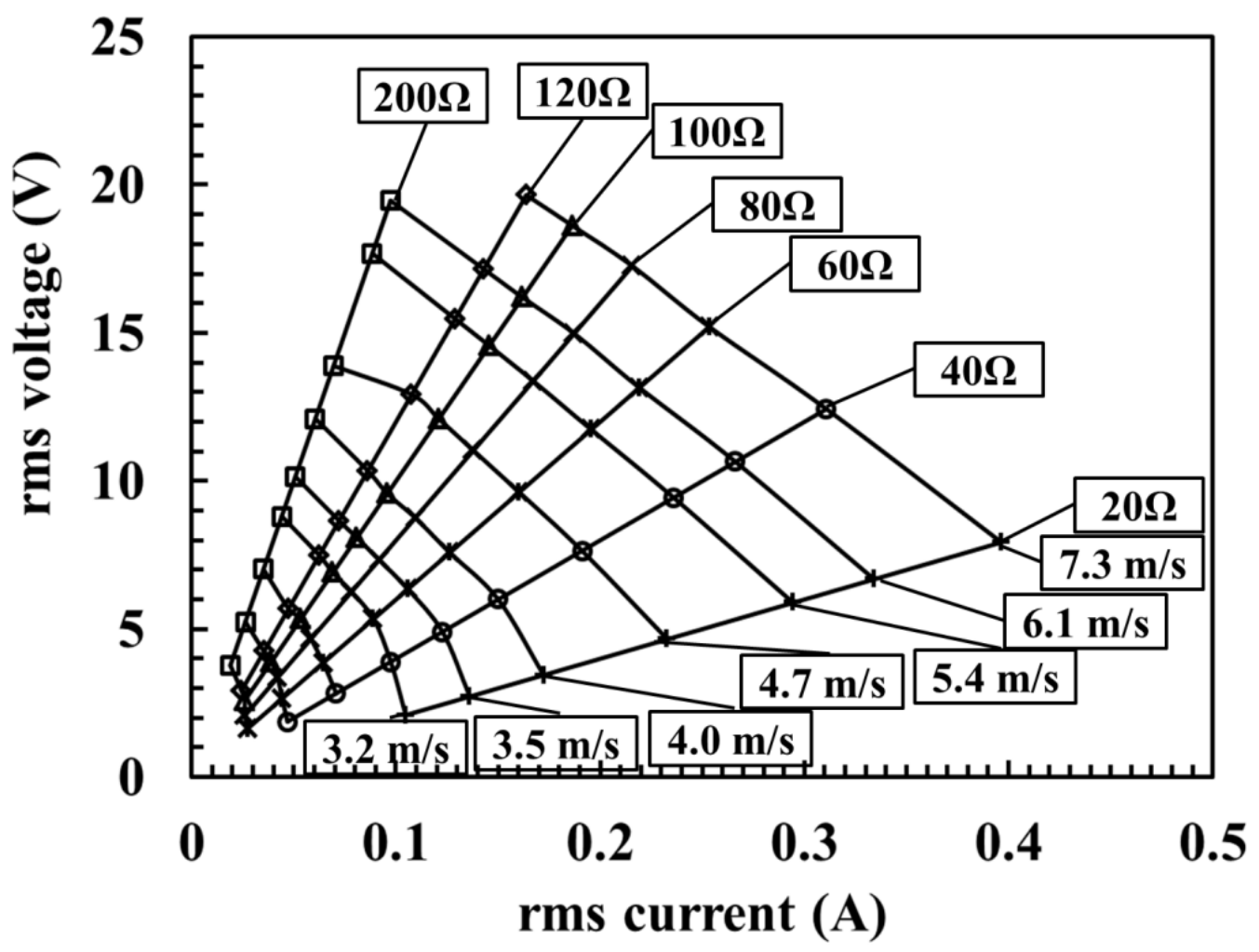

Figure 6.8. Voltage vs. current at various loading conditions and wind speeds. 
Figure 6.8 demonstrates the variation of root mean square (rms) voltage across the load as a function of load current at various loading conditions and the wind speeds. Voltage across the load is given by $V=I R$, where $V$ is the voltage, $I$ denotes current, and $R$ is the load resistance. It can be noted from Fig. 6.8 that at a fixed value of load resistance, voltage increases almost linearly with increase in current. Also, as expected, slope of the lines increases with increase in load resistance. Increase in wind speed increases both the current as well as voltage across the load, when load resistance is fixed. However, at the fixed value of wind speed, voltage and current has inverse relationship. Increase in load resistance increases voltage but decreases the current.

Figure 6.9 shows the relationship between voltage and the angular speed at different load resistance and wind speeds. Theoretically, voltage by the generator is directly proportional to the angular speed of the shaft. As shown in Fig. 6.9, for a fixed wind speed, voltage increases almost linearly with rpm. For a given value of wind speed, increase in load resistance causes increase in both, voltage by the generator as well as the angular speed of the rotor. Also, when external load is constant, increase in wind speed increases voltage as well as rpm.

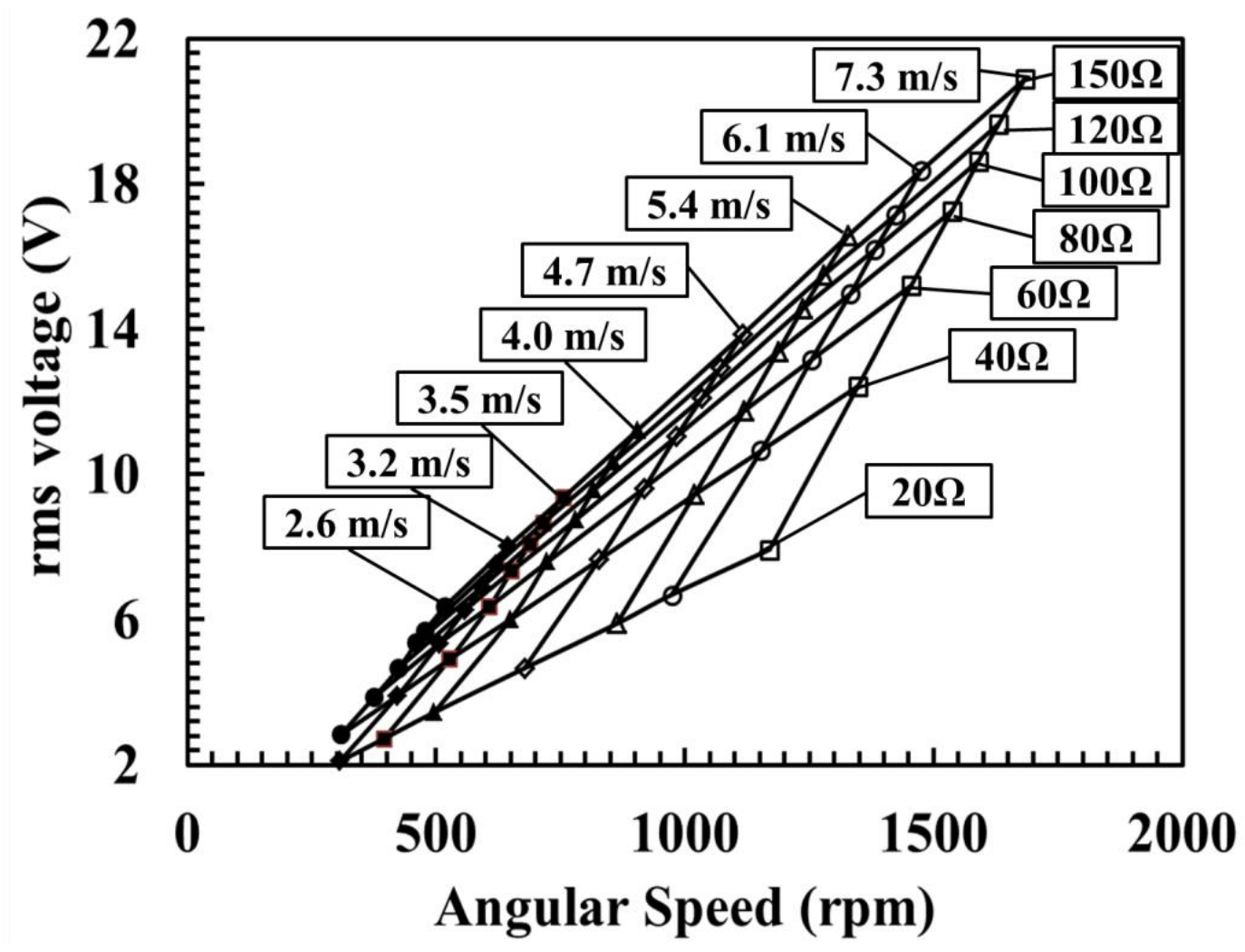

Figure 6.9. Voltage vs. angular speed at various loading conditions and wind speeds. 


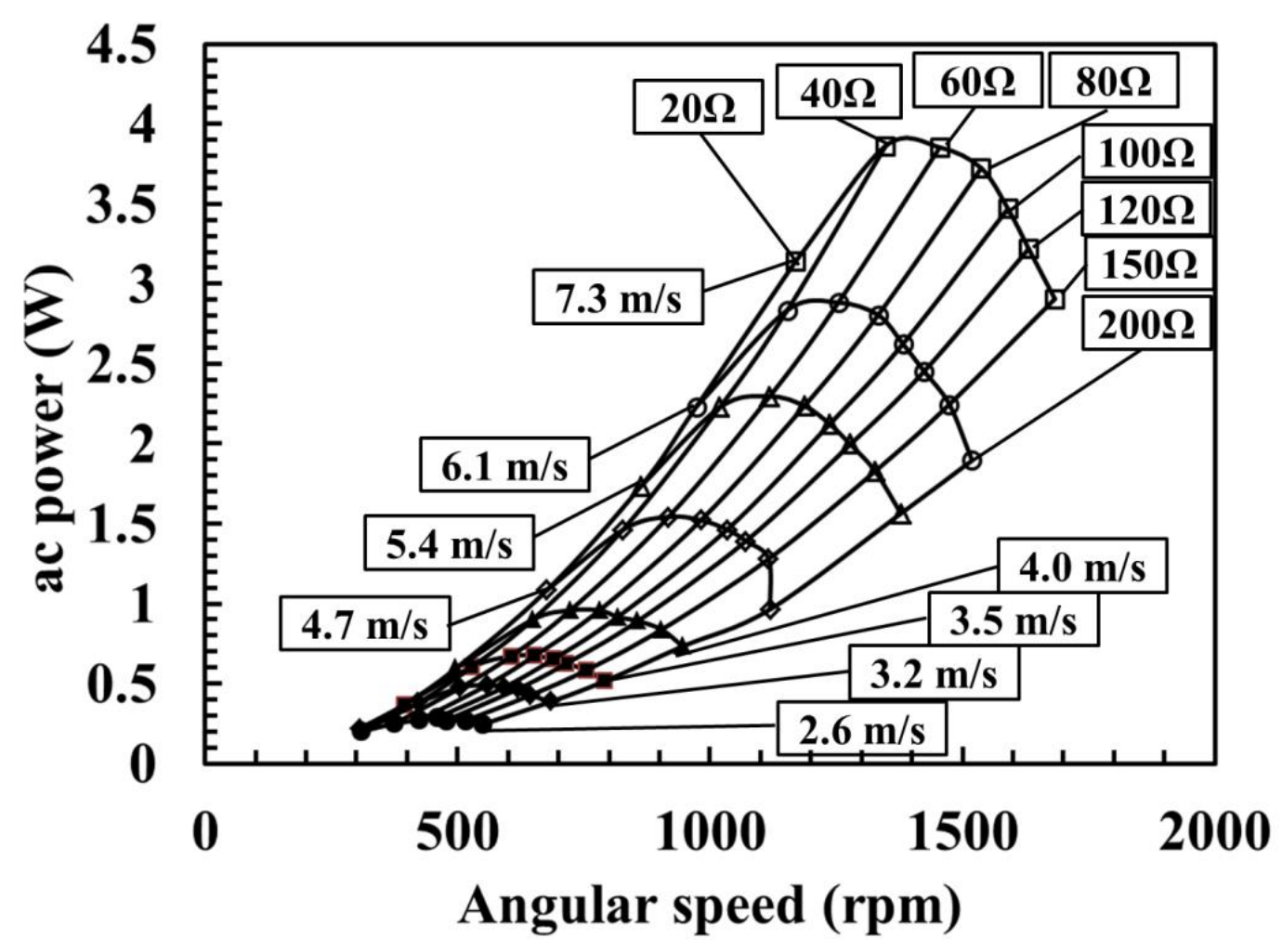

Figure 6.10. Power vs. angular speed at various loading conditions and wind speeds.

Figure 6.10 depicts the AC power produced by the generator as a function of the angular speed of the shaft at various loading conditions and wind speeds. In can be noted that at a fixed load resistance, power from the generator increases with increase in shaft rpm. Also, for a given load, increase in wind speed increases rotor speed as well as the power output because of the increase in aerodynamic torque on the rotor blades. For a fixed value of wind speed, the angular speed of the rotor increases with increase in load resistance. However, there exists an optimal load where power is highest, when wind speed is fixed.

The variation in shaft speed vs. load resistance at various wind speeds is shown in Figure 6.11. Increase in wind speed increases aerodynamic torque on the wind turbine rotor and therefore, at a fixed load resistance, shaft speed increases with increase in wind speed. However, at a fixed wind speed, rpm first increases with increase in load resistance, but it starts to saturate when load is too large. This can be explained if one can understand the interaction between the stator and the rotors of the generator when the generator is operating under different loading conditions. When the connection is open circuit, there is no current in the stator coil and therefore no induced magnetic field. But, when a finite amount of resistive load is applied, it delivers current which creates a magnetic field around the stator coils that reacts with the magnetic field of the rotors. The strength of the reacting magnetic force 
between stator and rotors depends on the current which is ultimately determined by the magnitude of the load resistance. Higher load resistance results in lower current and thus lowers magnetic reaction, which causes increase in shaft rpm.

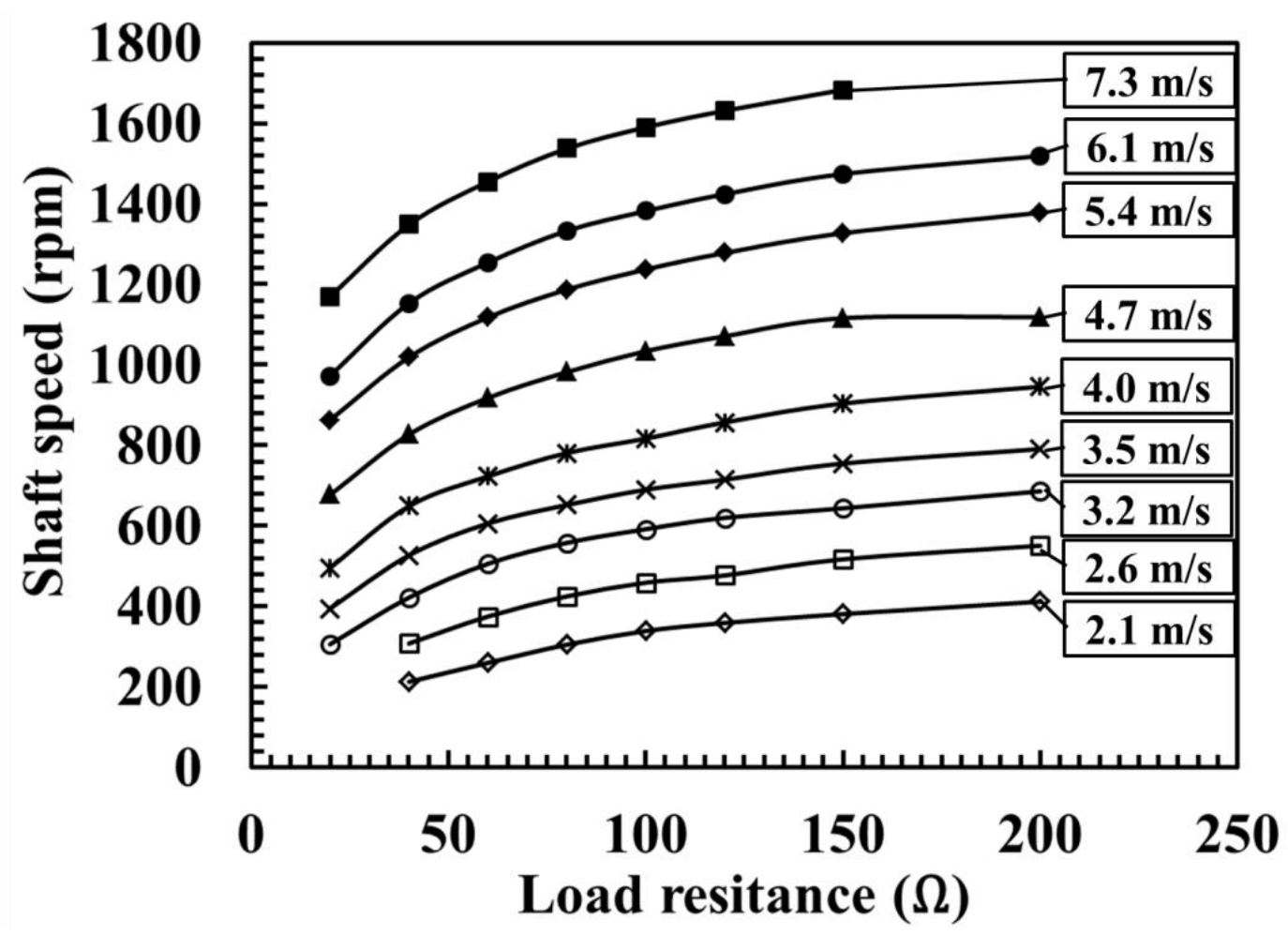

Figure 6.11. Angular speed vs. load resistance at various wind speeds.

\subsubsection{Wind turbine performance}

The direct-drive operation of the current generation SWEPT (with axial flux slotless generator) has two immediate advantages over the previous generation gear-drive prototypes: (i) the cut-in wind speed decreased to $1.7 \mathrm{~m} / \mathrm{s}$ in comparison to $2.7 \mathrm{~m} / \mathrm{s}$ of $1^{\text {st }}$ generation prototype and $3.0 \mathrm{~m} / \mathrm{s}$ of $2^{\text {nd }}$ generation prototype, and (ii) the range of operating wind speed increased to $1.7 \mathrm{~m} / \mathrm{s}-10 \mathrm{~m} / \mathrm{s}$ in comparison to $2.7 \mathrm{~m} / \mathrm{s}-5.0 \mathrm{~m} / \mathrm{s}$ of $1^{\text {st }}$ generation prototype and $3.0 \mathrm{~m} / \mathrm{s}-5.5 \mathrm{~m} / \mathrm{s}$ of $2^{\text {nd }}$ generation prototype. Figure 6.12 shows the electrical power output of the wind turbine vs. the load resistance at different wind speeds between $1.7 \mathrm{~m} / \mathrm{s}$ and $7.3 \mathrm{~m} / \mathrm{s}$. At a fixed wind speed, the electrical power first increases with increase in load resistance, it reaches to a maximum value at an optimal load, and it decreases thereafter with further increase in load resistance. Also, it can be seen that the electrical power increases with increase wind speed because theoretically, power output of a wind turbine is proportional to cube of wind speed. The optimal load decreases from $160 \Omega$ at $1.7 \mathrm{~m} / \mathrm{s}$ to $40 \Omega$ at $7.3 \mathrm{~m} / \mathrm{s}$. The 
peak electrical power produced by the wind turbine is about 1 watt at $4.0 \mathrm{~m} / \mathrm{s}$ of wind speed, which increases to around 4 watts at the wind speed of $7.3 \mathrm{~m} / \mathrm{s}$.

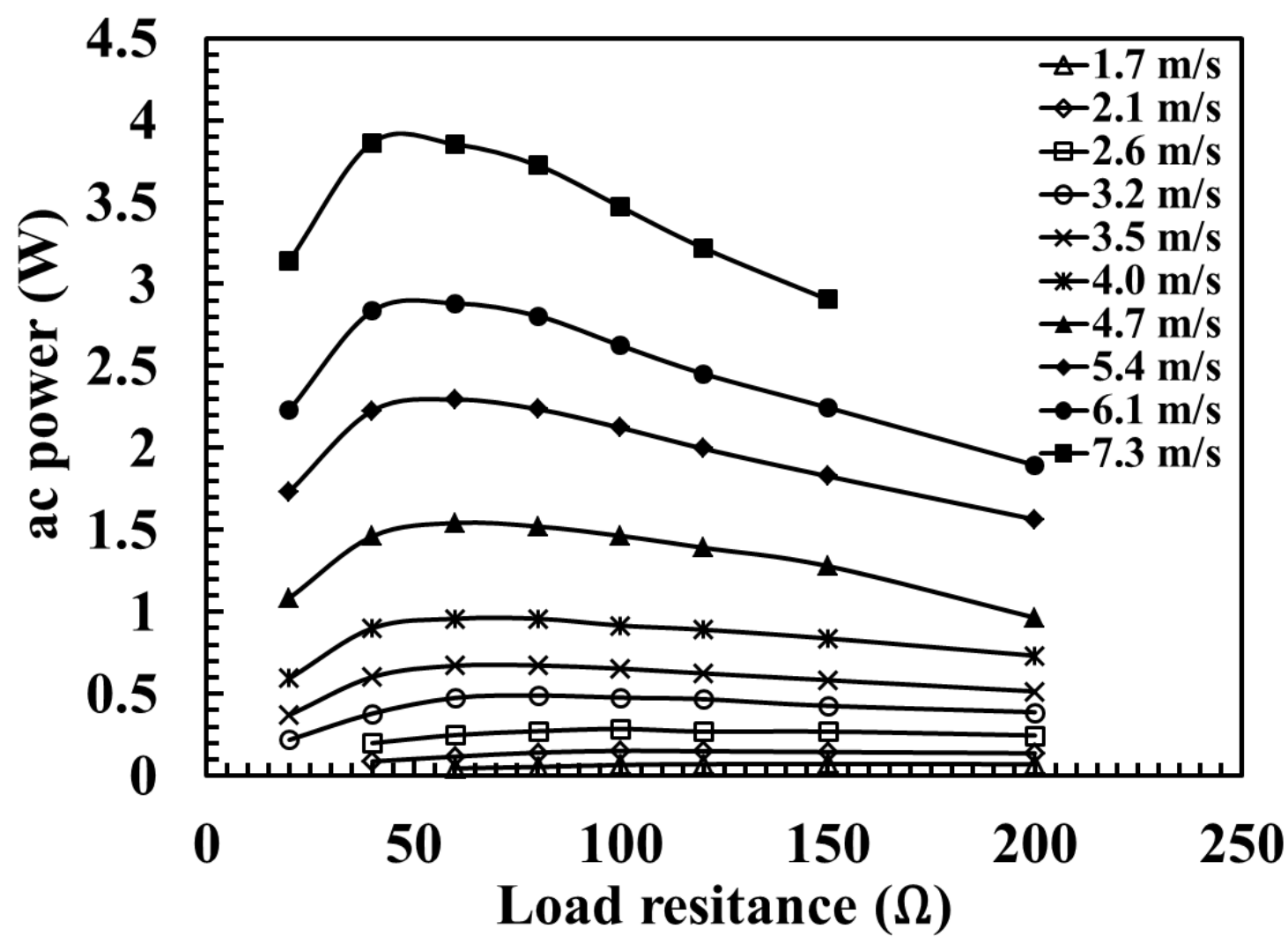

Figure 6.12. Power output vs. load resistance at different wind speeds.

To investigate the performance of the wind turbine at higher wind speeds, the wind tunnel experiment was conducted until $10 \mathrm{~m} / \mathrm{s}$. However, above $7.3 \mathrm{~m} / \mathrm{s}$ of wind speed, the wind turbine was allowed to run only at its optimal load in order to obviate its operation at very high rpm. Figure 6.13 shows the variation of peak electrical power of the wind turbine as a function of wind speed. As expected, the power has cubic relationship with the wind speed. The experiment also revealed that the wind turbine is capable of producing electrical power up to 9.3 watts at the wind speed of $10 \mathrm{~m} / \mathrm{s}$.

The net efficiency of the wind turbine is shown in Figure 6.14. The wind turbine has maximum efficiency of about $21 \%$ at the wind speed of $3.5 \mathrm{~m} / \mathrm{s}$. It is also interesting to note that the peak efficiency of the wind turbine lies between $19 \%-21 \%$ at lower wind speeds $(1.7 \mathrm{~m} / \mathrm{s}-5.4 \mathrm{~m} / \mathrm{s})$, however it decreases with further increase in wind speed. This happens because the blades of the wind turbine have been specifically designed for low wind speed 
operations (rated wind speed of $4.0 \mathrm{~m} / \mathrm{s}$ ), which causes the wind turbine to stall when wind speed is increased above $5.4 \mathrm{~m} / \mathrm{s}$.

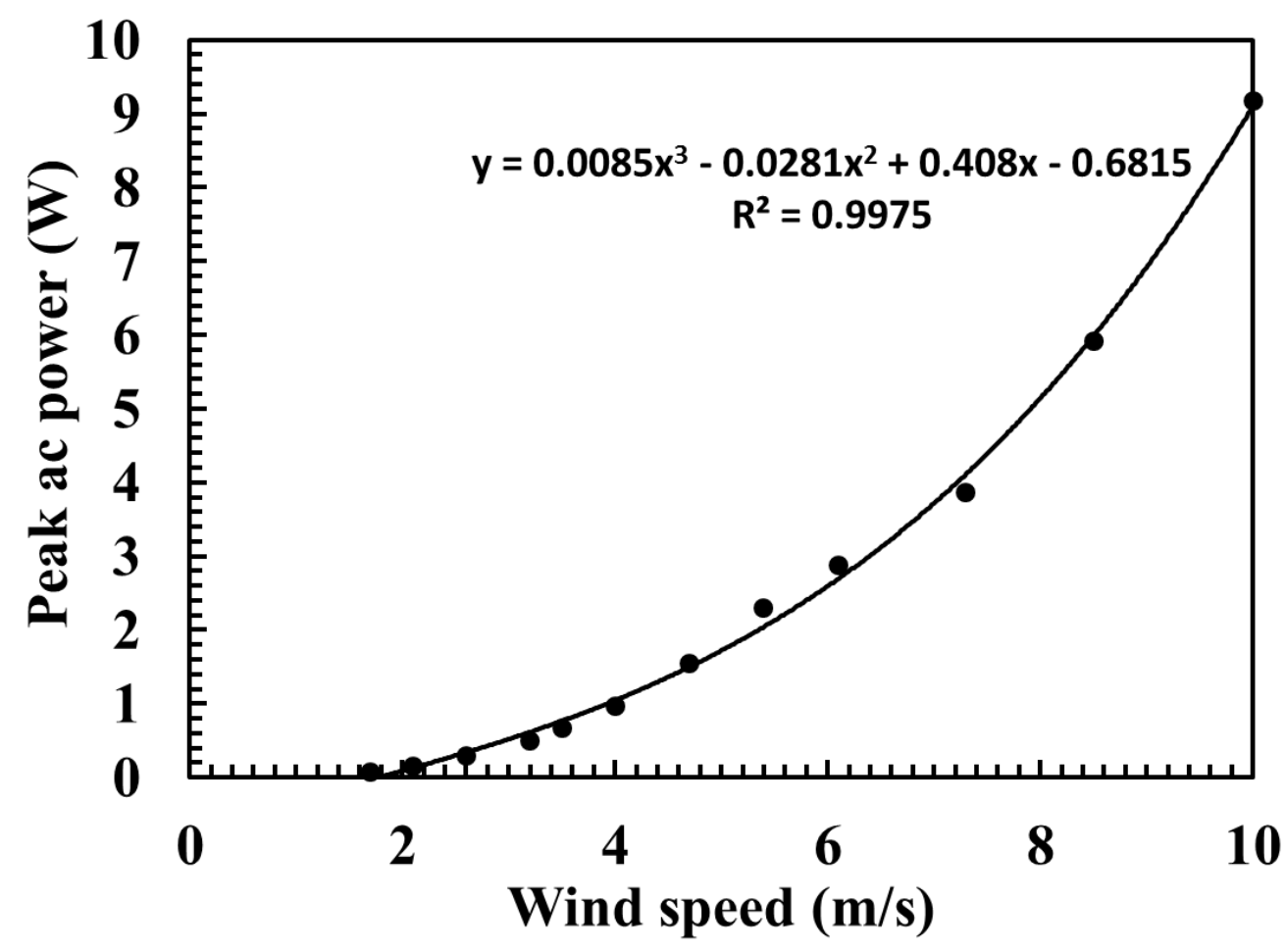

Figure 6.13. Peak electrical power vs. wind speed.

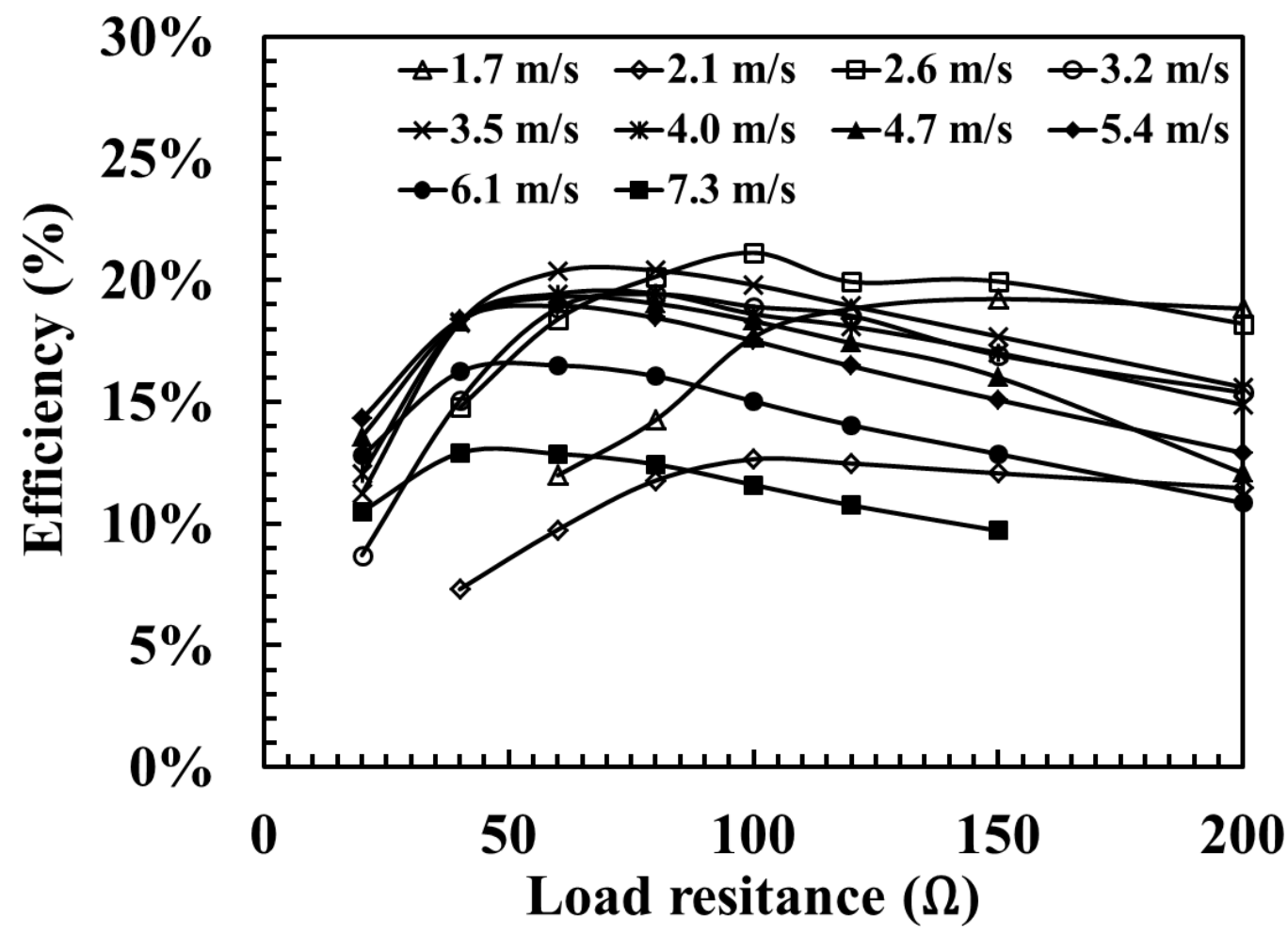

Figure 6.14. Net efficiency of the wind turbine vs. load resistance at various wind speeds. 


\subsection{Summary and conclusions}

In summary, this chapter presented the design, development, and experimental testing of an ultra-low start-up speed, highly efficient, direct drive small-scale wind energy portable turbine (SWEPT). An axial flux generator was developed which is suitable for the small size wind turbines at low wind speed applications. Wind tunnel experiments were conducted to characterize the performances of the generator and the wind turbine. The major findings of the study can be summarized as below:

(a) The cut-in speed of the wind turbine was found to be $1.7 \mathrm{~m} / \mathrm{s}$.

(b) The wind turbine operates in a very wide operating range of wind speeds, from few meters per second to $10 \mathrm{~m} / \mathrm{s}$.

(c) It produces electrical power of 1 watt at its rated wind speed of $4.0 \mathrm{~m} / \mathrm{s}$.

(d) The peak power by the wind turbine increases to 4 watts at $7.3 \mathrm{~m} / \mathrm{s}$, which further increase to 9.3 watts at $10 \mathrm{~m} / \mathrm{s}$.

(e) The peak efficiency of the wind turbine was found to be around $21 \%$. However, it decreases with increase in wind speed above $5.4 \mathrm{~m} / \mathrm{s}$. 


\section{CHAPTER 7}

\section{Ultra-low wind speed piezoelectric windmill}

SWEPT is a very efficient small-scale wind turbine and it is promising for applications such as charging sensor nodes in remote and far-to-reach areas. However, its applications may be limited by its cut-in wind speed. This chapter focuses on the development of an ultra-low wind speed piezoelectric windmill which operates below $2.0 \mathrm{~m} / \mathrm{s}$ of wind speed.

The low speed wind energy harvesting technique requires a non-conventional approach. Vortex Induced vibration (VIV), galloping, flutter, and buffeting are some of the approaches that have been recently proposed for harvesting energy from fluid flow [60-66]. They are essentially aerodynamic instability phenomena which occur when a structure is subjected to wind loads [61]. Energy harvesting using these methods requires an object which is mounted on a flexible support. When the object is exposed to an incident wind, the aerodynamic force due to the wind and the restoring force from the elastic mounting system react to impart periodic oscillation to the object. The vibrational energy of the oscillating cylinder is converted in to electrical energy using an electric generator. The use of conventional electric generator, however, has one major drawback. It normally has some cogging torque which restricts the cut-in speed of the wind energy harvester. A convenient way to convert the vibration energy into electrical energy is by using piezoelectric materials. Piezoelectric materials have low mechanical to electrical energy conversion efficiency and therefore they are generally not used for large scale power production. However, for a low wind speed, small scale wind energy harvester, it may prove better than a conventional generator.

The concept of piezoelectric windmill was first introduced by Priya et al. in year 2004 [67]. The proposed device had 11 piezoelectric bimorphs arranged along the circumference of a horizontal-axis wind turbine rotor shaft in the cantilever beam form. The oscillating torque to vibrate the bimorphs was generated using the camshaft gear mechanism. The study was further extended in year 2005 and a theoretical model to estimate the generated electric power output by above piezoelectric wind mill was presented [23]. The piezoelectric wind mill was found to be capable of producing electrical power upto $7.5 \mathrm{~mW}$ at the wind speed of $10 \mathrm{mph}$. In year 2010, Scott et al. attempted to develop a contact-less wind turbine which utilizes vertical axis Sarvonius wind turbine rotor and piezoelectric bimorphs [68]. This device has a 
series of piezoelectric bimorphs with magnets at the tip placed horizontally and around the wind turbine rotor shaft as cantilever beams. The alternating polarity magnets mounted at the periphery of the rotor were used to induce harmonic vibration in the piezoelectric elements. The optimal design of contactless wind turbine having two blades and four magnets was found to provide peak power output of about $1.2 \mathrm{~mW}$ at $9 \mathrm{mph}$ of wind speed. It can be noted that even though the concept of piezoelectric windmill was proposed about a decade ago, but there was not much progress made in this direction. One of the main reasons for the low adaptability of piezoelectric windmills is the fact that the previous prototypes were developed for wind speeds above $10 \mathrm{mph}$, where even a conventional generator based wind turbines run at quite reasonable efficiency. For practical applications, wind turbines need to charge sensor nodes by operating below $5 \mathrm{mph}$ of wind speed. Such harvesters would operate throughout the day and thus eliminate the need of any storage device which will reduce the overall cost of the device by multiple folds.

\subsection{Windmill design and experimental set-up}

Designing a micro wind turbine for very low wind speed applications is quite different than designing a conventional large scale wind turbine. There are several parameters such as blade profile, twist angle, chord length, number of blades, solidity, and tapering angle, which need to be optimized simultaneously according to the operating conditions at low Reynolds number. Figure 7.1(a) shows a prototype of the current piezoelectric windmill developed for wind speeds below $5 \mathrm{mph}$. The wind turbine has a $72 \mathrm{~mm}$ diameter horizontal axis wind turbine rotor having 12 equally spaced alternating polarity magnets attached around its periphery. This rotor is different from a conventional wind turbine rotor in many ways. A conventional wind turbine rotor normally has two or three blades; the rotor of this piezoelectric windmill however has eight blades. They are linearly twisted from $71^{\circ}$ at the hub to $28^{\circ}$ at the tip. Unlike the conventional wind turbine blades, the piezoelectric windmill blades are not tapered but they are fan type, i.e. the chord length increases linearly from 9 $\mathrm{mm}$ at the root to $19 \mathrm{~mm}$ at the tip. Also, they do not have a normal airfoil like profile instead they employ a flat plate type profile. It has been suggested that the flat plate has better aerodynamic performance in terms of life to drag ratio at low Reynolds number than a common airfoil [69]. The solidity of the piezoelectric windmill is around 50\% which is much higher than 5\%-7\% solidity of a conventional wind turbine. Lastly, in place of an electrical generator, the wind turbine has a piezoelectric bimorph element clamped in cantilever beam configuration near the base. There is a cap at the tip of the bimorph which contains a magnet. 
The magnets used for rotor as well as at the tip of bimorph are 1/8" x 1/8" x 1/8" thick, grade N42 - nickel plated magnets purchased from K \& J Magnetics, Inc., USA. The bimorph used in this study was purchased from APC International, Ltd. It is $60 \mathrm{~mm}$ long, $20 \mathrm{~mm}$ wide and $0.7 \mathrm{~mm}$ thick. The wind generates aerodynamic torque on the rotor causing it to rotate along its axis. The rotor's alternating polarity magnets generates an alternating magnetic field which interacts with the magnet attached at the tip of the bimorph causing it to deflect in a cyclic manner. This phenomenon generates an alternating stress in the piezoelectric bimorph and thus induces an alternating voltage across its output terminals.

Figure 7.1(b) shows the schematic of the experimental set-up of the wind tunnel experimentation used to characterize the performance of the windmill. The experiments were conducted using the Subsonic Open Jet Wind Tunnel facility available in the department of Aerospace and Ocean Engineering at Virginia Tech. The angular velocity of the wind turbine rotor was measured using non-contact type optical, digital Tachometer "DT-209X" (SHIMPO Instruments, USA). We used PASPORT, Model PS-2174 (PASCO, USA) anemometer to measure the wind speed. The output voltage of the bimorph was measured using "RadioShack Digital Multi-meter". The resistance box used to study the performance of the wind turbine at various loading conditions was an electronically controlled resistance box named “ohmSOURCE Model OS-260” manufactured by IET Labs, Inc.

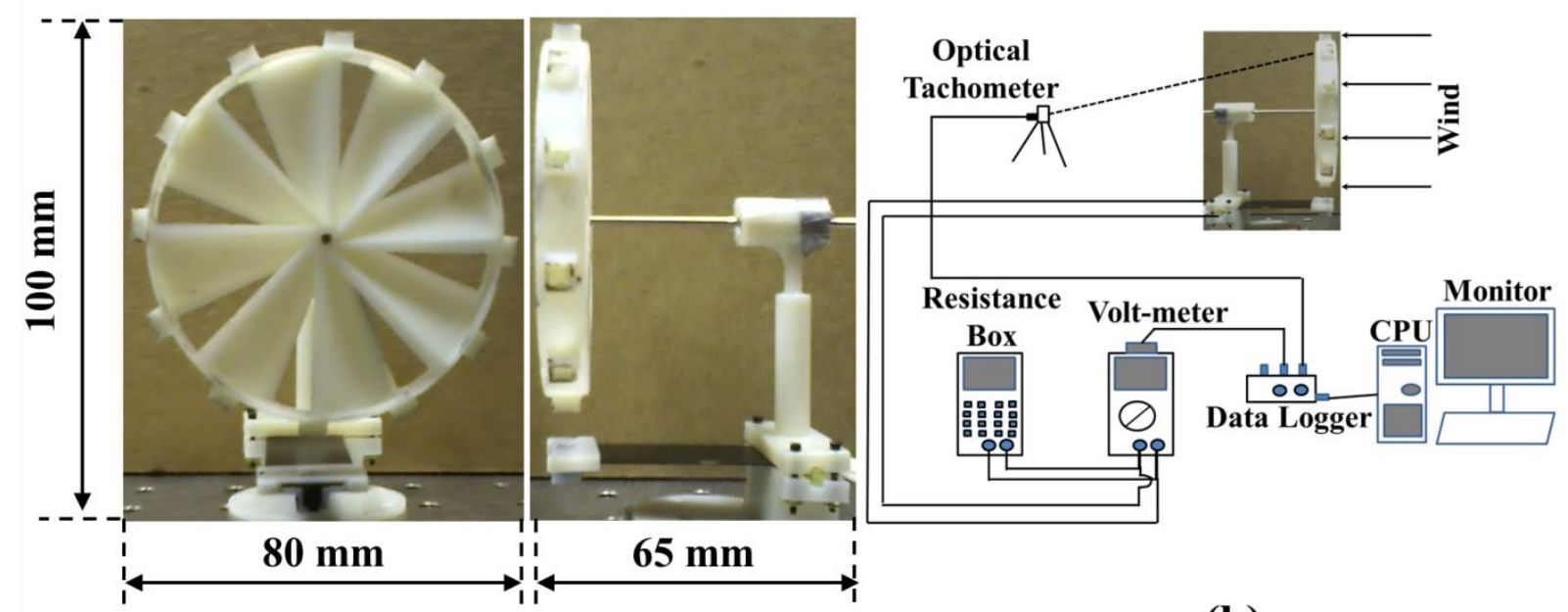

(a)

(b)

Figure 7.1. (a) Picture of the piezoelectric wind turbine fabricated in this study with all dimensions (in $\mathrm{mm}$ ); (b) Schematic of experimental set-up used for quantifying the performance of the windmill. 


\subsection{Results and discussion}

\subsubsection{Power coefficient}

To calculate the power coefficient of a wind turbine, it is necessary to know its mechanical power output which is given by the product of shaft torque and angular speed. Angular speed is easily measured using a tachometer but the torque transducer, which is generally used to measure the shaft torque, is quite expensive device. An alternative method was used to determine torque in this study as described earlier, which is based on the basic relationship: $\Gamma=J \alpha$, where $\Gamma$ is the torque generated by the wind turbine, $\mathrm{J}$ and $\alpha$ are the moment of inertia and the angular acceleration of the wind turbine rotor about the axis of rotation. The moment of inertia $\mathrm{J}$ was determined using the commercial software SolidWorks. The angular acceleration was calculated using the wind tunnel experimentation. To start the experiment, the magnet at the tip of the bimorph was removed to obviate the magnetic force between rotor and the bimorph. The fan of the wind tunnel was then switched on and the rotor of the wind turbine was held stationary until wind speed in the wind tunnel was stabilized. The rotor was then allowed to rotate and accelerate freely to its maximum constant speed. The rpm of the turbine blade, while it was accelerating, was recorded at the time interval of $100 \mathrm{~ms}$ using an optical tachometer. The curve fitting method was then employed to find the $6^{\text {th }}$ degree polynomial equation which describes the rpm as function of time. Figure 7.2(a) shows the angular speed of the wind turbine at the wind speed of $3.9 \mathrm{mph}$. The time derivative of the velocity gives the acceleration which multiplied by the moment of inertia provides the torque. Once torque is known, it can be multiplied by the angular speed to calculate the mechanical power and then the power coefficient can be determined using equation (1).

Figure 7.2(b) shows the power coefficient of the wind turbine rotor as a function of tip speed ratio. It can be noted that the turbine has maximum power coefficient between $9 \%$ and $11 \%$ at the optimal tip speed ratio of about 0.7 . The power coefficient may appear small but it is not surprising for a micro wind turbine operating at low wind speed below $5 \mathrm{mph}$. As stated earlier, the aerodynamic performance of wind turbines deteriorate with decrease in Reynolds number. The value of the Reynolds number for the given piezoelectric wind turbine at the wind speed of $4.2 \mathrm{mph}$ was found to be around $2 \times 10^{4}$. The range of Reynolds number between $10^{4}$ and $10^{6}$ is considered as very critical because in this region, there is sudden increase in drag coefficient and decrease in lift coefficient of an airfoil due to the formation of laminar separation bubbles [70]. Laminar separation bubble is essentially a separation region which occurs on the upper surface of an airfoil because of detachment and 
reattachment of the flow boundary layer at low Reynolds number. It causes a drastic decrease in lift but increase in drag force [71]. Decrease in lift to drag ratio ultimately results in poor performance of a low wind speed micro wind turbine.
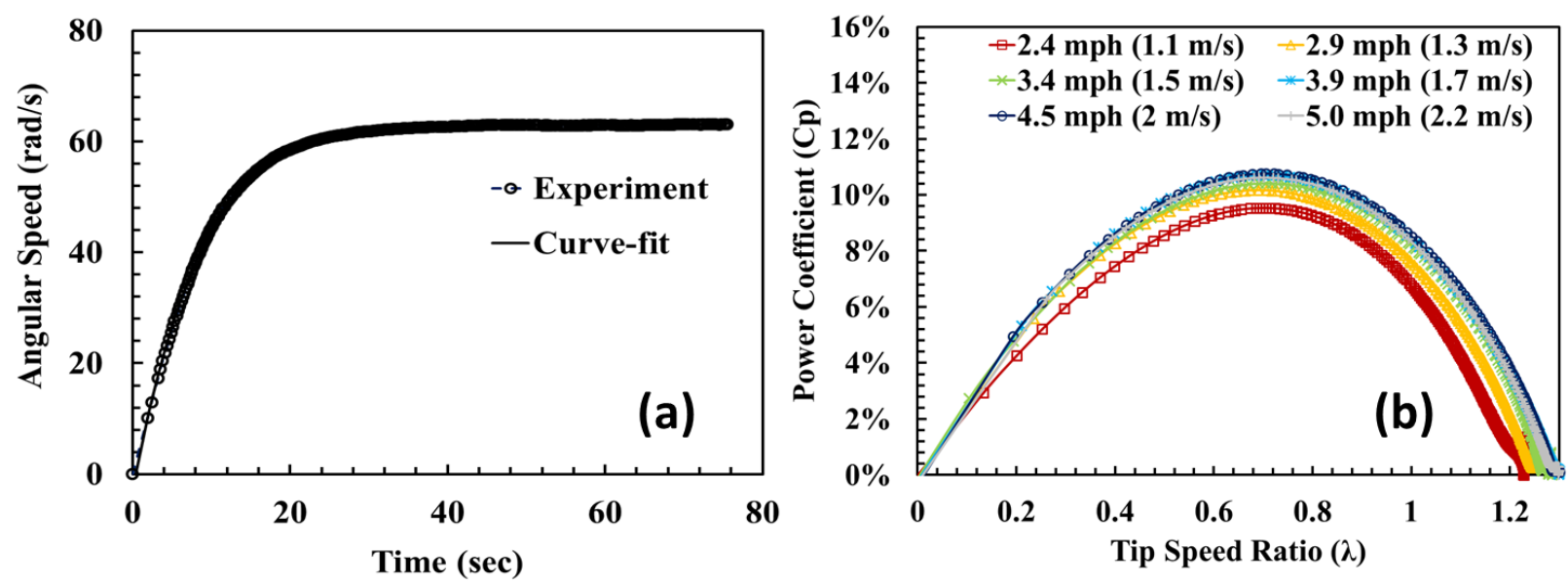

Figure 7.2. (a) Angular speed of the wind turbine at wind speed of $3.9 \mathrm{mph}$; (b) Power coefficient as a function of tip speed ratio.

\subsubsection{Start-up wind speed}

One of the main objectives of this study was to achieve as low start-up wind speed as possible. To solve this problem, we used the same piezoelectric bimorph as an actuator. To start the wind turbine, the output terminals of the bimorph was connected in series with a voltage source, an amplifier and a wave function generator. The alternating deflection produced by the bimorph causes an unbalanced force between the rotor's magnets and the magnet at the tip of the bimorph, which helps the wind turbine to overcome the static friction and start at lower wind speed. It was found that the square wave voltage input at amplitude of $120 \mathrm{~V}$ and frequency $1 \mathrm{~Hz}$ can start the wind turbine at a wind speed as low as $2.4 \mathrm{mph}$. This method requires 2 seconds on an average to start the wind turbine at $4.2 \mathrm{mph}$ which, in practice, could be easily achieved through a simple microcontroller circuit attached to the windmill. The energy required to start the wind turbine at $4.2 \mathrm{mph}$ in $2 \mathrm{sec}$ can be calculated using following equation [67].

$$
U=\frac{1}{2} C V_{O}^{2} f \Delta T
$$

where, $C$ is the capacitance of the bimorph, $V_{O}$ is the amplitude of the input square signal, $f$ is frequency, and $\Delta T$ is the time required during excitation. The capacitance of the given bimorph was measured to be $224 \mathrm{nF}$. Knowing the values of other variables: $V_{o}=120 \mathrm{~V}$, and $f=1 \mathrm{~Hz}$, we estimated that the amount of energy required to actuate the bimorph for 2 secs 
is about $3226 \mu \mathrm{J}$. This can be supplied by the piezoelectric wind turbine in about $7.2 \mathrm{sec}$ when it is generating $450 \mu \mathrm{W}$ at $4.2 \mathrm{mph}$.
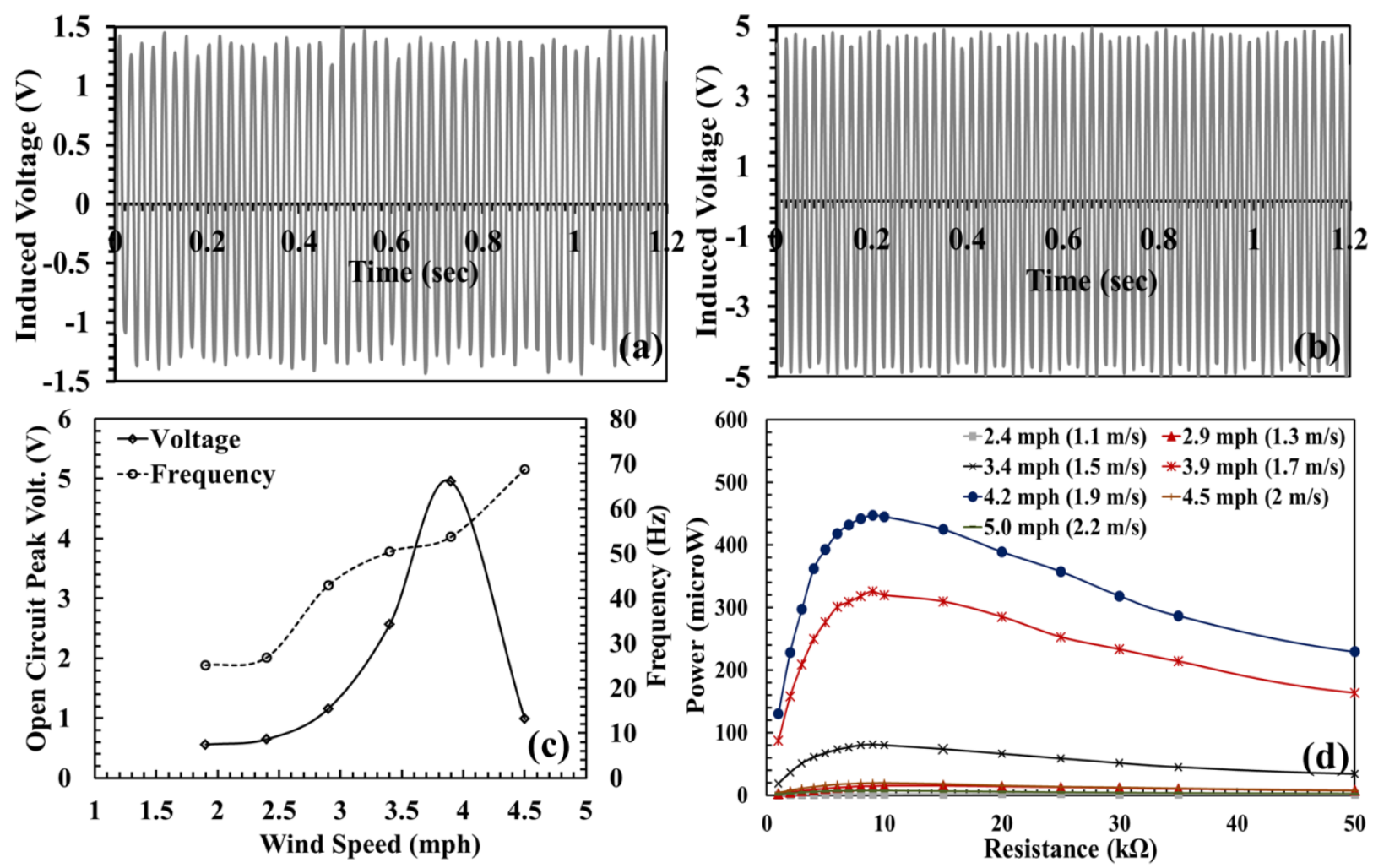

Figure 7.3. (a) Induced voltage profile at $2.9 \mathrm{mph}$; (b) Induced voltage profile at $4.2 \mathrm{mph}$; (c) Variation of open circuit voltage and oscillation frequency as function of wind speed; (d) Electrical power as a function of resistive load.

\subsubsection{Power output}

Figure 7.3 (a) and (b) show the induced voltage profile of the bimorph at the wind speeds of $2.9 \mathrm{mph}$ and $4.2 \mathrm{mph}$. It can be seen that the peak voltage is around $1.3 \mathrm{~V}$ at $2.4 \mathrm{mph}$ which increases to about $5.0 \mathrm{~V}$ when wind speed is increased to $4.2 \mathrm{mph}$. Figure 7.3(c) compares the peak induced voltage as the function of wind speed and oscillation frequency of the bimorph. It can be noted that the induced voltage is highest at the wind speed of $4.2 \mathrm{mph}$ where the bimorph vibrates near its resonance frequency, which is around $55 \mathrm{~Hz}$. Figure 7.3(d) shows the variation in the electrical power output of the piezoelectric wind turbine as a function of the load resistance at different wind speeds between $2.4 \mathrm{mph}$ and $5.0 \mathrm{mph}$. It can be seen that at a fixed wind speed, the power initially increases with load, reaches its maximum value at an optimal load resistance and then decreases. The optimal load resistance of the piezoelectric wind turbine was found to be around $9 \mathrm{k} \Omega$. It's also interesting to note that at any given 
resistive load, power increases when the wind speed is increased from $2.4 \mathrm{mph}$ to 4.2. Further increase in wind speed leads to sudden fall in power output and its value is almost negligible at $5 \mathrm{mph}$. The power output of the piezoelectric wind turbine is primarily influenced by the frequency of vibration of the piezoelectric bimorph. As it was noted in Fig. 7.3(c), the bimorph frequency increases with increase in wind speed and it reaches its resonance value at around the wind speed of $4.2 \mathrm{mph}$. Further increase in wind speed pushes bimorph to oscillate in off-resonance condition and therefore, the power output suddenly drops. It can be concluded that the piezoelectric wind turbine can produce electric power up to $450 \mu \mathrm{W}$ at the wind speed of $4.2 \mathrm{mph}$ when it is connected to an external load of $9 \mathrm{k} \Omega$.

\subsection{Summary and conclusions}

In summary, this study attempted to develop a very low wind speed wind turbine which does not utilize a conventional generator but piezoelectric bimorph actuator. Wind tunnel experiments were conducted to characterize the behavior of the wind turbine at various wind speeds. The wind tunnel experiments revealed that the flat blade profile, 8 bladed horizontal axis rotor of diameter $72 \mathrm{~mm}$ has power coefficient of 9\%-10\% at the wind speed between $2.4 \mathrm{mph}$ to $5.0 \mathrm{mph}$. The optimal tip speed ratio of the wind turbine rotor was found to be around 0.7. The wind turbine is capable of producing electrical power up to 450 microwatt at the wind speed of $4.2 \mathrm{mph}$ when it is connected to an external load of $9 \mathrm{k} \Omega$. 


\section{CHAPTER 8}

\section{Summary and conclusions}

The wind energy is a rapidly expanding field. Extensive research activities are being conducted across the globe in this area, with the goal of improving the efficiency of wind turbines. Several configurations of wind turbines have been proposed and the modern megawatt horizontal axis wind turbines are at this juncture very efficient with the power coefficient up to $45 \%$ to $50 \%$. In spite of all the efforts, as reported in chapter 1 , the overall contribution of wind power in the global total electricity generation is still a small fraction. One of the main reasons for the low success rate of wind turbines is the high rated wind speed. The low wind speed small scale wind turbines (SSWTs) are generally ignored because of their poor performance that does not allow justifying their installation and operational cost. The aim of this thesis was to develop the wind energy harvesters that can operate near the ground level where wind speed is very low $(<5 \mathrm{~m} / \mathrm{s})$.

Chapter 2 reported the development of the first generation small-scale wind energy portable turbine (SWEPT). Wind tunnel experiment revealed that the wind turbine has maximum coefficient of performance of $14 \%$ at the optimal tip speed ratio of 2.9. It has very low cut-in wind speed of $2.7 \mathrm{~m} / \mathrm{s}$ and it was found to generate mechanical power of $1.25 \mathrm{~W}$ and electrical power of up to $0.83 \mathrm{~W}$ at the wind speed of $5 \mathrm{~m} / \mathrm{s}$.

In the $3^{\text {rd }}$ chapter, a diffuser was designed and fabricated to contemplate its utility for the small-scale wind turbines. CFD studies revealed that the diverging section of the diffuser is stronger parameter than its converging section, which influences its performance. The optimal diffuser design has converging section length of 0.125 times throat diameter and half cone angle of $15^{\circ}$ while the length of diverging section is equal to the throat diameter with half cone angle of $10^{\circ}$. The diffuser produces velocity augmentation of about 1.2 times the upstream wind speed. Using wind tunnel experiments, it was found that the diffuseraugmented SWEPT of length approximately the same as the turbine's diameter could produce 1.4 to 1.6 times higher power output than a SWEPT without diffuser.

An inverse design and optimization tool based on Blade Element Momentum (BEM) theory was developed for the SSWTs in Chapter 4. It will not only help a designer to optimize one or more parameters of a SSWT but also provide a systematic design procedure based on inverse logic starting from the desired power output to the optimal blade design 
configuration of the wind turbine. This design tool was used to develop a $40 \mathrm{~cm}$ diameter HAWT having very low operating wind speed in the range of $2 \mathrm{~m} / \mathrm{s}-5 \mathrm{~m} / \mathrm{s}$. The wind turbine was found be very efficient with power coefficient of about $32 \%$ at its design point wind speed of $4.0 \mathrm{~m} / \mathrm{s}$. Wind tunnel experiments were then conducted to verify the numerical predictions. It was found that the numerical and experimental values of power and torque coefficients were close to each other.

In Chapter 5, the design, optimization and performance of $40 \mathrm{~cm}$ diameter high efficiency small scale wind energy portable turbine (SWEPT) was presented. This turbine can operate near the ground level where the wind speed is of the order of few meters per second. The various design parameters of the turbine like blade geometry, blade number, gear ratio and generator were optimized using numerical and experimental studies. The wind-tunnel experimentations were conducted to characterize the performance of the final design and it was observed that the SWEPT had very low start-up wind speed of $3.0 \mathrm{~m} / \mathrm{s}$. It is very efficient turbine with power coefficient ranging from $31 \%$ to $34 \%$. The maximum overall efficiency of the device was found to be $21 \%$ at the design wind speed of $4.0 \mathrm{~m} / \mathrm{s}$. SWEPT can produce electric power of $1 \mathrm{~W}$ at its rated wind speed of $4.0 \mathrm{~m} / \mathrm{s}$ which increases to 2.2 $\mathrm{W}$ at the wind speed of $5.5 \mathrm{~m} / \mathrm{s}$.

Chapter 6 presented the design, development, and experimental testing of $3^{\text {rd }}$ generation small-scale wind energy portable turbine (SWEPT). An axial flux generator was used in this study which allowed the wind turbine to run without gears. Wind tunnel experiments were conducted to characterize the performance of the generator and the wind turbine. It was found that the cut-in speed of the wind turbine was $1.7 \mathrm{~m} / \mathrm{s}$. It operated in a very wide range of wind speeds, from few meters per second to $10 \mathrm{~m} / \mathrm{s}$. The wind turbine produced electrical power of 1 watt at its rated wind speed of $4.0 \mathrm{~m} / \mathrm{s}$, but was capable of producing electrical power up to 9.3 watts at the wind speed of $10 \mathrm{~m} / \mathrm{s}$. The peak efficiency of the wind turbine was found to be around $21 \%$, which makes SWEPT one of the most efficient wind turbine reported at small scale and low wind speed. Figure 8.1 compares the overall efficiency of SWEPT with other existing small and mid-scale wind turbines. Clearly, SWEPT is among the very few wind turbines whose rated wind speed is below $5 \mathrm{~m} / \mathrm{s}$. More importantly, its performance is comparable to the other highly efficient SSWTs and MSWTs whose rated wind speed is above $10 \mathrm{~m} / \mathrm{s}$. The application areas of SWEPT shouldn't be underestimated on the basis of its low power output. It is modular, portable and light in weight. It could serve as carry-on modular wind mill for powering portable electronics like cellular phone, pocket radio, GPS etc. It can be easily integrated with health monitoring 
sensor nodes used on bridges and highways. It can also be used to power various household electronic devices including security system.

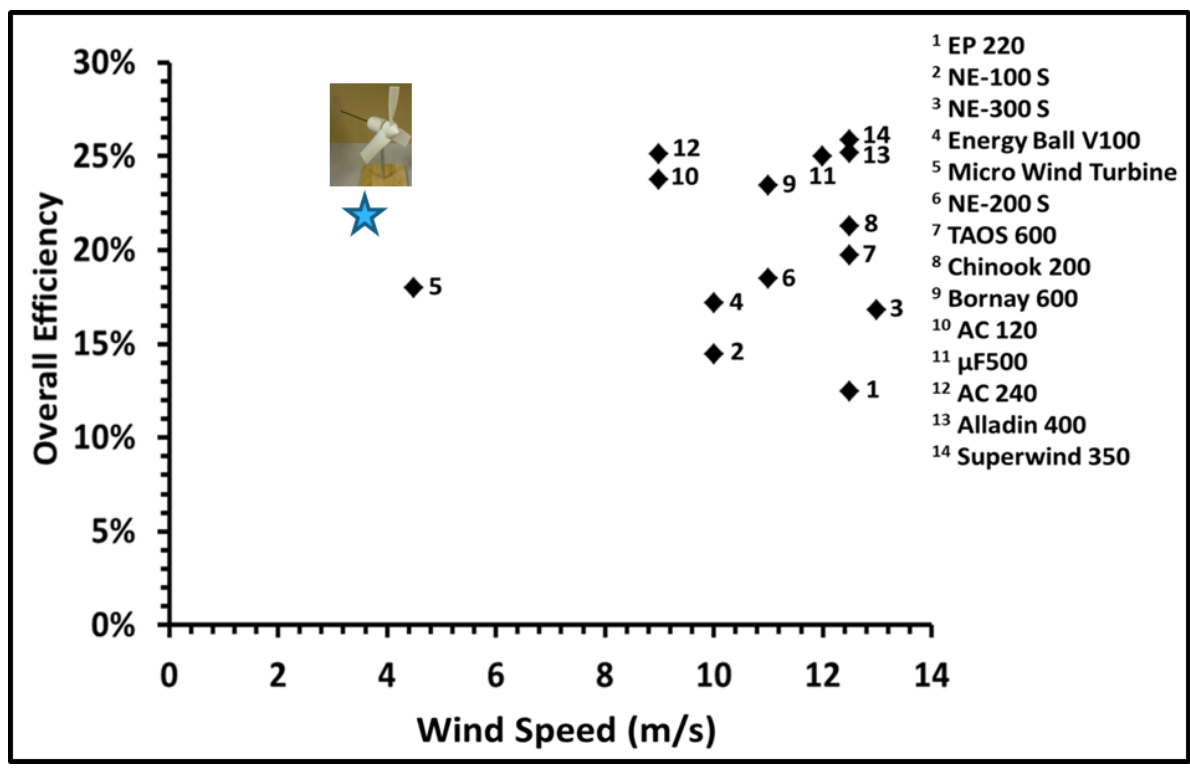

Figure 8.1. Overall efficiency of some of the small and mid-scale wind turbines.

Lastly, an ultra-low wind speed piezoelectric windmill was developed that can operate at wind speeds below $2.2 \mathrm{~m} / \mathrm{s}$. The device is highly compact having rotor diameter of $72 \mathrm{~mm}$ and the overall dimension of about $100 \mathrm{~mm} \times 78 \mathrm{~mm}$ x $65 \mathrm{~mm}$. The wind tunnel experiments revealed that the wind turbine has power coefficient of $9 \%-10 \%$ at the wind speeds between $1.9 \mathrm{mph}$ to $5.0 \mathrm{mph}$. The wind turbine was capable of producing $450 \mu \mathrm{W}$ of electrical power output at $1.9 \mathrm{~m} / \mathrm{s}$ wind speed. This device is very useful to charge wireless microelectronics like sensor nodes, especially for far-to-reach and remote applications. 


\section{CHAPTER 9}

\section{Fundamental scientific achievements}

This thesis successfully developed a small-scale wind energy portable turbine (SWEPT) of 40 $\mathrm{cm}$ diameter, which operates near ground level, below $5 \mathrm{~m} / \mathrm{s}$ of wind speed. The major scientific achievements of the study are summarized below:

(i) Novel torque measurement technique for small-scale wind turbine: This thesis developed a novel torque measurement technique for small-scale wind turbine, which does not require any torque sensor/transducer.

(ii) Diffuser design: A diffuser for SWEPT was successfully designed and optimized using computational fluid dynamics (CFD). It was found that the diffuser of about same length as the turbine diameter with inlet cone angle of $15^{\circ}$ and outlet cone angle of $10^{\circ}$ can amplify the wind speed by 1.2 times. The SWEPT with diffuser was found to produce about 1.5 times higher electrical power than SWEPT without diffuser. However, it was concluded that the diffuser augmentation was not a suitable solution for power augmentation for small-scale wind turbines because it makes the device bulky and increases the structural vibrations. The main design objectives: simplicity, compactness, and portability are lost.

(iii) Inverse design optimization tool: A numerical model to predict the performance of a small scale wind turbine for low wind speed applications was proposed. This model is based on blade element momentum (BEM) theory and it's called 'inverse design optimization tool' because it asks users to provide output power and operating wind speeds as input parameter and then optimizes all the geometrical variables of the wind turbine blades to provide best possible efficiency. The utility and efficacy of the model was validated by demonstrating a small wind turbine of $40 \mathrm{~cm}$ diameter having rated power output of 1 watt at $4.0 \mathrm{~m} / \mathrm{s}$. Wind tunnel experimentations revealed that the power and torque coefficients proposed by the model and the experimental results found using wind tunnel experiments are close.

(iv) High efficiency SWEPT: The biggest tangible achievement of this thesis was the development of high efficiency SWEPT. The final prototype is one the most efficient small-scale wind turbine reported in literature or available commercially. It has the lowest cut-in wind speed $(1.7 \mathrm{~m} / \mathrm{s})$ among all the other available wind turbines of 
diameter $<50 \mathrm{~cm}$. The wind turbine has rated power output of 1 watt at $4.0 \mathrm{~m} / \mathrm{s}$ wind speed, but it can produce electrical power up to 9.3 watts at $10 \mathrm{~m} / \mathrm{s}$ wind speed. Most importantly, it is simple in design, compact, and portable.

(v) Ultra-low wind speed piezoelectric windmill: An ultra-low start-up speed windmill was developed that consisted of a 72mm diameter horizontal-axis wind turbine rotor with 12 alternating polarity magnets around its periphery and a $60 \mathrm{~mm} \times 20 \mathrm{~mm} \times 0.7 \mathrm{~mm}$ piezoelectric bimorph element having a magnet at its tip. The windmill operates at very low Reynolds number (around 20000), but it has reasonably high power coefficient of about $11 \%$ at the optimal tip-speed-ratio of 0.7 . It was found to produce electric power up to $450 \mu \mathrm{W}$ at the rated wind speed of $4.2 \mathrm{mph}(1.9 \mathrm{~m} / \mathrm{s})$. An extremely low start-up wind speed of $2.4 \mathrm{mph}(1.1 \mathrm{~m} / \mathrm{s})$ was achieved by operating the bimorph in actuator mode. 


\section{CHAPTER 10}

\section{Future studies}

This thesis presented an inverse design and optimization tool based on Blade element momentum theory for small-scale wind turbine. The deviation between the power coefficient value predicted by the numerical model and that obtained experimentally was found to be around $12 \%$. The main reason for this deviation in the results is the fact that the design model considers the blade elements as 2-dimensional airfoil. It assumes that each of the elements is independent and they don't mutually affect the wind flow. This assumption fairly simplifies the numerical model and makes the simulations faster. But at the same time, it compromises the accuracy in the results. The accuracy of design model can be greatly improved if realistic 3-dimensional wind flow is taken into account. Also, in spite of the fact that the final SWEPT prototype is very efficient and operates in very wide range of wind speeds between $1.7 \mathrm{~m} / \mathrm{s}$ to $10 \mathrm{~m} / \mathrm{s}$, it cannot be deployed immediately in a real environment. There are three key issues which need to be addressed: (i) structural rigidity, (ii) breaking mechanism, and (iii) electronic circuit. Most of the components of the current wind turbine prototype were 3D printed using veroWhite plastic. Though this material is tough with tensile strength of about $50 \mathrm{MPa}$, but it's not weather-proof. The first step before deploying this wind turbine for real application would be to strengthen the structural reliability of the components, keeping the cost of the material and the manufacturing process simple and cheap. The components can be casted using light metals like aluminum. Also to make the blades as light in weight as possible, they can be casted hollow from inside. All the components then will be required to be painted/coated with a weather proof paint/coating in order to make them weather resistant from dust, sun, rain, and snow. The second step would be to provide a breaking mechanism to the wind turbine. SWEPT currently does not have any mechanical or electrical breaking mechanism that can restrict its operation at very high wind speeds. Before deploying the wind turbine in a real environment, it must be equipped with a safety feature which can protect it when wind speed it very high. Lastly, the voltage output from the wind turbine is dependent on the wind speed. Also, there exists an optimal external load where power output by the wind turbine is highest at a given wind speed. In order to charge an electronic device using this wind turbine, it needs to produce constant voltage. Also, the wind turbine should operate most of the time at its optimal load where power output is maximum. Therefore, an electronic 
circuit is needed that will track the maximum power point at every wind speed and produce constant voltage output required to charge sensor nodes. 


\section{REFERENCES}

[1] http://www.wwindea.org/technology/ch01/estructura-en.htm.

[2] Gasch R, Twele J. Wind power plants - fundamentals, design, construction and operation: Springer, 2012.

[3] http://www.ironmanwindmill.com/windmill-history.htm.

[4] http://www.midamericawindmillmuseum.org/imgs/home/windmill_2.jpg.

[5] http://www.gwec.net/publications/global-wind-energy-outlook/global-wind-energyoutlook-2012/.

[6] Global Wind Energy Council Report. Global Wind Statistics; 2012.

[7] Gsänger S, Pitteloud JD. World Wind Energy Report 2011. World Wind Energy Association (WWEA); 2012.

[8] http://www.eia.gov/electricity/monthly/pdf/epm.pdf.

[9] WIND AND WATER POWER PROGRAM. U.S. Department of Energy: Energy Efficiency and Renewable energy; 2011.

[10] http://www.windpoweringamerica.gov/pdfs/20_percent_wind_2.pdf.

[11] Islam M, Ting DSK, Fartaj A. Aerodynamic models for Darrieus-type straight-bladed vertical axis wind turbines. Renewable and Sustainable Energy Reviews. 2008;12(4):1087109.

[12] http://www.elite.tugraz.at/Jungbauer/3.htm.

[13] Akwa JV, Vielmo HA, Petry AP. A review on the performance of Savonius wind turbines. Renewable and Sustainable Energy Reviews. 2012;16(5):3054-64.

[14] Kirke BK. Evaluation of Self-Starting Vertical Axis Wind Turbines for Stand-Alone Applications. 1998.

[15] Eriksson S, Bernhoff H, Leijon M. Evaluation of different turbine concepts for wind power. Renewable and Sustainable Energy Reviews. 2008;12(5):1419-34.

[16] http://www.energy.siemens.com/us/pool/hq/power-generation/wind-power/E50001W310-A123-X-4A00_WS_SWT-2.3-82\%20VS_US.pdf.

[17] Crossley RJ, Schubel PJ. Wind Turbine Blade Design Review. Wind engineering. 2012;36(4):365-88.

[18] Burton T. Wind energy : handbook. Chichester; New York: J. Wiley, 2001.

[19] Zhang P. Small Wind World Report 2012. World Wind Energy Association (WWEA), Germany.; 2012.

[20] Kishore RA, Coudron T, Priya S. Small-scale wind energy portable turbine (SWEPT). Journal of Wind Engineering and Industrial Aerodynamics. 2013;116:21-31.

[21] http://upload.wikimedia.org/wikipedia/commons/c/c9/Wing_profile_nomenclature.svg.

[22] Duquette MM, Visser KD. Numerical Implications of Solidity and Blade Number on Rotor Performance of Horizontal-Axis Wind Turbines. Journal of Solar Energy Engineering. 2003;125(4):425.

[23] Priya S. Modeling of electric energy harvesting using piezoelectric windmill. Applied Physics Letters. 2005;87(18):184101--3.

[24] Ozgener O, Ozgener L. Exergy and reliability analysis of wind turbine systems: A case study. Renewable \& sustainable energy reviews. 2007;11(8):1811-26.

[25] www.wxnaier.com/ProductShow.asp?ID=790.

[26] www.home-energy.com/int/ebv100technical.htm.

[27] www.taoswind.com/TAOS600SPEC.pdf.

[28] www.chinookturbines.com/Products.html.

[29] www.electricpinwheels.com/Wind_Turbine.html.

[30] www.bornay.com/eolica/en/wind-turbines/4/models/17/bornay-600/1/specs. 
[31] www.aerocraft.de/downloads/AeroCraft-Systems_gb.pdf.

[32] www.taoswind.com/Alladin400SPEC.pdf.

[33] www.superwind.com/swe/index.htm.

[34] Hirahara H, Hossain MZ, Kawahashi M, Nonomura Y. Testing basic performance of a very small wind turbine designed for multi-purposes. Renewable Energy. 2005;30(8):127997.

[35] Leung DYC, Leung DYC, Deng Y, Leung MKH. Design Optimization of a CostEffective Micro Wind Turbine. Lecture notes in engineering and computer science. 2010;2184(1):988-93.

[36] Musial WD, Cromack DE. Influence of Reynolds number on performance modeling of horizontal axis wind rotors. Journal Name: J Sol Energy Eng; (United States); Journal Volume: 110:2. 1988:Medium: X; Size: Pages: 139-44.

[37] Vardar A, Alibas I. Research on wind turbine rotor models using NACA profiles. Renewable Energy. 2008;33(7):1721-32.

[38] Abe K, Nishida M, Sakurai A, Ohya Y, Kihara H, Wada E, et al. Experimental and numerical investigations of flow fields behind a small wind turbine with a flanged diffuser. Journal of Wind Engineering and Industrial Aerodynamics. 2005;93(12):951-70.

[39] Abe K-i, Ohya Y. An investigation of flow fields around flanged diffusers using CFD. Journal of Wind Engineering and Industrial Aerodynamics. 2004;92(3):315-30.

[40] Foreman KM, Gilbert B, Oman RA. Diffuser augmentation of wind turbines. Solar Energy. 1978;20(4):305-11.

[41] Matsushima T, Takagi S, Muroyama S. Characteristics of a highly efficient propeller type small wind turbine with a diffuser. Renewable Energy. 2006;31(9):1343-54.

[42] Ohya Y, Karasudani T, Sakurai A, Abe K-i, Inoue M. Development of a shrouded wind turbine with a flanged diffuser. Journal of Wind Engineering and Industrial Aerodynamics. 2008;96(5):524-39.

[43] http://www.windstuffnow.com/main/formulas.

[44] Wang F, Bai L, Fletcher J, Whiteford J. The methodology for aerodynamic study on a small domestic wind turbine with scoop. Journal of Wind Engineering and Industrial Aerodynamics. 2008;96(1):1-24.

[45] FLUENT. Theory Guide. ANSYS FLUENT 12.0. 2009.

[46] Manwell, Manwell JF, McCowan, McCowan JG, Rogers, Rogers AL. Wind Energy Explained: theory, design and application. Wind engineering. 2006;30(2):169-70.

[47] Lanzafame R, Messina M. Fluid dynamics wind turbine design: Critical analysis, optimization and application of BEM theory. Renewable Energy. 2007;32(14):2291-305.

[48] Lanzafame R, Messina M. Horizontal axis wind turbine working at maximum power coefficient continuously. Renewable Energy. 2010;35(1):301-6.

[49] Lanzafame R, Messina M. Power curve control in micro wind turbine design. Energy. 2010;35(2):556-61.

[50] Ahmed N, Yilbas BS, Budair MO. Computational study into the flow field developed around a cascade of NACA 0012 airfoils. Computer Methods in Applied Mechanics and Engineering. 1998;167(1-2):17-32.

[51] Alam MM, Zhou Y, Yang HX, Guo H, Mi J. The ultra-low Reynolds number airfoil wake. Exp Fluids. 2010;48(1):81-103.

[52] Counsil JNN, Goni Boulama K. Validating the URANS shear stress transport $\gamma-\operatorname{Re} \theta$ model for low-Reynolds-number external aerodynamics. International journal for numerical methods in fluids. 2012;69(8):1411-32.

[53] Laitone EV. Wind tunnel tests of wings at Reynolds numbers below 70 000. Exp Fluids. 1997;23(5):405-9. 
[54] Srinath DN, Mittal S. Optimal airfoil shapes for low Reynolds number flows. International journal for numerical methods in fluids. 2009;61(4):355-81.

[55] www.xflr5.com.

[56] Ani SO, Polinder H, Ferreira J. Low cost axial flux PM generator for small wind turbines. Conference Low cost axial flux PM generator for small wind turbines. IEEE, p. 2350-7.

[57] Park Y-S, Jang S-M, Choi J-H, Choi J-Y, You D-J. Characteristic Analysis on Axial Flux Permanent Magnet Synchronous Generator Considering Wind Turbine Characteristics According to Wind Speed for Small-Scale Power Application. Magnetics, IEEE Transactions on. 2012;48(11):2937-40.

[58] Latoufis K, Messinis G, Kotsampopoulos P, Hatziargyriou N. Axial Flux Permanent Magnet Generator Design for Low Cost Manufacturing of Small Wind Turbines. Wind engineering. 2012;36(4):411-32.

[59] Marin A. Mechanical Energy Harvesting for Powering Distributed Sensors and Recharging Storage Systems. Blacksburg, Virginia: Virginia polytechnic institute and state university, 2013.

[60] Akaydin HD, Elvin N, Andreopoulos Y. Energy Harvesting from Highly Unsteady Fluid Flows using Piezoelectric Materials. Journal of Intelligent Material Systems and Structures. 2010;21(13):1263-78.

[61] Jung H-J. The experimental validation of a new energy harvesting system based on the wake galloping phenomenon. Smart Materials and Structures. 2011;20(5):055022.

[62] Mahadik RR, Sirohi J. Harvesting Wind Energy Using a Galloping Piezoelectric Beam. Conference Harvesting Wind Energy Using a Galloping Piezoelectric Beam. ASME.

[63] Sirohi J. Harvesting wind energy using a galloping piezoelectric beam. Journal of vibration and acoustics. 2012;134(1):011009.

[64] Erturk A, Vieira W, De Marqui C, Inman D. On the energy harvesting potential of piezoaeroelastic systems. Applied Physics Letters. 2010;96(18):184103--3.

[65] Alonso G, Meseguer J. A parametric study of the galloping stability of two-dimensional triangular cross-section bodies. Journal of Wind Engineering and Industrial Aerodynamics. 2006;94(4):241-53.

[66] Sirohi J, Mahadik R. Piezoelectric wind energy harvester for low-power sensors. Journal of Intelligent Material Systems and Structures. 2011;22(18):2215-28.

[67] Priya S, Chen C-T, Fye D, Zahnd J. Piezoelectric windmill: a novel solution to remote sensing. Japanese journal of applied physics. 2005;44(3):104-7.

[68] Bressers S, Avirovik D, Lallart M, Inman D, Priya S. Contact-less Wind Turbine Utilizing Piezoelectric Bimorphs with Magnetic Actuation. Structural Dynamics, Volume 3: Springer; 2011. p. 233-43.

[69] Laitone E. Wind tunnel tests of wings at Reynolds numbers below 70 000. Experiments in Fluids. 1997;23(5):405-9.

[70] McArthur J. Aerodynamics of Wings at Low Reynolds Numbers: Boundary Layer Separation and Reattachment: University of Southern California, 2008.

[71] Mueller TJ, DeLaurier JD. Aerodynamics of small vehicles. Annual Review of Fluid Mechanics. 2003;35(1):89-111. 
NACA 0012 airfoil

Table A. Coordinates of NACA 0012 airfoil

\begin{tabular}{|c|c|}
\hline $\mathrm{X}$ & $\mathrm{Y}$ \\
\hline 0 & 0.00945 \\
\hline 0.054 & 0.017025 \\
\hline 0.150825 & 0.030375 \\
\hline 0.2736 & 0.047025 \\
\hline 0.415875 & 0.06585 \\
\hline 0.57375 & 0.086325 \\
\hline 0.744375 & 0.10785 \\
\hline 0.92565 & 0.130125 \\
\hline 1.115775 & 0.15285 \\
\hline 1.313325 & 0.175725 \\
\hline 1.51695 & 0.1986 \\
\hline 1.725675 & 0.22125 \\
\hline 1.93845 & 0.2436 \\
\hline 2.154375 & 0.265425 \\
\hline 2.372625 & 0.286575 \\
\hline 2.59245 & 0.306975 \\
\hline 2.8131 & 0.32655 \\
\hline 3.033975 & 0.345 \\
\hline 3.254475 & 0.3624 \\
\hline 3.474 & 0.378525 \\
\hline 3.69195 & 0.393375 \\
\hline 3.907875 & 0.40665 \\
\hline 4.12125 & 0.41835 \\
\hline 4.33155 & 0.4284 \\
\hline 4.5384 & 0.43665 \\
\hline 4.74135 & 0.44295 \\
\hline 4.939875 & 0.447375 \\
\hline 5.133675 & 0.4497 \\
\hline 5.322375 & 0.45 \\
\hline 5.50545 & 0.44805 \\
\hline 5.682675 & 0.444 \\
\hline 5.853675 & 0.4377 \\
\hline 6.018 & 0.429225 \\
\hline 6.175425 & 0.418575 \\
\hline 6.3255 & 0.40575 \\
\hline 6.468 & 0.390825 \\
\hline & \\
\hline
\end{tabular}




\begin{tabular}{|c|c|}
\hline 6.602625 & 0.373725 \\
\hline 6.729 & 0.354675 \\
\hline 6.846825 & 0.33375 \\
\hline 6.9558 & 0.310875 \\
\hline 7.0557 & 0.286275 \\
\hline 7.146225 & 0.260025 \\
\hline 7.227075 & 0.2322 \\
\hline 7.29795 & 0.202875 \\
\hline 7.358625 & 0.1722 \\
\hline 7.408875 & 0.140175 \\
\hline 7.4484 & 0.106875 \\
\hline 7.4769 & 0.072375 \\
\hline 7.49415 & 0.03675 \\
\hline 7.5 & 0 \\
\hline 7.49415 & -0.03675 \\
\hline 7.4769 & -0.07238 \\
\hline 7.4484 & -0.10688 \\
\hline 7.408875 & -0.14018 \\
\hline 7.358625 & -0.1722 \\
\hline 7.29795 & -0.20288 \\
\hline 7.227075 & -0.2322 \\
\hline 7.146225 & -0.26003 \\
\hline 7.0557 & -0.28628 \\
\hline 6.9558 & -0.31088 \\
\hline 6.846825 & -0.33375 \\
\hline 6.729 & -0.35468 \\
\hline 6.602625 & -0.37373 \\
\hline 6.468 & -0.39083 \\
\hline 6.3255 & -0.40575 \\
\hline 6.175425 & -0.41858 \\
\hline 6.018 & -0.42923 \\
\hline 5.853675 & -0.4377 \\
\hline 5.682675 & -0.444 \\
\hline 5.50545 & -0.44805 \\
\hline 5.322375 & -0.45 \\
\hline 5.133675 & -0.4497 \\
\hline 4.939875 & -0.44738 \\
\hline 4.74135 & -0.44295 \\
\hline 4.5384 & -0.43665 \\
\hline 4.33155 & -0.4284 \\
\hline 4.12125 & -0.41835 \\
\hline 3.907875 & -0.40665 \\
\hline 3.69195 & -0.39338 \\
\hline 3.474 & -0.37853 \\
\hline & \\
\hline
\end{tabular}




\begin{tabular}{|c|c|}
\hline 3.254475 & -0.3624 \\
\hline 3.033975 & -0.345 \\
\hline 2.8131 & -0.32655 \\
\hline 2.59245 & -0.30698 \\
\hline 2.372625 & -0.28658 \\
\hline 2.154375 & -0.26543 \\
\hline 1.93845 & -0.2436 \\
\hline 1.725675 & -0.22125 \\
\hline 1.51695 & -0.1986 \\
\hline 1.313325 & -0.17573 \\
\hline 1.115775 & -0.15285 \\
\hline 0.92565 & -0.13013 \\
\hline 0.744375 & -0.10785 \\
\hline 0.57375 & -0.08633 \\
\hline 0.415875 & -0.06585 \\
\hline 0.2736 & -0.04703 \\
\hline 0.150825 & -0.03038 \\
\hline 0.054 & -0.01703 \\
\hline 0 & -0.00945 \\
\hline
\end{tabular}

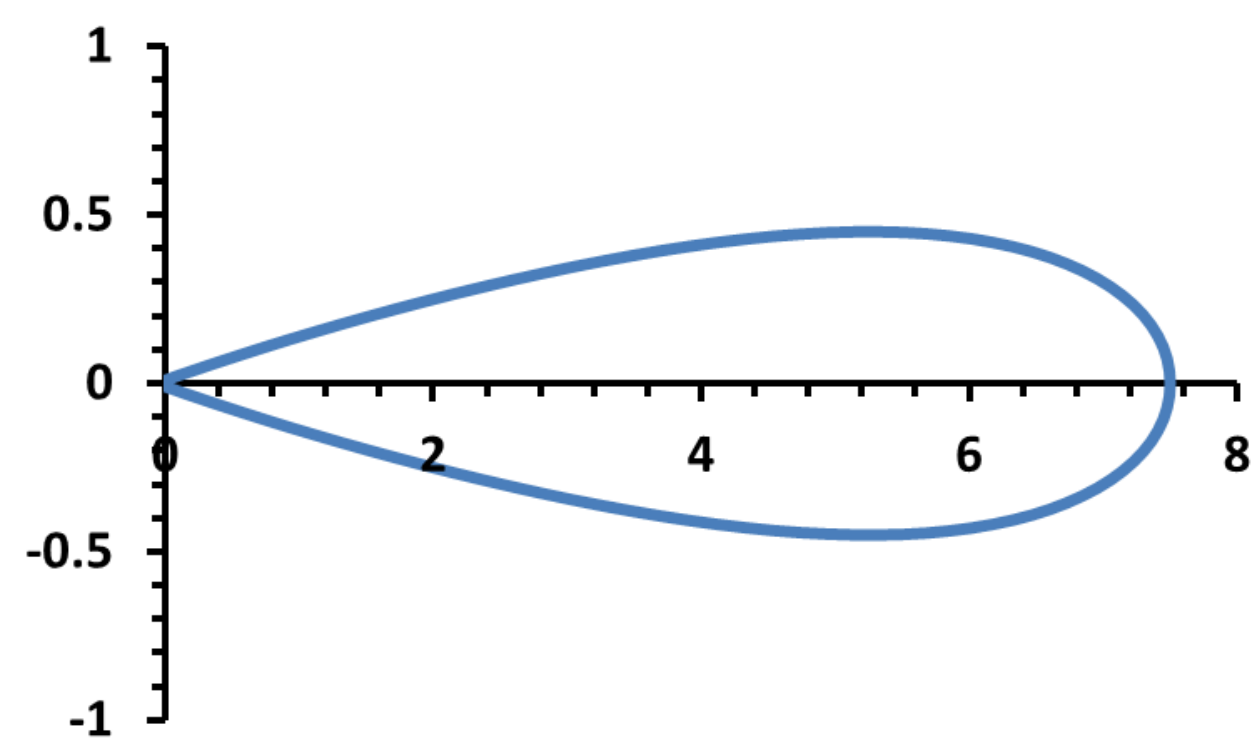

Figure A. Airfoil NACA 0012 used to design SWEPT blades. 


\section{APPENDIX B}

\section{Inverse design and optimization tool for small scale wind turbines: Part I}

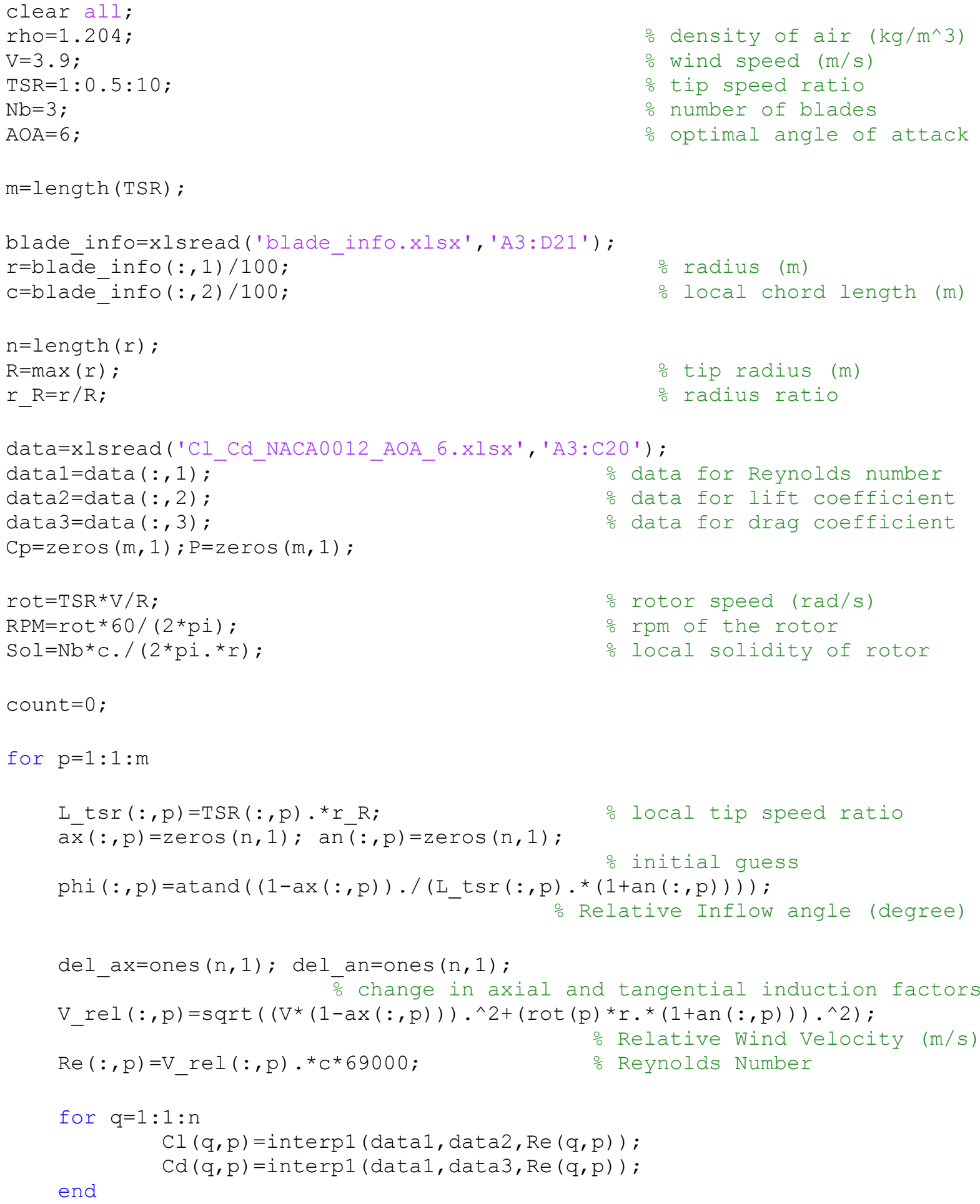




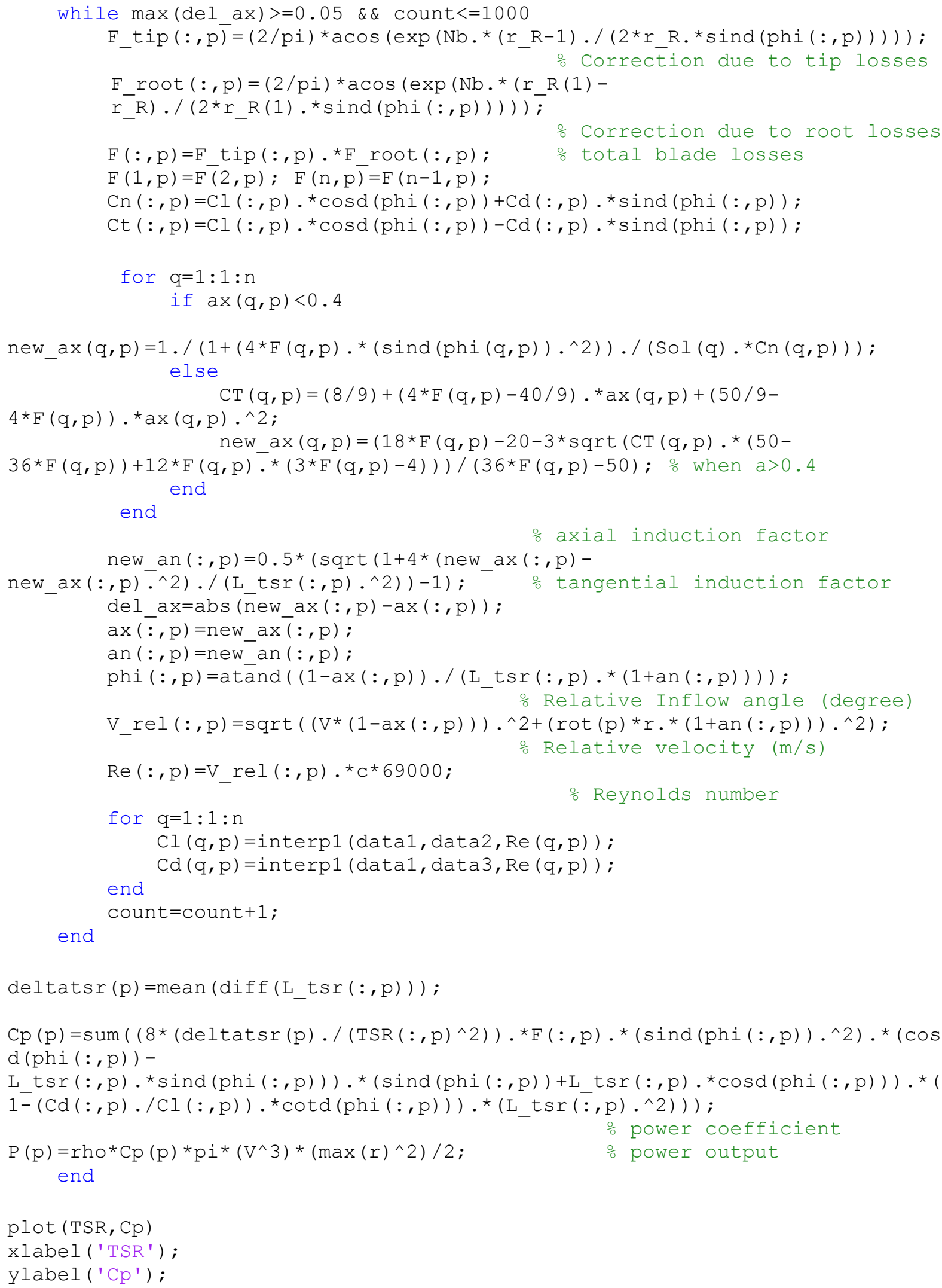


Inverse design and optimization tool for small scale wind turbines: Part II

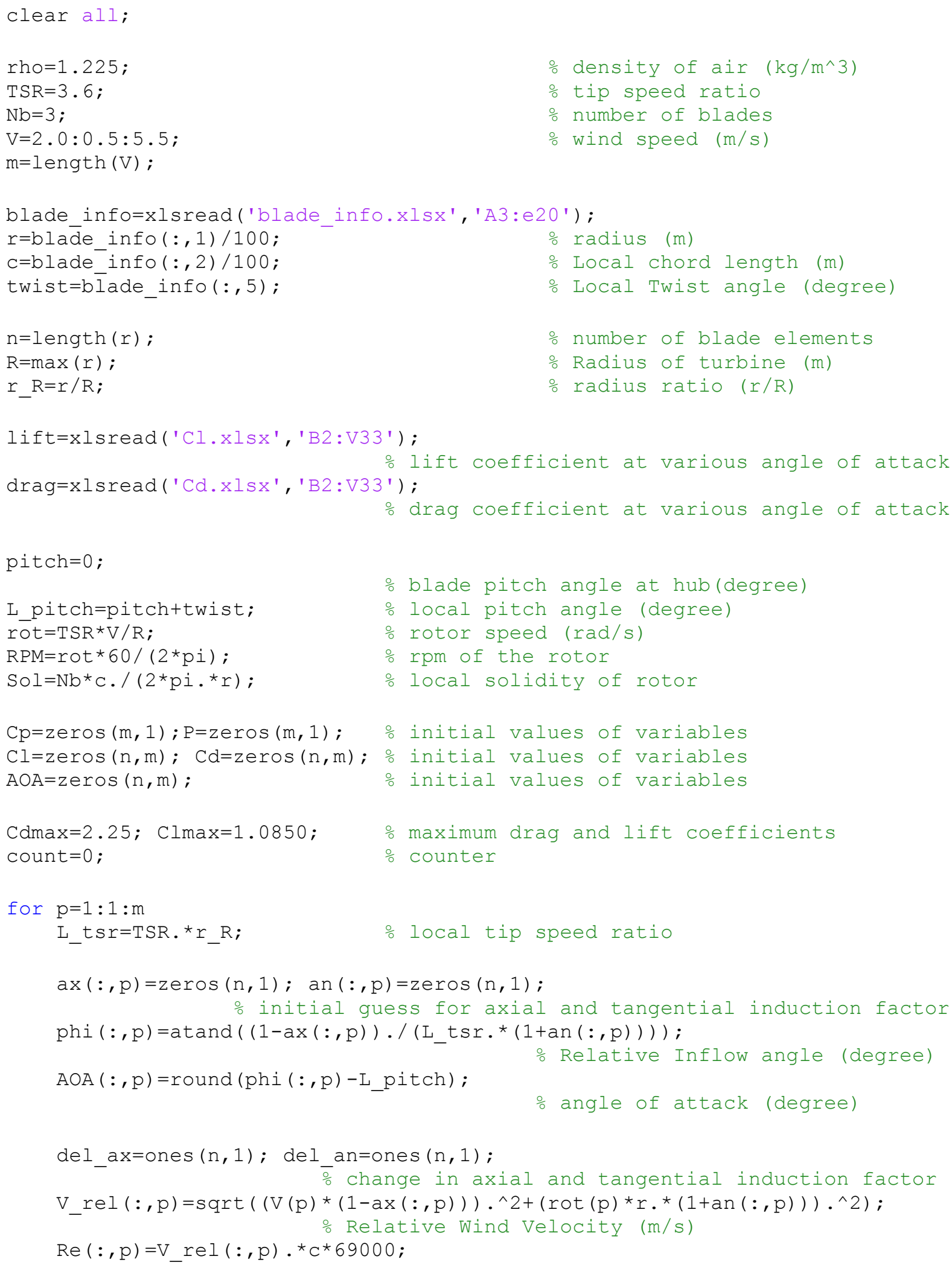




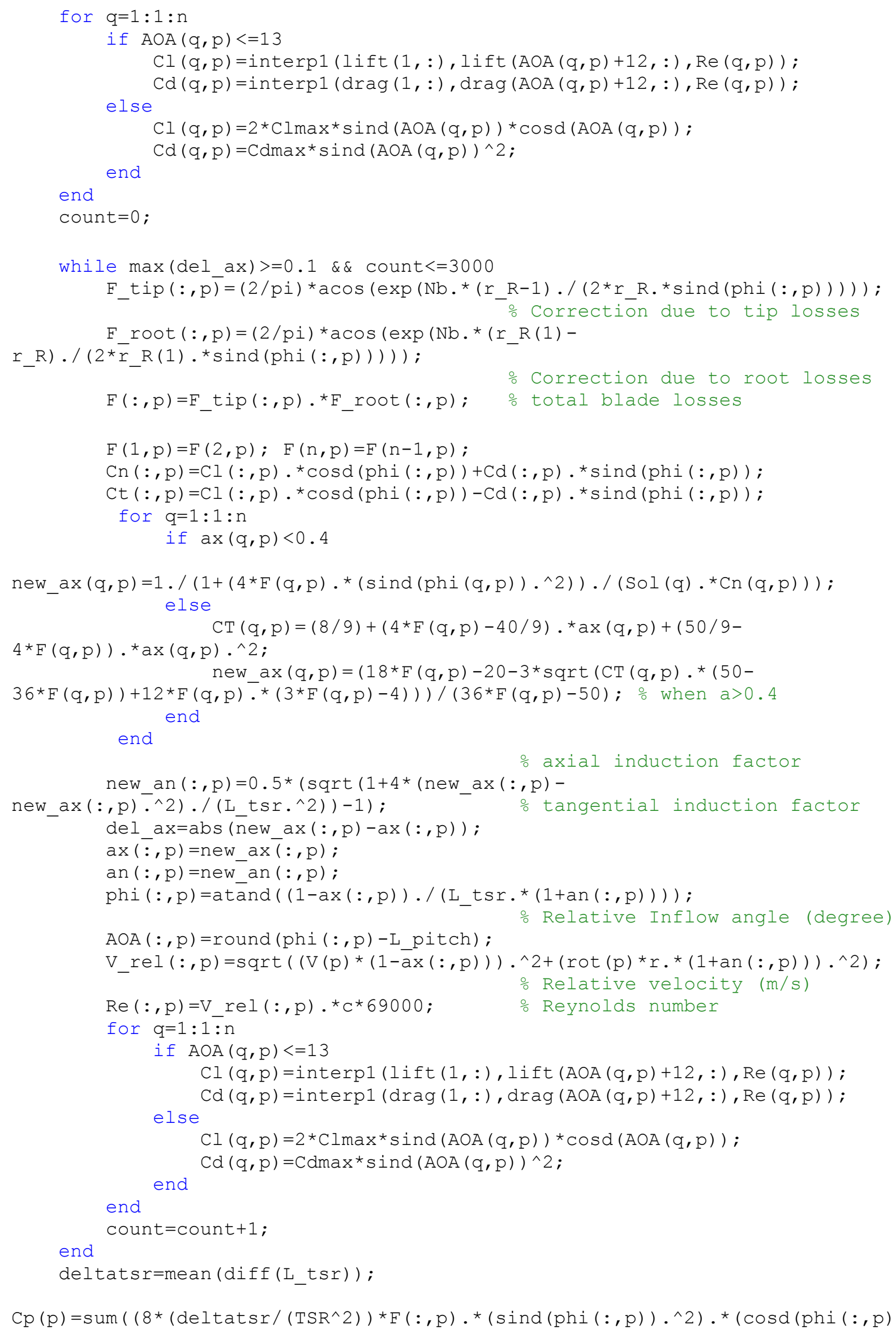


)$-\mathrm{L}$ tsr. $\left.{ }^{\star} \operatorname{sind}(\operatorname{phi}(:, \mathrm{p}))\right) \cdot{ }^{*}\left(\operatorname{sind}(\operatorname{phi}(:, \mathrm{p}))+\mathrm{L} \_t \mathrm{sr} \cdot{ }^{*} \operatorname{cosd}(\operatorname{phi}(:, \mathrm{p}))\right) \cdot{ }^{*}(1-$ $\left.\left.\left.(\operatorname{Cd}(:, p) \cdot / \operatorname{Cl}(:, p)) \cdot{ }^{*} \operatorname{cotd}(\operatorname{phi}(:, p))\right) \cdot{ }^{\star}\left(\operatorname{L}_{-} \operatorname{tsr} \cdot{ }^{\wedge} 2\right)\right)\right)$;

$\mathrm{P}(\mathrm{p})=\mathrm{rho}{ }^{*} \mathrm{Cp}(\mathrm{p}){ }^{*} \mathrm{pi} *\left(\mathrm{~V}(\mathrm{p})^{\wedge} 3\right)$ * $\left(\max (\mathrm{r})^{\wedge} 2\right) / 2$; $\mathrm{Cq}(\mathrm{p})=\mathrm{Cp}(\mathrm{p}) / \mathrm{TSR}$;

o power coefficient end

\% power output

\% torque coefficient

$\operatorname{plot}\left(\mathrm{V}, \mathrm{Cp}, \mathrm{I}^{\prime}: \mathrm{O}^{\prime}\right)$

xlabel ('wind speed');

ylabel ('Cp'); 


\section{APPENDIX D}

\section{CAD models}

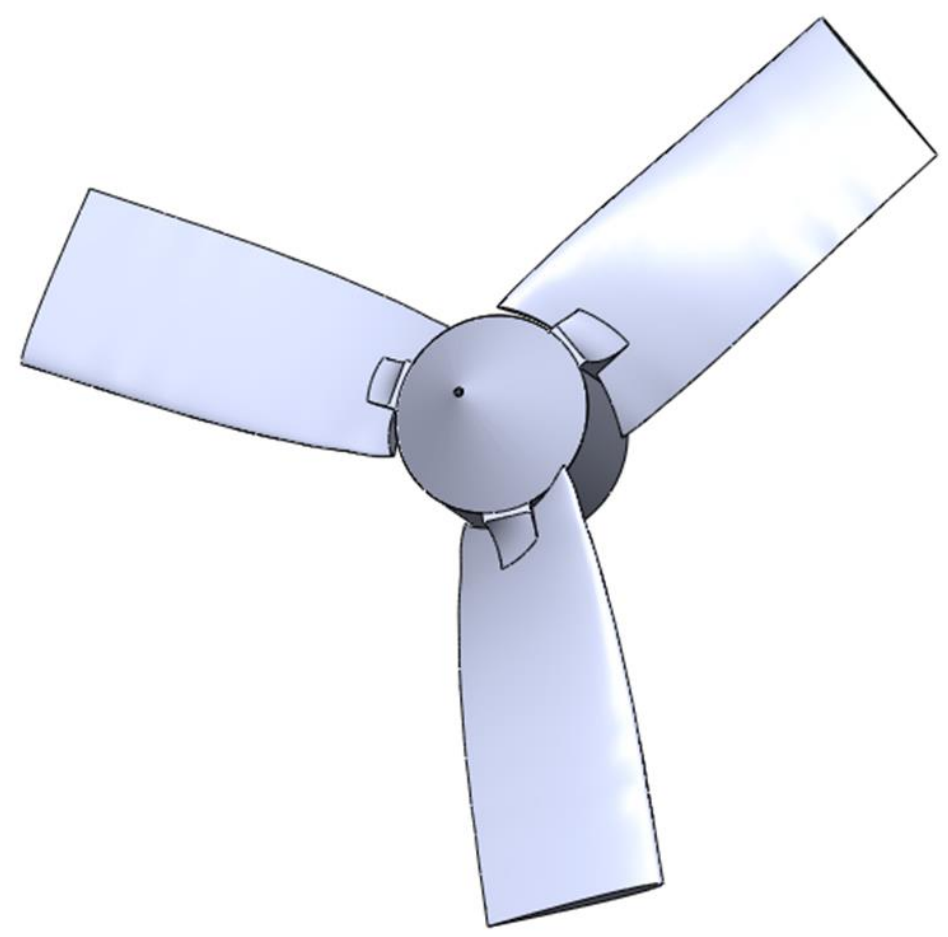

Figure D1. CAD model of SWEPT wind turbine rotor.
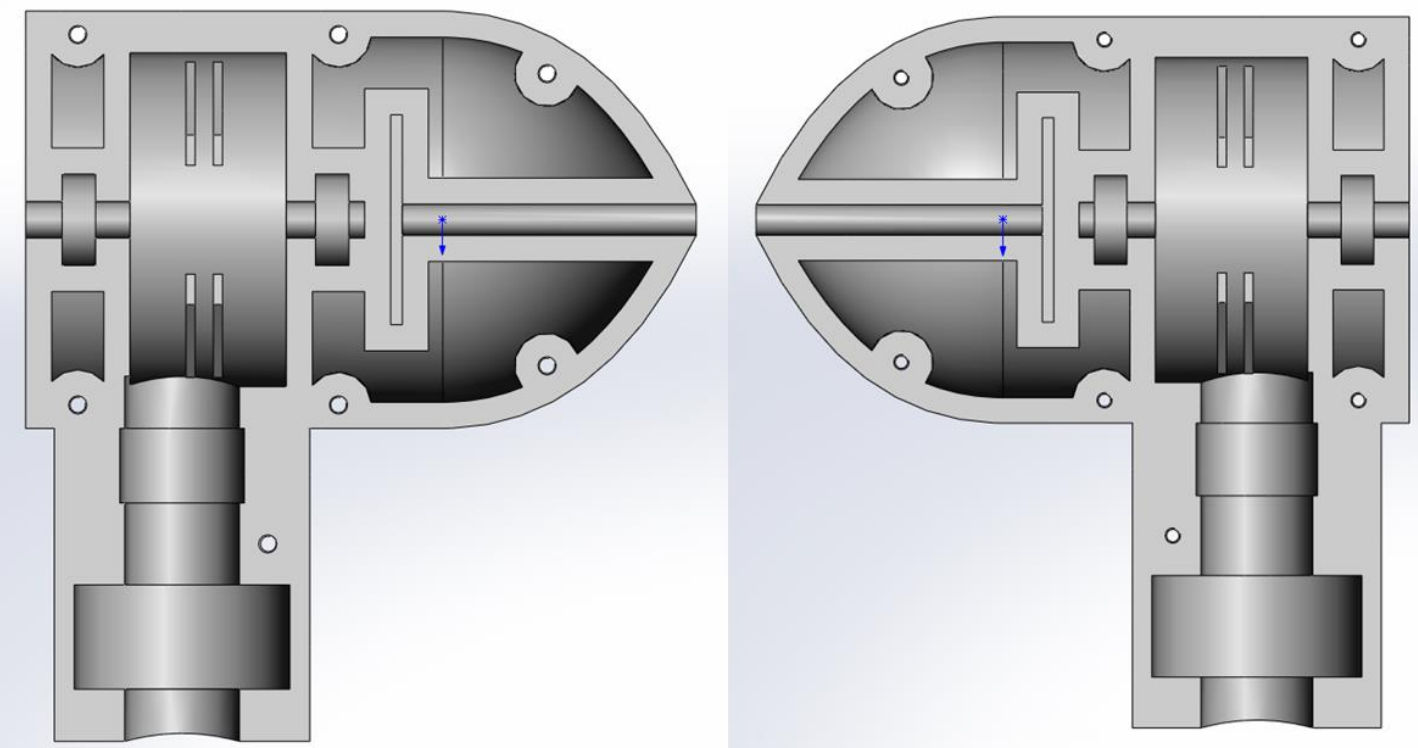

Figure D2. CAD model of SWEPT Nacelle box. 


\section{APPENDIX E}

\section{List of supplies}

\begin{tabular}{|c|l|c|c|}
\hline Sr. No. & \multicolumn{1}{|c|}{ Description } & Quantity & Supplier \\
\hline 1 & $3 / 16 "$ Axle 5" & 1 & Mc Master Carr \\
\hline 2 & $3 / 16 "$ Bearings & 2 & Mc Master Carr \\
\hline 3 & M3 18mm Socket Head Screws & 1 & Mc Master Carr \\
\hline 4 & Thrust Bearing 1/2 in 15/16 & 1 & Mc Master Carr \\
\hline 5 & 3/4" Bearing & 1 & Mc Master Carr \\
\hline 6 & SS Support Shaft 1' & 1 & Mc Master Carr \\
\hline 7 & $\begin{array}{l}\text { Custom magnets }(26.4 \mathrm{~mm}(\text { or }) \mathrm{x} \\
\left.10.5 \mathrm{~mm}(\mathrm{ir}) \times 6.35 \mathrm{~mm}(\mathrm{t}) \mathrm{x} 40^{\circ}\right)\end{array}$ & 16 & K\&J Magnetics \\
\hline
\end{tabular}

